Departamento de Economía y Ciencias Sociales

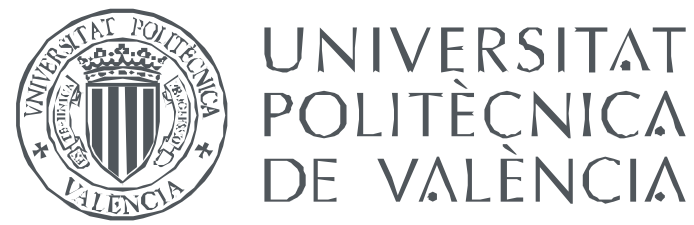

\title{
La adopción de tecnología en los invernaderos hortícolas mediterráneos
}

TESIS DOCTORAL

Presentada por:

Mํㅡㄹ Carmen García Martínez

Dirigida por:

Dr. Pedro Caballero Villar

Dra. Mํㅡ́n Ágeles Fernández Zamudio

Dr. Sebastià Balasch Parisi

Valencia, Octubre de 2009 

Memoria presentada para optar al grado de Doctora Ingeniera Agrónoma por $\mathrm{M}^{\mathrm{a}}$ Carmen García Martínez, bajo la dirección de D. Pedro Caballero Villar, Jefe del Dpto. de Economía y Sociología Agrarias del Instituto Valenciano de Investigaciones Agrarias, $D^{a}$. $M^{a}$ Ángeles Fernández Zamudio, Investigadora I.V.I.A. y D. Sebastià Balasch Parisi, Catedrático del Dpto de Estadística e Investigación Operativa de la Universidad Politécnica de Valencia. Ha sido tutor en la U.P.V., D. Baldomero Segura García del Río, Catedrático del Dpto de Economía y Ciencias Sociales. 

La presente Tesis ha sido posible gracias al Dpto. de Economía y Sociología Agrarias del IVIA y a la Conselleria de Agricultura de la Generalitat Valenciana que al concederme una beca de doctorado han permitido que me dedique plenamente a este trabajo, que forma parte de las investigaciones realizadas dentro del Proyecto de referencia RTA04-072, financiado por el Instituto Nacional de Investigaciones Agrarias (I.N.I.A.) y los Fondos FEDER dentro del Programa Nacional de Recursos y Tecnologías Agroalimentarias. 

A Javi

La alegría de mi vida 



\section{Agradecimientos}

Una vez llegado este anhelado momento, quisiera poner de manifiesto mi gratitud a todas aquellas personas que de algún modo han participado en el desarrollo de esta Tesis.

Quiero agradecer en primer lugar a mis directores Pedro y $\mathrm{M}^{\mathrm{a}}$ Ángeles por haber confiado en mí para realizar este trabajo, hace ya cuatro años, y a Sebastià por su aceptación y disposición inmediata. Ha sido una gran oportunidad trabajar con ellos, además del enriquecimiento personal que ha supuesto. También quisiera agradecer, especialmente a Pedro, toda su dedicación, en algunos momentos exclusiva, y que sin su valiosa ayuda esta tesis no hubiera sido posible. A $\mathrm{M}^{\mathrm{a}}$ Ángeles por sus buenos consejos e incondicional apoyo; siempre ha sabido transmitirme una actitud positiva y de superación. A Sebastià por su gran ayuda en el tema estadístico y por su total disponibilidad y atención en todo momento. A los tres gracias por el tiempo dedicado.

Agradecer la atención recibida en la estación experimental de la Fundación Cajamar El Ejido (Almería) y la colaboración prestada por sus investigadores para el desarrollo de la encuesta.

A los encuestadores Francisco Torró y Eva $\mathbf{M}^{\mathrm{a}}$ Toledo por la perfecta realización de su difícil tarea con la cual han 
contribuido a la fiabilidad y perfección de los datos exigible en una Tesis Doctoral.

A los jóvenes investigadores del IVIA por tantas experiencias, profesionales y personales, compartidas a diario. Particularmente a Sara por su voluntariosa disposición en las tareas iniciales y a Belinda, Jordi y Josep Vicent por echarme una mano con los problemas relacionados con la ofimática, con algún que otro gráfico y los programas de gestión bibliográfica en la elaboración final del documento.

A los que también considero compañeros, Francisco y Lita, con los que siempre es un placer trabajar por su gran calidad profesional y humana.

A mis excompañeros de CEGEA quienes me animaron a introducirme en el mundo de la investigación.

A mis hermanos, hermana, cuñados y cuñadas porque de una manera u otra siempre están ahí. En especial a Gabriel con quien comparto esta profesión y que ha sido para mí un ejemplo a seguir. Y por supuesto, a mis padres y abuela, a quienes les debo todo lo que soy.

Finalmente, por su apoyo, comprensión y amor, le dedico mi mayor agradecimiento a mi marido Javi, quien sabe que todo este esfuerzo ha merecido la pena. 


\section{Resumen}

En la horticultura intensiva española la mayor parte de las exportaciones procede de los cultivos de invernadero, localizados en Almería, Murcia y Alicante, donde se ha centrado el presente estudio. Actualmente la posición competitiva no presenta amenazas muy graves pero tampoco muestra una etapa creciente. Exportaciones y precios soportan la competencia de otros países del área mediterránea, con los cuales España debe competir en capital y en tecnología elevando el nivel de equipamiento de los invernaderos. Ante unas exigencias de reestructuración de las instalaciones actuales, no aplazables, se plantea la presente tesis con el fin de conocer el estado actual de la tecnología y su evolución y, además, las características de las explotaciones y la actitud de sus titulares respecto a las innovaciones necesarias.

Las fuentes de información se han basado en una toma de precios en origen del tomate y pimiento, como principales productos hortícolas, y en una encuesta, realizada en 242 explotaciones, mediante muestreo aleatorio estratificado proporcional al número de propietarios de invernadero, en las zonas de El Ejido (Almería), Valle del Guadalentín y Campo de Cartagena (Murcia) y Sur de Alicante.

El análisis de la información tuvo una primera parte dedicada a los precios, con el cálculo de la tendencia y la estacionalidad y la aplicación de modelos ARIMA. La finalidad ha sido conocer la evolución de las rentas de los productores, efectuar predicciones, y establecer una relación entre los precios y la tecnología adoptable.

El tratamiento de los datos de la encuesta con sus resultados comprende la mayor parte del contenido del trabajo. Se aplicó el análisis estadístico univariante a las características estructurales de explotaciones e invernaderos y el bivariante, con contraste de independencia, para determinar relaciones de interés entre los 
factores que influyen en los procesos de innovación. Con el análisis cluster se formaron niveles tecnológicos caracterizados por los elementos que los componen y su distribución porcentual. Con estos grupos se ha conocido la evolución de la tecnología.

Para analizar la actitud de los titulares de explotación respecto al cultivo en sustrato, se utilizó el Análisis de Componentes Principales (ACP). La importancia asignada en las encuestas a las variables referidas a las ventajas e inconvenientes que afectan al proceso se evaluó mediante la Regresión Multinomial Ordinal (RMO).

Como principales conclusiones se señalan: De acuerdo con la evolución de precios y exportaciones, la posición competitiva del tomate y pimiento no presenta amenazas graves pero sí una cierta estabilización, con mercados saturados y precios con tendencia decreciente. Actualmente la proporción de propietarios dispuestos a modificar el invernadero es baja, sólo un $10 \%$ de forma inmediata y un 35\% a medio o largo plazo; el resto no tiene intención de efectuar mejoras. El margen de crecimiento del cultivo en sustrato es escaso. La proporción de invernaderos con tecnología más completa se reduce al $6 \%$ del total. La estructura en multitúnel, idónea para todo tipo de mejoras y equipamiento, sólo alcanza una proporción de $11,2 \%$. El número de invernaderos que dispone de calefacción representa un $12 \%$ del total de la muestra. De las variables relacionadas con el cultivo en sustrato la más valorada es la calidad, a la cual le dan más importancia que a los rendimientos, le sigue la mejor aplicación del riego. Llama la atención que no señalen con prioridad al cultivo en sustrato como solución definitiva a los problemas de desinfección del suelo. Aunque existe conciencia medioambiental en la población analizada, el orden asignado a las variables relacionadas con temas medioambientales ha sido secundario. 


\section{Resum}

L'adopció de tecnologia en els hivernacles hortícoles mediterranis

En l'horticultura intensiva espanyola, la major part de les exportacions procedeix dels cultius d'hivernacle, localitzats a Almeria, Múrcia i Alacant, on s'ha centrat aquest estudi. Actualment, la posició competitiva no presenta amenaces molt greus, però tampoc no mostra una etapa creixent. Exportacions i preus suporten la competència d'altres països de l'àrea mediterrània, amb els quals Espanya ha de competir en capital $i$ en tecnologia elevant el nivell d'equipament dels hivernacles. Davant d'unes exigències de reestructuració de les instal-lacions actuals, que no són ajornables, es planteja aquesta tesi a fi de conèixer l'estat actual de la tecnologia i la seua evolució i, a més, les característiques de les explotacions i l'actitud dels titulars d'aquestes respecte a les innovacions necessàries.

Les fonts d'informació s'han basat en una presa de preus en origen de la tomaca i el pimentó, com a principals productes hortícoles, i en una enquesta, realitzada en 242 explotacions, mitjançant mostratge aleatori estratificat proporcional al nombre de propietaris, a les zones El Ejido (Almeria), Valle del Guadalentín i Campo de Cartagena (Múrcia) i sud d'Alacant.

L'anàlisi de la informació va tenir una primera part dedicada als preus, amb el càlcul de la tendència i l'estacionalitat i l'aplicació de models ARIMA. La finalitat ha sigut conèixer l'evolució de les rendes dels productors, efectuar prediccions i establir una relació entre els preus i la tecnologia adoptable.

El tractament de les dades de l'enquesta amb els resultats comprèn la major part del contingut del treball. S'hi va aplicar l'anàlisi estadística univariant a les característiques estructurals d'explotacions i hivernacles i el bivariant, amb contrast d'independència, per a 
determinar relacions d'interès entre els factors que influeixen en els processos d'innovació. Amb l'anàlisi clúster es van formar nivells tecnològics caracteritzats pels elements que els componen i la seua distribució percentual. Amb aquests grups s'ha conegut l'evolució de la tecnologia.

Per a analitzar l'actitud dels titulars d'explotació respecte al cultiu en substrat, es va utilitzar l'anàlisi de components principals $(\mathrm{ACP})$. La importància assignada en les enquestes a les variables referides als avantatges $i$ inconvenients que afecten el procés es va avaluar per mitjà de la regressió multinomial ordinal (RMO).

Com a principals conclusions, assenyalem: D'acord amb l'evolució de preus i exportacions, la posició competitiva de la tomaca i el pimentó no presenta amenaces greus però sí una certa estabilització, amb mercats saturats i preus amb tendència decreixent. Actualment, la proporció de propietaris disposats a modificar I'hivernacle és baixa, només un $10 \%$ de forma immediata i un $35 \%$ a mitjà o llarg termini; la resta no té intenció d'efectuar millores. El marge de creixement del cultiu en substrat és escàs. La proporció d'hivernacles amb tecnologia més completa es redueix al $6 \%$ del total. L'estructura en multitúnel, idònia per a tota classe de millores i equipament, només aconsegueix una proporció d'11,2\%. El nombre d'hivernacles que disposa de calefacció representa un $12 \%$ del total de la mostra. De les variables relacionades amb el cultiu en substrat, la més valorada és la qualitat, a la qual donen més importància que als rendiments, i la segueix la millor aplicació del reg. Crida l'atenció que no assenyalen amb prioritat el cultiu en substrat com a solució definitiva als problemes de desinfecció del sòl. Encara que hi ha consciència mediambiental en la població analitzada, l'ordre assignat a les variables relacionades amb temes mediambientals ha sigut secundari. 


\section{Summary}

Adoption of Technology in Mediterranean Horticultural Greenhouses

Most Spanish exports from intensive horticulture come from crops grown in greenhouses located in Almería, Murcia and Alicante, where the present study has been carried out. Today's competitive position is not seriously threatened; however, it not growing either. Exports and prices can stand up to competition from other Mediterranean countries with which Spain must compete in terms of capital and technology to raise the level of equipment in greenhouses. Faced with need to restructure existing facilities, which cannot be deferred, this Ph.D. dissertation sets out to establish the current state of technology and ongoing change and also the characteristics of farms and the attitudes of their owners with respect to the innovations required.

Information sources have been based on the price of tomatoes and peppers at source, as the main horticultural products, and a survey of 242 farms, using stratified random sampling proportional to the number of owners, in the areas of El Ejido (Almería), Valle Guadalentín and Campo de Cartagena (Murcia) and South of Alicante.

Data analysis was divided into a first part, devoted to pricing, calculating the trend and seasonality and the application of ARIMA models. The goal was to determine the time-course changes in farmers' incomes, make predictions, and establish a relationship between prices and adoptable technology.

Survey data processing and the results occupy most of the work. A one-way statistical analysis was applied to the structural characteristics of farms and greenhouses. A two-way analysis, with test for independence, was made to determine relationships of interest among factors influencing innovation processes. Cluster analysis was 
used to create technological levels characterized by their components and their percentage distribution. These groups have shed light on the ongoing changes in technology.

To analyze the attitude of the farm-owners with respect to soilless cultivation Principal Component Analysis (PCA) was applied. The importance assigned to variables in the surveys, concerning the advantages and drawbacks affecting the process, was evaluated by Ordinal Multinomial Regression (RMO).

The main conclusions drawn were: According to time-course changes in prices and exports, the competitive position of the tomato and pepper is not greatly threatened. However, there is certain stabilization, with market saturation and declining prices. Currently, the proportion of owners willing to modify their greenhouses is low, only $10 \%$ plan to do so immediately and $35 \%$ medium or long-term, the rest do not intend to make improvements. For soilless cultivation the growth margin is low. The proportion of greenhouses more fully equipped technologically represents only $6 \%$ of the total. Multi-tunnel structures, suitable for all kinds of improvements and equipment, only represent $11.2 \%$. The number of heated greenhouses comprises $12 \%$ of the total sample. The most highly valued variable related to soilless cultivation was quality, to which more importance is given than income, followed by better application of irrigation. It attracts attention that priority is not given to soilless cultivation as a final solution to problems of soil disinfection. Although the population analyzed demonstrated environmental awareness, the importance they assigned to the variables related to environmental issues was secondary. 


\section{Índice}

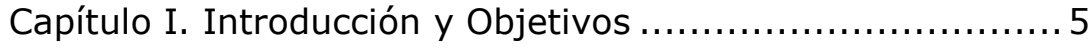

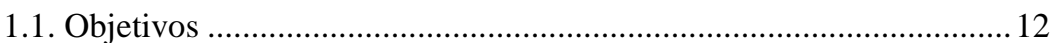

1.2. Contenido de la memoria......................................................................... 13

Capítulo II. Las innovaciones en la tecnología, base teórica.

Selección bibliográfica ...................................... 17

2.1. Adopción de innovaciones............................................................. 19

2.1.1. Etapas en la adopción .............................................................20

2.1.2. Categorías de adoptantes y su distribución................................ 21

2.1.3. Líneas de análisis del proceso de adopción ................................24

2.1.4. Factores que influyen en el proceso de adopción ........................25

2.2. Selección bibliográfica ................................................................... 26

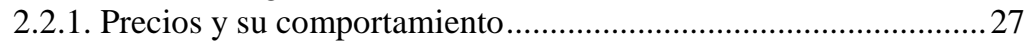

2.2.2. La adopción de tecnología .....................................................29

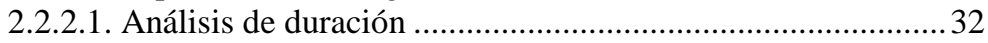

2.2.3. Adopción de tecnología en invernaderos ....................................... 34

2.2.4. El equipamiento en los invernaderos ........................................ 35

2.2.4.1. Tecnologías basadas en el sustrato ..................................... 37

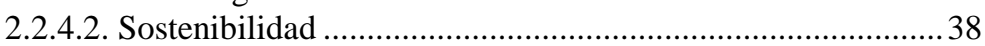

2.2.5. Aplicación de metodologías empleadas.................................... 41

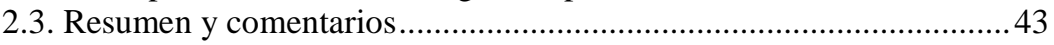

Capítulo III. Análisis de precios ............................. 47

3.1. Breve referencia a la posición competitiva del tomate y pimiento.....48

3.2. Los precios y la tecnología adoptable ..............................................55

3.3. Información y metodología …........................................................5 57

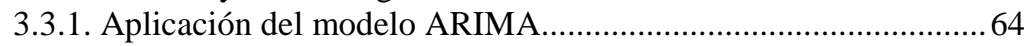

3.4. Cálculos y resultados ....................................................................66 66

3.5. Los precios en la Producción Integrada (PI) y Ecológica (PE)........... 84

3.6. Resumen y comentarios .............................................................. 86

Capítulo IV. Estado actual de la tecnología en los

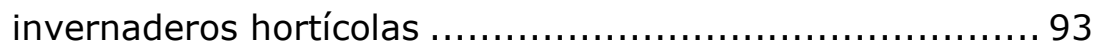

4.1. Características y dotación de los invernaderos ...................................94

4.2. Discusión sobre la evolución de la tecnología en los invernaderos....98

4.3. Grupos de elementos que componen la tecnología en los invernaderos

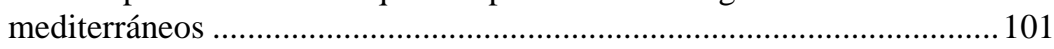

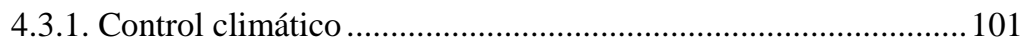

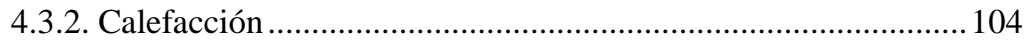

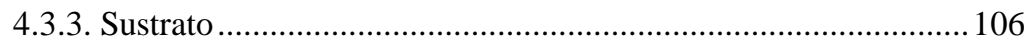


4.3.4. Riego y fertirrigación.......................................................... 108

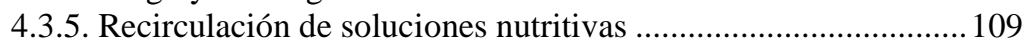

4.3.6. Fertilización carbónica ............................................................. 110

4.3.7. Informática aplicada a la agricultura ...................................... 110

4.4. Las explotaciones y la adopción de tecnología................................. 112

4.4.1. Toma de información por encuesta.......................................... 112

4.4.2. Representatividad de la muestra ............................................. 113

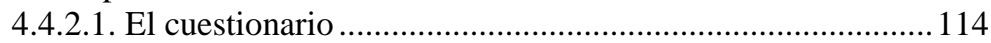

4.5. Resultados del análisis univariante ............................................... 117

4.6. Análisis bivariante ....................................................................... 128

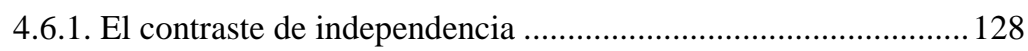

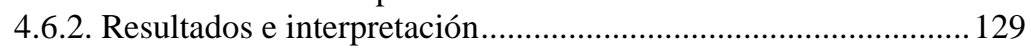

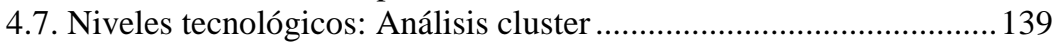

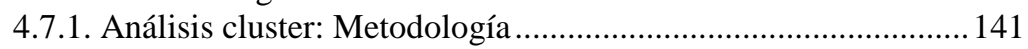

4.7.2. Resultados e interpretación......................................................... 143

4.7.2.1. Interpretación y caracterización de los niveles formados ... 146

4.7.2.2. Relación de los niveles tecnológicos de los invernaderos con variables de interés ........................................................................ 149

4.7.2.3. Relación de los niveles tecnológicos con los factores que

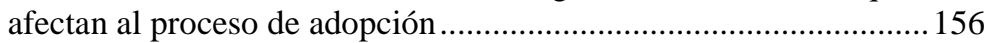

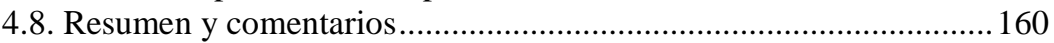

Capítulo V. Evolución hacia niveles superiores de tecnología:

el cultivo en sustrato...................................... 169

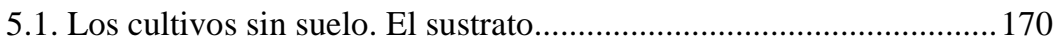

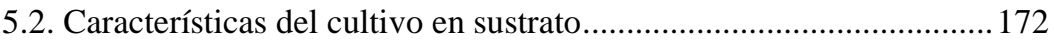

5.3. Necesidades tecnológicas en el cultivo en sustrato ............................ 175

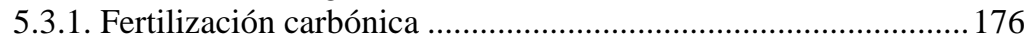

5.3.2. Recirculación de soluciones nutritivas ..................................... 178

5.4. La adopción del cultivo en sustrato con la tecnología asociada.

Planteamiento del análisis .................................................................... 180

5.4.1. Análisis de Componentes Principales: Metodología ................. 183

5.4.2. Resultados del Análisis de Componentes Principales (ACP) .... 185

5.4.2.1. Resultados del ACP para las variables "Ventajas" e

"Inconvenientes" del cultivo en sustrato .......................................... 185

5.4.2.2. Resultados del ACP para las variables "Ventajas" del cultivo

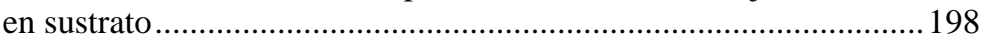

5.4.2.3. Resultados del ACP para las variables "Inconvenientes" del

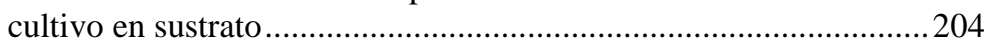

5.4.3. Influencia de las variables en la actitud hacia la adopción:

Regresión Multinomial Ordinal (RMO) ............................................2 210

5.4.3.1. Coeficiente de correlación por rangos de Spearman...........211

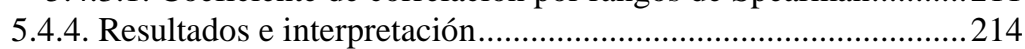

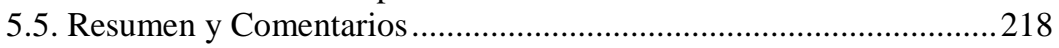

Capítulo VI. Conclusiones finales ........................... 229 
Bibliografía .................................................. 243

Anexos ...................................................... 257

Anexo 1. Series de precios ...............................................................261

Anexo 2. Cuestionario "Uso de la calefacción en invernadero"..............2273

Anexo 3. Cuestionario "Adopción Tecnología Invernaderos

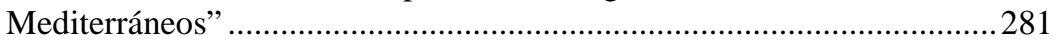

Anexo 4. Análisis descriptivo de las variables .....................................289

A4.1. Variables "Datos de Explotación" ............................................289

A4.2. Variables "Nivel de tecnología" ............................................... 312

A4.3. Variables "Actitud hacia la adopción del sustrato" ....................317

A4.4. Variables "Factores que afectan al proceso de innovación" ......318

A4.5. Variables "Percepción ambiental" ............................................320

Anexo 5. Modelos de Regresión Multinomial Ordinal obtenidos ............ 327

\section{Índice de Tablas}

Tabla 1.1. Evolución de las exportaciones de los principales cultivos

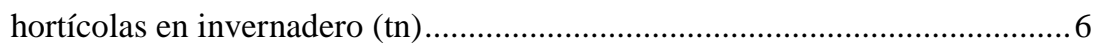

Tabla 3.1. Periodo, indicado en quincena, correspondiente a cada serie según

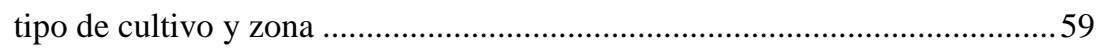

Tabla 3.2. Análisis de tendencia de las series quincenales de precios en origen, variación anual en $\%$.....

Tabla 3.3. Índices de estacionalidad de las series de precios en origen en porcentaje

Tabla 3.4. Meses de la campaña con mayores índices de estacionalidad de los precios en origen

Tabla 3.5. Resultados de la estimación del modelo $\operatorname{ARIMA}(0,1,2) \mathrm{x}(0,1,1)$

aplicado al pimiento verde y rojo de Almería .......................................... 81

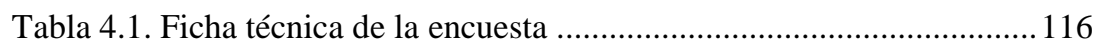

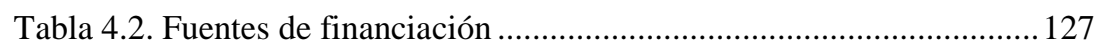

Tabla 4.3. Frecuencias cruzadas de las variables intención de modificar el invernadero y existencia de sucesión. 
Tabla 4.4. Frecuencias cruzadas de las variables intención de modificar el invernadero y tipo de invernadero

Tabla 4.5. Frecuencias cruzadas de las variables intención de modificar el invernadero e intervalos de edad de los propietarios.

Tabla 4.6. Frecuencias cruzadas de las variables disposición al endeudamiento e intervalos de edad de los propietarios.....

Tabla 4.7. Frecuencias cruzadas de las variables tenencia de sustrato e intervalos de edad de los propietarios

Tabla 4.8. Frecuencias cruzadas de las variables dotación de pantallas térmicas y zona

Tabla 4.9. Frecuencias cruzadas de las variables tipo de apertura de ventanas y zona

Tabla 4.10. Frecuencias cruzadas de las variables principal vía de comercialización y zona .....

Tabla 4.11. Frecuencias cruzadas de las variables consideración de la problemática ambiental al montar el invernadero y zona

Tabla 4.12. Frecuencias cruzadas de las variables interés por generalizar la lucha biológica y zona......

Tabla 4.13. Descripción e identificación de las variables analizadas 144

Tabla 4.14. Proporciones de las variables en cada nivel tecnológico

Tabla 4.15. Distribución de los niveles tecnológicos de los invernaderos según zona ....

Tabla 4.16. Distribución de los niveles tecnológicos de los invernaderos según su especialización por cultivos

Tabla 4.17. Distribución de los niveles tecnológicos de los invernaderos según intervalos de edad de los propietarios

Tabla 4.18. Distribución de los niveles tecnológicos de los invernaderos según la disposición de los propietarios al endeudamiento

Tabla 4.19. Distribución de los niveles tecnológicos de los invernaderos según las subvenciones o préstamos del Gobierno recibidos por los propietarios 
Tabla 4.20. Frecuencias cruzadas de los niveles tecnológicos con las fuentes de información inicial.....

Tabla 4.21. Frecuencias cruzadas de los niveles tecnológicos con las fuentes de formación. 158

Tabla 4.22. Frecuencias cruzadas de los niveles tecnológicos con las fuentes de asesoramiento .159

Tabla 5.1. Variables utilizadas en el ACP y su identificación. 186

Tabla 5.2. Autovalores y porcentaje de varianza de las componentes.... 187 para las variables ventajas e inconvenientes 187

Tabla 5.3. Pesos y coeficientes de correlación de las componentes C1 y C2 para las variables ventajas e inconvenientes. 188

Tabla 5.4. Proporción de explotaciones según la apreciación de los titulares respecto a las ventajas e inconvenientes del cultivo en sustrato. 190

Tabla 5.5. Autovalores y porcentaje de varianza de las componentes......... 198

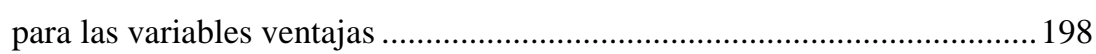

Tabla 5.6. Pesos y coeficientes de correlación de las componentes C1 y C2

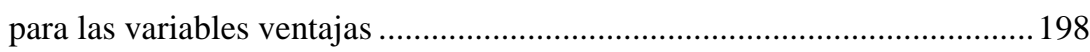

Tabla 5.7. Autovalores y porcentaje de varianza de las componentes.........204 para las variables inconvenientes 204

Tabla 5.8. Pesos y coeficientes de correlación de las componentes C1 y C2 para las variables inconvenientes 205

Tabla 5.9. Matriz de correlación por rangos de Spearman ..... 213

Tabla 5.10. Resultados del ajuste de los modelos de regresión multinomial ordinal.

Tabla 5.11. Niveles de importancia relativa de las variables ventajas e inconvenientes del cultivo en sustrato.

Tabla A1.1. Precios quincenales en origen del tomate acostillado en Almería (en $€ / \mathrm{kg}$, datos actualizados a Agosto de 2006) 261

Tabla A1.2. Precios quincenales en origen del tomate larga vida en Almería (en $€ / \mathrm{kg}$, datos actualizados a Agosto de 2006) 262 
Tabla A1.3. Precios quincenales en origen del pimiento verde en Almería (en $€ / \mathrm{kg}$, datos actualizados a Agosto de 2006). 263

Tabla A1.4. Precios quincenales en origen del pimiento rojo en Almería (en

$€ / \mathrm{kg}$, datos actualizados a Agosto de 2006). .264

Tabla A1.5. Precios quincenales en origen del tomate liso en Murcia (en $€ / \mathrm{kg}$, datos actualizados a Septiembre de 2006) 265

Tabla A1.6. Precios quincenales en origen del pimiento verde en Murcia (en $€ / \mathrm{kg}$, datos actualizados a Septiembre de 2006) 266

Tabla A1.7. Precios quincenales en origen del pimiento rojo en Murcia (en $€ / \mathrm{kg}$, datos actualizados a Septiembre de 2006) 267

Tabla A1.8. Precios quincenales en origen del tomate acostillado en Alicante (en $€ / \mathrm{kg}$, datos actualizados a Agosto de 2006) .268

Tabla A1.9. Precios quincenales en origen del tomate liso en Alicante (en $€ / \mathrm{kg}$, datos actualizados a Agosto de 2006) 268

Tabla A1.10. Precios quincenales en origen del pimiento verde en Alicante (en $€ / \mathrm{kg}$, datos actualizados a Agosto de 2006) 269

Tabla A1.11. Precios quincenales en origen del pimiento rojo en Alicante (en $€ / \mathrm{kg}$, datos actualizados a Agosto de 2006). 270

Tabla A4.1.1. Análisis descriptivo de la variable superficie de invernaderos 289

Tabla A4.1.2. Tabla análisis descriptivo de la variable superficie al aire libre (ha)

Tabla A4.1.3. Tabla análisis descriptivo de la variable superficie de invernadero en suelo

Tabla A4.1.4. Tabla análisis descriptivo de la variable superficie de invernadero en sustrato

Tabla A4.1.5. Tabla análisis descriptivo de la variable superficie parral básico

Tabla A4.1.6. Tabla análisis descriptivo de la variable superficie parral mejorado. 
Tabla A4.1.7. Tabla análisis descriptivo de la variable superficie parral multitúnel

Tabla A4.1.8. Tabla distribución de frecuencias de la variable número de familiares con dedicación total. 300

Tabla A4.1.9. Distribución de frecuencias de la variable número de familiares con dedicación parcial 301

Tabla A4.1.10. Distribución de frecuencias de la variable número de eventuales a tiempo total .303

Tabla A4.1.11. Distribución de frecuencias de la variable número de eventuales a tiempo parcial .304

Tabla A4.1.12. Distribución de frecuencias de la variable número de jornales al año por familiares a tiempo parcial . 306 Tabla A4.1.13. Distribución de frecuencias de la variable número de jornales al año por eventuales a tiempo parcial. 307

Tabla A4.2.1. Tabla análisis descriptivo de la variable superficie del invernadero más tecnificado de la explotación. 312

Tabla A4.2.1. Tipo estructura del invernadero..... 313

Tabla A4.2.2. Tipo cubierta del invernadero 313

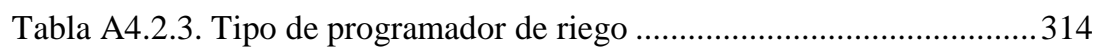

Tabla A4.2.4. Tipo de invernadero............................................................. 314

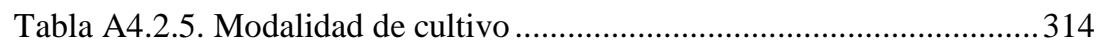

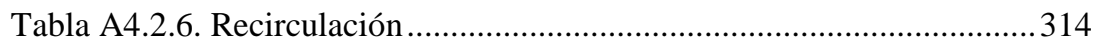

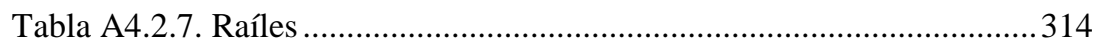

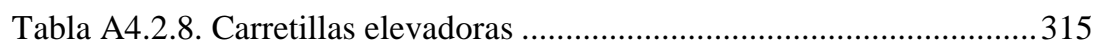

Tabla A4.2.9. Fertilización carbónica .............................................................315

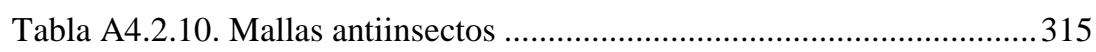

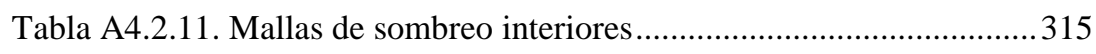

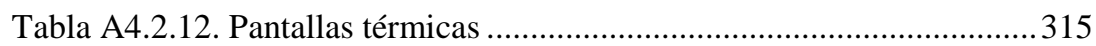

Tabla A4.2.13. Mallas de sombreo exteriores ...............................................315

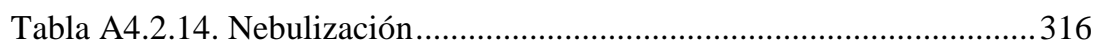

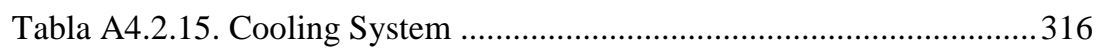


Tabla A4.2.16. Ventiladores (desestratificadores).

Tabla A4.2.17. Tipo calefacción

Tabla A4.2.18. Forma calefacción.

Tabla A4.4.1. Frecuencias de las Fuentes de Información Inicial 318

Tabla A4.4.2. Frecuencias de las vías de Formación. 318

Tabla A4.4.3. Frecuencias de las vías de Asesoramiento .319

Tabla A4.4.4. Frecuencias de las vías de Comercialización

Tabla A4.5.1. Importancia de la variable "Mayor consumo de agua" respecto al cultivo al aire libre. 320

Tabla A4.5.2. Importancia de la variable "Mayor consumo de energía" respecto al cultivo al aire libre.

Tabla A4.5.3. Importancia de la variable "Más consumo de productos químicos" respecto al cultivo al aire libre

Tabla A4.5.4. Importancia de la variable "Más desechos plásticos" respecto al cultivo al aire libre. 321

Tabla A4.5.5. Importancia de la variable "Más restos de cosechas" respecto al cultivo al aire libre.

Tabla A4.5.6. Importancia de la variable "Agua de drenaje con productos químicos"

Tabla A4.5.7. Interés de la variable "Reducir el consumo de productos químicos" como estrategia prioritaria para mejorar el medio ambiente en las zonas de invernaderos

Tabla A4.5.8. Interés de la variable "Aplicar la lucha biológica” como estrategia prioritaria para mejorar el medio ambiente en las zonas de invernaderos

Tabla A4.5.9. Interés de la variable "Reutilizar las soluciones de drenaje" como estrategia prioritaria para mejorar el medio ambiente en las zonas de invernaderos

Tabla A4.5.10. Interés de la variable "Optimizar el control climático de los invernaderos" como estrategia prioritaria para mejorar el medio ambiente en las zonas de invernaderos 
Tabla A4.5.11. Interés de la variable "Ordenar las nuevas superficies cubiertas" como estrategia prioritaria para mejorar el medio ambiente en las zonas de invernaderos

Tabla A4.5.12. Interés de la variable "Responsabilizarse de la eliminación de los vertidos" como estrategia prioritaria para mejorar el medio ambiente en las zonas de invernaderos

Tabla A4.5.13. Interés de la variable "Responsabilizarse de la restauración del paisaje tras abandonar un invernadero" como estrategia prioritaria para mejorar el medio ambiente en las zonas de invernaderos

Tabla A5.1. Número de casos y porcentaje marginal para cada nivel de las variables "Nivel de importancia del cultivo en sustrato" y "Rendimientos (por $\mathrm{m}^{2}$ ) más elevados"

Tabla A5.2. Coeficientes estimados, error estandar y significatividad del Modelo de Regresión Multinomial Ordinal para la variable "Rendimientos $\left(\right.$ por $\mathrm{m}^{2}$ ) más elevados" frente a "Nivel de importancia del cultivo en sustrato"

Tabla A5.3. Número de casos y porcentaje marginal para cada nivel de las variables "Nivel de importancia del cultivo en sustrato" y "Mayor calidad comercial de los productos"

Tabla A5.4. Coeficientes estimados, error estandar y significatividad del Modelo de Regresión Multinomial Ordinal para la variable "Mayor calidad comercial de los productos" frente a "Nivel de importancia del cultivo en sustrato".

Tabla A5.5. Número de casos y porcentaje marginal para cada nivel de las variables "Nivel de importancia del cultivo en sustrato" y "Más seguridad de obtener buenos resultados"

Tabla A5.6. Coeficientes estimados, error estandar y significatividad del Modelo de Regresión Multinomial Ordinal para la variable "Más seguridad de obtener buenos resultados" frente a "Nivel de importancia del cultivo en sustrato" 
Tabla A5.7. Número de casos y porcentaje marginal para cada nivel de las variables "Nivel de importancia del cultivo en sustrato" y "Periodo de producción y comercialización más amplio".

Tabla A5.8. Coeficientes estimados, error estandar y significatividad del Modelo de Regresión Multinomial Ordinal para la variable "Periodo de producción y comercialización más amplio" frente a "Nivel de importancia del cultivo en sustrato"

Tabla A5.9. Número de casos y porcentaje marginal para cada nivel de las variables "Nivel de importancia del cultivo en sustrato" y "Mejor control climático"

Tabla A5.10. Coeficientes estimados, error estandar y significatividad del Modelo de Regresión Multinomial Ordinal para la variable "Mejor control climático" frente a "Nivel de importancia del cultivo en sustrato" .331

Tabla A5.11. Número de casos y porcentaje marginal para cada nivel de las variables "Nivel de importancia del cultivo en sustrato" y "Mejor aplicación del riego" 332

Tabla A5.12 Coeficientes estimados, error estandar y significatividad del Modelo de Regresión Multinomial Ordinal para la variable "Mejor aplicación del riego" frente a "Nivel de importancia del cultivo en sustrato" 332

Tabla A5.13. Número de casos y porcentaje marginal para cada nivel de las variables "Nivel de importancia del cultivo en sustrato" y "Se recolectan más $\mathrm{kg} / \mathrm{hora}$ "

Tabla A5.14. Coeficientes estimados, error estandar y significatividad del Modelo de Regresión Multinomial Ordinal para la variable "Se recolectan más kg/hora" frente a "Nivel de importancia del cultivo en sustrato".

Tabla A5.15. Número de casos y porcentaje marginal para cada nivel de las variables "Nivel de importancia del cultivo en sustrato" y "Se puede reciclar el agua de drenaje" 334

Tabla A5.16. Coeficientes estimados, error estandar y significatividad del Modelo de Regresión Multinomial Ordinal para la variable "Se puede reciclar el agua de drenaje" frente a "Nivel de importancia del cultivo en sustrato"334 
Tabla A5.17. Número de casos y porcentaje marginal para cada nivel de las variables "Nivel de importancia del cultivo en sustrato" y "Se evita la desinfección del suelo",

Tabla A5.18. Coeficientes estimados, error estandar y significatividad del Modelo de Regresión Multinomial Ordinal para la variable "Se evita la desinfección del suelo" frente a "Nivel de importancia del cultivo en sustrato"

Tabla A5.19. Número de casos y porcentaje marginal para cada nivel de las variables "Nivel de importancia del cultivo en sustrato" y "Se reduce la cantidad de fitosanitarios"

Tabla A5.20. Coeficientes estimados, error estandar y significatividad del Modelo de Regresión Multinomial Ordinal para la variable "Se reduce la cantidad de fitosanitarios" frente a "Nivel de importancia del cultivo en sustrato"

Tabla A5.21. Número de casos y porcentaje marginal para cada nivel de las variables "Nivel de importancia del cultivo en sustrato" y "Más caro en todo"

Tabla A5.22 Coeficientes estimados, error estandar y significatividad del Modelo de Regresión Multinomial Ordinal para la variable "Más caro en todo" frente a "Nivel de importancia del cultivo en sustrato"

Tabla A5.23. Número de casos y porcentaje marginal para cada nivel de las variables "Nivel de importancia del cultivo en sustrato" y "Lo veo muy arriesgado",

Tabla A5.24. Coeficientes estimados, error estandar y significatividad del Modelo de Regresión Multinomial Ordinal para la variable "Lo veo muy arriesgado" frente a "Nivel de importancia del cultivo en sustrato".

Tabla A5.25. Número de casos y porcentaje marginal para cada nivel de las variables "Nivel de importancia del cultivo en sustrato" y "Es más difícil de manejar" .339 
Tabla A5.26. Coeficientes estimados, error estandar y significatividad del Modelo de Regresión Multinomial Ordinal para la variable "Es más difícil de manejar" frente a "Nivel de importancia del cultivo en sustrato" 339

Tabla A5.27. Número de casos y porcentaje marginal para cada nivel de las variables "Nivel de importancia del cultivo en sustrato" y "Se depende de empresas o técnicos que asesoren"

Tabla A5.28. Coeficientes estimados, error estandar y significatividad del Modelo de Regresión Multinomial Ordinal para la variable "Se depende de empresas o técnicos que asesoren" frente a "Nivel de importancia del cultivo en sustrato",

\section{Índice de Gráficos}

Gráfico 2.1. Gráfico de densidad de probabilidad normal de adoptantes ......23

Gráfico 3.1. Evolución de las exportaciones de tomate..................................51

Gráfico 3.2. Evolución de las exportaciones de pimiento ..............................51

Gráfico 3.3. Precio medio del tomate percibido por los agricultores desde 1985 a 1999

Gráfico 3.4. Precio medio del tomate percibido por los agricultores desde 2000 a 2006

Gráfico 3.5. Precio medio del pimiento percibido por los agricultores desde 1985 a 1999

Gráfico 3.6. Precio medio del pimiento percibido por los agricultores desde 1999 a 2006 54

Gráfico 3.7. Tendencia del tomate acostillado en Almería. 67

Gráfico 3.8. Tendencia del tomate larga vida en Almería. .67

Gráfico 3.9. Tendencia del pimiento verde en Almería.................................68

Gráfico 3.10. Tendencia del pimiento rojo en Almería .................................6 68

Gráfico 3.11. Tendencia del tomate liso en Murcia......................................69

Gráfico 3.12. Tendencia pimiento verde en Murcia .................................... 70

Gráfico 3.13. Tendencia pimiento rojo en Murcia ....................................... 70 
Gráfico 3.14. Tendencia del tomate acostillado en Alicante 71

Gráfico 3.15. Tendencia del tomate liso en Alicante................................... 71

Gráfico 3.16. Tendencia pimiento verde en Alicante .................................. 72

Gráfico 3.17. Tendencia pimiento rojo en Alicante..................................... 72

Gráfico 3.18. Estacionalidad del tomate liso en Murcia................................ 76

Gráfico 3.19. Estacionalidad del pimiento verde en Almería ....................... 77

Gráfico 3.20. Estacionalidad del pimiento rojo en Alicante .......................... 77

Gráfico 3.21. Autocorrelaciones estimadas en pimiento verde de Almería... 79

Gráfico 3.22. Autocorrelaciones parciales estimadas en pimiento verde de Almería..... 79

Gráfico 3.23. Autocorrelaciones estimadas en pimiento rojo de Almería .....80

Gráfico 3.24. Autocorrelaciones parciales estimadas en pimiento rojo de Almería.

Gráfico 3.25. Predicción frente a precios reales para pimiento verde en Almería.....

Gráfico 3.26. Predicción frente a precios reales para pimiento rojo en Almería

Gráfico 3.27. Evolución de la producción de los principales tipos de pimiento en el sur de Alicante 85

Gráfico 3.28. Evolución de los precios medios del pimiento en el sur de Alicante, según tipos comerciales 86

Gráfico 4.1. Histograma edad de los titulares de explotación con invernaderos

Gráfico 4.2. Edad de los titulares de explotaciones agrarias a nivel nacional

Gráfico 4.3. Satisfacción con el cultivo en sustrato...... 125

Gráfico 4.4. Disposición al endeudamiento. 126

Gráfico 4.5. Consideración de la problemática ambiental al montar el invernadero 127

Gráfico 5.1. Diagrama de dispersión 189 
Gráfico 5.2. Diagramas de Caja y Bigotes para la C1 a) y para la C2 b) según tipo de cultivo, para ventajas e inconvenientes

Gráfico 5.3. Gráficos de dispersión para la $\mathrm{C} 1$ a) y para la $\mathrm{C} 2$ b) según edad, para ventajas e inconvenientes

Gráfico 5.4. Diagramas de Caja y Bigotes para la $\mathrm{C} 1$ a) y para la $\mathrm{C} 2$ b) según zona, para ventajas e inconvenientes .193

Gráfico 5.5. Gráficos de dispersión para la $\mathrm{C} 1$ a) y para la $\mathrm{C} 2$ b) según superficie, para ventajas e inconvenientes 195

Gráfico 5.6. Diagramas de Caja y Bigotes para la C1 a) y para la C2 b) según sucesión, para ventajas e inconvenientes

Gráfico 5.7. Diagramas de Caja y Bigotes para la $\mathrm{C} 1$ a) y para la $\mathrm{C} 2$ b) según tenencia de sustrato, para ventajas e inconvenientes

Gráfico 5.8. Diagramas de Caja y Bigotes para la C1 a) y para la C2 b) según cultivo, para ventajas 200

Gráfico 5.9. Gráficos de dispersión para la C1 a) y para la C2 b) según edad, para ventajas 201

Gráfico 5.10. Diagramas de Caja y Bigotes para la C1 a) y para la C2 b) según zona, para ventajas 202

Gráfico 5.11. Gráficos de dispersión para la $\mathrm{C} 1$ a) y para la $\mathrm{C} 2$ b) según superficie, para ventajas

Gráfico 5.12. Diagramas de Caja y Bigotes para la C1 a) y para la C2 b) según sucesión, para ventajas 203

Gráfico 5.13. Diagramas de Caja y Bigotes para la C1 a) y para la C2 b) según tenencia de sustrato, para ventajas 204

Gráfico 5.14. Diagramas de Caja y Bigotes para la C1 a) y para la C2 b) según cultivo, para inconvenientes 206

Gráfico 5.15. Gráficos de dispersión para la C1 a) y para la C2 b) según edad, para inconvenientes 206 Gráfico 5.16. Diagramas de Caja y Bigotes para la C1 a) y para la C2 b) según zona, para inconvenientes 207 
Gráfico 5.17. Gráficos de dispersión para la $\mathrm{C} 1$ a) y para la $\mathrm{C} 2$ b) según superficie, para inconvenientes......

Gráfico 5.18. Diagramas de Caja y Bigotes para la C1 a) y para la C2 b) según sucesión, para inconvenientes

Gráfico 5.19. Diagramas de Caja y Bigotes para la C1 a) y para la C2 b)

según tenencia de sustrato, para inconvenientes.

Gráfico A2.1. Tipo de calefacción por temperatura de los invernaderos del Campo de Cartagena

Gráfico A2.2. Tipo de calefacción de los invernaderos del Campo de Cartagena

Gráfico A2.3. Distribución del calor de la calefacción de los invernaderos del Campo de Cartagena .275

Gráfico A2.4. Tipo de combustión de la calefacción de los invernaderos del Campo de Cartagena 275

Gráfico A2.5. Distribución en porcentaje de las mejoras por el uso de la calefacción en los invernaderos del Campo de Cartagena 276

Gráfico A2.6. Mejoras por el uso de la calefacción en los invernaderos del Campo de Cartagena ..... 276

Gráfico A2.7. Distribución en porcentaje de las mejoras en la calidad por el uso de la calefacción en los invernaderos del Campo de Cartagena............2277

Gráfico A4.1.1. Histograma de la variable superficie de invernaderos.... 289

Gráfico A4.1.2. Diagrama Caja-Bigotes de la variable superficie de invernaderos

Gráfico A4.1.3. Histograma de la variable superficie al aire libre (ha).......291 Gráfico A4.1.4. Diagrama Caja-Bigotes de la variable superficie al aire libre (ha) 291

Gráfico A4.1.5. Histograma de la variable superficie de invernadero en suelo

Gráfico A4.1.6. Diagrama Caja-Bigotes de la variable superficie de invernadero en suelo 
Gráfico A4.1.7. Histograma de la variable superficie de invernadero en sustrato .....

Gráfico A4.1.8. Diagrama Caja-Bigotes de la variable superficie de invernadero en sustrato

Gráfico A4.1.9. Histograma de la variable superficie de parral básico .296

Gráfico A4.1.10. Diagrama Caja-Bigotes de la variable superficie de parral básico. 296

Gráfico A4.1.11. Histograma de la variable superficie de parral mejorado 297 Gráfico A4.1.12. Diagrama Caja-Bigotes de la variable superficie de parral mejorado 298

Gráfico A4.1.13. Histograma de la variable superficie de parral multitúnel299 Gráfico A4.1.14. Diagrama Caja-Bigotes de la variable superficie de parral multitúnel 299

Gráfico A4.1.15. Histograma de la variable número de familiares con dedicación total.. 300

Gráfico A4.1.16. Diagrama Caja-Bigotes de la variable número de familiares con dedicación total. 301

Gráfico A4.1.17. Histograma de la variable número de familiares con dedicación parcial. 302

Gráfico A4.1.18. Diagrama Caja-Bigotes de la variable número de familiares con dedicación parcial .302

Gráfico A4.1.19. Histograma de la variable número de eventuales a tiempo total.

Gráfico A4.1.20. Diagrama Caja-Bigotes de la variable número de eventuales a tiempo total. .304

Gráfico A4.1.21. Histograma de la variable número de eventuales a tiempo parcial .305

Gráfico A4.1.22. Diagrama Caja-Bigotes de la variable número de eventuales a tiempo parcial. .305

Gráfico A4.1.23. Histograma de la variable número de jornales al año por familiares a tiempo parcial 306

xxiv 
Gráfico A4.1.24. Diagrama Caja-Bigotes de la variable número de jornales al año por familiares a tiempo parcial 307

Gráfico A4.1.25. Histograma de la variable número de jornales al año por eventuales a tiempo parcial

Gráfico A4.1.26. Diagrama Caja-Bigotes de la variable número de jornales al año por eventuales a tiempo parcial 308

Gráfico A4.1.27. Histograma de la variable rendimiento anual medio del pimiento $\left(\mathrm{kg} / \mathrm{m}^{2}\right)$. 309

Gráfico A4.1.28. Histograma de la variable rendimiento anual medio del tomate $\left(\mathrm{kg} / \mathrm{m}^{2}\right)$

Gráfico A4.1.29. Histograma de la variable rendimiento anual medio del pepino $\left(\mathrm{kg} / \mathrm{m}^{2}\right)$ 310

Gráfico A4.1.30. Histograma de la variable rendimiento anual medio del berenjena $\left(\mathrm{kg} / \mathrm{m}^{2}\right)$ 310

Gráfico A4.2.1. Histograma de la variable superficie del invernadero más tecnificado de la explotación $\left(\mathrm{m}^{2}\right)$

Gráfico A4.2.2. Diagrama Caja-Bigotes de la variable superficie del invernadero más tecnificado de la explotación.

Gráfico A4.2.3. Histograma de la variable temperatura de la calefacción ..316

Gráfico A4.3.1. Intención de modificar el tipo de invernadero

Gráfico A4.4.1. Lectura de publicaciones relacionadas con temas agrarios 319 

Capítulo I

Introducción y Objetivos 



\section{Capítulo I. Introducción y Objetivos}

La posición geográfica de España, con proximidad a los mercados europeos, y su favorable climatología en las regiones mediterráneas, se pueden considerar entre las características más fundamentales que han contribuido a un singular desarrollo de la horticultura española.

Hasta la expansión de los cultivos protegidos sólo existía la horticultura al aire libre, principalmente localizada en zonas con fertilidad natural. Desde los años 70 , con el crecimiento de la industria de los plásticos y sus aplicaciones a la agricultura, ha tenido lugar una transformación estructural y económica de las producciones hortícolas realmente espectacular, especialmente en Almería, Murcia y resto de las provincias mediterráneas.

El principal elemento estructural de esta evolución han sido los invernaderos en los que las condiciones de luminosidad y temperatura ambiente tienen una influencia primordial, superior a otras características y, por ello, la rápida expansión de las formas intensivas de cultivo han tenido lugar en las provincias más áridas.

La horticultura tiene una marcada significación en la agricultura española, en la que sobresale por la cantidad y el valor de las exportaciones. De acuerdo con la información del Anuario de Estadística Agroalimentaria (MAPA, 2007), aunque a nivel nacional son importantes las cantidades exportadas de algunas especies hortícolas al aire libre, como lechuga, coliflor y repollo, con un total de 897.245 tn, la proporción más importante procede de la aportación de los cultivos de invernadero que se reseñan en la Tabla 1.1, donde se indica también la evolución de sus exportaciones. 
Tabla 1.1. Evolución de las exportaciones de los principales

cultivos hortícolas en invernadero (tn)

\begin{tabular}{lrrrr}
\hline Cultivos & $\mathbf{1 9 9 0}$ & $\mathbf{1 9 9 8}$ & $\mathbf{2 0 0 4}$ & $\mathbf{2 0 0 6}$ \\
\hline Sandía & 131.174 & 336.314 & 311.058 & 363.168 \\
Melón & 145.067 & 386.311 & 396.793 & 380.039 \\
Pepino & 127.386 & 321.146 & 407.788 & 400.117 \\
Calabacín & 65.640 & 135.911 & 215.992 & 218.373 \\
Berenjena & 16.938 & 45.950 & 73.027 & 89.256 \\
Tomate & 336.915 & 865.128 & 1.036 .833 & 997.514 \\
Pimiento & 171.854 & 418.327 & 406.375 & 483.256 \\
\hline Total & 994.974 & 2.509 .087 & 2.847 .866 & 2.931 .723 \\
\hline
\end{tabular}

Fuente: Anuario de Estadística Agroalimentaria (MAPA, 2000 y 2007)

De los cultivos incluidos en la Tabla 1.1, si se consideran las tres áreas productivas más importantes de España, que son las provincias de Almería, Murcia y Alicante, se comprueba que, con una superficie más bien reducida de 53.735 ha, acumulan una producción de 3.486 .256 tn, (el $53 \%$ de la producción nacional). De la mencionada superficie, el $81 \%$ se localiza en cultivo protegido, la mayor parte en invernadero, y sólo el $19 \%$ tiene su origen en las plantaciones al aire libre.

Después de casi cuatro décadas de expansión de las producciones intensivas, en el sector hortícola de las mencionadas áreas, el invernadero constituye un factor de producción clave en la competitividad, la cual tiene su base en:

- La producción a coste más bajo que en la horticultura de invernadero localizada al norte de los Pirineos, a su vez, con menor dependencia de aportes de energía cuyo precio dificulta una mayor utilización.

- Una red de comercialización eficiente constituida por alhóndigas y cooperativas a las que se agregan grandes empresas con producción propia. 
- En la comercialización la proximidad a los mercados europeos ha propiciado una facilidad de suministro rápido y directo a las grandes superficies mediante transporte por carretera y con productos acondicionados.

- Continúa la disponibilidad de mano de obra en este tipo de trabajos que no requiere una gran especialización.

Las ventajas y la necesidad de utilizar el invernadero como principal elemento en la producción vienen impuestas por la mayor facilidad para proteger la plantación de las virosis y otras enfermedades, y por las exigencias técnicas y comerciales, ya que son evidentes las ventajas en cuanto a rendimientos, calidad y calendario de producción.

No obstante, la manifestación de crecimiento y firmeza de la horticultura que ha tenido lugar en las cuatro últimas décadas, no debe inducir a pensar que se trata de una posición inmóvil y definitiva.

Como se observa en la Tabla 1.1, entre los años 1990 y 2004 la cifra de las exportaciones casi se triplicó, sin embargo, en los dos últimos años hay una cierta estabilización que nos lleva a deducir que salvo expansión en nuevos mercados, en los actuales parece que existen límites.

Con referencia al tomate y pimiento, las dos producciones hortícolas bajo invernadero más importantes, el análisis de precios medios percibidos por los agricultores (MAPA, 2006), con actualización a diciembre de 2006, muestra la siguiente evolución de la tendencia:

- En el tomate, desde 1985 hasta el 1999, hay una disminución del $45 \%$ (3,2\% anual), y del 2000 al 2006 se registra un descenso menos acusado del $12 \%(1,7 \%$ anual). 
- En el pimiento, la tendencia es creciente hasta 1998 con un crecimiento del $32 \%$ (2,3\% anual); pero a partir del 1999 , experimenta un cambio de signo y se registra un descenso del $3 \%(0,4 \%$ anual $)$.

En consecuencia, se detecta una pérdida de poder adquisitivo para el productor que indica cierta dificultad, por lo que resulta necesario poner atención en nuevas estrategias.

La actual evolución de la horticultura hace prever dificultades para España creadas por la competencia cada vez mayor de otros países del área Mediterránea, del mismo modo que, en su día, España creó dificultades a la horticultura del centro de Europa, acaparando una proporción importante en las cantidades absorbidas por los mercados.

Frente a las presiones en el seno de la Organización Mundial de Comercio (OMC), resulta imprescindible aceptar que no es posible impedir la liberalización que se exige a los mercados, y que a la UE cada vez le es más difícil mantener una política proteccionista en el sector agrario.

Además de las consecuencias que se derivan de la inevitable globalización, ya es imparable la creación de una zona de libre cambio entre la UE y los países mediterráneos (García-Azcárate y Mastrostefano, 2006), a la que sucederán reajustes imprescindibles que afectarán a los sectores agrarios de ambos grupos de países, y muy directamente a la horticultura intensiva española.

La producción y comercialización de los productos hortícolas, especialmente los de consumo en fresco, va a estar muy condicionada por:

- El Acuerdo Euromediterráneo. 
- La tendencia descendente en las rentas percibidas por los productores.

- Unos mercados muy abastecidos, con riesgo de saturación y descenso en los precios.

- La comercialización cada vez más dominada por la gran distribución que actúa como un oligopolio que, debido a la sobreoferta, impone a los proveedores, muy numerosos, acusados descensos de los precios.

- La trazabilidad obligatoria desde el año 2005.

- La irregular aplicación de las normas sobre límites máximos de residuos (LMR) en la UE, que a pesar de la existencia de una ley sobre armonización de dichos límites, no parece que exista prohibición a la fijación discrecional por parte de algunas cadenas alimentarias. Todo ello, explotando la excesiva sensibilización de los consumidores por la sanidad y seguridad de los productos.

Es obvio que España no puede competir con terceros países en los costes de la mano de obra y, para mantener la posición competitiva, es preciso una mayor utilización de capital y técnica. Para ello, al mismo tiempo se ha de cumplir con las exigencias en materia de calidad y seguridad alimentaria marcadas por la trazabilidad sin dejar a un lado las normas medioambientales.

España debe seguir una vía paralela a la de Holanda en la horticultura intensiva, y elevar los niveles de tecnología e inversión, pero con adaptación a las condiciones naturales y socioeconómicas españolas. El desarrollo no tiene que centrarse solamente en la producción, también se ha de extender a la comercialización de estructuras y equipo para invernaderos y a la producción de semillas y plantas. El Acuerdo Euromediterráneo puede plantear graves 
dificultades en el calendario comercial pero, al mismo tiempo, hay que aprovechar las oportunidades que ofrezca.

Para atender las exigencias de los mercados, elevación de los niveles de calidad, diferenciación de productos y diversificación de la oferta, además de un mayor grado de equipamiento de los invernaderos, es posible elegir diferentes opciones entre las que se señalan: el cultivo en sustrato, la Producción Integrada (PI) y la Producción Ecológica (PE).

Un mayor nivel del equipamiento con mejora de las estructuras de los invernaderos resulta imprescindible para perfeccionar el manejo de las condiciones climáticas y aumentar la calidad, que ha de completarse con la implantación de la PI con control biológico para responder a las exigencias de los consumidores respecto a la sanidad de los alimentos y a la producción sin dañar al medio ambiente. A la opción, y más bien, a la necesidad de la PI, se une la introducción y expansión de la PE, que cumple fines parecidos a los de la PI pero más estrictos, y también representa una forma de diversificar la oferta, aunque posiblemente, con ciertos límites.

En el cultivo en sustrato la tecnología empleada lleva consigo una elevación considerable del capital invertido, mientras que en las producciones integrada y ecológica predomina el empleo de factores variables y de gestión humana.

Respecto a la estructura de los invernaderos, gran parte de ella ha procedido de una evolución de la tecnología propia, y se ha debido a la fácil implantación que tuvieron en principio los invernaderos del tipo parral plano, entre los años 1970 y 1990.

No obstante, su estructura presenta serias limitaciones para el control climático. De hecho, en los que tienen menos de 14 años ya 
ha disminuido considerablemente la proporción con la estructura plana (Molina et al., 2003).

Es necesario plantearse si el control climático que proporcionan las estructuras y el equipamiento actuales pueden ser viables económicamente de forma indefinida, o necesariamente tendrán que adoptar modificaciones importantes con mayores inversiones. Hay que vencer dificultades estructurales e institucionales, con el fin de llegar al nivel tecnológico que corresponde a la situación española.

El problema fundamental es la herencia de una posición conformista durante las décadas de rápida expansión, en las que los resultados económicos eran buenos, con niveles de inversión bajos. Actualmente son necesarias mayores inversiones cuando el beneficio marginal del capital disminuye (Fernández-Zamudio et al., 2006).

Por otra parte, la horticultura bajo abrigo es una actividad con suficiente peso en la agricultura, e incluso en la economía nacional, pero parece marginada de los grandes debates de la Política Agraria Comunitaria (PAC). No es agricultura continental y, desde luego, no es emblema de la biodiversidad, incluso se tiende a la asociación con criterios productivistas, cuando es una actividad más tecnificada y con mayor racionalidad en el empleo de los factores de producción.

Desde otra óptica, parece suficientemente demostrada la aptitud de los invernaderos para formas exigentes de PI y certificada, y para la $P E$.

Respecto a cualquier tipo de subvenciones o pagos desacoplados, aparte de ser insuficientes, la horticultura intensiva no aporta derechos históricos.

La actividad requiere el planteamiento de una reestructuración a fondo, que hará precisa una toma de conciencia 
por parte de las Administraciones para establecer las líneas de crédito y subvención necesarias. Se trata de una rama de la agricultura, cuya importancia respecto a las toneladas exportadas y a su valor, es comparable, e incluso superior, al de la citricultura.

Ante unas exigencias no aplazables de reestructuración en los invernaderos, surge la necesidad de conocer su estado actual y el grado de evolución en que se encuentran y, además, las características de las explotaciones y el estado de opinión y la actitud de sus titulares respecto a las innovaciones necesarias. Por todo ello, se ha elaborado la presente tesis con el fin de aportar un análisis científico que dé soporte y orientación a las decisiones sobre la problemática derivada de la reestructuración y sus implicaciones, tanto en Política Agraria como en entidades privadas.

\subsection{Objetivos}

Para valorar el estado actual de la tecnología en invernaderos mediterráneos, y determinar las necesidades y posibilidades de adopción de niveles superiores, se plantean los siguientes objetivos:

1. Determinar la incidencia de los precios en origen en la situación económica del pimiento y tomate como principales cultivos hortícolas, y la relación de las tecnologías susceptibles de adopción en los invernaderos con estos precios.

2. Estimar, a partir de la estructura y elementos que componen los invernaderos, el estado actual de la tecnología existente y las necesidades de adopción de nueva tecnología.

3. Analizar las características estructurales de las explotaciones y la disposición de los empresarios hacia las inversiones en los invernaderos. 
4. Establecer los niveles tecnológicos y elementos que los definen en el conjunto de invernaderos del área mediterránea, cuál es su grado de evolución en la tecnología y factores que afectan al proceso de adopción.

5. Estudiar la actitud de los titulares de explotación hacia el cultivo en sustrato como técnica fundamental y qué disposición tienen respecto a la adopción de esta técnica junto con el equipamiento asociado.

\subsection{Contenido de la memoria}

El contenido de la memoria comprende seis capítulos:

- En el primero, se formulan la introducción, el planteamiento y los objetivos.

- El segundo contiene, en la primera parte, unos fundamentos teóricos sobre las innovaciones, la adopción de tecnología y los factores que afectan a los procesos de adopción. Se ha incluido también en este capítulo una selección de la bibliografía básica para la realización del trabajo, así como las obras y artículos con técnica y metodología más relacionadas con los diversos temas analizados.

- El tercero incluye diversos análisis de precios del tomate y pimiento, como principales cultivos hortícolas intensivos. A través de estos análisis se efectúa una primera estimación de la posición competitiva de estos productos, se determinan la evolución de los precios a través de la tendencia y la estacionalidad, y se realiza una predicción de los precios en origen. Se valoran los elementos y 
técnicas más relacionadas con los precios de los productos.

- El cuarto presenta una exposición de la tecnología existente en los invernaderos mediterráneos, con la estructura y elementos que los componen, y las necesidades de adopción de nueva tecnología. En el análisis de las características estructurales de las explotaciones con invernaderos, se determina también la disposición de los empresarios hacia las inversiones y su actitud hacia la aceptación del riesgo. Finalmente se establecen niveles tecnológicos diferenciados, se señala el grado de evolución en que se encuentran los invernaderos mediterráneos y factores que afectan al proceso de adopción de la tecnología.

- En el quinto se describen, en principio, las características del cultivo en sustrato con la tecnología asociada. El resto del capítulo incide en el análisis de la actitud de los titulares de las explotaciones hacia el cultivo en sustrato y qué disposición tienen respecto a la adopción de esta técnica y el equipamiento que conlleva.

- En el capítulo sexto se exponen las conclusiones finales y se añade un apartado en el que se proponen futuras líneas de investigación.

- El desarrollo de la tesis termina con la relación de referencias bibliográficas y un grupo de cinco anexos que aportan información y complementan determinados aspectos descriptivos, a los que se agregan los cuestionarios de las encuestas realizadas. 
Capítulo II

Las innovaciones en la tecnología, base teórica.

Selección bibliográfica 



\section{Capítulo II. Las innovaciones en la tecnología, base teórica. Selección bibliográfica}

El incremento de la competitividad en una actividad productiva depende de la incorporación de equipo y tecnología que, en las condiciones socioeconómicas del sistema, proporcionen la máxima eficiencia. Si un sistema adopta tecnología con rapidez, la consecuencia será un rápido crecimiento económico.

La innovación se manifiesta:

- Por la obtención e introducción en el mercado de nuevos productos.

- Por cambios en el equipamiento y procesos productivos de la empresa.

Existe innovación en productos cuando son nuevos, o han experimentado un cambio significativo, y al introducirlos en el mercado son más competitivos y proporcionan incrementos de beneficio.

Cuando la innovación se refiere a un proceso productivo se modifica la tecnología empleada en la empresa hasta la fase comercial y, si es preciso el equipamiento, de forma que la nueva situación eleve la eficiencia técnica y económica.

Se distinguen dos tipos de innovación, tanto si se efectúa en forma de productos como de procesos:

- Drástica, cuando representa un cambio total o de gran alcance. En este caso, el producto obtenido o la 
tecnología y el equipamiento introducidos, originan una utilización, prestaciones y características totalmente distintas de situaciones anteriores.

- Gradual: En este caso, con la modificación van mejorando prestaciones y resultados económicos en función de la aplicación de la técnica y del aumento de la dotación de elementos necesarios. A su vez, los elementos pueden ser simples, cuando realicen por sí mismos o independientemente una función; o complejos, cuando una función puede ser realizada con mayor o menor nivel de perfección según la cantidad y calidad de los elementos que se agreguen.

La innovación, en términos económicos, fue definida como "cambio histórico e irreversible en el proceso de producción" (Schumpeter, 1939), lo que representa alterar las combinaciones de los factores de producción y la técnica empleada y, en consecuencia, que se origine un nuevo proceso gobernado por una función de producción distinta. Las empresas adoptando innovaciones van modificando la función de producción y con otras combinaciones de los factores van logrando mayores niveles de eficiencia.

La innovación también puede producirse en forma de cambio técnico sin que afecte a la cantidad de los factores de producción.

Precisando la distinción de los conceptos "tecnológico" y "técnico", se establece que el cambio tecnológico equivale al acto de producir nuevo conocimiento, y el cambio técnico se refiere a la incorporación del conocimiento en la actividad productiva de las empresas (Freeman, 1975; Fernández et al., 1983).

El proceso que sigue la generación de innovaciones se inicia en el proyecto de investigación sobre un problema existente y se 
extiende con su desarrollo hasta la comercialización del producto o proceso originado.

En una investigación realizada por Booz et al. (1968) se señalan las siguientes etapas en la innovación de un producto: selección de proyectos iniciales, primera evaluación técnica y económica, desarrollo, prueba definitiva y comercialización. Los autores estimaron que sólo sobrevive el $3,5 \%$ de los proyectos iniciales.

Para Sunding y Zilberman (2001) las fases que se requieren en la generación de un producto dependen de sus características, aceptándose como más comunes: descubrimiento, registro, desarrollo, producción y comercialización.

\subsection{Adopción de innovaciones}

Como concepto, la adopción es un conjunto de fases sucesivas en las decisiones de los individuos para acordar si aceptan o rechazan una innovación (Gatignon y Robertson, 1991). Para Rogers (1962) son las etapas mentales por las que pasa un individuo en sus reflexiones, desde que conoce la existencia de una innovación hasta que decide adoptarla.

La adopción es un proceso simple, a pesar de los diferentes tipos de innovaciones, de adoptantes dispuestos y tiempo que pueden emplear para decidir si aceptan o rechazan una innovación (Lidner, 1987); comprende dos aspectos fundamentales: el riesgo en la elección y la adquisición de conocimiento.

El riesgo que implica la determinación de adoptar, disminuye a medida que aumenta el conocimiento. La decisión, por tanto, depende del conocimiento de los distintos parámetros que la 
condicionan. Comprende un proceso de aprendizaje evolutivo que incluye la obtención de información y, a continuación, su incorporación y relación con los conocimientos de los adoptantes disponibles 0 el convencimiento que surge cuando se va desarrollando una innovación. Con el tiempo, varían las creencias que cambian la percepción sobre la tecnología y modifican las intenciones sobre la adopción (Panell et al., 2006).

\subsubsection{Etapas en la adopción}

La adopción de una innovación, vista individualmente, comprende varias etapas a través de las cuales un adoptante pasa por una serie de reflexiones que van desde conocer la innovación hasta decidir si la acepta o rechaza.

En este proceso se examinan diversas elecciones y acciones en el tiempo, mediante las cuales se decidirá en la empresa si una nueva idea es favorable y si es conveniente incorporar la innovación que representa a su funcionamiento habitual.

Las diferentes etapas del proceso se han definido y ordenado en cinco fases, según un modelo elaborado en la Universidad lowa, muy aceptado:

- Conocimiento: El titular de explotación conoce por primera vez la innovación pero sin apenas información.

- Interés: Se refiere al periodo en el que el titular perfecciona el conocimiento con una información adicional.

- Evaluación: En esta fase el titular procede a ordenar la información recibida y estimar la validez considerando sus condiciones, para lo cual tiene en cuenta las ventajas que proporciona, los posibles costes y vida útil. 
- $\quad$ Prueba: El titular toma la decisión de ensayar a pequeña escala en su explotación para comprobar personalmente los resultados de la innovación.

- $\quad$ Adopción: Se refiere a la introducción de la innovación en la explotación. Dependiendo de las características del elemento o procedimiento a adoptar, puede efectuarse en una sola vez con la adquisición, si es indivisible, o mediante una serie de compras, en caso de que la finalidad prevista se pueda cumplir gradualmente agregando elementos.

El primer autor que introdujo, en los modelos, factores relacionados con la conducta de los empresarios en la adopción fue Tan (1994); este autor demostró que había un conjunto de variables relativas al comportamiento personal, económicas y relacionadas con las características del producto o método de producción que afectaban a la decisión de adoptar.

Se consideraban variables fundamentales la actitud ante el riesgo, las características subjetivas en la percepción de la innovación, la incertidumbre en la información captada por el individuo adoptante y los condicionantes económicos de la empresa.

\subsubsection{Categorías de adoptantes y su distribución}

La mayor o menor rapidez en la aceptación de innovaciones por un individuo, respecto a otros miembros de su sistema social, se denomina innovatividad (Rogers, 2003). Tiene relación con las características personales del individuo adoptante y con el entorno, puesto que la rapidez de la adopción es diferente entre los miembros de un grupo social. 
Para estudiar la distribución de los integrantes de un grupo social de acuerdo con el tiempo empleado en una determinada adopción, se pueden formar categorías de adoptantes que incluyan individuos con un comportamiento similar en cuanto a la innovatividad. Para ello, desarrollando la función de densidad de probabilidad normal de adoptantes y su función acumulada, se determinan las cinco categorías a partir de la media y la distribución estándar que se representan en el Gráfico 2.1. Los grupos asignados a cada categoría representados en el gráfico son:

- Los innovadores, una baja proporción, sólo el 2,5\% de los individuos del sistema social; están situados a la izquierda del valor medio del tiempo de adopción, con un valor de la media de dicho tiempo menos el doble de la desviación estándar. Aunque el grupo es poco numeroso tiene gran interés por su escasa aversión al riesgo.

- Primeros adoptantes. Este grupo afecta al 13,5\% del sistema social y están situados entre el valor de los innovadores y el de la media menos la desviación estándar. Normalmente sus miembros están más integrados en el sistema social que el grupo de innovadores y más influenciados por los líderes de opinión. Su importancia radica en la función que pueden tener respecto a la transmisión de una información con la experiencia propia.

- La primera mayoría, es el primer grupo situado a la izquierda de la media, afecta al $34 \%$ de la población y su intervalo está definido por la media y la media menos una desviación estándar. Siguen deliberadamente a los primeros adoptantes y su periodo de innovación-adopción es más largo. 
- La última mayoría, es la que adopta en un tiempo superior a la media y su intervalo está acotado por el valor del tiempo medio y el de dicho valor medio más una desviación estándar. Afecta al $34 \%$ de los miembros del sistema social y en éste suelen estar incluidos individuos con alguna escasez de recursos que se deciden a adoptar cuando toda la incertidumbre que rodea al proceso ha desaparecido.

- Por último, el grupo de los rezagados, con un $16 \%$, se sitúan bajo el extremo derecho de la curva a partir del valor medio del tiempo más la desviación estándar. Sus miembros suelen tener dificultades en las explotaciones, no están influidos por los medios de comunicación y son personas poco inclinadas a las innovaciones.

\section{Gráfico 2.1. Gráfico de densidad de probabilidad normal de adoptantes}

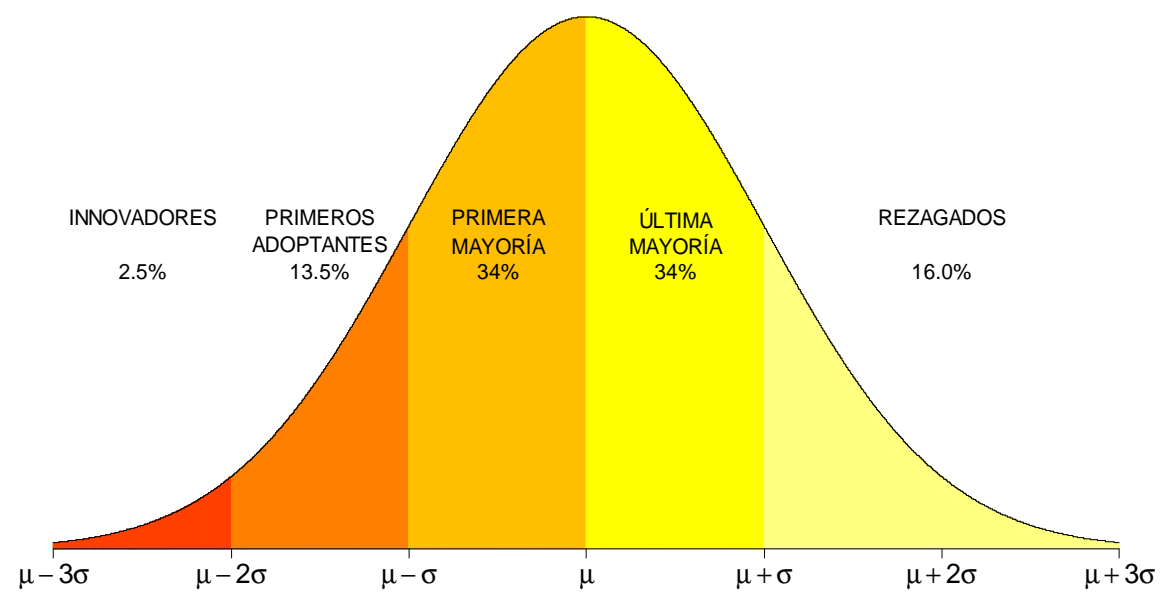

Fuente: Elaboración propia a partir de Rogers (2003). 


\subsubsection{Líneas de análisis del proceso de adopción}

La adquisición del conocimiento para la adopción depende de la disposición del individuo y de los canales de comunicación con los que le llega la información. Una interpretación correcta de la información reduce la incertidumbre que va asociada a la adopción. Los medios de comunicación masiva son capaces de llegar a la población de forma rápida pero se le atribuye un efecto débil para cambiar aptitudes preconcebidas. Sin embargo, los canales interpersonales con comunicación directa aclaran más la información acerca de la innovación y superan las barreras psicológicas y sociales de la exposición y percepción; a todo ello se añade un mayor efecto sobre el cambio de actitudes preconcebidas, lo que les hace más eficientes para la persuasión (Rogers y Shoemaker, 1971).

En los canales de comunicación interpersonales es importante la figura del agente de cambio, que suele ser un profesional que influye en las decisiones sobre las innovaciones según conveniencia de la organización a la que representa. Este agente, que suele acortar los periodos de adopción, puede ser desde el agente de ventas de una empresa distribuidora de determinadas innovaciones hasta, muy frecuente en el caso de la agricultura, empleados del servicio de extensión agraria o técnicos de cooperativas.

Aunque el fin fundamental de este estudio se centra en la adopción, la difusión constituye una prolongación de la adopción, por lo que se incluye su definición y se mencionan los modelos que comprenden ambas fases.

Se conoce como difusión tecnológica a la propagación de la adquisición y uso de una nueva tecnología (Karshenas y Stoneman, 1995). El efecto del cambio tecnológico sobre la situación de un 
sistema social tiene dependencia con el grado de difusión de las innovaciones, que influyen decisivamente en el crecimiento económico.

Como líneas de trabajo para el estudio de la actitud y factores que afectan a los procesos de adopción y difusión, en función de la perspectiva del análisis, se señalan:

- Estudios de sección cruzada, que tratan de determinar el comportamiento del titular de la explotación respecto a la adopción de una innovación, junto con los factores que la determinan en un momento definido; este momento suele corresponder con el periodo de la toma de información cuando ésta se realiza por encuesta.

- Estudios temporales. En este caso se determinan los periodos de tiempo y el retraso existente entre el desarrollo de una innovación y su adopción por el titular de la explotación. Con ello se analiza la evolución temporal, tratándose de explicar por qué unos adoptantes aceptan rápidamente mientras que otros retrasan la adopción.

\subsubsection{Factores que influyen en el proceso de adopción}

En la adopción de tecnología resulta fundamental identificar y evaluar la acción de los factores que pueden influir. Alcón et al. (2008) clasifican los factores en los siguientes grupos:

1) Características del agricultor. Se consideran como más significativas para tenerlas en cuenta: la edad, si la sucesión está asegurada o no, contacto con fuentes de información, asociacionismo, inclinación o aversión al riesgo, mentalidad 
empresarial, comportamiento innovador y criterios medioambientales.

2) Factores económicos. Entre ellos se encuentran: volumen de negocio de la empresa, productos obtenidos, disponibilidad de mano de obra y maquinaria, utilización de capitales y acceso al crédito y comercialización.

3) Características de la explotación. Se destacan: dimensión, orientaciones productivas, distribución de los cultivos, tecnología empleada, características de la mano de obra y dedicación total o parcial del titular.

4) Características de la innovación: importancia para el titular de la explotación y cómo influye en las variables económicas, complejidad en la utilización, riesgo percibido, valoración subjetiva de la inversión y experiencia en la aplicación de una técnica determinada.

5) Factores externos: existencia de canales de información y empresas técnicas de servicios, disponibilidad de técnicos especializados por parte de las cooperativas, disponibilidad de energía eléctrica y agua en cantidad o calidad, nivel de las instalaciones colindantes y cómo le afectan las subvenciones, los impuestos y las regulaciones ambientales.

\subsection{Selección bibliográfica}

Aunque la investigación realizada toma como punto de partida, sobre todo, el estado actual de la tecnología en invernaderos y la actitud de los titulares de explotaciones hacia la adopción de tecnología, considerando los objetivos se han tenido también en cuenta los trabajos de tipo técnico, y especialmente económico, más 
relacionados con el contenido de los diferentes capítulos, poniendo atención además en los artículos o tratados que dan soporte a la metodología y su aplicación.

Dada la amplitud y variedad de los diferentes temas tratados, la exposición bibliográfica que se realiza a continuación dista de ser amplia, y tiene como finalidad resumir de la forma más concreta posible el conjunto de trabajos consultados.

De acuerdo con la estructura y desarrollo de la tesis se agrupa la bibliografía en los siguientes temas:

- Precios y su comportamiento

- La adopción de tecnología

- Adopción de tecnología en invernaderos

- Bibliografía auxiliar:

La tecnología en los invernaderos

Aplicaciones de las metodologías empleadas

\subsubsection{Precios y su comportamiento}

Para calcular la variación de las rentas agrarias a través de los precios, se ha empleado la tendencia dentro del periodo de años que comprende la serie. Con esta finalidad se señalan los trabajos de Caballero et al. (1992) y De-Miguel et al. (1994) que analizan la variación de las rentas a través de los precios y los costes en las principales especies hortofrutícolas, incluyendo el cálculo del riesgo en los beneficios, Caballero y Fernández-Zamudio (2003) aplican al níspero las mismas determinaciones. Otras aplicaciones de la tendencia se encuentran en Hinojosa et al. (2003) a los mercados 
internacionales de cacao y banano orgánico y Arias (2002) a las ventas de tractores en España.

La metodología sobre los índices estacionales ha sido puesta a punto por numerosos autores, entre los que se señalan Lange (1974) y Uriel y Peiró (2000). Se ha empleado la determinación de índices estacionales de series de precios en hortofruticultura en los trabajos de Benedicto y Caballero (1983) para optimizar el empleo de las cámaras frigoríficas en la comercialización de los agrios, y Caballero et al. (1992) donde se utilizaron para calcular las variaciones relativas de los precios en los periodos de comercialización de agrios, frutales y principales especies hortícolas. Noguera (1996) examina el componente estacional de las series de precios de tomate y pimiento para consumo en fresco; GarcíaMartínez et al. (2008) determinan la tendencia y la estacionalidad de los precios en origen del tomate y pimiento en las zonas de Almería, Murcia y sur de Alicante; el estudio se completó con una predicción de los precios mediante modelos ARIMA.

Como aplicación de los modelos ARIMA (Box y Jenkins, 1976) a trabajos empíricos sobre series temporales en agricultura señalamos los trabajos de Albisu et al. (1984) en el sector de los vinos, Romero y Balasch (1986) en la evaluación de la efectividad de la lucha antigranizo, Cases (1994) en la predicción de los precios de las principales variedades citrícolas, Douvelis (1994) aplica dicha metodología a los precios de las semillas de girasol en Estados Unidos; dentro del área de producción, Arias y Alonso (2000) sobre predicción de superficie sembrada de remolacha en Castilla-León, Chambers (2004) lo emplea para predecir los precios del grano en alimentación animal. Finalmente, Guigó (2004) en un trabajo de carácter histórico, utiliza la metodología Box-Jenkins junto con el análisis espectral para explicar la presencia o ausencia de integración 
en los mercados de cebada y Najeeb et al. (2005) en el cálculo del área sembrada y la producción previsible de trigo en Pakistán.

\subsubsection{La adopción de tecnología}

Sin considerar criterios históricos, se va a efectuar una relación de trabajos más especializados en las diversas formas de adopción de tecnología. La descripción se inicia con los estudios que basan su información en una sección cruzada.

El estudio puede abordarse desde una perspectiva muy amplia o limitarse a una simple adopción de una técnica o un elemento fundamental en el proceso productivo. La adopción puede ser explicada tomando un número muy reducido de elementos y un modelo matemático que exprese con precisión las diversas relaciones, o por un análisis más extenso que contemple características de la tecnología, factores que condicionan su adopción, que pueden ser intrínsecos a dicha tecnología, o bien, formar parte de las más variadas características del sistema agrario.

La sección cruzada presenta la ventaja de obtener por muestreo en un momento determinado, una información amplia y contrastable con la realidad. A su vez, las relaciones que se detectan entre las variables como consecuencia del análisis efectuado, responden a una relación instantánea y no alterada por el tiempo.

Por otra parte, un estudio temporal basado en series con cierta amplitud, es capaz de explicar una adopción a través de factores que confirman su significación o importancia en el tiempo, pero con el inconveniente que presenta la rápida evolución de las condiciones técnicas y socioeconómicas que hace difícil la comparación entre dos periodos distintos. 
Los estudios que tienen su fundamento en identificar un determinado número de variables que explican o determinan la adopción de tecnología son muy numerosos. Sobre adopción de diversas tecnologías en agricultura, se encuentra el artículo de Rahm y Huffman (1984) sobre técnicas de reducción de laboreo; en éste se determinan las variables que más influyen en su elección que los autores agrupan en las que corresponden a las características del suelo, las empresariales y las que se refieren al capital humano. También sobre factores determinantes de la adopción Feder et al. (1985) elaboraron el mencionado trabajo a partir de una encuesta que tomaba información sobre un amplio conjunto de variables.

Del mismo modo, los factores condicionantes en la elección de tecnologías de riego son el tema principal en la publicación de Negri y Brooks (1990); estos autores estudian la probabilidad de elección de dos tecnologías de riego con ahorro de agua. Los resultados muestran que el tamaño pequeño de la explotación, el alto coste del agua, la mano de obra y la baja capacidad de retención de los suelos incrementan la probabilidad de elección del riego por aspersión, mientras que la irrigación por gravedad está más condicionada por la mayor extensión de las explotaciones, el agua cara y los suelos con alta capacidad de retención.

De-Cock (2005) determinó que un grupo de variables, junto con el negocio empresarial y los objetivos personales, condicionaban la voluntad de los agricultores hacia métodos de agricultura ecológica. En el análisis se aplicó la predicción a través de modelos de regresión ordinal. La caracterización del comportamiento económico del agricultor ecológico frente al convencional se expone en el trabajo de Serra et al. (2008), para lo cual se utilizó un modelo de decisión empresarial bajo riesgo que valora los incentivos para la adopción de prácticas ecológicas. 
Sobre el "no laboreo", en cuya difusión se actuó intensamente en Estados Unidos, especialmente desde el principio de los años 80, Krause y Black (1995) analizaron las estrategias óptimas en la adopción de esta técnica. Como metodología de análisis utilizaron la programación dinámica y entre las principales conclusiones señalan las variables que pueden retrasar la adopción, como la relación entre los costes y la aversión al riesgo y los procedimientos para promover la introducción del "no laboreo". Posteriormente han insistido en ese tema Kurkalova et al. (2006) y Jungklaus y Happe (2007) en Bulgaria.

En relación con la adopción de tecnologías del riego, cabe mencionar los artículos de Carey y Zilberman (2002), Dridi y Khanna (2005) y Baerenklau y Knapp (2007). El primero, aplica un modelo dinámico estocástico para estudiar la adopción de tecnología de la irrigación. Los mercados de agua son un tema fundamental de análisis, respecto a los cuales los autores indican que pueden retrasar la adopción. El segundo, analiza la asignación de recursos hídricos a través de información asimétrica para un mercado limitado. El tercero, aplica un modelo dinámico de adopción con el cual concluyen que la inversión óptima se ve afectada por la incertidumbre sobre la cual hay un efecto de disminución con la antigüedad de la tecnología.

La adopción de tecnología de riego bajo un contexto de incertidumbre ha sido estudiado por Koundouri et al. (2006) a través de un modelo estructural. Los resultados empíricos indican que los agricultores adoptan nueva tecnología en una situación de riesgo límite; también, resaltan el papel significante del capital humano.

Isik y Khanna (2003) determinan preferencias en el riesgo con análisis estocástico y concluyen que mejorando la precisión de las tecnologías específicas habituales podrían incrementarse los incentivos para la adopción. 
Un modelo dinámico de adopción de tecnología aplicado a la producción láctea se contempla en el trabajo de Barham et al. (2004) en cuyos resultados indican los grados de adopción según características de las explotaciones. En España, se aplicó un modelo dinámico de crecimiento para la adopción de innovaciones en el tractor agrícola, por Muñoz (2004).

Useche et al. (2009) estudia las preferencias en la adopción de semillas de producciones modificadas genéticamente para lo cual utilizan un modelo logit multinomial. Tomando como base una encuesta efectuada a 252 agricultores, Peterson et al. (2002) investigan cuál es el grado de modificación de la gestión en los años posteriores a la adopción de soja transgénica.

\subsubsection{Análisis de duración}

En general, las preferencias sobre el riesgo en posibles adoptantes han sido explicadas a través de diversos modelos por Abadi y Panell (1999) y Marra et al. (2003), considerando la evolución temporal más relacionada con el comportamiento de las personas en el cual hay una información recopilada sobre la tecnología que completa el conocimiento y reduce el riesgo propio de la innovación.

Una línea de investigación fundamental en la adopción de tecnología es la que emplea los modelos de duración, los cuales estudian el periodo de tiempo que requiere un proceso de adopción por un individuo con un perfil definido, y tratan de explicar por qué unos adoptan con rapidez y otros se retrasan o no llegan a adoptar. Kalbfleisch y Prentice (1980) y Kiefer (1988), con la estimación de funciones de riesgo, han explicado los factores que condicionan el tiempo de adopción y el orden de su importancia. Ejemplos de estudios que fijan la probabilidad para la adopción de una determinada tecnología por un adoptante en un momento dado son 
los de Colman et al. (2002), Dadi et al. (2004), Abdulai y Huffman (2005) y D'Emben et al. (2006), que para el análisis utilizan datos de sección cruzada combinados con otros procedentes de series temporales; con todo ello, además de la adopción, se estudia la difusión, cuya curva adopta la forma de $S$ (Pindyck y Rubinfeld, 1998; Train, 2003).

Los modelos temporales agregados determinan el ajuste de un proceso, y no sólo explican el último nivel de adopción sino que también incorporan la tasa de ajuste dinámica modelando el proceso de difusión en forma de $S$ (Alcón, 2007). Los modelos de difusión dan a conocer en el tiempo el nivel de transmisión de una innovación dentro de un conjunto dado de individuos adoptantes (Mahajan et al., 1990).

Una combinación de modelos de análisis de duración con regresión logística multinomial fueron utilizados por Wynn et al. (2001) para calcular la probabilidad y la proporción de agricultores que entran en los programas de áreas sensibles desde el punto de vista medioambiental. Los modelos se basaron en una encuesta realizada en Escocia. Con los resultados se identificaron un número genérico de factores que eran importantes en la decisión de entrar en dichos programas.

Matuschke y Qaim (2008) analizan la dinámica de adopción a través de modelos de duración y datos recogidos por encuesta. En los resultados se indican las variables que explican la adopción de híbridos de mijo. Por medio de un modelo logit anidado, en el artículo de Moreno y Sunding (2005) se estudia la tecnología y elección de cultivos. Burton et al. (2003) aplican el análisis de duración para determinar la adopción de tecnología en el Reino Unido en la horticultura ecológica. 


\subsubsection{Adopción de tecnología en invernaderos}

En general, la bibliografía relativa al análisis económico sobre adopción de innovaciones en invernaderos no es muy numerosa.

La actitud de los agricultores en la adopción de innovaciones y factores determinantes en invernaderos españoles, ha sido analizada por Millán y Ruiz (1987) para la zona de Almería, por medio de modelos de respuesta cualitativa, considerando los factores que influyen en la elección de las distintas innovaciones.

Sobre el análisis de inversiones en diversas tecnologías en invernaderos holandeses el artículo de Aramyan et al. (2007) incide sobre el ahorro de energía y con tema de estudio similar, aunque con modelos diferentes se incluye la publicación de Oude-Lansink y Pietola (2005). Goncharova et al. (2008) estudian los procesos de adopción a través de modelos de duración.

Una orientación diferente, dentro de la adopción de tecnologías en invernaderos, es la que proporcionan los trabajos que toman como base la programación matemática, aplicada en diversas ocasiones a las producciones en horticultura intensiva. Se ha utilizado la programación lineal en la determinación de combinaciones productivas para lograr una planificación de cultivos con un solo criterio, normalmente económico. Especialmente a partir de 1990, con la difusión de las técnicas multicriterio, ha sido aplicada la programación en la determinación de estrategias productivas a procesos de optimización con criterios a veces contradictorios.

Con la programación matemática se han desarrollado trabajos de tipo predictivo para analizar la adopción más conveniente, conforme a la variabilidad de los factores de producción y las producciones obtenidas. En este conjunto de trabajos figuran los de Berbel (1989) y Martínez-Paz (2003). 


\subsubsection{El equipamiento en los invernaderos}

Para analizar la tecnología empleada se ha seleccionado, en principio, una bibliografía básica con orientación técnica. Con un enfoque amplio, se ha tenido en cuenta la comunicación de Castilla (2004), en la que se presentan los tipos de estructuras más frecuentes así como los equipos para invernaderos mediterráneos en España con un enfoque técnico-económico. Tras la exposición de los costes de producción y su comparación con las mismas producciones en Europa, la publicación detalla el control climático para terminar concluyendo sobre la necesidad de mejorar el nivel tecnológico en los invernaderos españoles.

En la monografía de Hernández et al. (2000), sobre equipamientos y tecnología de los invernaderos, se indica la necesidad de evolucionar en los modelos optimizando las inversiones.

La obra de Matallana y Montero (2001) analiza la tecnología del diseño y construcción de invernaderos con la descripción de los materiales y métodos de cálculo necesarios.

Un tratado amplio y actual sobre los diversos tipos de invernaderos, con descripción detallada de sus elementos y las diferentes técnicas de su empleo y estrategias de producción, es el de Castilla (2005).

La evolución de los invernaderos en Almería, a través de una descripción histórica con la cronología de las diferentes etapas que la han caracterizado, se encuentra en la publicación de Navarro (2001) en la que se efectúa un desarrollo muy amplio de los cambios que han seguido las estructuras y materiales de los invernaderos y también de las técnicas de cultivo, con especial incidencia en la protección fitosanitaria. 
El artículo de Pérez et al. (2002) indica en sus primeras páginas la distribución de superficie de invernaderos en España, por provincias y en el conjunto del área mediterránea, para después reflejar las características de las estructuras productivas, equipamiento y tendencias del sistema de invernaderos en Almería. Martín (2001) da una visión panorámica sobre la evolución que deben seguir los invernaderos en el futuro.

De carácter técnico-económico se ha incluido la publicación de Caballero et al. (2001) que contiene una especial referencia a las modificaciones en la estructura y equipamiento que deben introducirse en los invernaderos españoles.

Sobre la base del control del clima en un invernadero, con un desarrollo histórico y económico para la horticultura holandesa, se encuentra el tratado de Bakker et al. (1995).

Martínez et al. (2002) describen la adopción de tecnología en los invernaderos en relación con la mayor aplicación de la informática y la electrónica. Todo ello incide en un mejor control del clima del invernadero, con un uso más eficiente de la energía y la mejora del rendimiento del trabajo.

Una descripción sobre la dotación de los invernaderos, la función de los diversos elementos y sistemas y la tecnología de control con sensores y material electrónico, se encuentra en el artículo de Blanque (2007). Con el equipamiento disponible el autor indica cómo se han de perfeccionar las funciones del control del clima (ventilación, pantallas térmicas, aporte de humedad y calefacción), fertirrigación, fertilización con $\mathrm{CO}_{2}$ y tratamientos fitosanitarios.

Con la misma problemática que el trabajo anterior, Valera y Molina (2008) inciden en la importancia de la gestión del clima, que puede abarcar desde el simple control de la apertura de ventanas en 
función de la temperatura interior a potentes equipos que actúan sobre varias funciones simultáneamente. Se insiste en el deficiente estado de la mecanización de las labores culturales en los invernaderos.

\subsubsection{Tecnologías basadas en el sustrato}

Para tener una visión panorámica de las diversas etapas de la introducción y difusión de los cultivos sin suelo en España, se han consultado las obras coordinadas de Martínez-Caldevilla y GarcíaLozano (1993), Marfá (2000) y Alarcón (2006). Cada una de ellas registra la tecnología y varias problemáticas relacionadas con los cultivos sin suelo y su difusión; así, en la primera, se trató los diversos sustratos, las soluciones nutritivas empleadas, los sistemas de riego y técnicas culturales; en la segunda, el tema base fue la reutilización del agua y las soluciones nutritivas; y en la tercera, con la experiencia adquirida desde el principio de los años 90 , se volvieron a analizar con mayor especialización los temas más importantes.

En la obra mencionada anteriormente, coordinada por Marfá (2000), en el capítulo 12, se efectúa un análisis económico sobre la viabilidad de la recirculación de soluciones nutritivas. En la tercera de las obras mencionadas, en el capítulo 14, Caballero y FernándezZamudio (2006) realizan una valoración económica de la implantación y gestión de los cultivos en sustrato, con análisis de su rentabilidad.

Dado que las tecnologías basadas en el sustrato y su adopción se consideran de forma especial en esta tesis, se ha examinado una extensa literatura en este contenido. Un tratado muy especializado de tipo técnico es el coordinado por Urrestarazu (2004) en el que se exponen los diversos tipos de cultivo sin suelo, el manejo del cultivo en sustrato y los aspectos químicos, biológicos, fisiológicos y sanitarios que le afectan, además de las exigencias en las 
características de la instalación. La obra finaliza con una evaluación económico-ambiental.

Un análisis económico de los efectos de la tecnología en la producción hortícola aplicado a los invernaderos de pimiento, se contempla en el artículo de Fernández-Zamudio et al. (2006), en el que la tecnología y el equipamiento de los invernaderos se agrupan en cuatro niveles a los que se aplica un cálculo de costes y una determinación de coeficientes que relacionan la ganancia y el beneficio con los costes totales de producción y la inversión.

\subsubsection{Sostenibilidad}

Además de los trabajos con enfoque técnico-económico se han considerado temas complementarios importantes, como la sostenibilidad. Sobre efectos en el medio ambiente, Scarascia (1995) plantea la necesidad de una producción sostenible en los invernaderos en Italia, después de analizar las consecuencias negativas de las innovaciones técnicas. Fernández-Zamudio y Caballero (2006) analizan la necesidad de cuantificar la sostenibilidad en los invernaderos de producción hortícola, para lo cual eligen dos modelos, uno con producción de pimiento en suelo, y otro, con cultivo de pimiento en sustrato.

Para avanzar hacia la sostenibilidad, Verguts et al. (2008) proponen como posible salida la agrupación de invernaderos en parques, que evitarían algunos costes elevados que se dan en la administración individual; de esta forma, habría efectos de escala compartiendo medios y se impulsaría la ecoeficiencia sin ampliaciones individuales. Gellynck et al. (2005) analizan idéntico problema a través de una encuesta realizada a los productores; el análisis se realiza mediante un modelo probit obteniéndose unos 
resultados que muestran cómo la concentración es una buena solución para los problemas espaciales.

Relacionado con la necesidad de atender los problemas de sostenibilidad en los procesos productivos, el artículo de Montero et al. (2008) describe cómo reducir el impacto ambiental utilizando adecuadamente los elementos y equipos controladores del clima, la aplicación óptima del $\mathrm{CO}_{2}$ y cuál puede ser la utilización idónea de la calefacción para causar el menor impacto ambiental.

Así como la sostenibilidad es un concepto muy amplio que influye en diversos aspectos (diseño de los invernaderos, manejo y legislación medioambiental), cuando la técnica actúa sobre la producción surgen las dos modalidades más representativas en la gestión de las operaciones culturales: la Producción Integrada (PI) y la Producción Ecológica (PE); la primera, utiliza los factores de producción con criterios sostenibles y, a su vez, económicamente viables; la segunda, utiliza factores de producción que han de cumplir la condición de no tener el origen en un proceso de síntesis.

Aunque hay especies en las que la superficie en PI no avanza, principalmente debido a la falta de apreciación comercial, sin embargo, en la horticultura intensiva va evolucionando hacia una situación generalizada. A ello ha contribuido la facilidad del control biológico dentro de los invernaderos, los cuales casi en su totalidad están dotados de mallas en las zonas de apertura. En las zonas mediterráneas la implantación de la PI se ha efectuado con mayor nivel de control que el previsto en los reglamentos iniciales.

En el trabajo de Navarro (2001) se describe la evolución de la tecnología y equipamiento en los invernaderos de Almería con orientación hacia el papel que va a desempeñar la PI. 
La implantación y evolución de la PI en la horticultura intensiva de Almería, con exposición de antecedentes, legislación basada en diversos reglamentos y órdenes de la Junta de Andalucía, tendencia y efectos previsibles, se han descrito en la publicación de Aparicio et al. (2001). Con enfoque económico, muy basado en la técnica de cultivo, Fernández-Zamudio et al. (2002) elaboraron un estudio sobre la $\mathrm{PI}$ en los invernaderos de pimiento en los que se efectúa una descripción diferenciada entre métodos y productos empleados en control químico y control integrado con empleo de fauna útil; finalmente, se evaluaron las diferencias de costes entre ambos procedimientos.

En la adopción, desarrollo y comercialización de la PI, en cuyo concepto se incluyen también diversas formas de producción certificada similares, son fundamentales los diferentes reglamentos y normas de inspección que, con aplicación a la horticultura, han sido analizados por Fernández-Sierra (2001).

Es muy reducido el número de publicaciones sobre el análisis económico de la producción ecológica en invernaderos. Con especialización en el tema, se señala el artículo de Ramos (2008) en el que se indican los factores de producción empleados y, sobre todo, la gestión del control de plagas y enfermedades.

Caballero et al. (2009) exponen las características de la PE del pimiento en invernadero calculando, a continuación, los costes y la rentabilidad. La comunicación comenta al final las dificultades de la PE para encontrar canales comerciales adecuados, la lentitud de su crecimiento (con referencia a las cantidades) y el perjuicio que le puede ocasionar, por juicio de similitud, la comercialización de frutas y hortalizas con residuo cero. 


\subsubsection{Aplicación de metodologías empleadas}

Como complemento a la selección de publicaciones relacionadas en los apartados anteriores, se efectúa una breve exposición de aplicaciones propias de los diversos procedimientos de análisis utilizados.

Entre las técnicas estadísticas elegidas, además de las que se han citado sobre el análisis de precios (apartado 2.2.1), se han introducido publicaciones sobre el análisis cluster, el análisis de componentes principales y la regresión multinomial ordinal.

Respecto al análisis cluster, se ha utilizado con frecuencia en marketing con diversos propósitos como son la segmentación de mercados y el análisis del comportamiento del consumidor (Pulido et al., 2001), entre otros. También ha sido aplicado en la investigación agraria, especialmente en la elaboración de tipologías de explotaciones. En el trabajo de Carbonell et al. (2004) para la agrupación de explotaciones porcinas, según el tratamiento de los purines, y en el estudio de "Caracterización de las explotaciones de pollos de engorde en la Comunitat Valenciana" (Martínez et al., 2008), además de un detallado análisis descriptivo, se realiza una clasificación de las naves de pollos de engorde en tres grandes grupos $y$, a partir de esta tipología, se identifican las variables responsables de la diferenciación.

En cuanto al análisis de componentes principales, parece una metodología muy aplicada dentro del ámbito agropecuario, a temas tan diversos como la producción de leche ecológica (Álvarez y Pérez, 2007), el análisis de los distritos de regadío (Rodríguez-Díaz et al., 2008), el estudio de los cambios de uso del suelo (Avellà et al., 2001), la comparación de explotaciones convencionales y ecológicas de viñedo (Amorós et al., 2005), el análisis del grado de parcelación de 
las explotaciones (Botey y Arias, 2007), la producción de vacuno en Galicia (Sineiro et al., 2005), la calidad sensorial de la Pera Rocha portuguesa (Jordao et al., 2005), la caracterización de los sistemas ganaderos extensivos (Macedo et al., 2003; Rapey et al., 2001), de los sistemas ovinos en Castilla-La Mancha (Torres et al., 1993), al estudio de los cambios morfométricos inducidos por crioconservación en esperma de macho cabrío (Marco-Jiménez et al., 2006) y con la problemática anterior se aplicó al esperma de anguilas para detectar los cambios que coinciden con las calidades más elevadas (Asturiano et al., 2006).

Como publicaciones que aplican la regresión multinomial se destacan las de Burton et al., (1999) que aplican técnicas de análisis binomial y logit multinomial para estudiar los factores determinantes del proceso de adopción de técnicas de horticultura orgánica en el Reino Unido; Barreiro, et al., (2004) establecen una aproximación al valor de marca comercial en el proceso de elección del consumidor con la utilización de dos metodologías: un modelo logit multinomial y un modelo de regresión con variables ficticias; Gentile y Rodríguez (2004) analizan el mercado interno argentino de alimentos orgánicos con caracterización de los consumidores; en el análisis se utiliza una prueba Chi-cuadrado para conocer si hay asociación entre las distintas variables y un modelo logit multinomial para precisar las probabilidades de elección de un canal de compra. La identificación de factores de riesgo en la alteración de la carne de cerdo debido a tratamientos previos al sacrificio fue analizada por Guàrdia et al. (2004) y Guàrdia et al. (2005) y Althaus et al. (2003) también utilizaron un modelo de regresión multinomial para establecer los límites de detección mediante test de inhibidores microbianos en leche de oveja. Además se puede incluir en este apartado la publicación de Useche et al. (2009) ya citada. 


\subsection{Resumen y comentarios}

La exposición de este capítulo se ha desarrollado en dos partes. En la primera se ha efectuado una relación de base teórica para tener una descripción ordenada de conceptos como la innovación, tipos y formas de manifestarse, la adopción de innovaciones y sus etapas, y los principales grupos de adoptantes. También se establecen las dos grandes líneas de investigación en los procesos de adopción de tecnología que se agrupan en estudios de sección cruzada y estudios temporales, que pueden incluir también la difusión. Finaliza la relación de conceptos con la clasificación de los factores que afectan al proceso de adopción que ha de tenerse en cuenta en la elaboración del cuestionario que será utilizado en la encuesta a las explotaciones.

En la segunda parte del capítulo, se detalla la selección bibliográfica que resulta imprescindible para plantear y realizar el estudio. Comprende dos apartados: el primero, incluye una mención de obras y artículos, con enfoque económico y relación más directa con los temas de los diferentes capítulos; el segundo, reúne la bibliografía auxiliar en dos grupos muy diferenciados, uno engloba publicaciones técnicas sobre invernaderos y equipamiento, y el otro, distintas aplicaciones de la metodología empleada.

En general, la literatura hallada en los diversos temas es muy numerosa excepto en el apartado de "Adopción de tecnología en invernaderos" desde el punto de vista económico.

En el tema de precios se encontraron diversos modelos y aplicaciones para los objetivos previstos. En el apartado "Bibliografía auxiliar" también se han localizado tratados y artículos para disponer de suficiente documentación en tecnología y tener ejemplos de aplicaciones metodológicas. Precisa una mención especial el 
apartado "Adopción de tecnología" en el que figuran los trabajos pertenecientes a los diversos modelos de análisis.

Básicamente, la adopción puede estudiarse con modelos estáticos, detectando el grado de influencia de los distintos factores que la condicionan, o bien, aplicando modelos propios de adopcióndifusión en el denominado análisis de duración.

En los modelos estáticos, la información suele proceder de una toma en sección cruzada, representativa de la realidad del momento, y en cuanto a las relaciones entre las variables o su influencia en la adopción, tienen la ventaja de no estar alteradas por el tiempo.

Los análisis de duración se basan en series de datos, y por medio de modelos se trata de explicar la adopción y difusión al mismo tiempo y la significación de los distintos factores. Cada caso tiene su interpretación; no obstante, hay que tener en cuenta la rápida evolución de las condiciones técnicas y socioeconómicas.

En resumen, con los modelos basados en secciones cruzadas se obtienen las variables que más influyen y el comportamiento de los adoptantes a corto y medio plazo. Los modelos de duración hallan las variables que más han influido en periodos pasados, con predicciones basadas en información anterior. 
Capítulo III

Análisis de precios 



\section{Capítulo III. Análisis de precios}

Antes de iniciar el estudio asignado a los capítulos IV y V, sobre el estado actual de la tecnología en los invernaderos hortícolas mediterráneos y los factores condicionantes de su adopción en las explotaciones, en el presente capítulo se introduce el análisis de precios de los principales productos hortícolas, el tomate y el pimiento, con el fin de establecer como punto de partida: la situación de la competitividad en estos productos, basada en la evolución de precios y exportaciones; el comportamiento seguido por los precios en las zonas en las que está prevista la realización del estudio con las deducciones correspondientes; finalmente, la relación comparativa de liquidaciones de origen cooperativo agregadas según modalidades productivas.

El precio que perciben los agricultores por sus producciones, es un elemento fundamental en la formación de su renta, y por tanto, un claro determinante de las decisiones empresariales.

Se ha creído conveniente la dedicación de un capítulo al estudio del papel de los precios en relación con la tecnología adoptable, que puede exigir, o bien inversiones en el equipamiento de los invernaderos dirigidas a la mejora de las funciones de control climático, o bien a la introducción de nuevas modalidades de cultivo, de las cuales señalamos por una parte el cultivo en sustrato, que requiere un esfuerzo económico importante, o la Producción Integrada y la Producción Ecológica que no precisan adaptaciones especiales pero, en cambio, suponen un mayor empleo de capital humano. 


\subsection{Breve referencia a la posición competitiva del tomate y pimiento.}

Después de la inevitable internacionalización de los mercados con el desarme arancelario correspondiente, parece conveniente plantear cuál es la situación actual de la posición competitiva en los dos productos hortícolas con mayor significación económica: el tomate y el pimiento.

En el primer capítulo ya se han reseñado algunas dificultades del cultivo en lo que concierne a los mercados, la PAC y diferentes aspectos de la comercialización.

A continuación se mencionan una serie de factores que condicionan la competitividad, a los que se agregan la información estadística sobre precios medios y valor de las exportaciones, unas variables que no sólo determinan la competitividad sino también proporcionan una cierta estimación de su nivel.

En la horticultura mediterránea, muy orientada a la exportación y diversificada por productos, de los que se reitera la importancia del tomate y del pimiento, una de las bases de su competitividad es el clima suave que permite obtener productos fuera de estación con bajo empleo de la calefacción.

Sobresale la disponibilidad de medios productivos entre los que se cuentan los invernaderos, con tecnología muy variada y en constante evolución.

Aunque el agua como recurso natural es un factor muy limitante en estas zonas, existen infraestructuras importantes para su conducción y almacenamiento. El invernadero, como soporte de la producción hortícola intensiva no va a tener más aportaciones de agua que otras actividades agrarias de su propia zona, aunque su 
mayor eficiencia productiva le permite utilizarla con mayores precios. Los empresarios, en sus explotaciones, han dado preferencia a las inversiones que optimizan el uso del agua, dotando a los invernaderos de balsa para almacenamiento y de un sistema de distribución más o menos automatizado.

También se cuenta con los conocimientos técnicos por parte de los agricultores; con dotación de técnicos especializados en las cooperativas, empresas de asesoramiento y empresas suministradoras; para la comercialización se cuenta con capacidad suficiente en los almacenes de confección, cámaras frigoríficas y medios de trasporte.

Una característica muy positiva en este sector es la existencia de cooperativas que comercializan los productos tanto en el mercado exterior como en el interior y de alhóndigas que, además de concentrar el producto, dotan a su comercio de unas subastas diarias con la trasparencia en los precios que de ello se deriva.

Todos los factores y elementos mencionados contribuyen a una actividad productiva y comercial en cada cultivo, la cual considerando el nivel existente en la apertura de mercados y con situaciones de sobreoferta casi todo el año, se traduce en una posición competitiva cuya evolución se puede determinar.

Una primera evaluación puede obtenerse a través de las cifras del comercio exterior en momentos de creciente globalización. Es donde se proyecta la fortaleza o debilidad del sector, con la evolución de la capacidad exportadora, para entrar y mantenerse en los mercados exteriores.

Los costes de producción y comercialización tienen un papel importante para las empresas, sobre todo de cara al incentivo 
inversor inicial, pero no son la única explicación de la competitividad (Barceló, 1987).

Hay múltiples factores que inciden en la competitividad, y deben introducirse en un análisis económico sobre este tema, son entre otros, los precios y su evolución, la calidad, servicios empresariales, especialización, diferenciación de productos, promoción y tecnología (Chebil y Briz, 1999).

En el breve análisis que se incorpora, se consideran únicamente la evolución de las exportaciones y los precios.

Los Gráficos 3.1 y 3.2 reflejan la evolución de las exportaciones de ambos productos y de cuyo comportamiento se puede deducir que, para la competitividad que presentan las producciones españolas, parece ya ocupado el espacio propio en unos mercados maduros característicos de los grandes países consumidores europeos. Aún hay posibilidades de expansión en nuevos mercados pero, a primera vista, las capacidades de absorción parecen menores. 
Gráfico 3.1. Evolución de las exportaciones de tomate

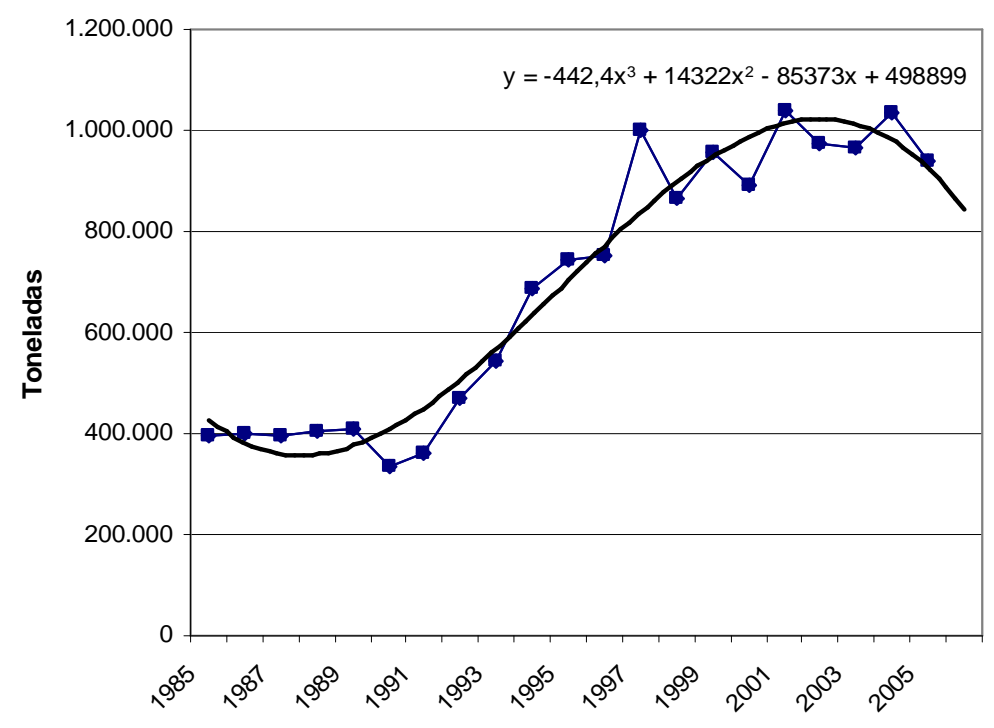

Fuente: Anuario de Estadística Agroalimentaria (MAPA, 2006).

Gráfico 3.2. Evolución de las exportaciones de pimiento

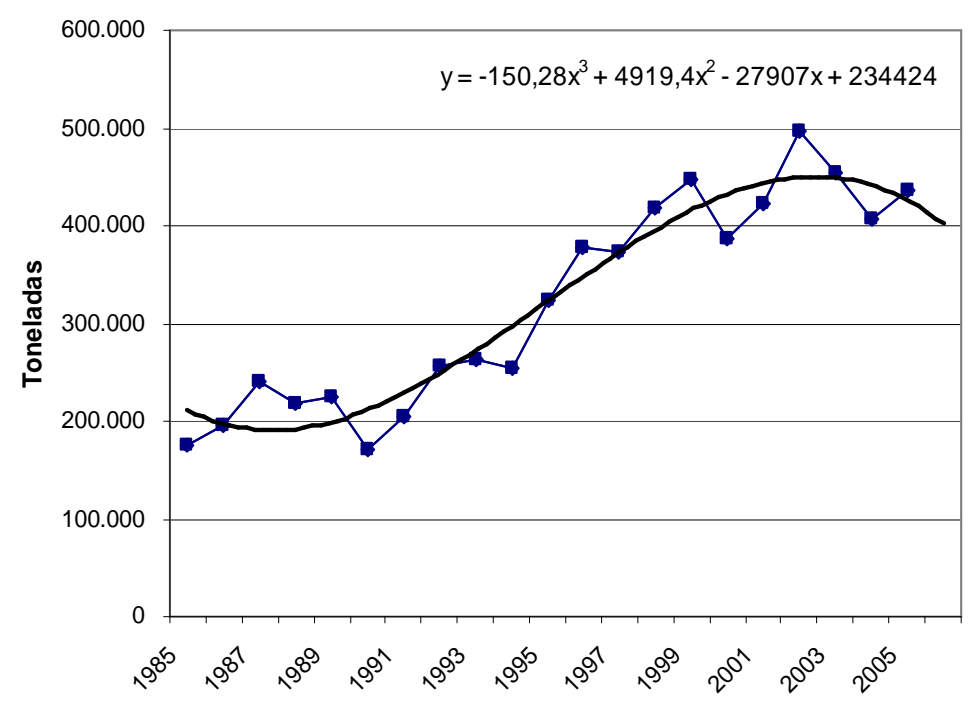

Fuente: Anuario de Estadística Agroalimentaria (MAPA, 2006). 
En los Gráficos 3.3 y 3.4 se representa la evolución de los precios del tomate considerando cifras medias a nivel nacional y actualizadas al año 2006. Ambos gráficos pertenecen a la misma serie y se ha preferido expresar la tendencia de los precios en dos figuras, para hacer notar que en la primera, la tendencia presenta una pendiente con un decrecimiento muy acusado propio de un producto que partía de niveles altos, después en la segunda figura, la pendiente se suaviza, pero en todo caso, salvo tipos especiales de tomate, se mantiene decreciente sin que haya variado el sentido.

En el primer tramo se puede aceptar que existían beneficios superiores a los normales pero, en el último tramo, los beneficios han disminuido o anulado en muchos casos.

Gráfico 3.3. Precio medio del tomate percibido por los agricultores desde 1985 a 1999

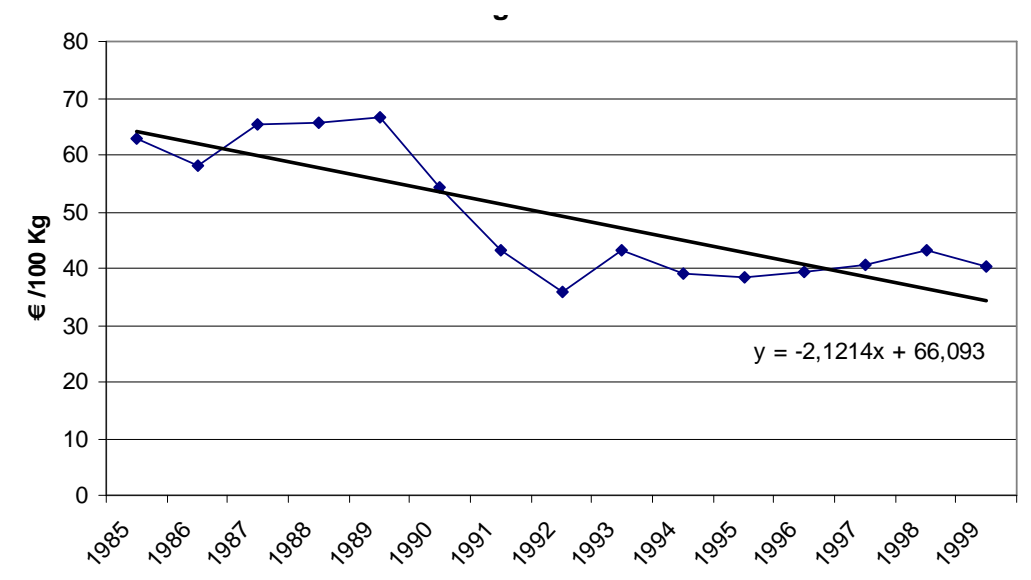

Fuente: Anuario de Estadística Agroalimentaria (MAPA, 1985 - 1999). 
Gráfico 3.4. Precio medio del tomate percibido por los agricultores desde 2000 a 2006

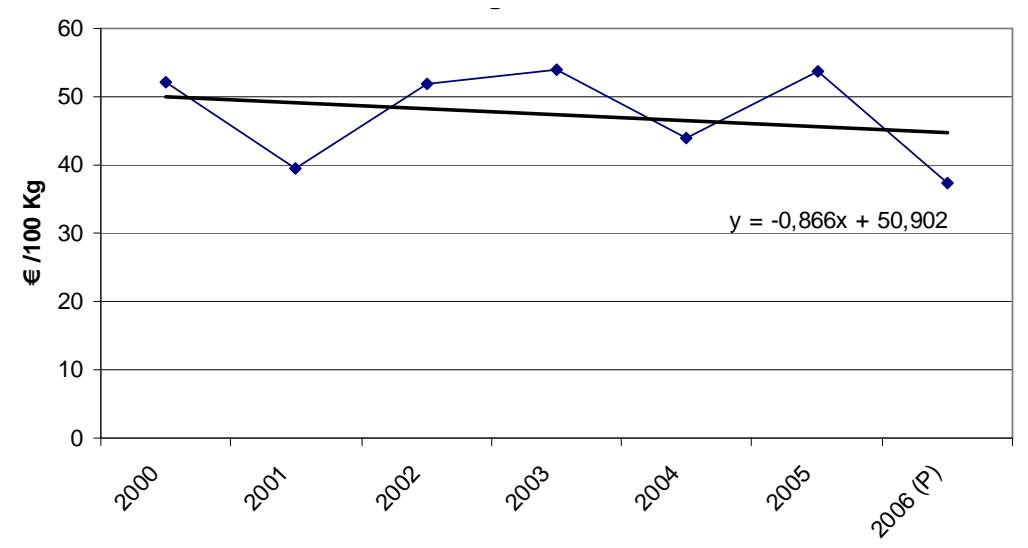

Fuente: Anuario de Estadística Agroalimentaria (MAPA, 1999 - 2006).

En los Gráficos 3.5 y 3.6 se describen los precios del pimiento con dos tendencias, creciente en el periodo 1985-1998, una notable excepción en productos agrícolas, y con sentido decreciente, muy suave entre 1999 y 2006, lo cual puede indicar que no se han dado situaciones graves de sobreoferta, y que los mercados comienzan a saturarse. 
Gráfico 3.5. Precio medio del pimiento percibido por los agricultores desde 1985 a 1999

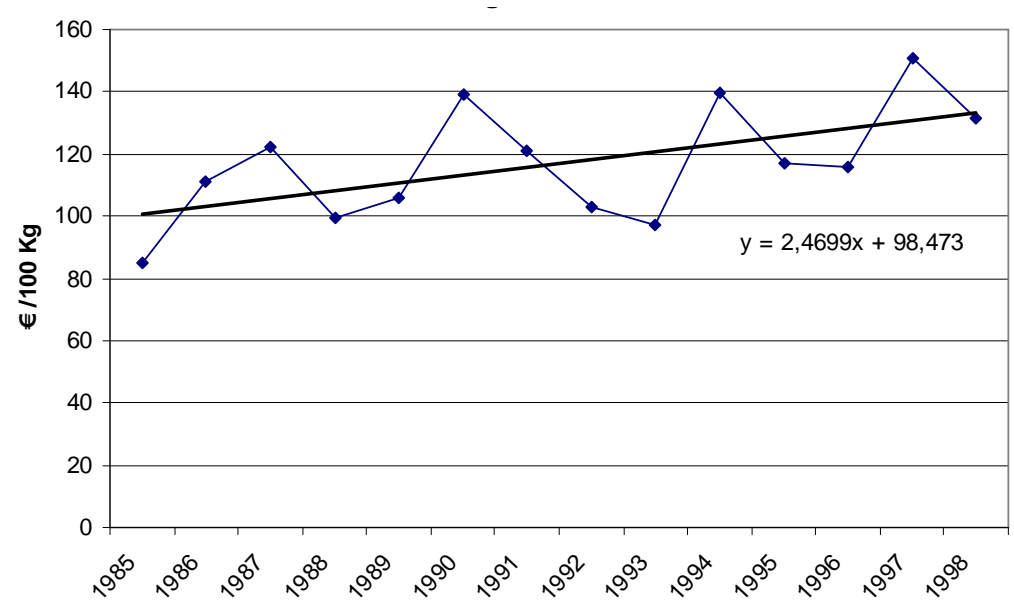

Fuente: Anuario de Estadística Agroalimentaria (MAPA, 1985 - 1998).

Gráfico 3.6. Precio medio del pimiento percibido por los agricultores desde 1999 a 2006

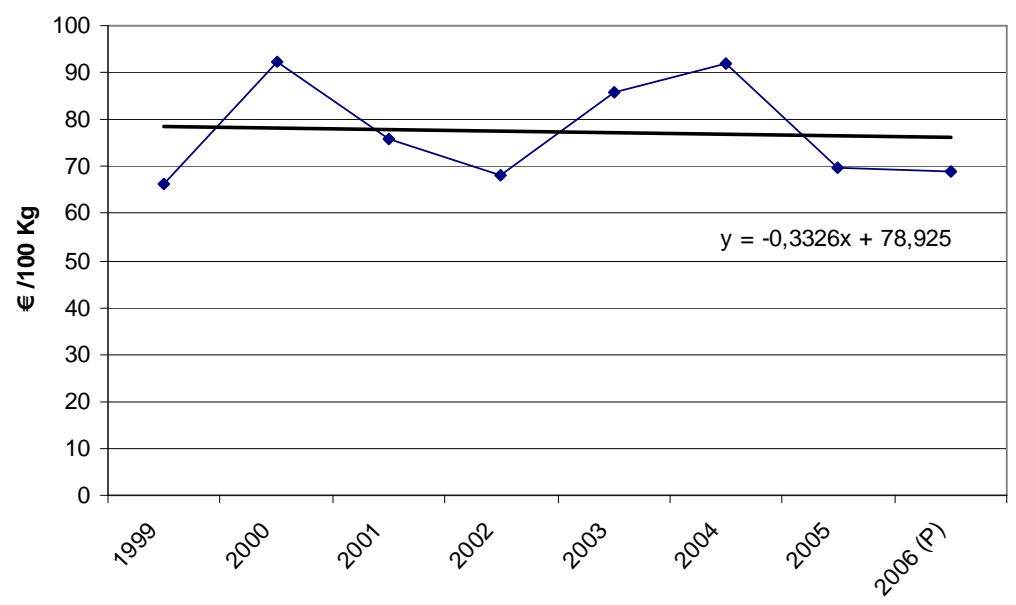

Fuente: Anuario de Estadística Agroalimentaria (MAPA, 1999 - 2006). 
De todo ello se deduce que la posición competitiva no presenta amenazas graves, pero tampoco se encuentra en una época con ventajas claras y expansión creciente. Se precisa por tanto un elevado esfuerzo inversor con elevación del nivel de equipamiento y de tecnología para mantener la competitividad.

\subsection{Los precios y la tecnología adoptable}

La adopción de tecnología va unida a un reflexivo proceso de decisión empresarial, el cual viene condicionado por diversos factores que, según las necesidades de cambio, se pueden considerar de tipo técnico, económico y social. La principal finalidad de los cambios es elevar los posibles beneficios con disminución de riesgos.

Los cambios técnicos que son precisos, incluyen modificaciones de procesos productivos (por ejemplo, las que vienen impuestas por exigencias en la desinfección del suelo y las virosis) y de las características de la tecnología y equipamiento (estructura y dotación del invernadero, material vegetal, etc).

Entre los factores de tipo económico se van a considerar básicamente los precios, mientras que los de tipo social comprenden un numeroso grupo que afectan a los cambios familiares, y de carácter socioeconómico como variación de las estructuras comerciales y preferencias del consumidor.

El presente apartado se centra en los móviles de carácter económico, concretamente en los precios y su relación con la tecnología adoptable, que se puede contemplar desde dos puntos de vista diferentes:

- Por su relación con las técnicas de producción, calendarios, especies y variedades, posibilidades en el 
mercado, y en consecuencia el equipamiento idóneo en los invernaderos.

- Por la influencia en los móviles del empresario hacia la inversión, teniendo en cuenta que su comportamiento viene determinado en función de la situación económica de las distintas especies.

Ante esta problemática surge el interés de analizar la influencia que pueden tener los precios en la adopción de tecnología en los invernaderos.

El análisis se propone con la finalidad de:

1. Determinar cómo se refleja en los precios en origen la situación económica actual del tomate y pimiento.

2. Establecer la relación que pueden tener los precios con la tecnología y dotación de los invernaderos, y a su vez, qué elementos de su equipamiento están más condicionados por los precios percibidos por los productores.

El desarrollo de estas propuestas implica la elaboración y análisis de series de precios en un amplio periodo, y también las posibilidades de efectuar predicciones.

Con el análisis de precios se contribuye a la racionalización de las decisiones empresariales, que tienen posibilidad de basarse en conceptos, resultados y predicciones sobre la información de un amplio periodo de años, y no de forma precipitada y fundada en situaciones coyunturales.

Además de las modificaciones en las estructuras de los invernaderos y de los elementos que cabe introducir para la mejora del control climático, son también decisivas las variaciones en las técnicas productivas 0 modalidades de cultivo. Se consideran 
principalmente el cultivo en sustrato, que exige elevadas inversiones y un nivel tecnológico mayor, y la Producción Integrada (PI) y la Producción Ecológica (PE) cuya importancia se basa en que no requieren elevadas inversiones en capital fijo, más bien representan una sustitución de capital por técnicas de producción y, sin embargo, suelen tener un marcado efecto en los precios.

Una vez expuesta la justificación y finalidad de este apartado, se describe la metodología y el análisis, y finalmente, se extraen las conclusiones más relevantes.

\subsection{Información y metodología}

En el estudio se consideran las dos principales especies hortícolas con cultivo en invernadero en España: el tomate y el pimiento. La información tiene como referencia las principales zonas de invernaderos en el Mediterráneo localizadas en Almería, Murcia y Sur de Alicante, y comprende:

- Información de precios en origen que figuran en las publicaciones periódicas de las Consejerías de Agricultura de Andalucía, Murcia y Comunidad Valenciana (CAP, 2006; CARM, 2006; CAPA, 2006).

- Informaciones estadísticas del MAPA (MAPA, 2007).

- Se ha incluido la información sobre precios facilitada por la cooperativa Surinver de Pilar de la Horadada, la cual sobresale en la producción y comercialización del pimiento en el mediterráneo español.

- A todos los conjuntos de datos anteriores, se agrega la información procedente de la bibliografía y documentación existente. 
La utilización de registros históricos de precios para la elaboración de series temporales ha sido muy frecuente en los estudios económicos, con temas de análisis muy variados, centrados bien en conocer diversos aspectos de periodos anteriores y del momento actual, bien orientados hacia la predicción.

Para analizar la evolución histórica y la situación actual se han aplicado en este trabajo, como principales determinaciones, la tendencia y los índices estacionales. Para efectuar predicciones, a partir de las series de precios en origen, se han empleado los modelos ARIMA.

Un tratado de interés en el análisis de tendencia ha sido el de Makridakis y Wheelwright (1978). En el campo de la predicción por medio de series temporales de precios con modelos ARIMA se encuentran numerosas publicaciones dada la facilidad de aplicación de este método y la comprobación de su validez. Con aporte metodológico señalamos las obras de Box y Jenkins (1976) y Peña (2005).

Se tomaron precios quincenales con los periodos indicados en la Tabla 3.1. Los tipos estudiados son tomate acostillado y liso, que en Almería coincide con el larga vida, así como los tipos de pimiento verde y rojo. 
Tabla 3.1. Periodo, indicado en quincena, correspondiente a cada serie según tipo de cultivo y zona

\begin{tabular}{|c|c|c|c|}
\hline $\begin{array}{l}\text { Tipos de } \\
\text { producto }\end{array}$ & Almería $^{(1)}$ & Murcia $^{(2)}$ & Alicante $^{(1)}$ \\
\hline $\begin{array}{l}\text { Tomate } \\
\text { acostillado }\end{array}$ & $\begin{array}{l}1^{\text {a }} \text { q. Oct'92- } \\
2^{\underline{a}} \text { q. Jul'06 }\end{array}$ & ------------- & $\begin{array}{l}1^{\text {a }} \text { q. Sep'98 } \\
2^{\text {a }} \text { q. Ago'06 }\end{array}$ \\
\hline Tomate liso & $\begin{array}{l}1^{\underline{a}} \text { q. Oct'97 - } \\
2^{\underline{a}} \text { q. Jul'06 }\end{array}$ & $\begin{array}{l}1^{\text {a }} \text { q. Oct'92 - } \\
2^{\underline{a}} \text { q. Sep'06 }\end{array}$ & $\begin{array}{l}1^{\text {a }} \text { q. Sep'92- } \\
2^{\text {a }} \text { q. Ago'06 }\end{array}$ \\
\hline $\begin{array}{l}\text { Pimiento } \\
\text { verde }\end{array}$ & $\begin{array}{l}1^{\text {a }} \text { q. Oct'92- } \\
2^{-\underline{a}} \text { q. Jul'06 }\end{array}$ & $\begin{array}{l}2^{\mathrm{a}} \mathrm{q} . \mathrm{Mar}^{\prime} 92- \\
1^{\mathrm{a}} \mathrm{q} \text { q. Ago'06 }\end{array}$ & $\begin{array}{l}2^{\underline{a}} \text { q. Mar'90 - } \\
1^{\underline{a}} \text { q. Oct'06 }\end{array}$ \\
\hline Pimiento rojo & $\begin{array}{l}1^{\text {a }} \text { q. Oct'92- } \\
2^{-a} \text { q. Jul'06 }\end{array}$ & $\begin{array}{l}1^{\text {a }} \text { q. Abr'92 - } \\
1^{\text {a }} \text { q. Sep'06 }\end{array}$ & $\begin{array}{l}2^{\text {a }} \text { q. Abr'90 - } \\
1^{\text {a }} \text { q. Oct'06 }\end{array}$ \\
\hline
\end{tabular}

Fuente: Elaboración propia.

Una vez construidas las series temporales, con periodos y fechas de actualización indicadas en la Tabla 3.1, se han efectuado las siguientes determinaciones:

a. Análisis de tendencia, con el que se pone de manifiesto cuál ha sido el comportamiento económico de las distintas especies respecto a los precios y su perspectiva actual. Cuando la tendencia es creciente, aporta unas perspectivas muy seguras; en caso de ser decreciente, conviene comprobar detenidamente si se debe a un lento decrecimiento en el poder adquisitivo de una variedad determinada, que aunque inevitable sea soportable, o bien si la caída es brusca e irrecuperable dadas las características técnicas y económicas que le afectan. Por último, una situación muy común es que se trate de una variedad nueva que ha partido de niveles en los precios muy altos en los primeros años, capaces de aportar beneficios extraordinarios, 
para pasar ya en los años siguientes a un beneficio normal (Caballero et al, 1992).

La tendencia viene dada por el movimiento general a largo plazo de la serie, y en su análisis, se trata de separar este movimiento de las variaciones cíclicas, estacionales y residuales que, según la teoría clásica, se consideran en una serie temporal. Los valores de las series se han ajustado a una función del tiempo con una ecuación lineal, ya que aún siendo la más sencilla, recoge de manera satisfactoria la tendencia de la serie de precios en hortícolas.

b. Los índices estacionales dan a conocer el nivel relativo que han tenido los precios, respecto al valor medio 100 , en las campañas que abarca la serie. Con sus datos es posible planificar la optimización del ingreso considerando las producciones esperadas, y en consecuencia, de acuerdo con la climatología, las características del invernadero y los medios técnicos disponibles, se puede elegir el calendario de producción más interesante.

Para obtener los índices de estacionalidad, se ha realizado una descomposición estacional según el método multiplicativo. Mediante este procedimiento, se pueden aislar las variaciones estacionales $\left(E_{i k}\right)$ de las componentes de tendencia $\left(T_{i k}\right)$, las variaciones cíclicas $\left(C_{i k}\right)$ y las variaciones residuales $\left(\mathrm{R}_{\mathrm{ik}}\right)$ (Pérez 2002), resultando $Y_{i k}=T_{i k} * E_{i k} * C_{i k} *$ $R_{i k}$, donde $Y_{i k}$ es la serie temporal, $i$ toma los valores $1,2, \ldots, N$ (representa años) y $k$ toma los valores $1,2, \ldots, m$ (representa quincenas).

c. La predicción mediante modelos ARIMA, para los cuales se ha obtenido también información de su validez estadística, ha permitido estimar los precios y su evolución en la campaña 
siguiente, dentro de un intervalo de probabilidad. No obstante, las limitaciones de esta técnica de predicción son la naturaleza de la serie, por una parte, y sobre todo, el escaso número de años para el que se puede predecir (Cases, 1994).

Los modelos ARIMA, con la predicción para un año, pueden ser más utilizables en cultivos hortícolas muy comerciales, donde sea importante la toma de decisiones a corto plazo. Así pues, estos modelos ofrecen la posibilidad de efectuar en la campaña inmediata planificaciones de la técnica y los factores de producción que conviene utilizar, como la elección de la variedad, calendario de producción, realización de desinfecciones de suelo, uso de planta injertada, etc.

En la identificación y estimación de los modelos ARIMA (AutoRegressive Integrated Moving Average) se usa la metodología desarrollada por Box y Jenkins (1976), la cual se utiliza para analizar modelos univariantes de series temporales. En estos modelos, una variable dinámica que fluctúa a lo largo del tiempo, (en el caso que nos ocupa, el precio), es explicada utilizando una única variable, el registro histórico de sus valores pasados (Uriel y Peiró, 2000).

Para aplicar la metodología ARIMA es indispensable que la serie temporal sea estacionaria. Para ello es necesario conocer una serie de términos, que a continuación se definen:

Un proceso estocástico es una sucesión de variables aleatorias $Y_{t}$ ordenadas, donde $t$ puede ser cualquier valor entre $-\infty \mathrm{y}$ $+\infty$, y representa el paso del tiempo, cuando se trata de series temporales, como es el caso. 
Los procesos estocásticos, se pueden definir especificando la media y la varianza para cada $Y_{t}$, y los que nos interesan son:

- El proceso estocástico con media cero, varianza constante y donde las variables aleatorias son independientes para distintos valores de $t$ (covarianza nula). A este proceso estocástico se le llama ruido blanco.

- El proceso estocástico estacionario, que se da cuando las funciones de distribución conjuntas son invariantes con respecto a un desplazamiento en el tiempo.

En los modelos ARIMA univariantes se parte de la consideración inicial de que la serie temporal ha sido generada por un proceso estocástico y precisamente las técnicas de elaboración de los modelos ARIMA tratan de identificar el modelo generador de las observaciones que, una vez estimado y validado, en un proceso iterativo, se utiliza para predecir valores futuros de la serie temporal, (Uriel y Peiró, 2000).

A continuación se describe el modelo general Box-Jenkins para una serie estacionaria. Previamente indicamos que si una serie no es estacionaria, puede transformarse en estacionaria mediante el operador de diferencia de orden $d$, pudiendo ser descrito como:

$$
\phi(L)(1-L)^{d} Y_{t}=\phi(L) a_{t}
$$

siendo:

- $L$ el operador polinomial de retardos.

- $d$ el número de diferencias para transformar la serie en estacionaria.

De este modo, el modelo general Box-Jenkins para una serie estacionaria queda de la siguiente forma:

$$
\left(1-\phi_{1} L-\phi_{2} L^{2}-\ldots \ldots-\phi_{p} L_{p}\right)(1-L)^{d} Y_{t}^{\lambda}=\left(1-\theta_{1} L-\theta_{2} L^{2}-\ldots-\theta_{q} L^{q}\right) a_{t}
$$
donde: 
$\lambda=$ parámetro de la transformación Box-Cox. Toma valores 0 y 1 .

$\left[\phi_{1}, \phi_{2, \ldots,}, \phi_{p}, \theta_{1}, \theta_{2}, \ldots, \theta_{q}\right]$ son los coeficientes de la parte autorregresiva y de medias móviles respectivamente.

Esta ecuación se suele abreviar utilizando la terminología ARIMA (p,d,q), donde:

$\mathrm{p}=$ grado de la parte autorregresiva.

$\mathrm{d}=$ número de diferenciaciones en la parte regular.

$\mathrm{q}=$ grado de la parte de medias móviles

Definimos un modelo como autorregresivo (AR) si la variable $Y_{t}$, puede expresarse como una combinación lineal de sus valores pasados añadiendo un término de error. La expresión general de un modelo AR sería la siguiente:

$$
Y_{t}=\phi_{0}+\phi_{1} Y_{t-1}+\phi_{2} Y_{t-2}+\ldots \ldots+\phi_{p} Y_{t-p}+a_{t}
$$

donde $a_{t}$ es la secuencia de desviaciones idénticamente distribuidas y no correlacionadas, denominada ruido blanco, que corresponde al ya definido proceso estocástico con media cero y varianza constante.

Definimos un modelo de medias móviles (MA) como aquel que explica el valor de una determinada variable en un período $t$ en función de un término independiente y una sucesión de errores que corresponden a períodos pasados, ponderados convenientemente. Así, un modelo MA con $q$ términos de error se expresaría de la siguiente manera:

$$
Y_{t}=\mu+a_{t}+\theta_{1} a_{t-1}+\theta_{2} a_{t-2}+\ldots .+\theta_{q} a_{t-q}
$$

En las series temporales que tienen una componente estacional, los modelos serán ARIMA (p,d,q) x (P,D,Q)s cuya fórmula general sería: 
siendo:

$$
\begin{aligned}
& Y_{T}=\phi_{1} Y_{T-1}+\phi_{2} Y_{T-2}+\ldots+\phi_{P_{S}+p+D_{S}+d} Y_{T-P_{S}-p-s D-d}+ \\
& +\delta+U_{T}+\theta_{1} U_{T-1}+\ldots+\theta_{Q_{S}+q} U_{T-s Q-q}
\end{aligned}
$$

$\mathrm{S}=$ periodo estacional.

$\mathrm{P}=$ grado de la parte autorregresiva de la componente estacional.

$\mathrm{D}$ = número de diferenciaciones en la componente estacional.

$\mathrm{Q}=$ grado de la parte de medias móviles de la componente estacional.

\subsubsection{Aplicación del modelo ARIMA}

En la búsqueda de un modelo ARIMA para una serie temporal determinada, se siguen las siguientes fases, según la metodología Box-Jenkins:

1.- Identificación.

En primer lugar, la serie ha de ser estacionaria. Existen dos formas de estacionariedad:

- Estacionariedad en media: si la serie no es estacionaria en media, habrá que diferenciar la serie hasta que la tendencia desaparezca. El número de veces que se diferencia es el valor de $d$.

- Estacionariedad en varianza: mediante la observación de la representación gráfica de la serie, se puede ver si se mantiene o no la dispersión en torno al nivel existente en cada momento. Si se observa que a medida que aumenta el nivel aumenta la dispersión, se dice que no hay estacionariedad en varianza, y habrá que realizar la 
transformación de Box-Cox. De este modo, hay que aplicar logaritmo natural a la serie si $\alpha=1$, cuando la relación entre la desviación típica y la media sea: $\sigma=k m \alpha$, para así, estabilizar la varianza.

Respecto a la determinación de $p$ y $q$ se utilizan las funciones de autocorrelación estimada y autocorrelación parcial estimada de la serie objeto de estudio, comparándolas con las funciones de autocorrelación de los modelos teóricos $\operatorname{AR}(p), \operatorname{MA}(q)$ o $\operatorname{ARMA}(p, q)$, siendo éste último combinación de los dos anteriores. De esta forma se puede asociar a la serie temporal estudiada un modelo ARIMA que identifique su proceso generador de datos.

\section{2.- Estimación.}

$\mathrm{Si}$ el proceso está bien identificado, se procede a la estimación de los parámetros de la parte autorregresiva y de la parte de medias móviles tanto de la componente regular como de la estacional.

En cambio, si el proceso no está bien identificado, habrá que realizar una nueva estimación. Por tanto, se trata de un sistema iterativo, donde la experiencia del analista, para la adecuada contrastación crítica de los resultados en cada etapa, es fundamental (Peña, 2005).

3.- Validación.

En la fase de validación, se trata de demostrar que el modelo encontrado es el que mejor representa el comportamiento de la serie objeto de estudio, que, a su vez, será el que cumpla en mayor medida los requisitos siguientes:

- Los coeficientes del modelo han de ser significativos estadísticamente. 
- Los residuos del modelo estimado se han de aproximar al comportamiento de un ruido blanco, para ello los coeficientes de las funciones de autocorrelación estimada y autocorrelación parcial estimada no deben ser significativamente distintos de cero.

- El modelo estimado es estacionario.

- La predicción sea adecuada.

\subsection{Cálculos y resultados}

Para los cálculos efectuados en los tres conceptos incluidos en las determinaciones: tendencia, índices estacionales y predicción, se ha utilizado el paquete informático Statgraphics Plus versión 5.1.

El análisis de tendencia se ha efectuado ajustando las series a con una ecuación lineal donde el precio $(p)$ está en función del tiempo $(t)$. Tras obtener la ecuación de tendencia, se somete a unos tests ejecutados sobre los residuos del modelo lineal para determinar la adecuación del modelo a los datos. Estos tests son el de la diferencia en la media entre la $1^{\underline{a}}$ mitad y la $2^{\underline{a}}$ mitad de la serie (MEAN) y el de la diferencia en la varianza entre la $1^{\underline{a}}$ mitad y la $2^{\underline{a}}$ mitad de la serie (VAR). Si el modelo supera los tests, significa que la diferencia no es estadísticamente significativa ( $p$-valor $\geq 0,05$ ), y por tanto, se verifica la igualdad entre la $1^{\underline{a}}$ y la $2^{\underline{a}}$ mitad de la serie, tanto en media como en varianza.

Una primera aplicación de la tendencia ha sido la evaluación de la situación económica del producto en función de la evolución de los precios a lo largo del periodo analizado. 
La tendencia que siguen las series se puede observar en los gráficos que se exponen a continuación, los cuales muestran su comportamiento en el tomate y el pimiento para cada zona y según los tipos estudiados.

\section{Gráfico 3.7. Tendencia del tomate acostillado en Almería}

Ecuación: $p=1,01197+0,00171884 t$

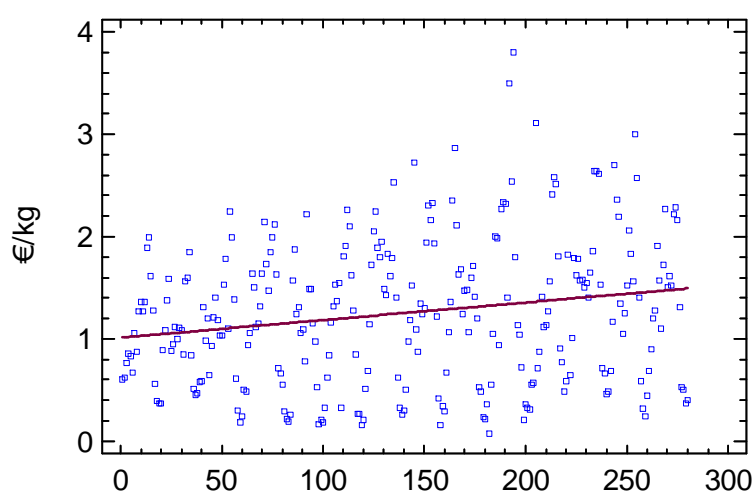

Periodo: $1^{\mathrm{a}}$ quincena Octubre 1992 - $2^{\underline{a}}$ quincena Julio 2006

Gráfico 3.8. Tendencia del tomate larga vida en Almería

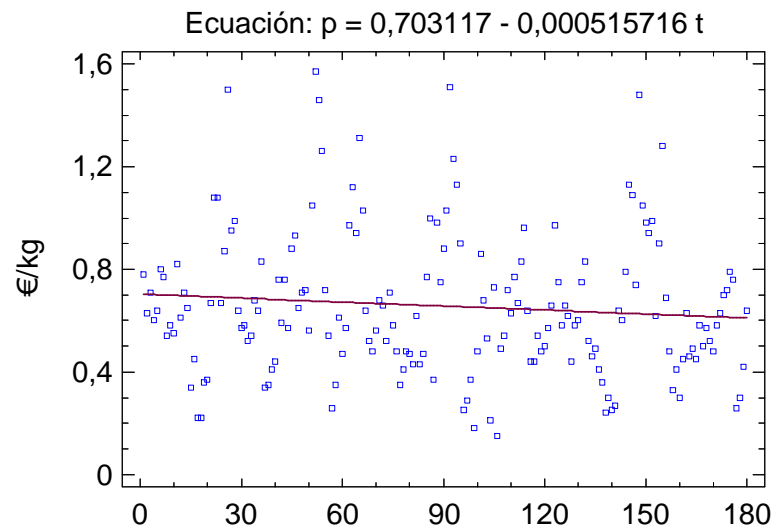

Periodo: $1^{\mathrm{a}}$ quincena Octubre $1997-2^{\mathrm{a}}$ quincena Julio 2006 


\section{Gráfico 3.9. Tendencia del pimiento verde en Almería}

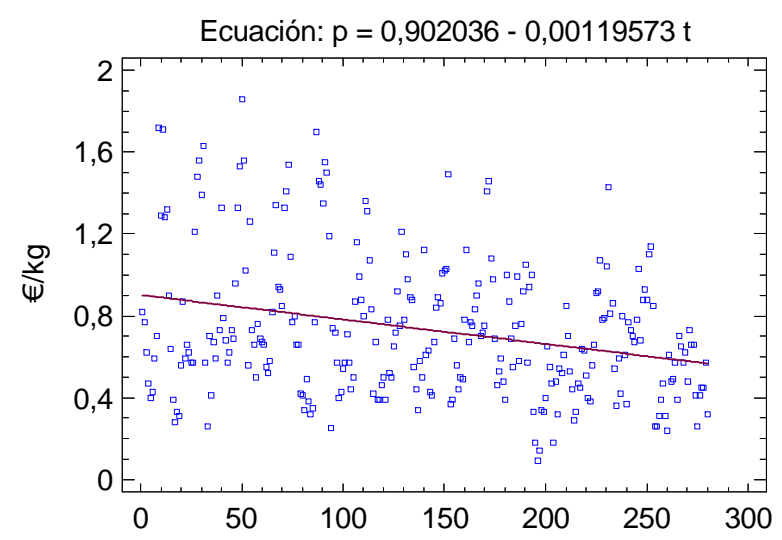

Periodo: $1^{\underline{a}}$ quincena Octubre 1992 - $2^{\underline{a}}$ quincena Julio 2006

\section{Gráfico 3.10. Tendencia del pimiento rojo en Almería}

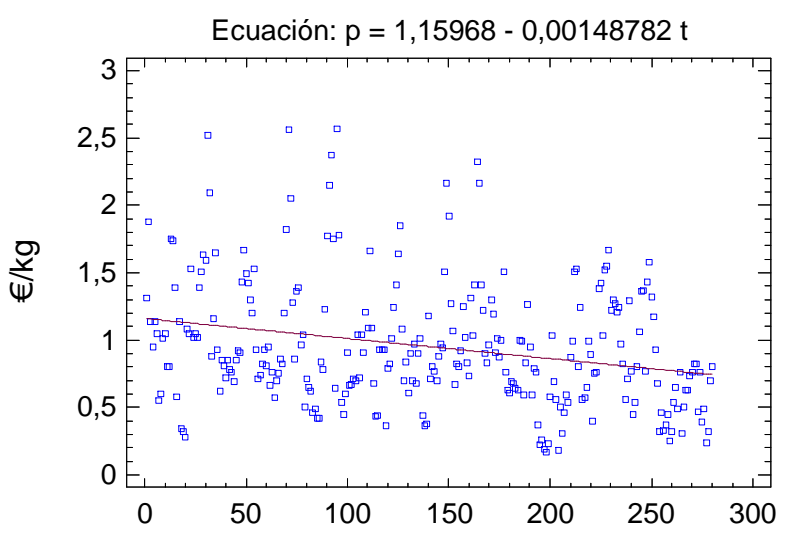

Periodo: $1^{\mathrm{a}}$ quincena Octubre $1992-2^{\underline{a}}$ quincena Julio 2006

Los cálculos y representación gráfica para las series de Almería (Gráficos 3.7, 3.8, 3.9 y 3.10) muestran que los modelos lineales aplicados superan, en el caso del tomate acostillado y pimiento verde, el test para la diferencia en la media de la $1^{\text {a }}$ mitad a la $2^{\text {a }}$ mitad, ya que estas diferencias no son estadísticamente 
significativas, ( $p$-valor $\geq 0,05$ ), y por tanto, se verifica la igualdad de media en las series. Para el tomate liso y el pimiento rojo, además de superar el test para la diferencia en la media de la $1^{\underline{a}}$ mitad a la $2^{\underline{a}}$ mitad, superan también el test para la diferencia en la varianza entre la 1 a mitad y la $2 \underline{ }$ - mitad de las series, ya que estas diferencias no son estadísticamente significativas, ( $p$-valor $\geq 0,05$ ).

\section{Gráfico 3.11. Tendencia del tomate liso en Murcia}

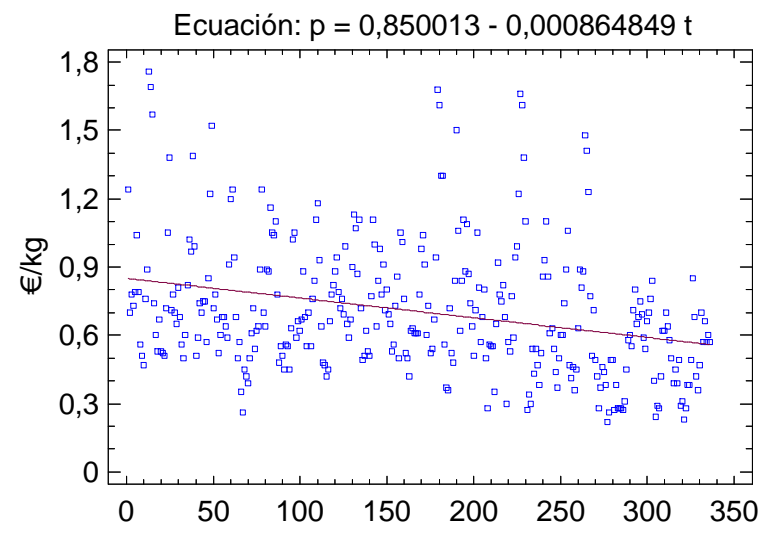

Periodo: $1^{\mathrm{a}}$ quincena Octubre $1992-2^{\mathrm{a}}$ quincena Septiembre 2006 


\section{Gráfico 3.12. Tendencia pimiento verde en Murcia}

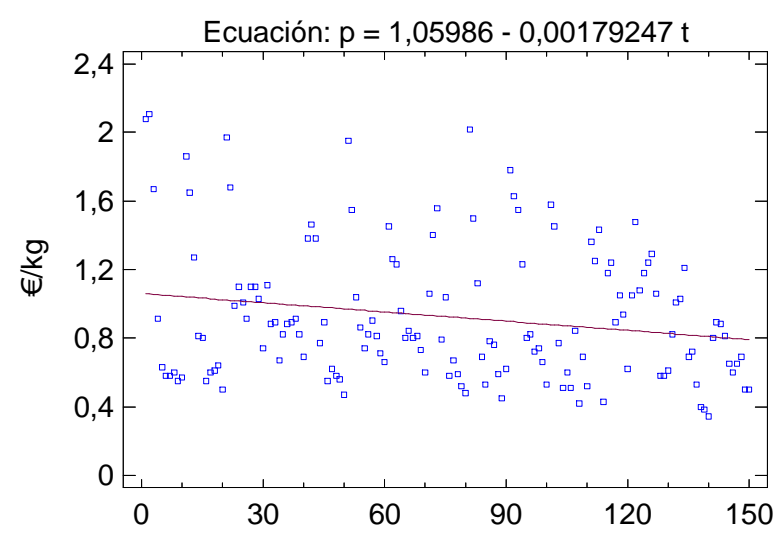

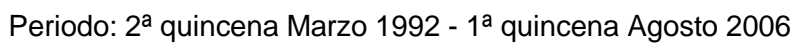

\section{Gráfico 3.13. Tendencia pimiento rojo en Murcia}

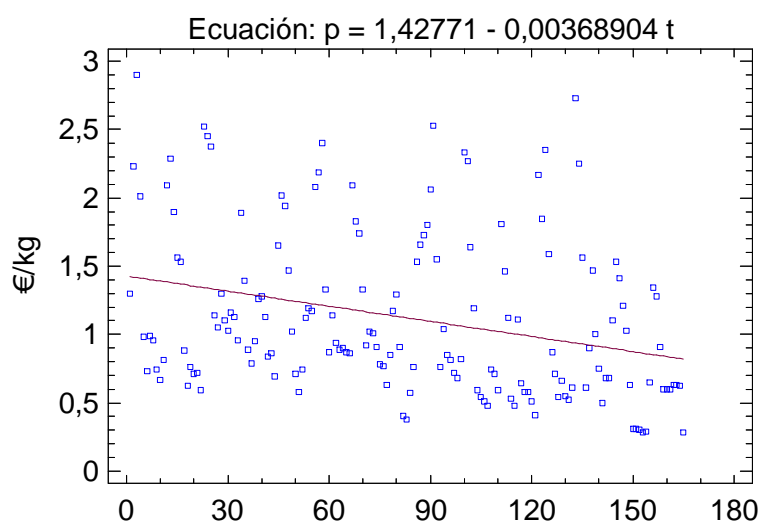

Periodo: $1^{\underline{a}}$ quincena Abril 1992 - $1^{\text {a }}$ quincena Septiembre 2006

Los modelos lineales ajustados a las series del tomate liso, pimiento verde y pimiento rojo en Murcia representadas en los Gráficos $3.11,3.12$ y 3.13 , verifican la igualdad de media y de varianza entre la $1^{\mathrm{a}}$ y la $2^{\mathrm{a}}$ mitad en cada una de estas series. 


\section{Gráfico 3.14. Tendencia del tomate acostillado en Alicante}

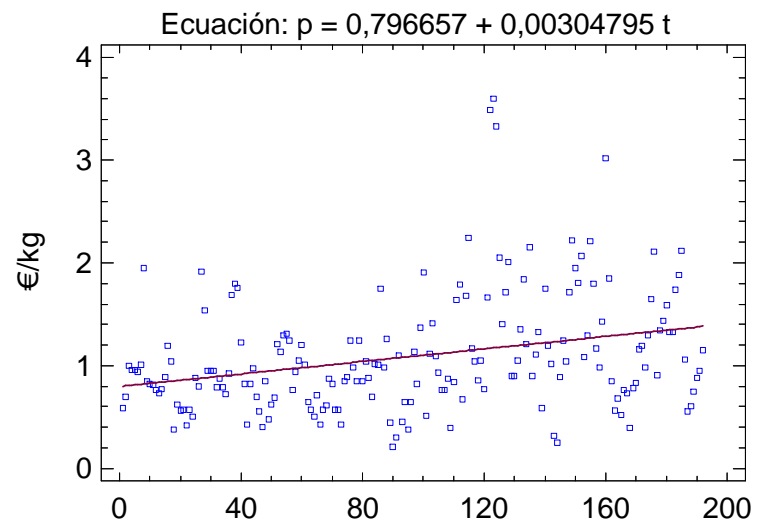

Periodo: $1^{\mathrm{a}}$ quincena Septiembre $1998-2^{\mathrm{a}}$ quincena Agosto 2006

\section{Gráfico 3.15. Tendencia del tomate liso en Alicante}

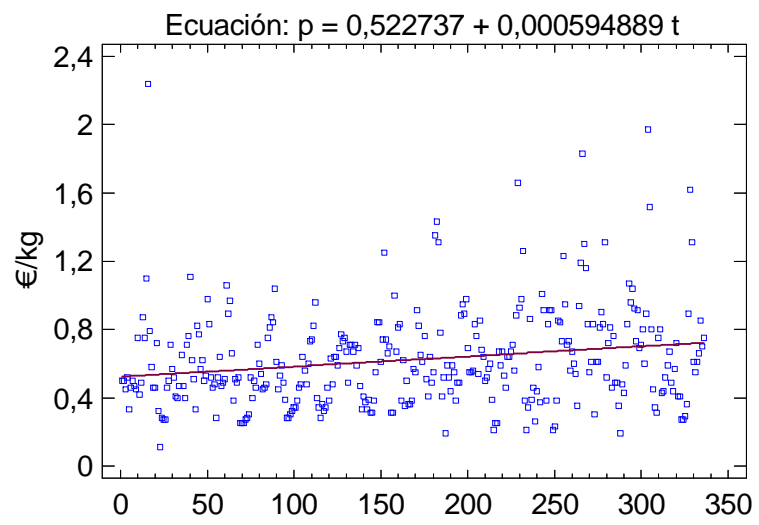

Periodo: $1^{\underline{a}}$ quincena Septiembre 1992 - $2^{\underline{a}}$ quincena Agosto 2006 


\section{Gráfico 3.16. Tendencia pimiento verde en Alicante}

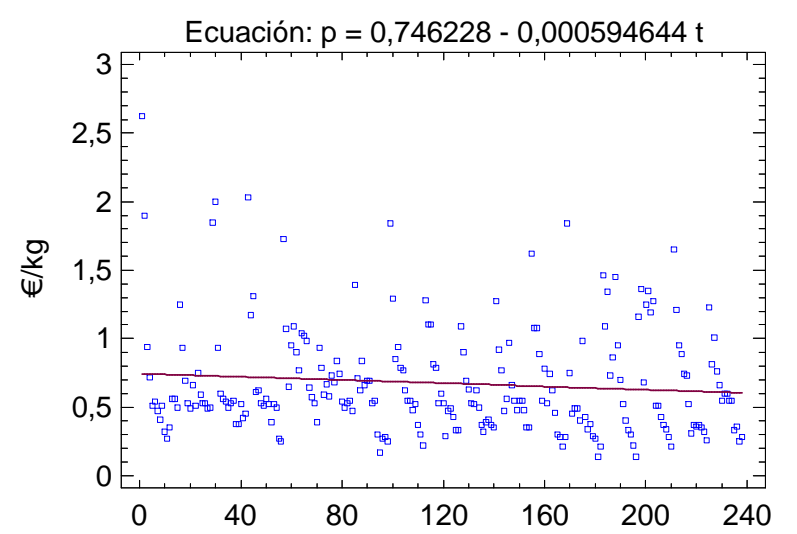

Periodo: $2^{\underline{a}}$ quincena Marzo 1990 - $1^{\underline{a}}$ quincena Octubre 2006

\section{Gráfico 3.17. Tendencia pimiento rojo en Alicante}

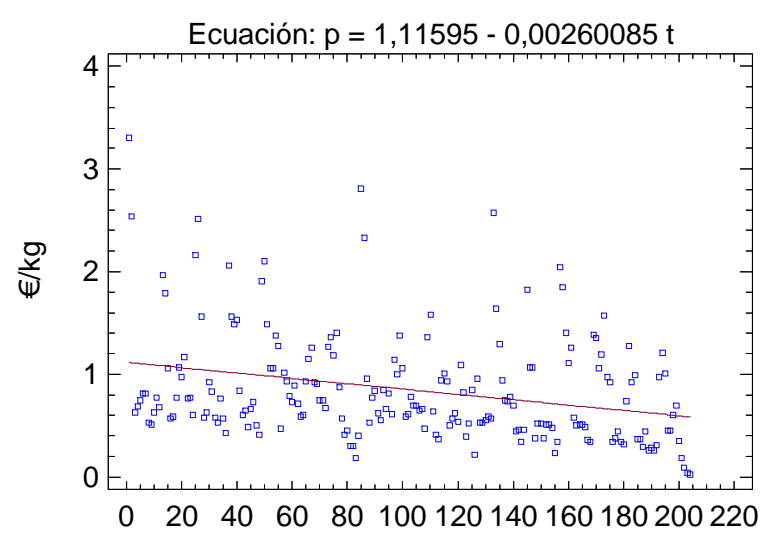

Periodo: $2^{\underline{a}}$ quincena Abril 1990 - $1^{1 \mathfrak{a}}$ quincena Octubre 2006

Los modelos lineales utilizados para explicar la tendencia de las series de tomate acostillado, liso y pimiento rojo en Alicante (Gráficos 3.14, 3.15 y 3.17), superan el test para la diferencia en la media entre la $1^{\underline{a}}$ y la $2^{\underline{a}}$ mitad de la serie. $Y$ la serie del pimiento verde, en Alicante también, se ajusta al modelo lineal indicado (Gráfico 3.16) que supera tanto el test para la diferencia en la media, 
como para la diferencia en la varianza entre la $1^{\underline{a}}$ y la $2^{\underline{a}}$ mitad de la serie.

En la Tabla 3.2 se muestran las ecuaciones de tendencia obtenidas en el análisis de los precios en origen, junto con la variación porcentual anual, por zonas de producción y tipos de producto.

Tabla 3.2. Análisis de tendencia de las series quincenales de precios en origen, variación anual en \%

\begin{tabular}{cccc}
\hline Tipos de producto & Almería & Murcia & Alicante \\
\hline Tomate acostillado & $2 \%$ incremento & & $5 \%$ incremento \\
Tomate liso & $1 \%$ descenso & $2 \%$ descenso & $2 \%$ incremento \\
Pimiento verde & $3 \%$ descenso & $2 \%$ descenso & $1 \%$ descenso \\
Pimiento rojo & $2 \%$ descenso & $2 \%$ descenso & $3 \%$ descenso \\
\hline Fuente: Elaboración propia. & & & \\
En lo que se & refiere al tomate, el tipo diferenciado
\end{tabular}
(acostillado) ha presentado un incremento anual en sus precios tanto en Almería como en Alicante, mientras que el tipo liso sigue una tendencia descendente que oscila del $1 \%$ anual en Almería al $2 \%$ anual en Murcia; se registra una excepción en Alicante donde la cantidad producida es menor que en las otras dos zonas y el incremento se debe especialmente a la forma de comercialización. El pimiento también ha bajado sus precios en los últimos años con descensos que oscilan del 1\% para el pimiento verde en Alicante al $3 \%$ para el pimiento verde en Almería y rojo en Alicante. Puede considerarse un comportamiento normal de los precios en un producto que, desde la expansión de los invernaderos, partía de niveles altos, no obstante un descenso tan continuo e inevitable da lugar a una erosión en las rentas, que a medio y largo plazo, obliga a cambiar de estrategia productiva. 
Respecto a los índices de estacionalidad, éstos han sido obtenidos a partir de las series de datos indicadas en la Tabla 3.1, y reflejan en porcentaje, la oscilación de los precios a lo largo de una campaña media. Los resultados se muestran en la Tabla 3.3.

Los periodos de comercialización más amplios corresponden al cultivo del tomate que ocupa las 24 quincenas del año en Murcia y Alicante. En el caso de Almería, se registran periodos de 20 quincenas tanto para el tomate como para el pimiento. En Murcia y Alicante las campañas del pimiento son más cortas, unas 13 quincenas. 


\begin{tabular}{|c|c|c|c|c|c|c|c|c|c|c|c|}
\hline \multirow{2}{*}{ Quincenas (q.) } & \multicolumn{4}{|c|}{ Almería } & \multicolumn{3}{|c|}{ Murcia } & \multicolumn{4}{|c|}{ Alicante } \\
\hline & T. acostillado & T. larga vida & P. verde & P.rojo & T. liso & P. verde & P.rojo & T. acostillado & $\mathrm{T}$. liso & P. verde & P.rojo \\
\hline $1^{\text {a }}$ q. Sep. & - & - & - & - & 101,87 & - & 67,17 & 81,63 & 74,44 & 61,08 & 68,78 \\
\hline $2^{\mathrm{a}} \mathrm{q}$. Sep. & - & - & - & - & 118,91 & - & - & 105,08 & 89,66 & 53,24 & 62,31 \\
\hline $1^{\underline{a}}$ q. Oct. & 53,10 & 88,26 & 93,12 & 86,55 & 135,49 & - & - & 135,10 & 107,32 & 49,67 & 58,52 \\
\hline $2^{\mathrm{a}}$ q. Oct. & 53,68 & 112,00 & 86,42 & 83,02 & 117,59 & - & - & 156,94 & 112,44 & - & - \\
\hline $1^{a}$ q. Nov. & 77,61 & 113,05 & 78,99 & 87,36 & 101,32 & - & - & 110,76 & 103,27 & - & - \\
\hline $2^{\mathrm{a}}$ q. Nov. & 104,55 & 92,89 & 72,77 & 94,66 & 101,61 & - & - & 115,83 & 98,54 & - & - \\
\hline $1^{\mathrm{a}} \mathrm{q}$. Dic. & 149,84 & 127,06 & 90,02 & 105,78 & 97,61 & - & - & 132,09 & 111,88 & - & - \\
\hline $2^{\mathrm{a}} \mathrm{q}$. Dic. & 124,62 & 128,51 & 110,59 & 99,53 & 108,09 & - & - & 128,45 & 114,22 & - & - \\
\hline $1^{\underline{a}} \mathrm{q}$. Ene. & 100,71 & 94,52 & 131,93 & 99,07 & 85,04 & - & - & 86,95 & 89,25 & - & - \\
\hline $2^{\mathrm{a}} \mathrm{q}$. Ene. & 115,29 & 115,59 & 125,01 & 111,45 & 81,71 & - & - & 91,35 & 91,63 & - & - \\
\hline $1^{\mathrm{a}} \mathrm{q}$. Feb. & 105,57 & 103,44 & 137,32 & 136,42 & 88,89 & - & - & 101,41 & 85,48 & - & - \\
\hline $2^{\mathrm{a}} \mathrm{q}$. Feb. & 114,33 & 99,67 & 136,83 & 133,57 & 100,42 & - & - & 113,54 & 98,61 & - & - \\
\hline $1^{\mathrm{a}} \mathrm{q}$. Mar. & 120,15 & 125,96 & 166,52 & 143,96 & 124,74 & - & - & 106,82 & 138,10 & - & - \\
\hline $2^{\mathrm{a}} \mathrm{q}$. Mar. & 154,03 & 137,33 & 148,30 & 135,07 & 129,09 & 153,87 & - & 112,71 & 133,32 & 213,78 & - \\
\hline $1^{1 \mathrm{a}} \mathrm{q}$. Abr. & 145,00 & 120,29 & 118,41 & 115,64 & 131,98 & 150,39 & 169,65 & 123,97 & 155,00 & 162,94 & - \\
\hline $2^{\mathrm{a}}$ q. Abr. & 176,18 & 126,10 & 86,93 & 90,61 & 143,48 & 128,18 & 177,73 & 129,32 & 164,55 & 130,60 & 191,04 \\
\hline $1^{a}$ q. May. & 146,48 & 104,49 & 67,81 & 106,40 & 106,23 & 105,24 & 163,58 & 89,16 & 111,87 & 113,76 & 177,73 \\
\hline $2^{\mathrm{a}}$ q. May. & 108,05 & 78,30 & 68,61 & 87,30 & 71,05 & 82,56 & 107,16 & 65,10 & 86,01 & 104,90 & 129,75 \\
\hline $1^{\text {a }}$ q. Jun. & 58,18 & 53,32 & 57,95 & 77,01 & 65,19 & 93,64 & 82,44 & 72,30 & 68,46 & 108,67 & 100,04 \\
\hline $2^{\mathrm{a}} \mathrm{q}$. Jun. & 35,15 & 54,42 & 75,93 & 66,87 & 70,85 & 88,13 & 80,70 & 90,84 & 89,46 & 105,50 & 92,79 \\
\hline $1^{1^{\mathrm{a}} \mathrm{q} . ~ J u l .}$ & 28,11 & 61,68 & 66,30 & 63,37 & 64,15 & 69,34 & 60,36 & 72,04 & 80,09 & 85,34 & 87,11 \\
\hline $2^{\mathrm{a}} \mathrm{q}$. Jul. & 29,36 & 63,11 & 80,24 & 76,36 & 71,34 & 68,19 & 59,05 & 68,59 & 70,17 & 80,25 & 90,16 \\
\hline $1^{\mathrm{a}} \mathrm{q}$. Ago. & - & - & - & - & 87,57 & 60,45 & 65,49 & 53,94 & 63,40 & 68,23 & 71,26 \\
\hline $2^{\mathrm{a}}$ q. Ago. & - & - & - & - & 95,79 & - & 66,68 & 56,08 & 62,82 & 62,04 & 70,51 \\
\hline
\end{tabular}


Para completar de forma gráfica la explicación de la Tabla 3.3, se presentan a continuación los gráficos correspondientes al análisis de estacionalidad para tomate liso en Murcia, pimiento verde en Almería y pimiento rojo en Alicante, que es similar al de Murcia.

Los cultivos del tomate en las tres zonas y del pimiento en Almería responden a una planificación de campaña propia de las regiones mediterráneas, cuya comercialización se inicia en el otoño y presenta su momento más favorable a final de invierno o principio de primavera. De esta forma, aunque las producciones medias no sean elevadas, la elección de este periodo de cultivo permite una oferta en momentos óptimos, y en la mayoría de los casos sin inversiones en calefacción.

La campaña del pimiento rojo en Alicante y Murcia se inicia con altos precios en las primeras quincenas cuando finaliza el grueso de la producción de Almería, y por lo tanto, es complementaria de la producción en dicha provincia.

\section{Gráfico 3.18. Estacionalidad del tomate liso en Murcia}

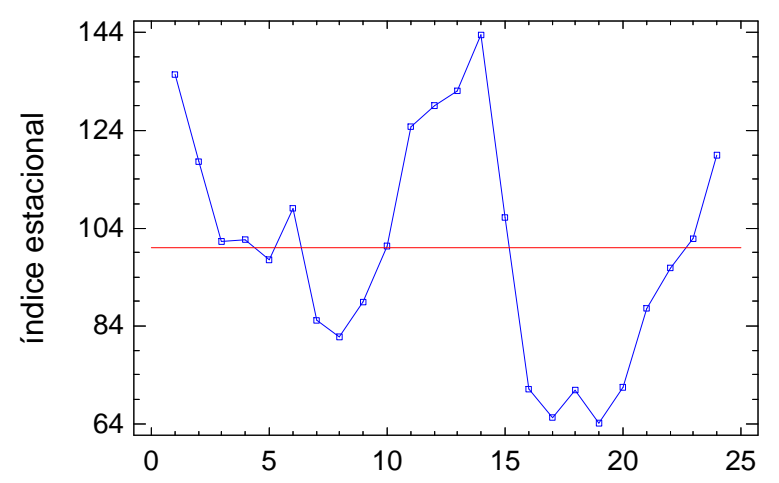

Campaña ( $1^{\underline{a}}$ quincena Octubre - $2^{\underline{a}}$ quincena Septiembre) 


\section{Gráfico 3.19. Estacionalidad del pimiento verde en Almería}

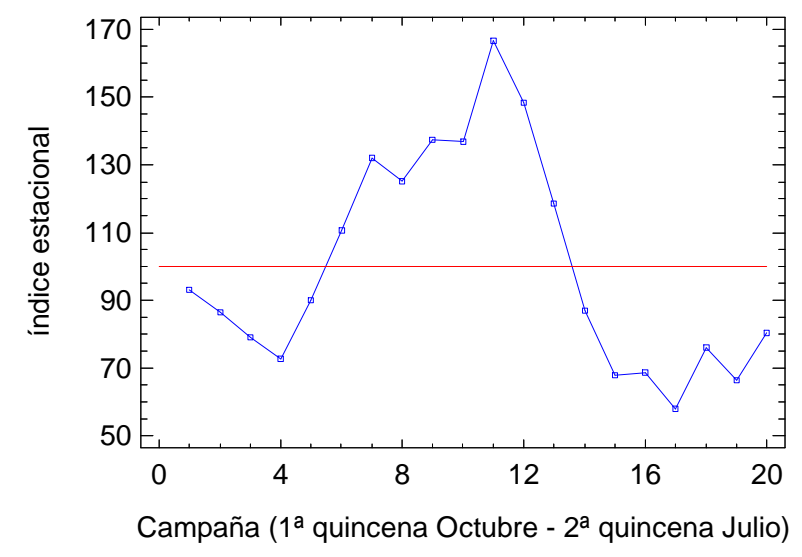

Tanto en el Gráfico 3.18 como en el 3.19, se observa un comportamiento muy irregular a lo largo del año con las gráficas en dientes de sierra. La primera de ellas da un máximo en el índice estacional en la primera quincena de abril, mientras que en la segunda el máximo se adelanta un mes.

\section{Gráfico 3.20. Estacionalidad del pimiento rojo en Alicante}

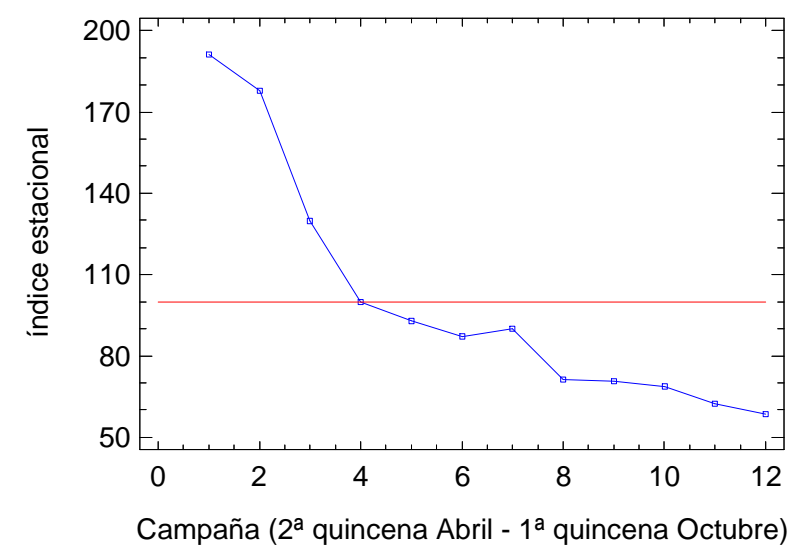

La comercialización de pimiento en Alicante e igualmente en Murcia evidencia un descenso muy acusado en las cuatro o seis primeras 
campañas con el índice por encima de 100 con un nivel de 190 en la primera. A continuación, los descensos son de menor intensidad hasta un nivel de 60. Los gráficos no presentan dientes de sierra.

En la Tabla 3.4 figuran los meses de la campaña donde se obtienen los valores más altos de los índices estacionales de precios. Aquí también se pueden observar las similitudes entre Murcia y Alicante y cómo en Almería los picos estacionales se adelantan en el caso del pimiento.

Tabla 3.4. Meses de la campaña con mayores índices de estacionalidad de los precios en origen

\begin{tabular}{cccc}
\hline Tipos de producto & Almería & Murcia & Alicante \\
\hline Tomate acostillado & Dic. y Abr. & & Oct. y Dic. \\
Tomate liso & Dic. y Marz. & Oct.y Abr. & Dic. y Abr. \\
Pimiento verde & Feb. y Marz. & Marz. y Abr. & Marz. y Abr. \\
Pimiento rojo & Feb. y Marz. & Abr. y May. & Abr. y May. \\
\hline Fuente: Elaboración propia. & & &
\end{tabular}

Para completar el capítulo se presentan los resultados de la predicción obtenida aplicando modelos ARIMA a las series temporales de precios del pimiento verde y rojo para Almería. En estas series de periodicidad quincenal, el periodo de tiempo estudiado comprende desde la primera quincena de octubre de 1992 a la segunda quincena de julio de 2006. En primer lugar, las series se ajustaron para que fueran estacionarias en media, diferenciándolas una vez en la parte regular $(\mathrm{d}=1)$ y en la estacional $(D=1)$, y se aplicó la transformación logaritmo natural para hacerlas estacionarias en varianza.

Los autocorrelogramas obtenidos se recogen en los Gráficos 3.21 $3.22,3.23$ y 3.24 . 
Gráfico 3.21. Autocorrelaciones estimadas en pimiento verde de Almería

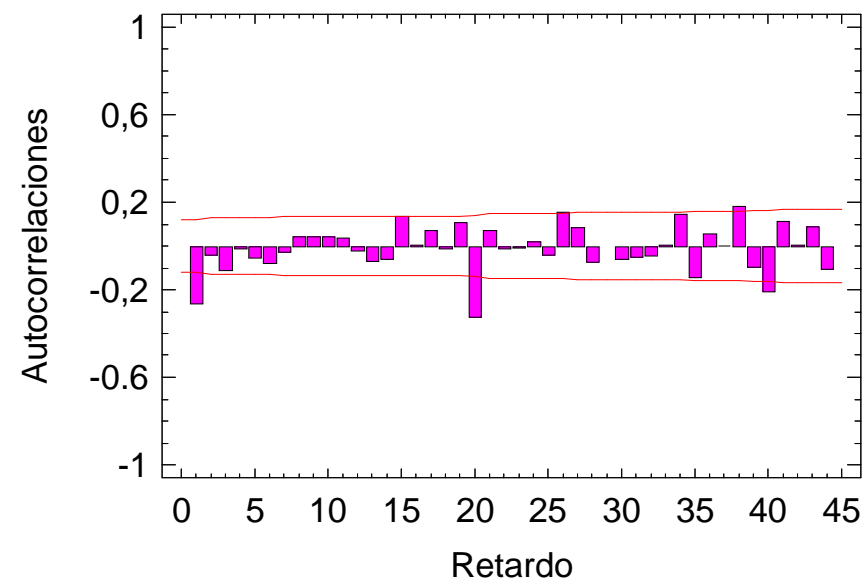

Gráfico 3.22. Autocorrelaciones parciales estimadas en pimiento verde de Almería

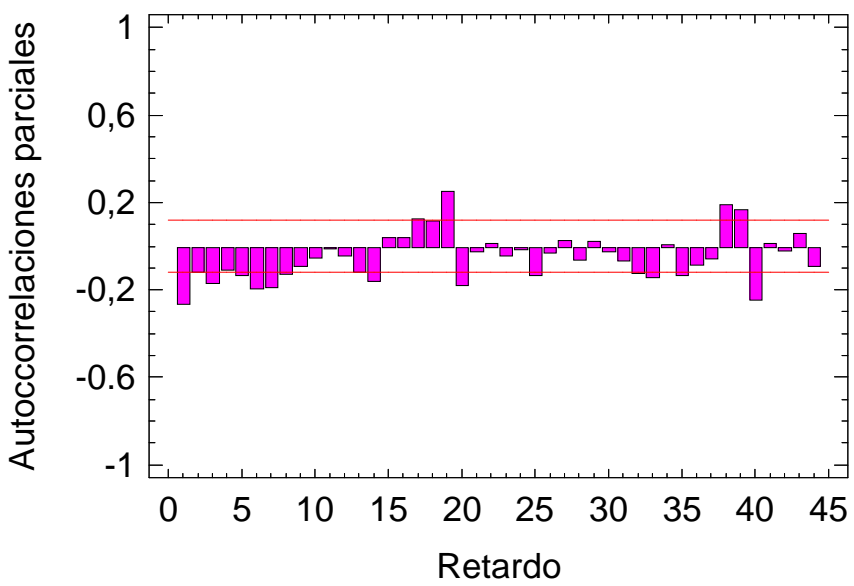


Gráfico 3.23. Autocorrelaciones estimadas en pimiento rojo de Almería

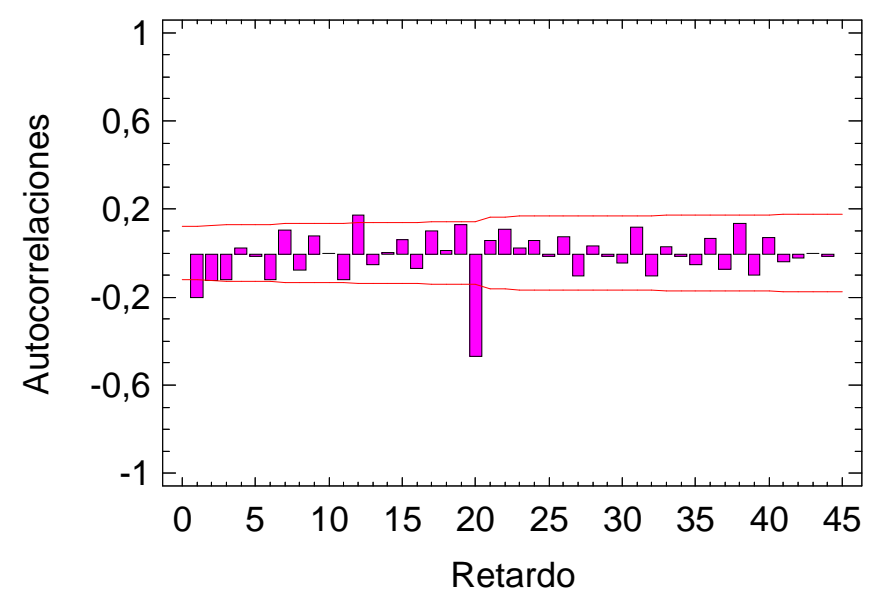

Gráfico 3.24. Autocorrelaciones parciales estimadas en pimiento rojo de Almería

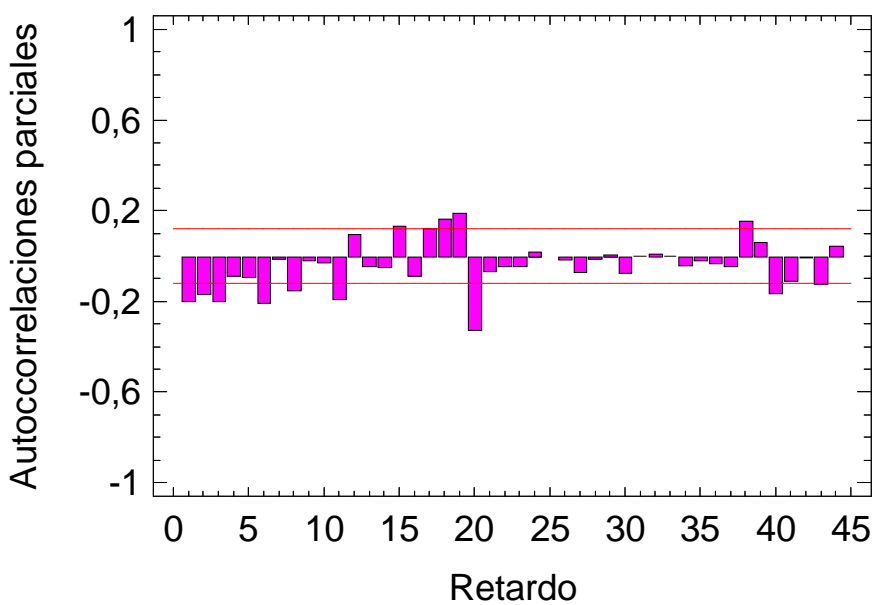


El análisis de estas autocorrelaciones, refleja la consideración de un MA(2) y de un SMA(1), por tanto, las series se modelizaron mediante un ARIMA $(0,1,2) \times(0,1,1)$,20 , con el que los residuos se aproximaron a un ruido blanco.

Los coeficientes estimados del modelo (Tabla 3.5), tanto el coeficiente de medias móviles de la parte regular de grado $1, M A(1)$, como el de grado 2, MA(2) y el coeficiente de medias móviles de la parte estacional, SMA(1), son estadísticamente significativos (P-valor $<0,05)$.

Tabla 3.5. Resultados de la estimación del modelo ARIMA $(0,1,2) \times(0,1,1)$ aplicado al pimiento verde y rojo de Almería

\begin{tabular}{cccccc} 
Modelos & Parámetros & $\begin{array}{l}\text { Coef. } \\
\text { Estimados }\end{array}$ & $\begin{array}{l}\text { Error } \\
\text { estándar }\end{array}$ & Estadístico t & P-valor \\
\hline Pimiento & MA (1) & 0,543 & 0,060 & 9,09 & 0,0000 \\
verde & MA (2) & 0,307 & 0,060 & 5,11 & 0,0000 \\
& SMA (1) & 0,892 & 0,019 & 46,11 & 0,0000 \\
\hline \multirow{2}{*}{ Pimiento } & MA (1) & 0,425 & 0,061 & 7,02 & 0,0000 \\
rojo & MA (2) & 0,257 & 0,060 & 4,26 & 0,0000 \\
& SMA (1) & 0,888 & 0,018 & 48,63 & 0,0000 \\
\hline
\end{tabular}

MA = media móvil; SMA = media móvil estacional .

Fuente: elaboración propia.

Para la validación del modelo, se comprobó que los residuos siguen un proceso de ruido blanco (se distribuyen aproximadamente como una normal, de media cero y varianza constante) y que además para los sucesivos test, se obtiene un $p$-valor estadísticamente no significativo ( $p$ valor $\geq 0,05)$. Los test son los siguientes:

RUNS = Test para excesivas ejecuciones arriba y abajo.

RUNM = Test para excesivas ejecuciones por encima y por debajo de la mediana.

AUTO $=$ Test de Box-Pierce para excesivas autocorrelaciones. 
MEAN = Test para la diferencia en la media de la $1^{\underline{a}}$ mitad a la $2^{\underline{a}}$ mitad.

$\mathrm{VAR}=$ Test para la diferencia en la varianza en la $1^{\underline{a}}$ mitad a la $2^{\underline{a}}$ mitad.

Los Gráficos 3.25 y 3.26 muestran los resultados de la predicción de precios obtenidos con este modelo, para el pimiento verde y pimiento rojo en Almería. En ambos casos, se comprueba que las desviaciones entre las predicciones y los precios reales son reducidas, y el comportamiento que siguen las dos series es muy similar a lo largo de la campaña. Todos los valores de los precios reales están siempre comprendidos entre los límites que marcan las líneas de los intervalos de confianza al 90\% obtenidos en la predicción.

Gráfico 3.25. Predicción frente a precios reales para pimiento verde en

\section{Almería}
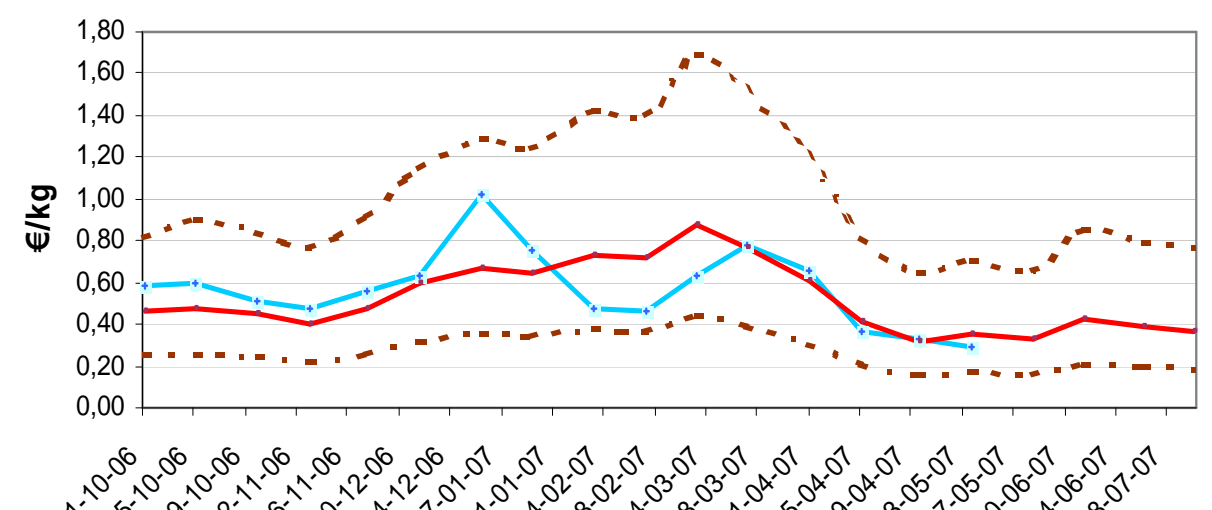

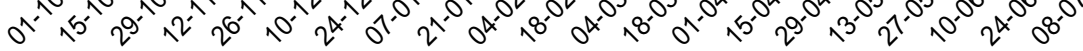

Campaña (1 $1^{\mathrm{a}}$ quincena Oct.'06 - 2ª quincena Jul.'07)

_+_Precio real ___Predicción - - - - Límites al 90\%

Fuente: Elaboración propia. 


\section{Gráfico 3.26. Predicción frente a precios reales para pimiento rojo en}

\section{Almería}

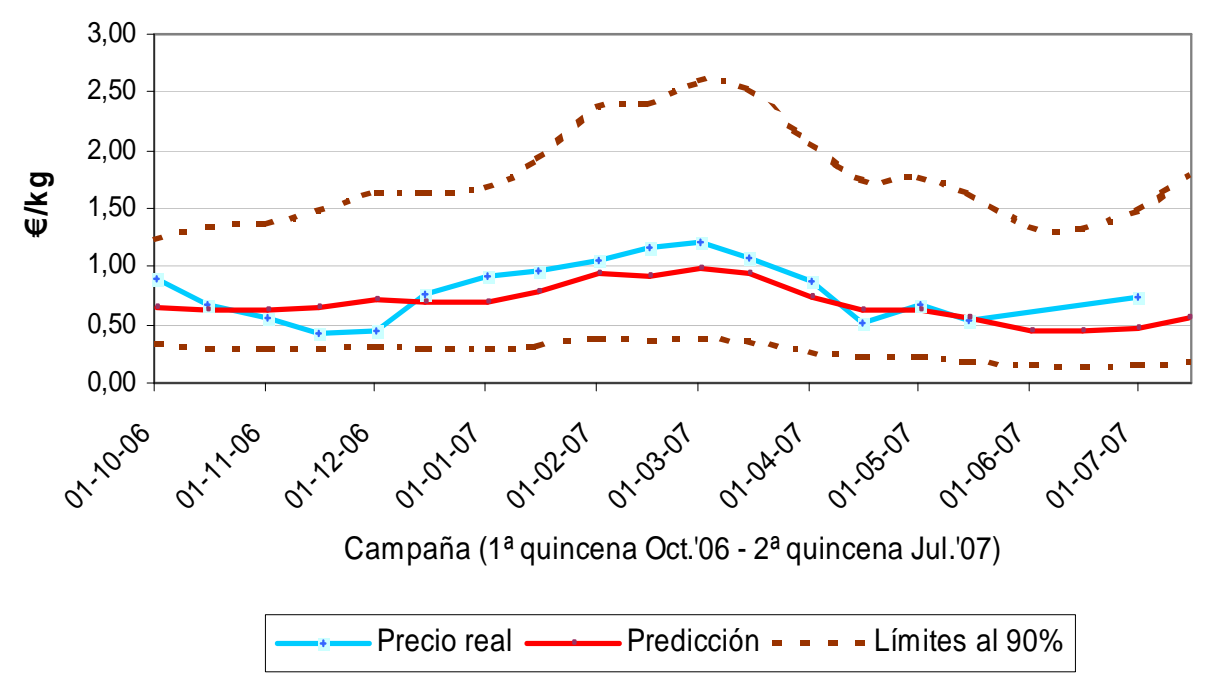

Fuente: Elaboración propia.

La principal alteración que se detecta en los precios reales, entre finales de noviembre y principios de enero, puede deberse a la perturbación comercial que generó la aparición de residuos no autorizados, que al ser detectados en algunos mercados europeos ocasionaron una fuerte caída de los precios (Junta de Andalucía, 2007). Corregido este incidente, los precios se recuperaron a partir de febrero, lo que se aprecia más en el pimiento verde.

En cuanto al pimiento verde (Gráfico 3.25), los valores de la predicción muestran, de acuerdo con lo obtenido en el análisis de la estacionalidad, que los precios más altos tendrían lugar entre los meses de enero y marzo, y el mayor descenso de precios se daría en el periodo de la campaña comprendido entre la $1^{\underline{a}}$ quincena de marzo y la $2^{\underline{a}}$ quincena de abril.

Para la serie de precios del pimiento rojo en Almería las predicciones se muestran en el Gráfico 3.26. En este caso, también coincidiendo con la estacionalidad, la predicción señala que los precios más 
altos se dan entre los meses de febrero y marzo, mientras que el mayor descenso de precios en la campaña tendría lugar entre la $2^{2}$ quincena de marzo y la $1^{\text {a }}$ de junio.

\subsection{Los precios en la Producción Integrada (PI) y Ecológica (PE)}

Dada la amplitud alcanzada por las diversas formas de PI desde su introducción y la expansión de la $\mathrm{PE}$ en los últimos años, parece conveniente introducir también en este apartado, la información de precios del pimiento cultivado en estas modalidades, a la que se ha podido tener acceso.

Ante la carencia de registros estadísticos amplios, que serían los necesarios para la formación de series convencionales, solamente van a quedar expuestos los precios medios obtenidos en la cooperativa Surinver de Pilar de la Horadada (sur de Alicante), entidad importante en la producción y comercialización de pimiento en España, con un volumen total de 25.000 a 30.000 toneladas.

Por otra parte, esta fuente de información presenta la ventaja de permitir la comparación de los precios obtenidos, bajo una misma unidad comercial, para tres tipos de producto diferente: variedades comunes, categoría Wonder y pimiento ecológico.

En el Gráfico 3.27 se representa la evolución porcentual de los principales tipos de pimiento en el sur de Alicante desde la campaña 2003/2004 a la 2006/2007. 
Gráfico 3.27. Evolución de la producción de los principales tipos de pimiento en el sur de Alicante

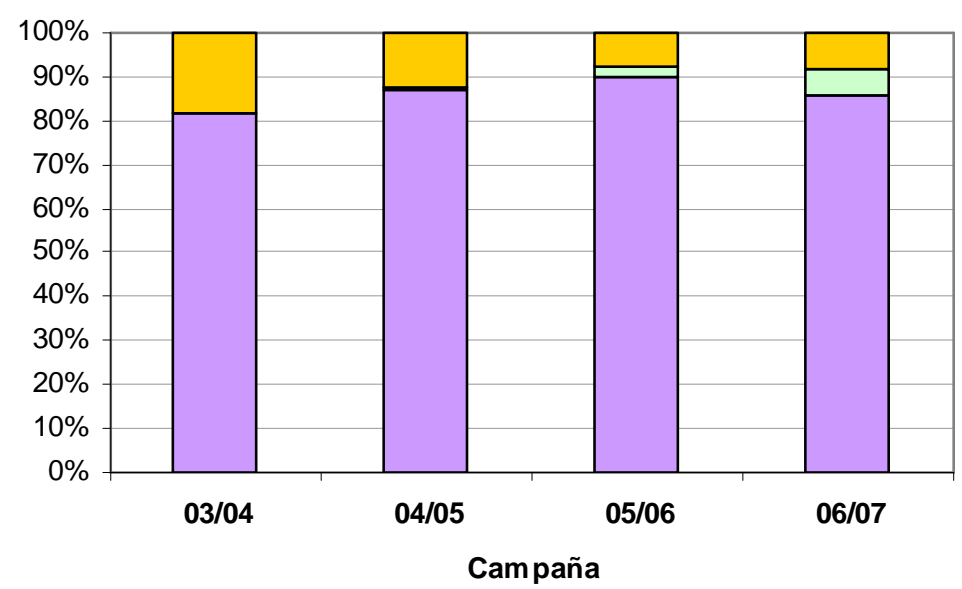

$\square$ Resto de tipos $\square$ Ecológico y Bio-conversión $\square$ Wonder

Fuente: Elaboración propia.

Se observa un notable incremento de la producción de pimiento ecológico y en bio-conversión (fase de reconversión a ecológico), coincidiendo con una disminución de la producción de Wonder respecto a las primeras campañas analizadas.

El Gráfico 3.28 muestra la evolución de los precios medios obtenidos en la cooperativa Surinver durante las campañas indicadas. 
Gráfico 3.28. Evolución de los precios medios del pimiento en el sur de Alicante, según tipos comerciales

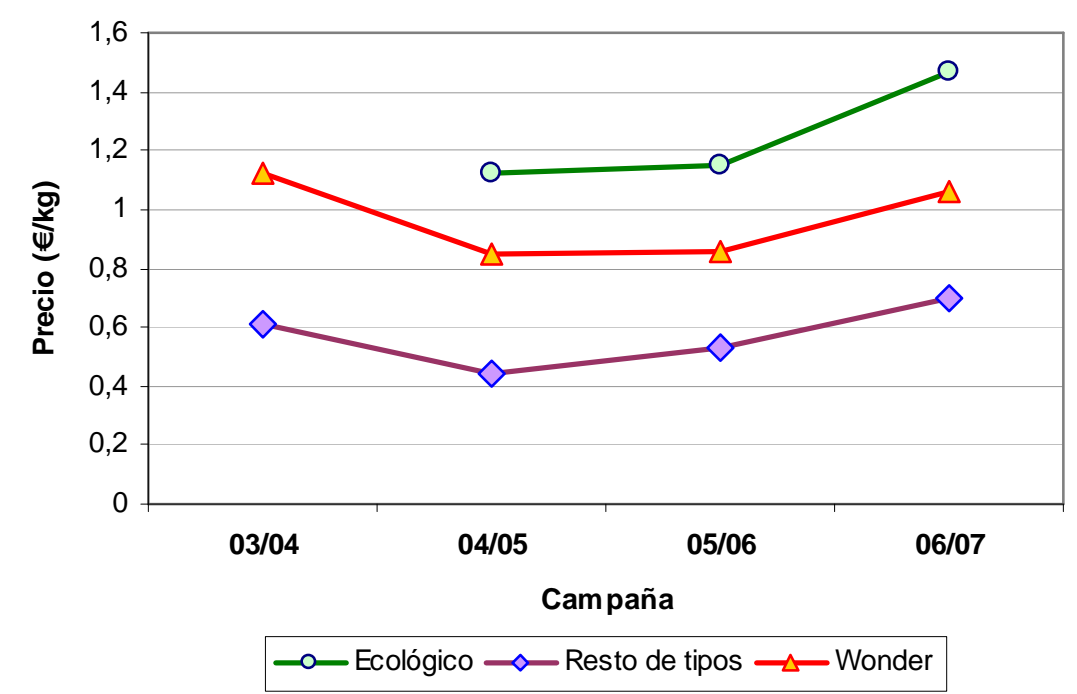

Fuente: Elaboración propia.

Se comprueba que existe un grupo de consumidores dispuestos a pagar entre un 25 y un 30\% más por el pimiento ecológico que por otras calidades superiores. Además, se observa una tendencia de estos precios al alza.

\subsection{Resumen y comentarios}

En el desarrollo de este capítulo, se ha realizado un estudio basado en el análisis de precios con tres enfoques diferentes. En primer lugar, se ha efectuado de forma breve una determinación de la posición competitiva del tomate y pimiento. El segundo, más amplio, ha comprendido el cálculo en las series de precios formadas, de la tendencia y estacionalidad, y junto a estos dos conceptos, se ha introducido la predicción por modelos ARIMA. Finalmente, se incluye una relación de precios con referencias comparativas entre la producción de variedades comunes, calidad Wonder y producción ecológica. 
La documentación y el análisis inicial de precios y exportaciones ponen en evidencia que no parece peligrar la posición competitiva, pero el sector no recorre las favorables etapas expansivas iniciales y la imposición de la globalización va a obligar inexorablemente a la actualización de las inversiones y de las técnicas productivas.

Las tendencias decrecientes en los precios indican una pérdida gradual de renta por parte de los productores, y ante esta situación son precisas nuevas orientaciones y modificaciones en la estructura y las técnicas productivas junto con la opción de incrementar la dimensión de la explotación.

El análisis de precios en origen, además de constituir una referencia en la evolución de las rentas de los productores, se ha orientado a establecer una relación entre los precios y la tecnología adoptable, con posibilidad de servir de orientación económica en las decisiones empresariales.

En el análisis de las series de precios se han incluido los conceptos de tendencia e índices estacionales, dentro del periodo que comprende cada serie. En el caso del pimiento también se incluye una predicción de los precios para el año siguiente.

Teniendo en cuenta la amplitud de las series y la periodicidad quincenal de los precios, el número de datos introducidos es elevado, por lo que la tendencia resultante ofrece información muy sólida como expresión del comportamiento de los precios medios. Al estar los valores actualizados con el IPC a la fecha final de cada serie, se puede calcular con facilidad el aumento o disminución del poder adquisitivo del producto y deducir su influencia en las rentas del agricultor.

En función de los resultados del análisis de la tendencia en los precios se deduce que existe un estancamiento o suave descenso para el tomate liso en las zonas de producción mayoritaria como son Almería y Murcia. Sin embargo, en Alicante se registra una tendencia positiva para 
este tipo de producto, lo cual puede responder a las diferencias en el proceso de comercialización.

En cuanto a los tipos diferenciados, el tomate acostillado presenta una evolución de los precios positiva, tanto en Almería como en Alicante. Esto es debido a que se trata de un tipo especial de tomate, por tanto, es necesario buscar huecos de mercado en los que se consiguen mayores precios, lo que es posible con productos diferenciados, como es el caso de los tomates acostillados, los de ramillete, Cherry (rojos, naranjas, amarillos), etc, o los pimientos naranjas, amarillos, blancos, etc, y para ello es necesario efectuar mejoras en la estructura y dotación del invernadero.

En pimiento rojo y verde, $y$ en las tres zonas productoras estudiadas, la evolución de las series de precios muestra una tendencia descendente que no es muy acusada, propia de un producto que partía de niveles de precios altos, y conforme la producción ha ido aumentando los precios han tenido tendencia a un decrecimiento suave o a una estabilización.

El pimiento, como producto, se encuentra en una situación económica más favorable que el tomate y cuando se aplica una tecnología elevada se obtiene un buen nivel de precios, tal es el caso del pimiento tipo Wonder.

Los resultados obtenidos con los índices estacionales proporcionan una información muy válida entre la relación de los calendarios de producción y los precios, y qué actuaciones convienen en cuanto a la elección de la variedad, técnicas productivas y dotación del invernadero en aspectos tan decisivos como la calefacción.

Los modelos ARIMA han presentado validez a corto plazo, una campaña. No obstante, los resultados que aportan son de gran interés en cultivos como el pimiento en invernadero, en el que es muy patente la respuesta obtenida, en producción y precios respecto a las técnicas y los medios empleados. 
Como consecuencia de la evolución de los precios en la que los empresarios no perciben de forma clara unas perspectivas favorables, se dan situaciones de utilización del capital fijo a menores niveles en cuanto a las inversiones fijas, como ocurre en el caso de los invernaderos cubiertos sólo con mallas, más empleados en el tomate. En este caso el cultivo está protegido de los insectos; la protección climatológica es más limitada, sobre los vientos y el efecto en las temperaturas es mínimo, por lo que no hay incidencia en el calendario de producción.

Aun considerando una evolución poco favorable en los precios, se ve necesaria una mayor adopción de tecnología si el agricultor quiere elevar la calidad y adaptar su sistema de producción a los máximos estacionales de los precios; y es que, cuando el invernadero está mejor dotado, incluso con alguna modalidad de calefacción, se pueden alcanzar con más facilidad los niveles superiores de precios, y adelantarse en el mercado al ciclo normal que tiene lugar en verano-otoño.

Además de las dimensiones y equipamiento del invernadero, tienen relación muy directa sobre los precios de los productos, la calefacción, el cultivo en sustrato y diversas modalidades de PI.

La calefacción repercute en el calendario de producción y estacionalidad de los productos, eleva la calidad y, a su vez, proporciona seguridad ante riesgos de bajas temperaturas. No obstante, su uso presenta ciertas limitaciones debido en gran parte a la variabilidad en los precios de los combustibles habituales, por lo que su utilización, tanto de forma permanente como puntual, exige un control técnico y económico muy estricto, pues siempre representa un coste considerable.

La tendencia descendente, seguida por los precios en los productos mayoritarios, explica que modificaciones tecnológicas importantes y que requieren elevadas inversiones, como es el cultivo en sustrato, se estén implantando lentamente, incluso llegando a un cierto estancamiento. Así, desde el año 2000, en Almería la superficie en sustrato no supera el $20 \%$. 
Por otra parte, el cultivo en modalidades de PI con técnicas de control biológico, que siempre exigen un nivel mayor de tecnología, contribuye a una mejora de la imagen comercial del producto. Hoy por hoy, sigue siendo difícil cuantificar diferencias económicas a favor de la PI, pero la prioridad de elección en la fase de comercialización siempre podrá generar alguna ventaja en el precio final del producto.

A diferencia de lo que suele acontecer en la venta de productos con técnicas $\mathrm{PI}$, cuando se comercializan productos con origen ecológico sí existe discriminación favorable en los precios. Ello es consecuencia, por una parte, de las exigencias actuales de los consumidores respecto a la seguridad y sanidad de los alimentos, y por otra, de las garantías que se atribuyen a la etiqueta de PE. 
Capítulo IV

Estado actual de la tecnología en los invernaderos hortícolas 



\section{Capítulo IV. Estado actual de la tecnología en los invernaderos hortícolas}

Se efectúa una descripción de los diversos elementos y sistemas incluidos en el equipamiento de los invernaderos, con las funciones de los diversos grupos de componentes, unido al conocimiento de algunas características empresariales que se consideran más relacionadas con la inversión y las técnicas productivas.

En esta primera descripción, imprescindible para un conocimiento básico de la situación y previo a la elaboración de la encuesta principal (Anexo 3), se han utilizado las siguientes vías de aporte de información:

1. Documentación y bibliografía técnica y económica existente.

2. Notas procedentes del reconocimiento directo de las zonas de referencia del trabajo.

3. Entrevistas de segundo nivel efectuadas a empresas, cooperativas y técnicos, localizados en dichas áreas.

4. Una primera encuesta de sondeo, breve y complementaria, para determinar la situación actual del uso de la calefacción, dada la importancia de este elemento desde el punto de vista técnico y económico.

Una vez se dispuso de suficiente información de las zonas de estudio, se planteó y realizó la encuesta fundamental del trabajo, que se centra en la adopción de tecnología, con las características que la determinan.

Con independencia de la amplitud con la que se han tratado los diferentes temas, uno de los objetivos esenciales ha sido la determinación de grupos de invernaderos que marcan la existencia de niveles tecnológicos y su evolución para lo cual se aplicó el análisis cluster. 
A continuación otro aspecto analizado han sido los factores que afectan al proceso de innovación.

Finalmente se concluye con una síntesis de resultados y deducciones de los temas analizados.

\subsection{Características y dotación de los invernaderos}

Antes de iniciar el análisis sobre adopción de tecnología, con base empírica, deducida de información tomada por encuesta, se ha procedido a la descripción del estado actual de la tecnología y equipamiento de los invernaderos hortícolas.

La obtención de hortalizas fuera de estación ya se realizaba en pequeñas proporciones en la segunda mitad del Siglo XIX (García-Sanz, 1865). En dicho trabajo se menciona la existencia de cultivo forzado mediante abrigo, invernáculos y estufas. Algunas de estas construcciones ya entonces alcanzaban gran perfección con el empleo de madera, vidrio y perfiles de acero, que se acababan sellando para conseguir un aislamiento del exterior en épocas frías. En Inglaterra y Estados Unidos estas construcciones tuvieron importancia para la obtención de hortalizas y flores con destino a los mercados de Londres y Nueva York; sin embargo, en España debido a la benignidad del clima, la producción a gran escala de hortalizas en invernadero se efectuó, en un primer periodo, con modelos artesanales muy simples y surgió desde una experiencia gradual en campo en los primeros años 60 .

Parece evidente que el rápido incremento de la superficie de invernaderos ha sido motivado por la serie de cambios generados en la tecnología, entre los que ha tenido un efecto muy especial el uso de los plásticos.

En las primeras etapas, la producción en cultivo protegido se basó en la implantación de invernaderos de bajo coste, la mayoría de tipo "parral" 
sobre el que se fundamentó la rapidísima expansión de la superficie cubierta (Caballero et al., 2001). El primer tipo de invernadero "parral" tuvo su origen en la provincia de Almería y no es más que una adaptación de las estructuras de los antiguos parrales utilizados en las plantaciones de uva de mesa para sostener la cubierta de plástico.

Con anterioridad a la instalación de los primeros invernaderos se extendió en Almería, a partir de 1957, la utilización de la técnica de cultivo con el suelo enarenado, que desde 30 años antes se venía practicando en la costa de Granada.

Para la formación de un suelo enarenado se efectúa, en principio, una labor de desfonde y nivelado; a continuación, si no hay suelo adecuado, se coloca una capa de tierra vegetal de unos $20 \mathrm{~cm}$ mezclada con unos 5 $\mathrm{kg} / \mathrm{m}^{2}$ de estiércol. Encima de este estrato, se sitúa una capa de estiércol de $2 \mathrm{~cm}$ y en la parte superior una capa de arena de $10 \mathrm{~cm}$. La capa de estiércol se repone cada 3 o 4 años, separando previamente la arena, una operación que denominan retranqueo, que se va reduciendo debido a su elevado coste y sólo se practica por bandas estrechas. El suelo enarenado en Almería comprende casi toda la superficie que no se cultiva en sustrato.

La estructura del invernadero de parral suele estar formada por pilares de madera y un entramado doble de alambre, entre el cual se coloca una lámina de plástico delimitando así una zona de cultivo protegido. Este tipo de invernadero plano hoy día aún supone un $27 \%$ de la superficie total de invernaderos $y$, en cierto modo, ha sido el más identificado con el tipo mediterráneo; no obstante está sufriendo una gran reestructuración, y su evolución, marcada por las necesidades tecnológicas, parece necesaria e inevitable (Molina et al., 2003).

Gorini (1962) definió el invernadero como "una construcción de madera o de hierro u otro material, cubierta por cristales, provista por lo general de calefacción que, a veces, esta iluminada artificialmente y donde se pueden cultivar hortalizas tempranas, flores y plantas verdes, en épocas 
en las que la temperatura y la luz serían insuficientes para su crecimiento y su fructificación".

Más reciente es la expresión recogida en la norma UNE-EN-130311 (Invernaderos: Proyecto y Construcción) en la que se define el invernadero como "una estructura usada para el cultivo y/o protección de plantas y cosechas, la cual optimiza la transmisión de radiación solar bajo condiciones controladas para mejorar el entorno del cultivo y cuyas dimensiones posibilitan el trabajo de las personas en su interior" (AENOR, 2002).

Estas definiciones pueden dar cabida a una amplia gama de formas constructivas con las que realizar un invernadero, variedad de materiales estructurales, así como la posibilidad de que se incorporen diversos aparatos de climatización (Alpi y Tognoni, 1991), con lo que se originan numerosos tipos de invernaderos.

Atendiendo a los elementos estructurales, los invernaderos más simples y económicos son los que utilizan como material de sostenimiento la madera. Este tipo de invernadero tiene una media de antigüedad de 14 años, persistiendo todavía un $13 \%$ del total de invernaderos en la provincia de Almería, con más de 15 años (Fernández-Sierra y Pérez, 2004). Estas circunstancias son provocadas por la falta de motivación del propietario en aportar capital a la explotación en inversiones fijas, debido a la falta de sucesión o por rápidos cambios, a veces consecuencia de situaciones especulativas.

Otro material empleado como sostenimiento es el acero, que tiene la ventaja de presentar mayor resistencia a las cargas con secciones inferiores a la madera, pudiendo adaptarse mejor a las estructuras curvas, con lo que se consigue, además de un menor sombreado, reducir la dispersión de calor en los puntos de unión, lo que compensa la mayor pérdida de calor por conducción por parte del acero. Por otra parte, sus mayores problemas son el desembolso inicial más elevado y la corrosión, 
por lo que se suele elegir un acero galvanizado para evitar tener que pintarlo cada año para protegerlo.

Por último está la aleación de aluminio que presenta ciertas ventajas e inconvenientes con respecto al acero. De entrada resiste mejor la corrosión y permite construir perfiles más complicados que el acero; eso sí, a cambio de un precio más caro y de soportar menor sobrecarga, sobre todo en los puntos de soldadura.

Conforme los invernaderos se han ido renovando y haciendo más modernos también ha ido aumentando la superficie media, siendo ésta de $8.107 \mathrm{~m}^{2}$ para los invernaderos metálicos, de $6.008 \mathrm{~m}^{2}$ para los de madera y de $7.044 \mathrm{~m}^{2}$ para los de estructura mixta, según la publicación sobre caracterización de los invernaderos en la provincia de Almería (FernándezSierra y Pérez, 2004).

Los plásticos utilizados como recubrimiento eran en un principio una mera protección física y, más adelante, han ido incorporando más cualidades como mayor durabilidad, elasticidad, termicidad y antigoteo para evitar condensaciones interiores. Actualmente se pueden añadir además, las propiedades de fotoselectividad para aprovechar mejor la luz fotosintéticamente más activa y como medida de control de plagas y enfermedades. Hoy día, el plástico más usado es el Tricapa incoloro difuso y con 200 micras de espesor.

También existen invernaderos en los que se utiliza una malla como alternativa a la cubierta de plástico. Resultados de experiencias en Almería han puesto de manifiesto la importancia de la porosidad de las mallas cuya densidad ha de ser suficiente para reducir de forma significativa el nivel de plagas pero sin afectar a la tasa de ventilación y de luminosidad (Gázquez et al., 2006; Cabrera et al., 2006; Soriano et al., 2006).

Junto con los materiales estructurales y de cubierta, la geometría y altura de los invernaderos también han ido evolucionando; los invernaderos a dos aguas (simétrico y asimétrico) fueron sustituyendo a los planos, ya que estos últimos presentan una limitación en la producción en otoño e 
invierno debido a su baja transmisividad de la radiación solar (Castilla, 1994). En la actualidad la evolución se está produciendo hacia la estructura multitúnel. En cuanto a la altura, en la provincia de Almería, generalmente, un invernadero parral multicapilla tiene una altura de $4 \mathrm{~m}$, frente a los $3 \mathrm{~m}$ de las construcciones más antiguas. Sin embargo, en la zona del sur de Alicante y Campo de Cartagena, el tipo parral simple suele tener una altura de $1,8 \mathrm{~m}$ a la canal, el parral mejorado unos $2 \mathrm{~m}$ a la canal y alrededor de 3,5 m en el centro y, por último, el más avanzado, el multitúnel, alcanzaría los $4 \mathrm{~m}$ a la canal y aproximadamente $7 \mathrm{~m}$ en el centro.

Otro factor importante a tener en cuenta es la pendiente de cubierta. Experiencias con invernaderos mediterráneos han demostrado el interés, considerando la orientación del invernadero, de aumentar las pendientes de cubierta para conseguir mayores producciones en ciclos de otoño-inviernoprimavera (Quesada et al., 1998; Castilla et al., 2001).

\subsection{Discusión sobre la evolución de la tecnología en los invernaderos}

Los invernaderos tipo parral, de amplia implantación en el mediterráneo español, han ido evolucionando y mejorando a partir de los años 90 a causa de los numerosos inconvenientes que presentan. En las primeras etapas su rápida expansión fue posible principalmente debido a la favorable situación de los precios y a la baja capitalización de las explotaciones pero, gradualmente, se fueron imponiendo las exigencias en cuanto al control climático que no se logran con el invernadero de parral. Desde el final de la década de los 90 y en los primeros años del 2000, se ha incrementado la superficie de cultivo en sustrato.

Los inconvenientes más destacables del invernadero tipo parral se presentan a continuación:

- Debido a su escasa altura, la regulación de la temperatura es muy deficiente $y$, como consecuencia del bajo volumen de aire 
contenido, que tarda poco tiempo en enfriarse y calentarse, se producen altas oscilaciones térmicas entre el día y la noche.

- La altura y el bajo volumen de aire también son impedimentos para la adecuada realización de los tratamientos fitosanitarios que, a veces, es necesario hacerlos desde el exterior mediante un cañón, lo que implica una mala distribución de los plaguicidas.

- Son muy difíciles de manejar en verano, y las dificultades de las elevadas temperaturas suelen paliarse con el encalado, el cual a su vez, si no es debidamente lavado en otoño limita considerablemente la luminosidad a partir de esta época del año.

- Requieren especialización en su construcción y conservación, siendo costosa la mano de obra de la instalación, presentando además un rápido envejecimiento.

- La forma de sujeción del recubrimiento mediante un entramado de alambre y el sostenimiento con postes de madera dan lugar a una pérdida de luminosidad. Además, la forma en que el alambre une las dos láminas de plástico a través de orificios, permite el paso de agua de lluvia que, a menudo lleva esporas, ocasionando daños en el cultivo al provocar enfermedades criptogámicas. También, la baja hermeticidad permite la entrada de plagas.

- La escasa pendiente del techo origina una baja captación de la luz solar $y$, por tanto, una menor luminosidad en el interior del invernadero.

- El excesivo número de postes y los elementos de anclaje necesarios para sostener la estructura ocupan espacio e impiden un fácil movimiento en el interior; a su vez, los tirantes exteriores también dificultan la maniobrabilidad en un amplio espacio alrededor del invernadero.

- Si es antiguo suele tener únicamente ventilación lateral; sin embargo, el paso del tiempo ha demostrado que la ventilación 
cenital es muy importante, ya que la escasa ventilación aumenta la humedad relativa, lo que produce condensación de agua que reduce la transmisividad de la luz solar y causa goteo sobre el cultivo provocando el riesgo de enfermedades fúngicas. Por otra parte, esta ventilación lateral no suele estar motorizada y es accionada de forma manual.

- El techo plano conlleva un alto riesgo de rotura por precipitaciones intensas, además de peligro de hundimiento por las bolsas de agua de lluvia que se pueden formar en la superficie de la cubierta, siendo también altamente vulnerable a los vientos fuertes.

- Como consecuencia de las deficiencias en la regulación medioambiental, especialmente respecto a la temperatura $y$ luminosidad, los rendimientos de las cosechas son más bajos y suele resentirse la calidad. Las variedades más selectas sólo son posibles en invernaderos más avanzados.

El resto de los inconvenientes de los invernaderos de escasa altura se deben a su bajo nivel tecnológico, pero obviamente de ahí se deriva la principal ventaja: son de menor coste.

La evolución en la estructura y equipamiento de los invernaderos ha ido produciéndose de forma gradual, de modo que los primeros cambios fueron el paso de los postes de madera a los metálicos; después, la elevación de la altura y la inclinación de las cubiertas. Más tarde se introducen las mejoras en la ventilación a través de colocación de ventanas cenitales, apertura mecanizada y control automatizado de las ventanas.

Para la regulación de la temperatura se adoptan procedimientos diversos como pueden ser el encalado o la colocación de pantallas de sombreo, o sistemas como la nebulización o el Cooling System, en las épocas en que se alcanzan altas temperaturas. En épocas de temperaturas bajas se usan pantallas térmicas o dobles cubiertas.

En invernaderos con mayor capacidad de aislamiento, se introduce el uso de la calefacción, siendo los sistemas más comúnmente empleados 100 
de dos tipos: de aire caliente, se usan para evitar descensos puntuales de temperatura y de agua caliente, con dedicación permanente en las épocas de temperaturas bajas.

Por otra parte, desde los años 80, ha aumentado paulatinamente el uso de ordenadores y aplicaciones informáticas en las explotaciones con cultivos intensivos.

En cuanto al riego, se ha llegado a un gran nivel de perfeccionamiento en el riego por goteo y elementos automáticos de fertirrigación.

Algunos invernaderos incorporan quemadores de azufre para la realización de los tratamientos antifúngicos. En los invernaderos con mayor grado de tecnología se utiliza la fertilización carbónica, con el fin de aumentar la fotosíntesis y con ello la producción. El empleo del $\mathrm{CO}_{2}$ es muy escaso y más frecuente en el pimiento que en el tomate.

En los cultivos con Producción Integrada se instalan mallas antiinsectos que son indispensables para la lucha biológica.

Respecto al cultivo en sustrato, aumentó con rapidez entre el año 2000 y 2005 , pero actualmente se detecta un avance más bien lento.

\subsection{Grupos de elementos que componen la tecnología en los invernaderos mediterráneos}

\subsubsection{Control climático}

Con la utilización de los invernaderos es posible controlar y mejorar el clima, creando un microclima interior en función de las necesidades de los cultivos y aumentar la rentabilidad de las explotaciones, bien a través de mayores rendimientos y con la posibilidad de variar el periodo de comercialización, o bien buscando una mayor eficiencia en la energía empleada. 
El exceso de temperatura provoca en los cultivos estrés y parada del metabolismo; para evitarlo existen diferentes soluciones, como son la ventilación y la refrigeración.

La ventilación resulta imprescindible para la renovación del aire. Con esta técnica, lo que se pretende es la reducción de la temperatura y de la humedad y la distribución correcta del $\mathrm{CO}_{2}$, siendo necesarias entre 60 y 80 renovaciones por hora del aire total del interior del invernadero (Tendero, 2004). Los sistemas de ventilación más utilizados son los de tipo pasivo mediante ventanas laterales y cenitales. Se recomienda una superficie de ventilación del $22 \%$ en relación con la superficie total del invernadero. En Almería destacan, en ventilación lateral, los sistemas de bandas deslizantes, y van incorporándose paulatinamente a las estructuras de los invernaderos, las ventanas plegables y enrollables; por otro lado, las más comunes en la ventilación cenital, son las abatibles en los invernaderos de mayor altura de cumbrera.

Una de las técnicas de refrigeración es la humidificación mediante paneles evaporativos (Cooling System) que se saturan de agua por medio de un equipo de riego y, cuando el aire exterior entra a través de ellos, absorben la humedad y bajan la temperatura interior del invernadero; posteriormente, mediante unos ventiladores helicoidales colocados en extremo opuesto a los paneles, el aire es expulsado al exterior. Este sistema tiene como desventaja que es caro y su mantenimiento costoso.

Otra de las técnicas de refrigeración es la nebulización, que adopta dos formas: con alta presión $\left(>40 \mathrm{~kg} / \mathrm{cm}^{2}\right)$, más conocida como Fog System, y la de baja presión (de 4 a $6 \mathrm{~kg} / \mathrm{cm}^{2}$ ). El Fog System consiste en unas boquillas colocadas en las tuberías del riego con un obstáculo a la salida del chorro de agua, de tal forma que se dispersa formando un cono de pequeñas gotas de agua del orden de 20 micras de diámetro. Es un requerimiento indispensable que el agua sea de muy buena calidad ya que, de otro modo, las boquillas se obstruyen y, en ese caso, sería necesario un sistema de eliminación de sales. A baja presión se evita el problema de la calidad deficiente del agua, pero al ser el tamaño de las gotas mayor, puede 102 
provocar manchas perjudiciales para algunos cultivos, sobre todo en semillas y ornamentales. Otras boquillas que trabajan entre 3 y $5 \mathrm{~kg} / \mathrm{cm}^{2}$, mezclan agua y aire a presión $\left(6-8 \mathrm{~kg} / \mathrm{cm}^{2}\right)$. La mayor ventaja de este sistema es que la corriente de aire limpia la boquilla e impide el goteo cuando se corta el agua.

En las épocas de mayor insolación, con el fin de reducir la temperatura, además de la nebulización y la ventilación, se suelen colocar pantallas de sombreo y, en el caso de invernaderos que no disponen de ellas, tradicionalmente se realiza un encalado, consistente en la aplicación de una capa de cal en toda la superficie de la cubierta. La ventaja de la pantalla de sombreo frente al encalado es que, a pesar de ser más cara, es más homogénea y presenta mayor flexibilidad al ser automática (Callejón et al., 2003).

El inconveniente del encalado y de la pantalla de sombreo es que reducen la radiación solar, lo que da lugar a un descenso en la producción. Por eso se aconseja que se utilice cuando existan problemas de exceso de radiación (golpes de calor) en pimiento y tomate.

Para combatir las bajas temperaturas que han de soportar los cultivos que se desarrollan durante el invierno, y así aumentar su productividad y calidad, se utilizan pantallas térmicas, dobles cubiertas y sistemas de calefacción.

Las pantallas térmicas han de ser móviles para poder retirarlas durante el día, y así evitar la reducción de la radiación. Por este motivo son poco frecuentes, dado que su instalación en estructuras simples es complicada. Suelen aumentar la temperatura entre 2 y $4 \stackrel{\circ}{\circ}$.

En invernaderos con calefacción es posible la colocación de pantallas para el ahorro de energía que, además, evitan el exceso de radiación y dejan pasar suficiente vapor de agua impidiendo la condensación bajo la pantalla.

Las dobles cubiertas infladas consisten en la colocación interior de otra película plástica separada de la cubierta, por aire a presión, entre 2 y 
$10 \mathrm{~cm}$, lo que reduce las pérdidas de calor y resiste mejor el viento que la lámina simple. El inconveniente que presentan es que no pueden ser retiradas durante el día y, por esto, reducen la transmisividad de la radiación solar.

Un estudio realizado en un invernadero parral, en el que se comparaba la pantalla móvil aluminizada frente a la pantalla térmica fija, dio como resultado que la pantalla móvil aluminizada, durante las noches más frías, incrementó en $0,5{ }^{\circ} \mathrm{C}$ la temperatura respecto a la pantalla térmica fija; además el uso de la pantalla fija disminuyó un $21 \%$ la producción comercial frente a la testigo, mientras que la móvil la incrementó en un 15\% (López et al., 2003b).

\subsubsection{Calefacción}

Con la aplicación de los plásticos en la agricultura y la creación de ambientes tan aislados, en principio se pensó que en climas templados el abrigo del plástico ya proporcionaba temperatura suficiente. Pronto se vio que era económico el empleo de un generador de calor para evitar los riesgos de las heladas que sucedían un mínimo de días al año.

En un corto periodo de tiempo los invernaderos se fueron perfeccionando $y$, gracias a la experiencia internacional existente, sobre todo en los países de Europa, se han ido conociendo para cada especie los efectos de la temperatura en el crecimiento según los estados fenológicos de la planta. Así en un estudio realizado con cultivo de pimiento en invernadero, el uso de la calefacción aumentó la precocidad, la producción total y comercial y disminuyó la proporción de destrío (Gázquez et al., 2005).

La elección del tipo de calefacción dependerá de la estrategia productiva. La calefacción por aire caliente se utiliza para evitar descensos puntuales, pero no para mantener valores constantes de temperatura, ya que el coste se dispararía debido a que la masa de aire se calienta rápido, pero también se enfría rápidamente al estar en movimiento y en contacto con la cubierta. Estos sistemas están siendo lentamente introducidos en el 
litoral de Almería por su menor coste y facilidad para adaptarse a los invernaderos tipo parral (López et al., 2003a).

El otro tipo de calefacción es por agua caliente y, dentro de este tipo, el sistema más utilizado es el de conducción de agua a 30-40 ํㅡ por tuberías de polipropileno corrugado, frente a otros sistemas con mayor coste de instalación, que llevan agua a 80-90 ํㅡ a través de tuberías de acero o aluminio. Estos tipos de tubos se pueden utilizar además como raíles para el paso de carretillas elevadoras que aumentan el rendimiento en las operaciones manuales como la poda, recolección, etc.

Para evitar la acumulación del aire caliente en la parte alta del invernadero, se colocan desestratificadores que actúan recirculando el aire caliente distribuyéndolo de manera uniforme.

Se ha dedicado una especial atención a este apartado dada la relevancia de este factor de producción y sus múltiples efectos. Para su análisis se realizó una encuesta de sondeo (Anexo 2), con un total de 75 entrevistas sobre calefacción de invernaderos de pimiento en el sur de Alicante, en julio de 2005, de la que se dedujeron los siguientes resultados en cuanto a equipamiento de invernaderos con calefacción y efectos de la misma:

- Un 33\% disponía de pantalla de sombreo, un $13 \%$ de doble cámara, un 14\% de mallas de sombreo, un $8 \%$ de nebulización, un $8 \%$ de quemadores de azufre y sólo el $1 \%$ aplicaban $\mathrm{CO}_{2}$.

- Según la información de los propietarios con invernaderos dotados de calefacción, un 34\% manifiestan haber obtenido adelanto en la cosecha, un $35 \%$ más calidad y un $21 \%$ más producción.

- Respecto a las mejoras de la calidad por el uso de la calefacción, las respuestas eran las siguientes: un $42 \%$ mejor forma, tamaño y color; un $5 \%$ indicaban una cosecha más uniforme, y un $53 \%$ menos pimiento de segunda categoría. 
- Respecto a los tipos de calefacción en los invernaderos de pimiento, en el $76 \%$ de los casos se trataba de calefacción de mínimos y en el $24 \%$ de calefacción permanente.

- Los combustibles utilizados son el gasóleo C en el $27 \%$ de los casos, el fuel en el $68 \%$, y diferentes tipos de gas en el $5 \%$.

El tipo de calefacción dependerá de la estrategia productiva adoptada por el agricultor. En caso de que la calefacción se utilice puntualmente para evitar heladas, es más eficiente la calefacción por aire, mientras que si se utiliza de forma continua interesará más la calefacción por conducción de agua.

Como conclusión se puede decir que la calefacción, como factor de producción, tiene acusadas limitaciones por ser un elemento muy determinante en los costes. Por todo ello, aunque produce un efecto favorable sobre calidades y periodos de recolección, el coste de la calefacción exige un control técnico y económico muy estricto.

\subsubsection{Sustrato}

Con el cultivo en sustrato el cambio técnico y biológico es radical respecto al cultivo tradicional, por lo que significa independizar el desarrollo de la planta de las funciones de la tierra. En consecuencia, al cultivo no le afectan las enfermedades del suelo, ni precisa desinfecciones previas a la plantación, se evita la competencia de las malas hierbas y no es necesario el uso de herbicidas.

Los sustratos para cultivo con soluciones nutritivas deben tener una serie de características, según Maroto (2008):

- Ser química y biológicamente inertes, poseer una capacidad de cambio iónico escasa o nula, elevada capacidad tampón y no contener elementos tóxicos o microorganismos patógenos para las plantas.

- Poseer una granulometría lo más uniforme posible. 
- Estar dotado de una adecuada estabilidad estructural para evitar la degradación con el tiempo.

- Tener buena capacidad de retención de agua.

- Ser de fácil desinfección.

Respecto a los diferentes tipos de sustratos utilizados se puede diferenciar entre sustratos naturales clásicos y sustratos artificiales. Algunos de los principales sustratos utilizados se describen a continuación:

- Agua: Representa al cultivo hidropónico propiamente dicho, ya que realiza el papel de portadora de nutrientes además de la función como sustrato.

- Gravas: Suelen utilizarse las que tienen un diámetro entre 5 y 15 $\mathrm{mm}$. Probablemente las más indicadas son el cuarzo, piedra pómez y las que contienen menos de un $10 \%$ de carbonato de cal. Poseen buena estabilidad estructural, capacidad de retención de agua baja y porosidad elevada. Su uso como sustrato puede extenderse a varios años.

- Arenas: Las que mejor resultado dan son las de río, preferentemente las de granulometría entre 0,5 y $2 \mathrm{~mm}$. de diámetro. Su capacidad de retención de agua es media, de un $20 \%$ de su peso, y capacidad de aireación elevada. La capacidad de intercambio catiónico es mínima, tienen una duración elevada y un $\mathrm{pH}$ entre 4 y 8.

- Perlita: Sustrato artificial obtenido por tratamiento térmico a unos $1000{ }^{\circ} \mathrm{C}$ de una roca silícea volcánica del grupo de las riolitas. Su estructura adopta formas de partículas blancas de entre 1,5 y $6 \mathrm{~mm}$. de diámetro y su densidad es inferior a los $100 \mathrm{~kg} / \mathrm{m}^{3}$. Tiene una capacidad de retención de agua de hasta cinco veces su peso, y su capacidad de intercambio iónico es prácticamente nula.

- Lana de roca: Se obtiene al fundir a temperaturas inferiores a los $1500 \stackrel{\circ}{\circ}$ una mezcla de rocas volcánicas, calcáreas y carbón de 
coque, produciendo unas fibras que, para darle estabilidad, se mezclan con una resina llamada bakelita. Su densidad aparente es de $80 \mathrm{~kg} / \mathrm{m}^{3}$. Puede retener hasta el $80 \%$ de su volumen en agua y su capacidad de intercambio iónico, al igual que en la perlita, es casi nula. Su pH está entre 7 y 9,5.

- Fibra de coco: Tiene una porosidad de entre 94 y $99 \%$ y una capacidad de retención de agua de entre el 12 y $14 \%$ de su volumen. Su capacidad de intercambio catiónico se sitúa entre 31 y $97 \mathrm{meq} / 100 \mathrm{~g}$, y posee niveles significativos de P, K, Ca y Mg. Su pH se sitúa entre 4,5 y 6 .

- Algunos de los sustratos anteriores pueden, además, ir mezclados con turbas para adecuar las condiciones del sustrato a las necesidades de cultivo. Las turbas proceden de la vegetación antigua de áreas pantanosas que han sufrido descomposición parcial. Algunos tipos de turbas también se usan como sustratos específicos, sin necesidad de ser mezcladas con otros materiales.

El cultivo en sustrato en horticultura supone una innovación de gran trascendencia por lo que representa en tecnología e inversiones en equipamiento. En general, se requiere un invernadero con estructura de mayor altura, ventilación cenital y capaz de soportar elementos de climatización, con apertura y cierre automático de ventanas, y un equipo de riego y fertirrigación completo y programado. Muy conveniente es la dotación de calefacción permanente, aunque según zonas y cultivo también son frecuentes invernaderos que utilizan sustrato sin calefacción o sólo con calefacción puntual.

\subsubsection{Riego y fertirrigación}

Los riegos por gravedad, por surcos o tablas, que se han utilizado tanto en invernadero como en cultivo al aire libre, han ido desapareciendo para dejar paso a estos nuevos sistemas que optimizan el uso del agua y 
permiten su automatización. Así, hoy en día los sistemas de riego más utilizados en invernadero son los de riego por goteo de alta frecuencia.

La implantación de riegos localizados exige conocer la clase de suelo en el que se cultiva y la calidad del agua, así como las necesidades del cultivo, con el fin de aportar las dosis que realmente sean necesarias.

El riego por goteo da la oportunidad de aprovechar aguas de mala calidad, además de no requerir movimientos de tierra. Al mojar sólo la zona del bulbo de la planta reduce el riesgo de aparición de malas hierbas, facilita la realización de prácticas culturales y posibilita la fertirrigación. Esta serie de ventajas se traducen en un aumento de los rendimientos y de la calidad final de los productos.

Por otra parte, estos sistemas de riego requieren una serie de mantenimientos y cuidados para evitar la obturación de los emisores. Los fertilizantes aplicados en la fertirrigación han de ser solubles, con el inconveniente de que son más caros, y periódicamente hay que realizar lavados por inundación para evitar la concentración de sales. Además no hay que olvidar que el equipo completo y la instalación suelen incluir también la construcción de una balsa, y en conjunto la inversión es bastante elevada.

La fertirrigación consiste en aportar a la planta todos los nutrientes que necesita a través del agua de riego, localizándolos en la zona de tierra mojada donde se desarrollan las raíces para facilitar su absorción. Para esto se instalan tanques de fertilización en el cabezal de riego, en los que se coloca la solución de fertilizante que pasa a la red de riego mediante sistemas de succión tipo Venturi o bombas dosificadoras. La solución fertilizante se prepara basándose en las necesidades del cultivo en ese momento, y con el fin de evitar aportes excesivos de productos, sobre todo nitratos, e impedir, o disminuir en lo posible, la contaminación de acuíferos por lixiviación.

\subsubsection{Recirculación de soluciones nutritivas}

La instalación de este sistema va unida a la modalidad de cultivo en sustrato por lo que el tema se tratará en el capítulo V. Actualmente cabe 
indicar que constituye una técnica con un desarrollo bastante avanzado pero no completo y su adopción parece limitada. En la mayor parte de los casos su viabilidad es parcial, al tratarse de una aplicación cuyo interés es más ecológico que económico.

El sistema requiere de la instalación de canalización de lixiviados, con canalón de poliestireno colocado con pendiente adecuada, y tuberías y colectores para la recogida. Los lixiviados se almacenan en un depósito de recogida y, después de pasar por una unidad de desinfección, se regulan por otro depósito para ser introducidos mediante el equipo de bombeo en el sistema de fertirrigación del cultivo.

\subsubsection{Fertilización carbónica}

La técnica del abonado carbónico ya se viene realizando desde hace años en el centro y norte de Europa, y en España ha sido adaptada en determinadas situaciones considerando las condiciones ambientales de nuestras latitudes.

Se puede considerar una técnica suficientemente desarrollada, si bien su aplicación se asocia a cultivos intensivos con elevados rendimientos e ingresos.

Para su aplicación son precisos invernaderos con calidad constructiva, por lo que se ha empleado más en los cultivos en sustrato. En consecuencia, se efectuará una descripción de este tema en el capítulo $\mathrm{V}$ (apartado 5.3.2).

\subsubsection{Informática aplicada a la agricultura}

Para conseguir una gestión idónea del cultivo bajo invernadero que cumpla con los objetivos del productor es necesario disponer de sistemas de control y de ayuda a la decisión que asistan a los horticultores en la elección óptima de las consignas ambientales (clima y fertirrigación), en las intervenciones culturales (podas y tratamientos) y en la planificación de los cultivos (Baille et al., 1990).

En la actualidad, una parte de los horticultores han incorporado en sus invernaderos equipos e instalaciones que hacen posible la regulación 110 
del clima, lo que ha sido favorecido por el avance y el abaratamiento de esta tecnología (Martínez et al., 2002).

A través de modelos matemáticos que posibilitan la toma de decisiones de modo automático, es posible integrar el control climático con el ajuste del suministro del agua y los fertilizantes a las plantas. Además, por medio de la información introducida previamente, el sistema puede detectar las desviaciones que se produzcan en las condiciones de cultivo y poner en marcha alarmas de advertencia de peligro (Alarcón, 2003). Actualmente se añade la ventaja de la posible conexión de estos sistemas a Internet, permitiendo dar órdenes a distancia.

Cabe mencionar también la aplicación de tratamientos fitosanitarios por medio de redes instaladas en el invernadero, que se aplican de forma automática programándose a la hora más conveniente para el cultivo, por supuesto con el invernadero cerrado y sin presencia de personal en su interior.

Hoy día, la optimización de la producción bajo invernadero no se entiende sin el apoyo de modelos eficientes de control del clima y del cultivo, siendo este requisito compatible con los objetivos que se plantea el agricultor de rendimiento y calidad de la producción (Baille y González-Real, 2001).

Como resumen de este apartado 4.3, es necesario señalar que la descripción realizada se ha centrado más en la tecnología de equipamiento, con predominio de capital, en la que se incluyen tanto las construcciones tradicionales de invernadero como las más modernas de cultivo sin suelo.

Además del cultivo en sustrato, hay otras tecnologías a considerar que condicionan la gestión de los procesos productivos, especialmente el manejo del cultivo; éstas son la Producción Integrada $(\mathrm{Pl})$ y la Producción Ecológica (PE), en las cuales el factor humano con su nivel técnico tienen prioridad sobre el equipamiento del invernadero. 


\subsection{Las explotaciones y la adopción de tecnología}

\subsubsection{Toma de información por encuesta}

La descripción realizada anteriormente constituye la base sobre la que se plantea el análisis empírico, de cuyos resultados se tratará de obtener:

- Información sobre características estructurales de las explotaciones con invernaderos, junto con la composición de dichos invernaderos.

- Explicación sobre los aspectos que caracterizan la adopción de tecnología que, a su vez, comprenderá dos vías: la actitud hacia la adopción y los factores que la determinan.

En la redacción del cuestionario (Anexo 3), una vez tomada la información de las tres zonas de estudio, se eligieron como temas principales:

- Por una parte, conocer algunas de las características estructurales de la explotación que se consideraban más relacionadas con la tecnología y los modelos de los invernaderos.

- El análisis de la situación actual de la tecnología existente, orientado a conocer su evolución. En las cuestiones sobre tecnología de los invernaderos se le da prioridad al invernadero con mayor nivel de tecnología en cada explotación.

- Para el análisis de la adopción de tecnología se consideró fundamental estudiar la actitud de los empresarios hacia la adopción del sustrato, como modalidad de cultivo más avanzada en la evolución actual, y los factores que determinan el proceso de innovación.

- Finalmente, dada la importancia que actualmente se concede a los temas medioambientales y a que su problemática sea 
considerada en los objetivos de las explotaciones, se le dedica un apartado que incide en la percepción medioambiental de los empresarios y su relación con las técnicas de producción empleadas.

Como zonas más importantes y representativas para el desarrollo del trabajo se han elegido las del sur de Alicante, Campo de Cartagena y Valle del Guadalentín en Murcia, y el Poniente almeriense.

En la zona de Campo de Cartagena y sur de Alicante predomina el cultivo de pimiento, en el Valle del Guadalentín el tomate, y en el Poniente almeriense se cultivan hasta ocho especies hortícolas; entre ellas, las que ocupan mayor superficie son tomate, pimiento y pepino.

\subsubsection{Representatividad de la muestra}

El tipo de muestreo realizado es el aleatorio estratificado proporcional al número de propietarios según zona, correspondiendo los estratos al Campo de Cartagena (comarca perteneciente a Murcia, donde también se incluye el sur de Alicante), Valle del Guadalentín (Murcia) y El Ejido (Almería).

Siendo el tamaño de la población de 6.917 propietarios de invernaderos (3.714 propietarios en la zona de El Ejido, 1.314 en la zona del Valle del Guadalentín y 1.888 en el Campo de Cartagena), y sabiendo que el tamaño de la muestra, calculado para proporciones, es:

$$
n=\frac{N p q k^{2}}{e^{2}(N-1)+p q k^{2}}
$$

Siendo:

$n=$ tamaño de la muestra.

$N=$ tamaño de la población.

$k=$ coeficiente según el nivel de confianza de los resultados.

$p=$ porcentaje de población con presencia de la característica. 
$q=$ porcentaje de población con ausencia de la característica (1-p).

$e=$ error máximo admisible para un nivel de confianza del $95 \%$.

Se determinó el tamaño de la muestra para un nivel de confianza del $95 \%$ y un error máximo admisible de $\pm 6 \%$, obteniéndose un tamaño de muestra de 257 encuestas, algunas de las cuales tuvieron que ser rechazadas por incluir un gran número de preguntas sin contestar, quedando finalmente un total de 242 encuestas, para las cuales el error muestral es de $\pm 6,2 \%$.

Hay que indicar que el error máximo admisible de $\pm 6,2 \%$ se da en el caso de que la estimación de la proporción sea del 50\%, es decir, $p=q=$ 0,5 siendo ésta la situación más desfavorable. Sin embargo, para $p=0,4$ (o $p=0,6$ ) el error muestral sería de $\pm 6,1 \%$; para $p=0,3$ (o $p=0,7$ ) sería de $\pm 5,7 \%$ y si $p=0,2($ o $p=0,8)$ sería de $\pm 5 \%$.

El número de encuestas quedan repartidas por zonas de la siguiente forma: el Campo de Cartagena supone un 27,3\% de la muestra (66 encuestas), el Valle del Guadalentín un 19,0\% (46 encuestas) y El Ejido que supone un $53,8 \%$ del total, con 130 encuestas.

El método de recogida de la información fue la entrevista personal e individual dirigida a los propietarios de invernaderos, elegido al azar sobre la lista total de propietarios. Estas entrevistas fueron realizadas por encuestadores que eran técnicos especializados en las producciones de estas zonas.

\subsubsection{El cuestionario}

Tras la fase de diseño del cuestionario, y con la finalidad de mejorarlo y completarlo, se realizó una prueba piloto en la que fueron entrevistados diez agricultores seleccionados aleatoriamente. Los resultados obtenidos por este cuestionario previo indicaron la necesidad de introducir las siguientes modificaciones: 
- En las preguntas 16, 17 y 18 se acortó la longitud de la escala de Líkert de 10 a 5 categorías, para simplificarla.

- En la pregunta 22 se añadió que respondieran a si tenían o no interés para ellos las diversas cuestiones de tema medioambiental que se planteaban.

Incorporadas estas modificaciones, se llegó al cuestionario definitivo (Anexo 3), dividido en cinco bloques, con un total de 22 preguntas:

1.- DATOS DE LA EXPLOTACIÓN, que incluye las preguntas de la 1 a la 6 , la 9 y la 15, las cuales se refieren a la superficie, otros cultivos al aire libre, la edad del titular, dedicación, sucesión, cantidad y tipo de mano de obra empleada, cultivos, variedad y rendimientos y forma de comercialización.

2.- NIVEL DE TECNOLOGÍA DE LA EXPLOTACIÓN, que incluye la pregunta 8 (superficie e inversión del invernadero más tecnificado y tabla que recoge los aspectos básicos que incorpora el invernadero en cuanto a estructura, cubierta, elementos del riego, suelo o sustrato, elementos de climatización y de gestión mecanizada de las labores culturales).

3.- ACTITUD:

- DE MEJORAR: Incluye la pregunta 7 (intención de modificar la explotación).

- hACIA LA ADOPCIÓN DEL SUSTRATO: Incluye las preguntas $10,11,12,16$ y 17 (año y superficie de instalación del sustrato, nivel de importancia y las ventajas e inconvenientes más habituales de éste, y el nivel de satisfacción y la importancia de los principales problemas para adoptar sustrato).

4.- FACTORES QUE AFECTAN AL PROCESO DE INNOVACIÓN: Incluye las preguntas 13,14, 18 y 19 (fuentes de información, vías de formación y de asesoramiento, grado de disposición al endeudamiento y fuentes de financiación). 
5.- PERCEPCIÓN AMBIENTAL: Incluye las preguntas 20, 21 y 22 (importancia que se le da al efecto de los invernaderos sobre el medio ambiente (conciencia ecológica), consideración de la problemática ambiental a la hora de montar un nuevo invernadero e interés y orden de prioridad de estrategias para mejorar el medio ambiente en las zonas de invernadero).

\section{Tabla 4.1. Ficha técnica de la encuesta}

Población: Propietarios de explotación agraria con invernaderos.

Ámbito: Campo de Cartagena, Valle del Guadalentín y El Ejido (Almería).

Tipo de encuesta: Entrevista personal.

Tamaño de la población: 6.917 propietarios con explotaciones en el ámbito de la encuesta.

Tamaño de la muestra: 242 encuestas.

Error muestral: $\pm 6,2 \%$

Nivel de confianza: $95 \%(K=1,96)$

Tipo de muestreo: Muestreo aleatorio estratificado.

Fecha de realización del trabajo de campo: De julio de 2006 a enero de 2007.

Cuestionario previo: Prueba piloto a 10 agricultores.

Una vez finalizada la fase de realización del trabajo de campo y revisados los cuestionarios de las entrevistas para comprobar su validez y posible corrección de errores, en el primer semestre de 2007 se procedió a la codificación de las respuestas, lo que dio lugar a variables de tipo cualitativo y cuantitativo. Los datos obtenidos fueron tratados con los programas informáticos SPSS 13.0 para Windows y Statgraphics Plus 5.1.

El tratamiento informático se orientó en principio hacia el análisis univariante para reflejar las características de las explotaciones y de los invernaderos, los resultados de las variables relativas a los factores que 
afectan a los procesos de adopción e innovación y a cuestiones medioambientales.

Con la aplicación del análisis bivariante se ha puesto de manifiesto el contraste de independencia en los pares de variables que se consideraban de mayor interés.

El análisis de la situación actual finaliza con el desarrollo del análisis cluster para determinar los diferentes niveles tecnológicos que constituyen el conjunto de invernaderos.

\subsection{Resultados del análisis univariante}

A continuación se presentan los resultados obtenidos al aplicar el programa de cálculo a variables contenidas en los cinco bloques de preguntas del cuestionario.

Características de las explotaciones:

\section{Superficie:}

La media de la superficie de invernaderos en la explotación es de $26.560,12 \mathrm{~m}^{2}$, con un máximo de $260.000 \mathrm{~m}^{2}$ y un mínimo de $2.000 \mathrm{~m}^{2}$. En el $25,6 \%$ de los casos, casi todos localizados en la provincia de Murcia, las explotaciones disponen de superficie cultivada al aire libre, con una extensión media de 7,57 Ha.

Para los invernaderos cultivados en suelo, el valor medio de la superficie es de $23.666,44 \mathrm{~m}^{2}$, mientras que los cultivados en sustrato disponen de $21.714,04 \mathrm{~m}^{2}$. La superficie media de parral básico es de $15.348,91 \mathrm{~m}^{2}$, de parral mejorado de 19.675,13 $\mathrm{m}^{2}$ y de multitúnel de $13.487,10 \mathrm{~m}^{2}$.

En relación con el invernadero mejor dotado en cada una de las explotaciones, su superficie media es de $9.888 \mathrm{~m}^{2}$.

En general, la superficie de invernadero por explotación ha ido creciendo en el tiempo para adaptarse a la necesidad de aumentar los 
ingresos en las explotaciones familiares, que son mayoría en esta actividad. Es una posibilidad que proporciona la especialización en cultivo hortícola intensivo.

Titulares y características de la mano de obra:

La edad media de los titulares es de 42 años, y su distribución por frecuencias figura en el Gráfico 4.1. Esta característica es importante, y muy diferente a la que presenta el resto de la agricultura en España. Para efectuar una comparación, se ha elaborado el Gráfico 4.2 en el que se representan los intervalos de las edades de los titulares de explotación y el número de titulares que corresponde a cada intervalo, según la encuesta sobre la estructura de las explotaciones agrícolas 2007.

Puede comprobarse que la distribución de edades de los titulares de explotación con invernaderos (Gráfico 4.1), forman una curva de Gauss en torno al valor medio de 42 años, mientras que en el Gráfico 4.2, los valores de las edades de los titulares de explotación a nivel nacional muestran unas cifras mínimas en los intervalos correspondientes a los menores de 25 años, un crecimiento según aumentan las edades, y finalmente unas cifras máximas muy elevadas en los titulares de más de 65 años. Por tanto, se puede deducir que a la población de titulares de invernaderos no le afecta el envejecimiento en la misma medida que a los titulares de explotación en la agricultura española. 
Gráfico 4.1. Histograma edad de los titulares de explotación con invernaderos

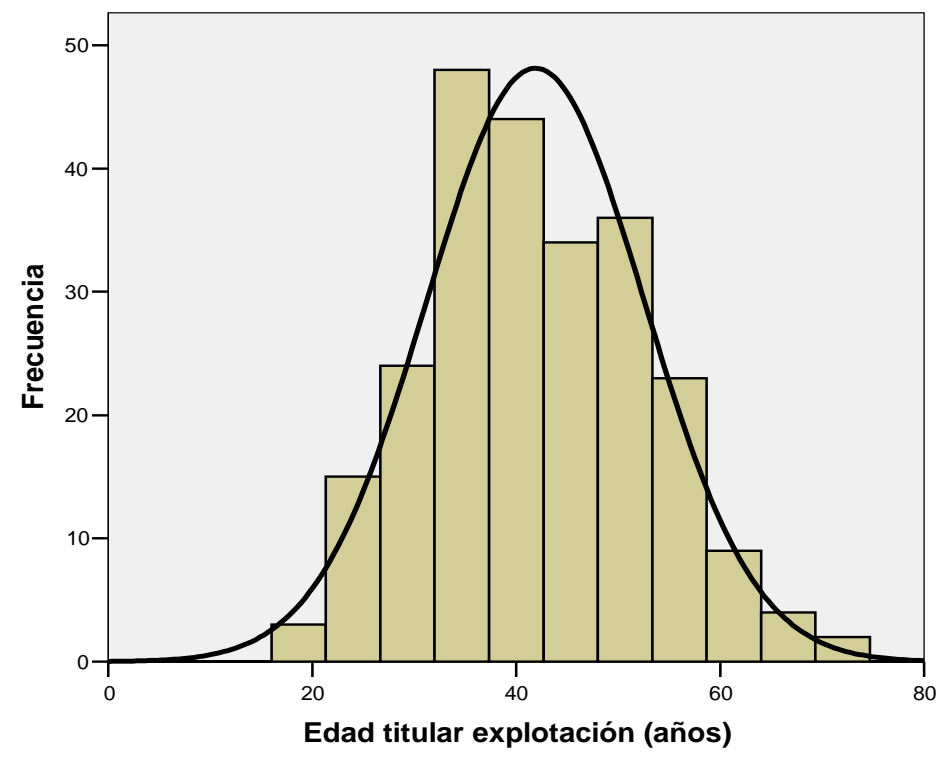

Fuente: Elaboración propia.

Gráfico 4.2. Edad de los titulares de explotaciones agrarias a nivel nacional

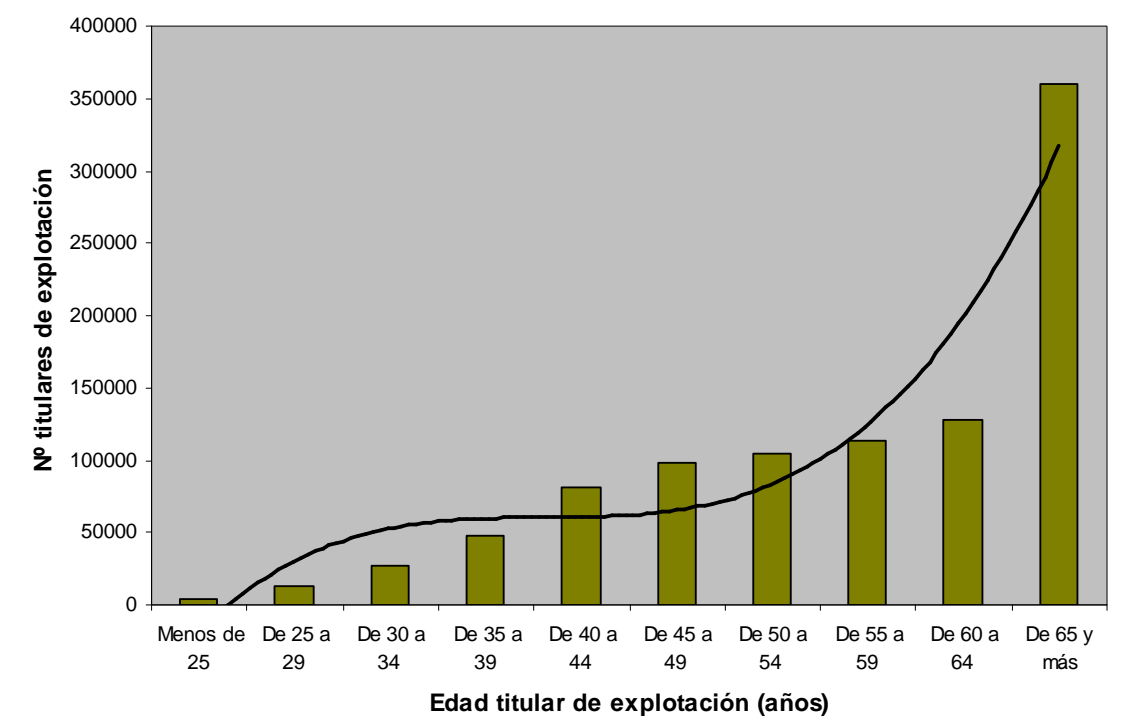

Fuente: Elaboración propia con datos del INE, 2009. 
Otra característica que diferencia la actividad hortícola intensiva de la mayor parte de las actividades agrarias es el reducido porcentaje de dedicación parcial que presentan los titulares de explotación, tan sólo el $4,5 \%$; el resto de los titulares se ocupan a tiempo completo, lo que indica un elevado índice respecto a la existencia de una dimensión suficiente en la mayoría de las explotaciones.

Tiene sucesión asegurada el $31,1 \%$ de los agricultores, una proporción que ha ido disminuyendo en los últimos años, a lo que ha contribuido la continua, aunque lenta, disminución de la rentabilidad en las explotaciones y el mayor prestigio de una formación académica para los hijos.

Para el global de explotaciones resulta una media de dos familiares con dedicación a tiempo total, mientras que se atribuye a tiempo parcial una proporción insignificante.

La mano de obra familiar, en todo el conjunto de explotaciones, alcanza una proporción del 8,2\%, por lo que la mayor parte de las horas de trabajo procede de mano de obra eventual ajena a la explotación, con un porcentaje del $92,8 \%$, que es aportada principalmente por población inmigrante. Su disponibilidad ha influido considerablemente en la amplia expansión y en la competitividad de los sistemas productivos en invernadero.

Se considera una pregunta clave la intención que tienen los agricultores de modificar el tipo de invernadero empleado. Sólo el 10,9\% piensan hacerlo pronto, mientras que el $37,4 \%$, aunque reconoce que necesitaría cambiar, no prevé hacerlo pronto; el resto $(51,7 \%)$ no tiene previsto modificarlo.

Los principales cultivos son el tomate y el pimiento, a bastante distancia de los demás, ya que afectan a un $73,5 \%$ de las explotaciones; a continuación se sitúa el pepino con un $20,2 \%$ y en menores proporciones $(6,2 \%)$ se sitúan otros como el calabacín, la sandía, el melón, la berenjena y la judía. 
Respecto a las especies cultivadas, se registra una notable diferenciación por zonas productivas; así hay una elevada especialización en pimiento en el Campo de Cartagena y una situación análoga, pero con dedicación al tomate, se da en la comarca de Valle del Guadalentín, con las localidades de Mazarrón y Águilas como núcleos principales. En Almería, la elevada extensión en cultivo protegido no sólo permite una mayor diversificación de los cultivos, sino que la hace necesaria $y$, aunque la mayor proporción la ocupan el pimiento y el tomate, también hay una elevada oferta del resto de los productos mencionados.

Los modelos de comercialización adoptados en las zonas productoras y su evolución han sido fundamentales en el amplio desarrollo de la horticultura intensiva de estas zonas, importante a nivel mundial. En las primeras fases, predominaba la venta en la propia explotación y era considerable la actividad de los comerciantes mayoristas. Hoy día la evolución ha implantado dos modelos de integración de la oferta, las cooperativas y las alhóndigas, que son muy diferentes, pero con la ventaja de ser complementarios entre sí y de estimular la competitividad y la competencia.

A través de cooperativas comercializan el $58,3 \%$ de explotaciones, mediante alhóndigas el $37,6 \%$ y el grupo de comerciantes mayoristas sólo comercializa directamente el $1,2 \%$, lo que con bastante seguridad puede afirmarse que se debe a que adquieren producto principalmente en alhóndigas y, en menor medida, en cooperativas.

\section{Características de los invernaderos:}

Como el enfoque del trabajo ha incidido fundamentalmente en la adopción de tecnología, la información sobre el nivel de tecnología en las diferentes explotaciones se ha tomado respecto al invernadero más dotado en cada explotación.

El análisis de los datos contenidos en los cuestionario proporciona las características que presenta la dotación en el conjunto de invernaderos incluido. 
El tipo de estructura más común es la metálica con perfiles de acero $(92,6 \%)$, quedando en un $7,4 \%$ la estructura de madera. Disponen de apertura motorizada de ventanas el $14,5 \%$.

En cuanto al tipo de invernadero, el $88,8 \%$ es parral, que en los más antiguos correspondía al parral plano y en los últimos 20 años se ha ido mejorando con la elevación de su altura, adopción de formas simétricas o asimétricas y aumento de la superficie de ventilación, especialmente la cenital. El 11,2\% de los invernaderos son de tipo multitúnel, una estructura de más calidad y apta para que la instalación pueda incorporar elementos que mejoren su función.

La mayoría de los invernaderos (85,5\%) están recubiertos completamente con plástico flexible. Se considera una mejora la instalación de frontales de PVC implantados en el 10\% de invernaderos; ha resultado una proporción del 4,6\% para las instalaciones con recubrimiento mediante mallas, que permite un considerable ahorro, si bien la protección es menor y de escaso efecto en la temperatura.

A tenor de los datos existentes en las encuestas, la adopción de tecnología en elementos del sistema de riego ha sido importante. Como corresponde a tres zonas de extremada aridez y donde es muy necesario disponer de elementos de almacenamiento y aplicación eficiente del riego, el $90 \%$ de las explotaciones dispone de balsa de riego; la fertirrigación regulada por programación afecta a un $47,5 \%$, y el $15 \%$ de las instalaciones están completamente informatizadas.

El riego por goteo experimentó un considerable desarrollo en el principio de la década de los $80 \mathrm{y}$, a finales de los 90 , se ha multiplicado la automatización de los cabezales de riego.

La instalación de mallas antiinsectos se ha efectuado casi en el $100 \%$ de los invernaderos, con excepción de los que están formados exclusivamente por una cubierta de malla. A pesar de que las mallas reducen la ventilación y es un elemento más a tener en cuenta en el manejo, se han considerado imprescindibles para el control biológico, 
especialmente en los últimos años cuando se impone la reducción de insecticidas, las prácticas de la producción integrada y la introducción de la producción ecológica.

Hay operaciones culturales, como es la recolección, que presentan un nivel de mecanización bastante bajo ya que sólo un 3,7\% dispone de carretillas de ayuda. Por otra parte la proporción de invernaderos con raíles, que pueden facilitar un uso más eficiente de la maquinaria, es mínima.

El conjunto de invernaderos contenido en la muestra presenta un bajo nivel en cuanto a los elementos de tecnología para el control climático. Las pantallas térmicas están instaladas en el 8,7\% del total, el 6,6\% tiene mallas de sombreo interiores y el $5,8 \%$ tiene mallas de sombreo exteriores.

Sólo el 6,2\% dispone de instalación de nebulización, una técnica eficiente en la regulación de la temperatura. Los desestratificadores están instalados en el $12 \%$ de los invernaderos.

Una programación relativamente completa de elementos de climatización figura en el $8,7 \%$ de las instalaciones. Las reducidas proporciones de los elementos que favorecen el control climático (mallas, pantallas, nebulización y desestratificadores) induce a pensar que el conjunto de titulares de explotaciones de invernaderos no ha encontrado una clara y eficaz justificación económica a su instalación, ni han visto clara la repercusión que éstos pueden tener en la calidad de los productos y en el calendario de venta. Por otra parte, está muy generalizada la práctica del encalado cuya eficacia está demostrada a pesar de sus inconvenientes.

Por la repercusión económica que suponen las instalaciones de calefacción, tanto en lo concerniente a las inversiones como en el consumo de combustible, son aplicadas a la producción hortícola en proporciones relativamente bajas. Atendiendo a la totalidad del conjunto analizado, tienen calefacción por agua caliente el $7,4 \%$ y son de aire caliente el $5,4 \%$. La totalidad de las instalaciones de agua caliente se emplean, o pueden emplearse, con carácter permanente, mientras que en las de aire sólo se 
suelen utilizar de forma permanente el 1,3\%. Con temperaturas mayores de $14 \stackrel{\circ}{\mathrm{C}}$ sólo utilizan la calefacción el 3,3\% de las explotaciones.

En cuanto a la modalidad de cultivo, en el $77,7 \%$ de los invernaderos se cultiva en suelo, mientras que en el $22,3 \%$ se practica el cultivo en sustrato, el cual se distribuye entre un $14 \%$ de perlita, un $4,1 \%$ de lana de roca, un $3,7 \%$ de fibra de coco y el resto otros sustratos.

\section{Actitud hacia la adopción del sustrato:}

El $72,3 \%$ de los propietarios encuestados consideran el cultivo en sustrato desde "nada interesante" a mostrar indiferencia hacia este tipo de cultivo. El 27,7\% lo considera importante o imprescindible.

Las ventajas del cultivo en sustrato, que en mayor porcentaje manifiestan como muy importantes, son la "mayor calidad comercial de los productos" (20,2\%) y la "forma más perfecta de aplicación del riego", como consecuencia de la disponibilidad de una mejor instalación (19,1\%).

Los inconvenientes del cultivo en sustrato que figuran en mayor porcentaje como muy importantes son: "que es más caro en todo" el 53,3\% y que "lo ven muy arriesgado" el 46,3\%.

\section{Factores que afectan al proceso de innovación:}

La principal fuente de información para los agricultores sobre el cultivo en sustrato ha sido a través de otros agricultores con un 39,4\%, y la segunda forma más importante es a través de otros, principalmente familiares agricultores, con un $36,5 \%$.

En cuanto al proceso de formación sobre cultivo en sustrato la vía más elegida han sido los familiares con un $32,5 \%$.

Para los problemas relativos al asesoramiento técnico, la vía principalmente elegida han sido los técnicos de cooperativas con un $39,6 \%$.

Del total de empresarios, el 55\% lee algún tipo de publicación agraria, que en un $49,2 \%$ se trata de revistas técnicas. 
Los agricultores que practican la modalidad de cultivo en sustrato han manifestado su satisfacción con su uso según la siguiente distribución porcentual:

\section{Gráfico 4.3. Satisfacción con el cultivo en sustrato}

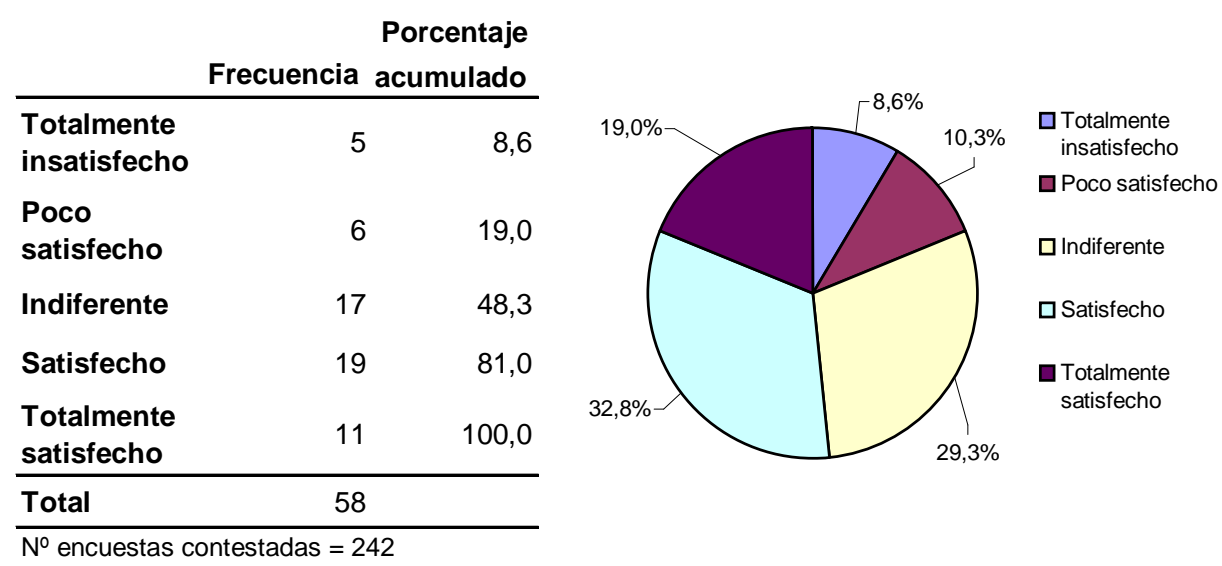

Los resultados del Gráfico 4.3, que muestra a primera vista el estado de opinión sobre la satisfacción que los agricultores de sustrato tienen de esta modalidad, indican que la opinión es muy favorable por parte de los propietarios, puesto que solamente hay contestaciones negativas poco favorables en un $19,0 \%$ de los casos.

Sobre los problemas principales en la adopción del cultivo en sustrato, el elevado coste de inversión lo consideran muy importante un $42,1 \%$ de los encuestados; las dificultades de manejo un $14,9 \%$; que cualquier deficiencia pueda originar la pérdida de una campaña un $43 \%$, y la exigencia de una asistencia técnica muy puntual un $15,7 \%$.

Se comprueba que a las dificultades de manejo le dan una importancia menor, lo que indica que el nivel de información es bueno; tampoco le dan una importancia excesiva a la asistencia técnica muy puntual, en parte porque hay empresas y técnicos disponibles.

La mayor importancia en los problemas se atribuye al elevado coste de la inversión y también al riesgo de perder una campaña por errores en la 
gestión de esta técnica de cultivo o deficiencias en el funcionamiento de las instalaciones.

\section{Financiación:}

La disposición al endeudamiento se distribuye según el Gráfico 4.4.

\section{Gráfico 4.4. Disposición al endeudamiento}

\begin{tabular}{lrr} 
& Frecuencia & $\begin{array}{r}\text { Porcentaje } \\
\text { acumulado }\end{array}$ \\
\hline Muy baja & 80 & 33,1 \\
Baja & 69 & 61,6 \\
Indiferente & 56 & 84,7 \\
Alta & 17 & 91,7 \\
Muy alta & 20 & 100 \\
\hline Total & 242 & \\
\hline № encuestas contestadas $=242$ &
\end{tabular}

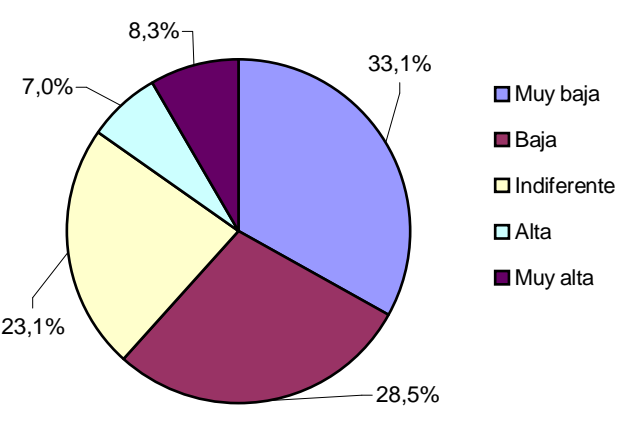

Los agricultores que se sitúan en los niveles más bajos suponen un $61,6 \%$, un $23,1 \%$ se muestran indiferentes y sólo el $15,3 \%$ muestran una alta o muy alta disposición al endeudamiento. De todas formas, parece existir una actitud empresarial bastante favorable respecto a la aceptación del riesgo propio del endeudamiento, ya que la actitud no es negativa en un $38,4 \%$.

Las fuentes de financiación utilizadas por los propietarios figuran en la Tabla 4.2. Dicha tabla expresa los resultados de la pregunta $19 \mathrm{del}$ cuestionario (Anexo 3 ) en la que se pedía a los encuestados que indicaran la procedencia de los fondos solicitados para sus inversiones, y se daba la opción a cada propietario para señalar una o varias de las fuentes indicadas. 
Tabla 4.2. Fuentes de financiación

\begin{tabular}{|c|c|c|c|c|c|c|c|c|c|c|c|c|}
\hline & \multicolumn{2}{|c|}{ 1) } & \multicolumn{2}{|c|}{ 2) } & \multicolumn{2}{|c|}{ 3) } & \multicolumn{2}{|c|}{ 4) } & \multicolumn{2}{|c|}{ 5) } & \multicolumn{2}{|c|}{ 6) } \\
\hline & № & $\%$ & № & $\%$ & № & $\%$ & № & $\%$ & № & $\%$ & № & $\%$ \\
\hline No & 105 & 43,4 & 204 & 84,3 & 45 & 18,6 & 184 & 76,0 & 208 & 86,0 & 241 & 99,6 \\
\hline Sí & 137 & 56,6 & 38 & 15,7 & 197 & 81,4 & 58 & 24,0 & 34 & 14,0 & 1 & 0,4 \\
\hline Total & 242 & 100,0 & 242 & 100,0 & 242 & 100,0 & 242 & 100,0 & 242 & 100,0 & 242 & 100,0 \\
\hline
\end{tabular}

1) Procede Recursos Propios

2) Financiación Empresas

3) Procede créditos Bancos y Cajas Ahorro

4) Subvenciones o préstamos Gobierno

5) Procede de Fondos UE

6) Otras fuentes de financiación

La fuente más elegida han sido los Bancos y Cajas de Ahorro o Rurales con un $81,4 \%$ de propietarios. Le sigue a bastante distancia la opción de emplear recursos propios con el $56,6 \%$ de propietarios.

\section{Percepción ambiental:}

Respecto a la opinión de los titulares de invernadero sobre los efectos de su actividad en el medio ambiente, en comparación con los ocasionados por el cultivo al aire libre, el 17,8\% indicaron que los desechos plásticos afectan de forma muy importante al medio ambiente.

Algo más de la mitad de los encuestados declararon no haber tenido en cuenta la problemática ambiental a la hora de montar un nuevo invernadero, como aparece reseñado en el Gráfico 4.5.

\section{Gráfico 4.5. Consideración de la problemática ambiental al montar el} invernadero

\begin{tabular}{|c|c|c|c|c|}
\hline & Frecuencia & $\begin{array}{r}\text { Porcentaje } \\
\text { acumulado }\end{array}$ & $17,5 \%$ & \\
\hline No & 124 & 54,4 & & 口No \\
\hline $\begin{array}{l}\text { Sí lo pensé, } \\
\text { pero no lo } \\
\text { he tenido en } \\
\text { cuenta }\end{array}$ & 64 & 82,5 & & $\begin{array}{l}\square \text { Sí lo pensé, pero no } \\
\text { lo he tenido en } \\
\text { cuenta } \\
\square \text { Sí }\end{array}$ \\
\hline Sí & 40 & 100 & & \\
\hline Total & 228 & & & \\
\hline
\end{tabular}


Teniendo en cuenta la evolución seguida por los agricultores en los temas medioambientales, en los que el cumplimiento de las normas puede aportarle cierta satisfacción personal y cívica, pero casi siempre le produce alguna perturbación económica, parece una proporción bastante aceptable que el $17,5 \%$ hayan tenido en cuenta la problemática medioambiental al montar el invernadero; en cierto modo, se pone de manifiesto que los cultivadores de horticultura intensiva van tomando conciencia en los temas relativos al medio ambiente.

Las estrategias que recogen un mayor interés a efectos de producir mejoras en el medio ambiente son "reducir el consumo de productos químicos" (97,5\%), "generalizar la lucha biológica" (95\%) y "optimizar el control climático" (77,7\%). La obligación de "responsabilizarse en la eliminación de vertidos" parece bien aceptada de forma general, puesto que la han considerado de interés el $73,6 \%$ de los propietarios. Menor interés le asignan a la "reutilización de las soluciones nutritivas" (42,6\%). Por otro lado, al definir prioridades, la "generalización de la lucha biológica" figura con el $47,4 \%$ del total de casos, como la estrategia de mayor prioridad.

\subsection{Análisis bivariante}

\subsubsection{El contraste de independencia}

Pearson (1914) planteó la utilización del estadístico $\chi^{2}$ para analizar si existe o no relación entre las variables fila y columna en una tabla de contingencia. El estadístico $\chi^{2}$ se define de la siguiente forma:

$$
\chi^{2}=\sum_{i=1}^{k} \sum_{j=1}^{r} \frac{\left(n_{i j}-\frac{n_{i} \cdot n_{j}}{n}\right)^{2}}{\frac{n_{i} \cdot n_{j}}{n}}
$$

Donde $n_{i j}$ es la frecuencia observada en la casilla de la fila $i$ y la columna $j$. 
Donde $\frac{n_{i} \cdot n_{j}}{n}$ es la frecuencia esperada (en la casilla de la fila $i$ y la columna $j$ ) en caso de que las variables sean independientes. Siendo $n_{i}$ la frecuencia total en la fila $i, n_{j}$ la frecuencia total en la columna $j$ y $n$ el número total de casos.

Siendo $k$ el número de filas y $r$ el número de columnas de la tabla de contingencia de orden $k \times r$.

Las hipótesis que se plantean en la prueba de independencia son:

$\mathrm{H}_{0}$ : las variables son independientes.

$\mathrm{H}_{1}$ : las variables son dependientes.

El valor del estadístico chi-cuadrado así calculado se compara con el valor tabulado de un chi-cuadrado para un nivel de significación $\alpha$ y con $(k-1) \times(r-1)$ grados de libertad. De manera que si se cumple que $\chi^{2} \leq \chi_{(k-1) \cdot(r-1)}^{2}(\alpha)$ entonces no podemos rechazar la $\mathrm{H}_{0}$.

En cambio, si $\chi^{2}>\chi_{(k-1) \cdot(r-1)}^{2}(\alpha)$ entonces se rechaza la $\mathrm{H}_{0}$. $\alpha$ indica el nivel de significación utilizado en la prueba.

En caso de rechazar la hipótesis nula de independencia entre las variables se puede decir que, con un nivel de confianza de $(1-\alpha)$, entre las variables estudiadas existe una relación.

\subsubsection{Resultados e interpretación}

A continuación se procede a la aplicación de la teoría anterior para determinar la existencia o no de independencia entre los siguientes pares de variables:

1. Intención de modificar el invernadero - existencia de sucesión.

2. Intención de modificar el invernadero - tipo de invernadero.

3. Intención de modificar el invernadero - edad agricultor.

4. Disposición al endeudamiento - edad agricultor. 
5. Tenencia sustrato - edad agricultor.

6. Dotación de pantallas térmicas - zona.

7. Apertura informatizada de ventanas - zona.

8. Principal vía de comercialización - zona.

9. Consideración de la problemática ambiental al montar un nuevo invernadero - zona.

10. Interés en lucha biológica - zona.

En la Tabla 4.3, se analiza la variable intención de modificar el invernadero frente a la existencia o no de sucesión, y se obtiene que de los agricultores con sucesión, el 37,50\% no tienen intención de modificar, siendo esta celda la de mayor contribución al estadístico chi-cuadrado; mientras que en el caso de los que no cuentan con sucesión, el porcentaje aún es más alto $(57,58 \%)$.

Tabla 4.3. Frecuencias cruzadas de las variables intención de modificar el invernadero y existencia de sucesión

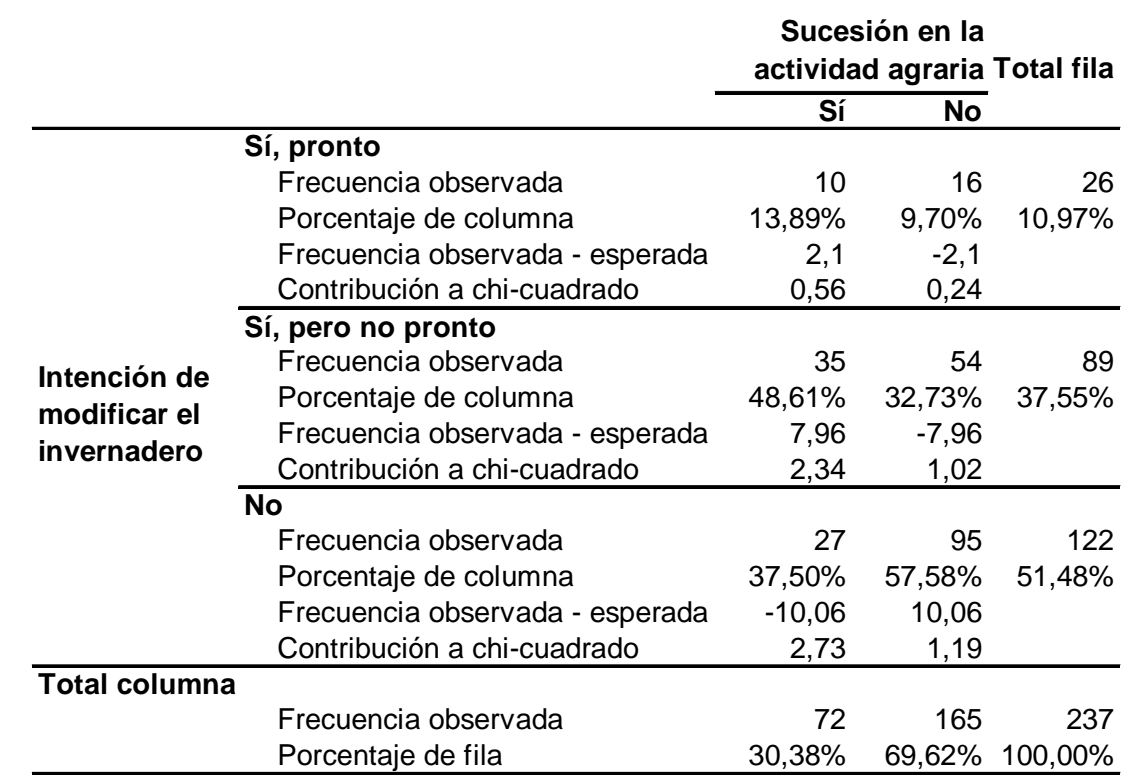

Estadístico $\chi^{2}=8,10$; Grados de libertad $=2$; P-valor $=0,017$ 
El p-valor obtenido para el estadístico $\chi^{2}$ ha indicado una probabilidad muy baja de que la asociación entre las variables sea debida al azar. Por tanto, se rechaza la hipótesis nula de que exista independencia entre las dos variables cualitativas estudiadas.

La relación entre las variables intención de modificar y tipo de invernadero se presenta en la Tabla 4.4. El test de independencia no resulta significativo ( $p$-valor $>0,05$ ), por lo que no puede afirmarse que la intención de modificar el invernadero esté asociada en mayor o menor medida al tipo de invernadero disponible.

Tabla 4.4. Frecuencias cruzadas de las variables intención de modificar el invernadero y tipo de invernadero

\begin{tabular}{|c|c|c|c|c|}
\hline & & \multicolumn{2}{|c|}{ Tipo de invernadero } & \multirow{2}{*}{ Total fila } \\
\hline & & Multitúnel & Tipo parral & \\
\hline \multicolumn{5}{|c|}{ Sí, pronto } \\
\hline & Frecuencia observada & 1 & 25 & \\
\hline & Porcentaje de columna & $3,70 \%$ & $11,85 \%$ & $10,92 \%$ \\
\hline & Frecuencia observada - esperada & -1.95 & 1.95 & \\
\hline & Contribución a chi-cuadrado & 1,29 & 0,16 & \\
\hline \multicolumn{5}{|c|}{ Sí, pero no pronto } \\
\hline Intención de & Frecuencia observada & 13 & 76 & \\
\hline modificar el & Porcentaje de columna & $48,15 \%$ & $36,02 \%$ & $37,39 \%$ \\
\hline \multirow[t]{7}{*}{ invernadero } & Frecuencia observada - esperada & 2,9 & $-2,9$ & \\
\hline & Contribución a chi-cuadrado & 0,83 & 0,11 & \\
\hline & \multicolumn{4}{|l|}{ No } \\
\hline & Frecuencia observada & 13 & 110 & 123 \\
\hline & Porcentaje de columna & $48,15 \%$ & $52,13 \%$ & $51,68 \%$ \\
\hline & Frecuencia observada - esperada & $-0,95$ & 0,95 & \\
\hline & Contribución a chi-cuadrado & 0,07 & 0,01 & \\
\hline \multicolumn{5}{|c|}{ Total columna } \\
\hline & Frecuencia observada & 27 & 211 & 238 \\
\hline & Porcentaje de fila & $11,34 \%$ & $88,66 \%$ & $100,00 \%$ \\
\hline
\end{tabular}

Estadístico $\chi^{2}=2,47$; Grados de libertad $=2$; P-valor $=0,291$

El invernadero tipo parral mejorado es el más extendido y presenta cierta resistencia a la modificación, ya que si se quieren alcanzar dotaciones de elementos más completas todo ello supondría una elevada inversión.

Con los resultados de la Tabla 4.5 se comprueba que la intención de modificar el invernadero no depende de la edad, ya que la prueba no resulta significativa. 
Tabla 4.5. Frecuencias cruzadas de las variables intención de modificar el invernadero e intervalos de edad de los propietarios

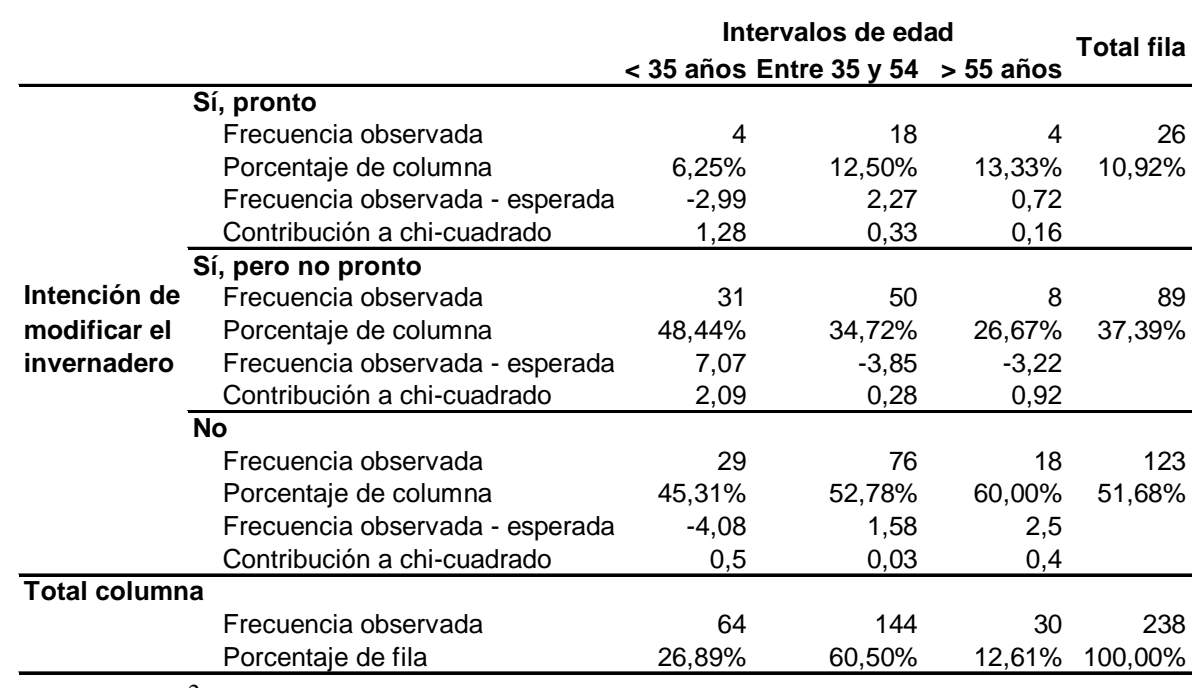

Estadístico $\chi^{2}=5,99$; Grados de libertad $=4$; P-valor $=0,200$

En la Tabla 4.6. se recogen los resultados de la prueba de independencia de las variables disposición al endeudamiento y edad, resultando el test no significativo. Existe cierta analogía o coincidencia con el caso anterior en el que se relaciona la iniciativa o disposición a la innovación empresarial con la edad y se puede ver que ésta no resulta decisiva. 
Tabla 4.6. Frecuencias cruzadas de las variables disposición al endeudamiento e intervalos de edad de los propietarios

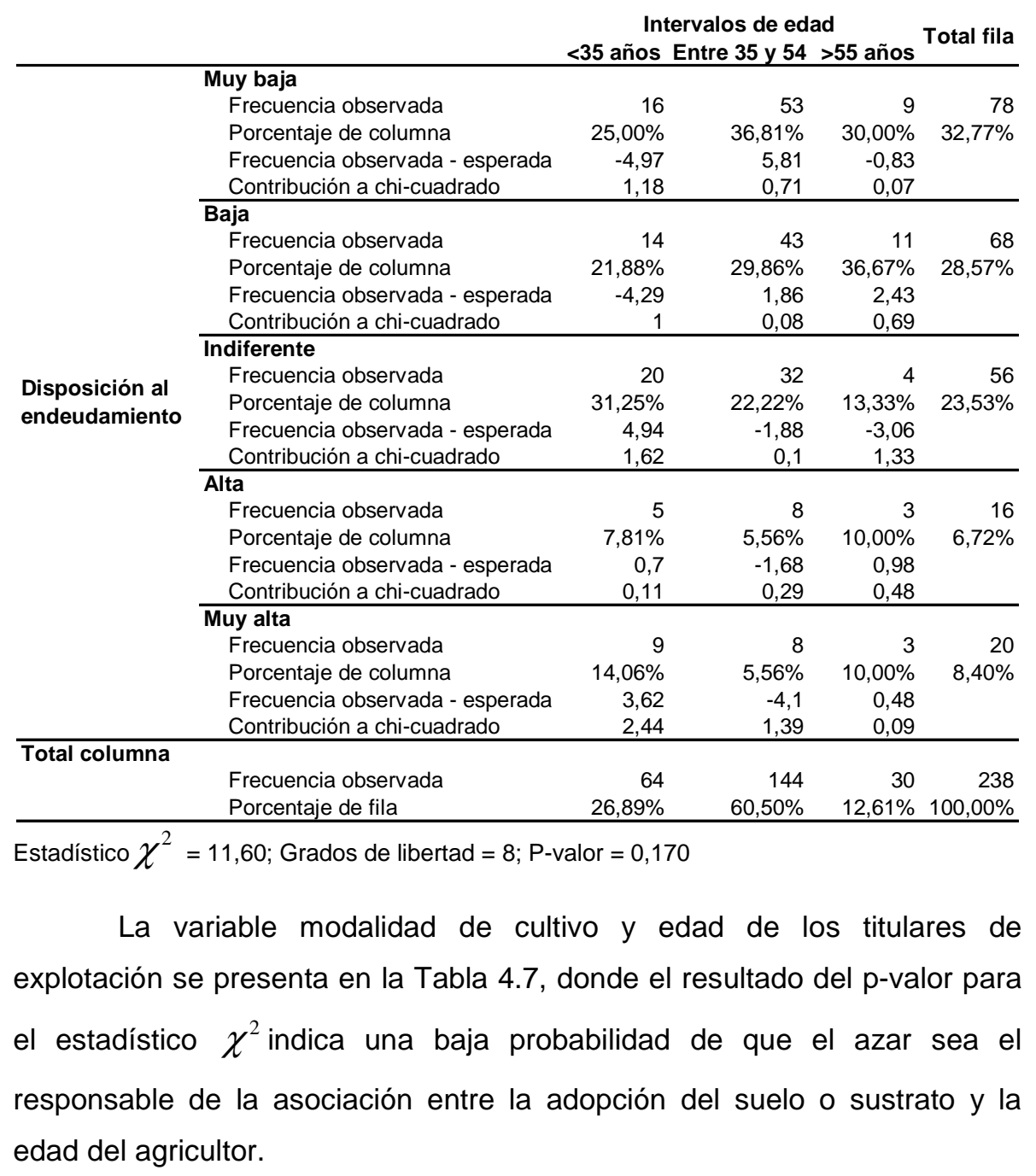


Tabla 4.7. Frecuencias cruzadas de las variables tenencia de sustrato e intervalos de edad de los propietarios

\begin{tabular}{|c|c|c|c|c|c|}
\hline & & $\begin{array}{r}\text { Int } \\
<35 \text { años } \\
\end{array}$ & $\begin{array}{l}\text { los de ed } \\
\text { e } 35 \text { y } 54 \\
\end{array}$ & $\begin{array}{l}\text { ad } \\
>55 \text { años }\end{array}$ & Total fila \\
\hline & Sustrato & & & & \\
\hline & Frecuencia observada & 8 & 36 & 9 & 53 \\
\hline & Porcentaje de columna & $12,50 \%$ & $25,00 \%$ & $30,00 \%$ & $22,27 \%$ \\
\hline & Frecuencia observada - esperada & $-6,25$ & 3,93 & 2,32 & \\
\hline Modalidad & Contribución a chi-cuadrado & 2,74 & 0,48 & 0,81 & \\
\hline de cultivo & Suelo & & & & \\
\hline & Frecuencia observada & 56 & 108 & 21 & 185 \\
\hline & Porcentaje de columna & $87,50 \%$ & $75,00 \%$ & $70,00 \%$ & $77,73 \%$ \\
\hline & Frecuencia observada - esperada & 6,25 & $-3,93$ & $-2,32$ & \\
\hline & Contribución a chi-cuadrado & 0,79 & 0,14 & 0,23 & \\
\hline Total colur & & & & & \\
\hline & Frecuencia observada & 64 & 144 & 30 & 238 \\
\hline & Porcentaje de fila & $26,89 \%$ & $60,50 \%$ & $12,61 \%$ & $100,00 \%$ \\
\hline
\end{tabular}

Estadístico $\chi^{2}=5,18 ;$ Grados de libertad $=2 ;$ P-valor $=0,075$

Es de destacar que la proporción de invernaderos con cultivo en sustrato es más elevada entre los agricultores mayores de 55 años, mientras que el porcentaje de suelo es mayor entre los propietarios menores de 35 años, lo que hace pensar que en éstos es donde se ha de producir el cambio.

La Tabla 4.8 muestra los resultados del análisis de las variables dotación de pantallas térmicas y zona de cultivo. El estadístico $\chi^{2}$ ha resultado altamente significativo. Por tanto, se rechaza la hipótesis nula de que exista independencia entre las dos variables. 
Tabla 4.8. Frecuencias cruzadas de las variables dotación de pantallas térmicas y zona

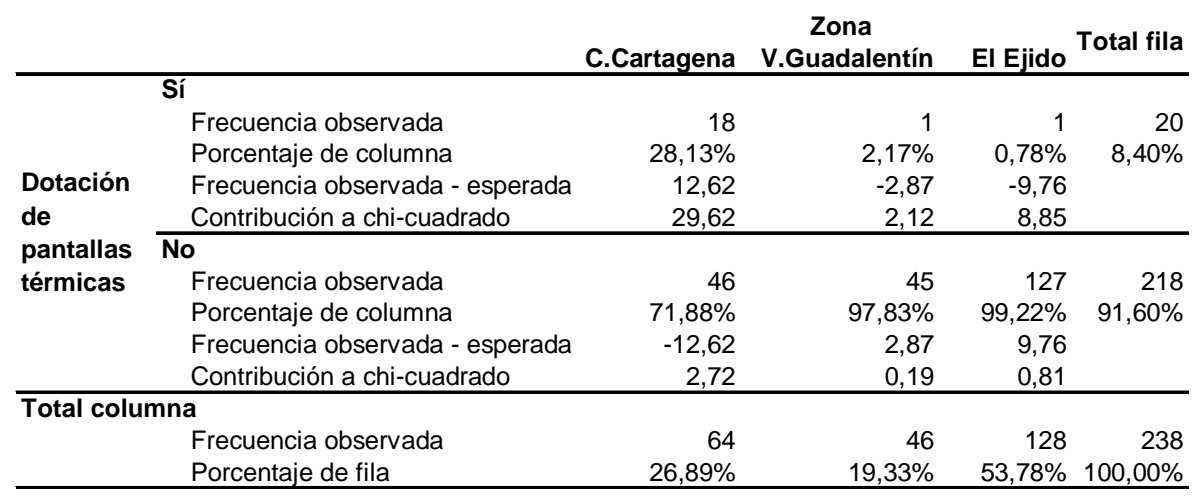

Estadístico $\chi^{2}=44,32 ;$ Grados de libertad $=2 ;$ P-valor $=0,000$

La contribución más elevada al estadístico chi-cuadrado se encuentra en la celda donde se cruzan la existencia de pantallas térmicas con la zona de Campo de Cartagena que, según los resultados, es donde se localizan la práctica totalidad de estos elementos de control climático (Tabla 4.8).

En la Tabla 4.9 se comprueba la falta de independencia entre las variables apertura de ventanas y zona de cultivo, al resultar el estadístico $\chi^{2}$ altamente significativo. Por tanto, se rechaza la hipótesis nula, admitiéndose la existencia de asociaciones significativas entre los niveles de las dos variables cualitativas estudiadas. 
Tabla 4.9. Frecuencias cruzadas de las variables tipo de apertura de ventanas y zona

\begin{tabular}{|c|c|c|c|c|c|}
\hline & & C.Cartagena & $\begin{array}{c}\text { Zona } \\
\text { V.Guadalentín }\end{array}$ & El Ejido & Total fila \\
\hline \multirow{10}{*}{$\begin{array}{l}\text { Apertura } \\
\text { informatizada } \\
\text { de ventanas }\end{array}$} & Sí & & & & \\
\hline & Frecuencia observada & 29 & 4 & 1 & 34 \\
\hline & Porcentaje de columna & $45,31 \%$ & $8,70 \%$ & $0,79 \%$ & $14,35 \%$ \\
\hline & Frecuencia observada - esperada & 19,82 & -2.6 & $-17,22$ & \\
\hline & Contribución a chi-cuadrado & 42,78 & 1,02 & 16,27 & \\
\hline & No & & & & \\
\hline & Frecuencia observada & 35 & 42 & 126 & \\
\hline & Porcentaje de columna & $54,69 \%$ & $91,30 \%$ & $99,21 \%$ & $85,65 \%$ \\
\hline & Frecuencia observada - esperada & $-19,82$ & 2,6 & 17,22 & \\
\hline & Contribución a chi-cuadrado & 7,17 & 0,17 & 2,73 & \\
\hline \multirow[t]{3}{*}{ Total columna } & & & & & \\
\hline & Frecuencia observada & 64 & 46 & 127 & 237 \\
\hline & Porcentaje de fila & $27,00 \%$ & $19,41 \%$ & $53,59 \%$ & $100,00 \%$ \\
\hline
\end{tabular}

Estadístico $\chi^{2}=70,14 ;$ Grados de libertad $=2 ;$ P-valor $=0,000$

Al igual que en el tema de las pantallas térmicas, se comprueba que prácticamente todos los invernaderos con apertura informatizada se encuentran en una zona concreta, el Campo de Cartagena.

El análisis de la relación entre las variables vía principal de comercialización de las empresas y zonas productoras en las que están ubicadas, indica que dicha relación existe con el nivel de significación del $10 \%$. Es más frecuente la existencia de alhóndigas en Valle de Guadalentín y El Ejido y predomina la vía de comercialización por cooperativa en el Campo de Cartagena (Tabla 4.10). 
Tabla 4.10. Frecuencias cruzadas de las variables principal vía de comercialización y zona

\begin{tabular}{|c|c|c|c|c|c|}
\hline & & C.Cartagena & $\begin{array}{c}\text { Zona } \\
\text { V.Guadalentín }\end{array}$ & El Ejido & Total fila \\
\hline \multirow{15}{*}{$\begin{array}{l}\text { Principal vía de } \\
\text { comercialización }\end{array}$} & Cooperativa & & & & \\
\hline & Frecuencia observada & 48 & 25 & 73 & 146 \\
\hline & Porcentaje de columna & $75,00 \%$ & $54,35 \%$ & $57,03 \%$ & $61,34 \%$ \\
\hline & Frecuencia observada - esperada & 8,74 & $-3,22$ & $-5,52$ & \\
\hline & Contribución a chi-cuadrado & 1,95 & 0,37 & 0,39 & \\
\hline & Mayorista & & & & \\
\hline & Frecuencia observada & 0 & 1 & 3 & \\
\hline & Porcentaje de columna & $0,00 \%$ & $2,17 \%$ & $2,34 \%$ & $1,68 \%$ \\
\hline & Frecuencia observada - esperada & $-1,08$ & 0,23 & 0,85 & \\
\hline & Contribución a chi-cuadrado & 1,08 & 0,07 & 0,33 & \\
\hline & Alhóndiga & & & & \\
\hline & Frecuencia observada & 16 & 20 & 52 & 88 \\
\hline & Porcentaje de columna & $25,00 \%$ & $43,48 \%$ & $40,63 \%$ & $36,97 \%$ \\
\hline & Frecuencia observada - esperada & $-7,66$ & 2,99 & 4,67 & \\
\hline & Contribución a chi-cuadrado & 2,48 & 0,53 & 0,46 & \\
\hline \multirow{2}{*}{$\begin{array}{l}\text { Total } \\
\text { columna }\end{array}$} & & 64 & 46 & 128 & 238 \\
\hline & & $26,89 \%$ & $19,33 \%$ & $53,78 \%$ & $100,00 \%$ \\
\hline
\end{tabular}

Estadístico $\chi^{2}=7,65$; Grados de libertad $=4$; $\mathrm{P}$-valor $=0,105$

No obstante, más que la cifra del porcentaje en cada caso, a la que no se le puede atribuir un valor censual, lo importante es que en las tres zonas coexisten cantidades significativas tanto de alhóndigas como de cooperativas (incluimos en esta forma las sociedades agrarias de transformación o SATs). Esta posibilidad de elección de la vía de comercialización tiene un gran interés si se considera la radical diferencia de funcionamiento entre ambas formas.

En el caso de las cooperativas, el socio cobra su liquidación en función de la diferencia entre el precio pagado por la entidad comercializadora minorista en destino y los gastos de comercialización y transporte. El producto se clasifica y acondiciona en el almacén de la cooperativa y el pago se aplaza un tiempo variable. Suelen destinar mayor proporción del producto a las exportaciones.

La alhóndiga implica una mayor libertad para el productor, ya que, para él, la venta y la cotización resultante se deriva de una subasta diaria, y el agricultor puede aceptar el precio o retirar la mercancía. El producto se ha 
de llevar cada mañana con un cierto grado de clasificación y acondicionamiento y el cobro es inmediato y garantizado.

El hecho de existir una proporción significativa de alhóndigas resulta muy positiva para el proceso de comercialización en general de todo el sector hortícola de estas zonas, pues contribuye a proporcionar las características de concurrencia y transparencia necesarias para una formación de precios lo más adecuada posible.

En la Tabla 4.11 se presenta la relación entre las variables consideración de la problemática ambiental al montar el invernadero y zona de cultivo.

Tabla 4.11. Frecuencias cruzadas de las variables consideración de la problemática ambiental al montar el invernadero y zona

\begin{tabular}{|c|c|c|c|c|c|}
\hline & & C.Cartagena & $\begin{array}{c}\text { Zona } \\
\text { V.Guadalentín }\end{array}$ & EI Ejido & Total fila \\
\hline \multirow{15}{*}{$\begin{array}{l}\text { Consideración } \\
\text { de la } \\
\text { problemática } \\
\text { ambiental al } \\
\text { montar el } \\
\text { invernadero }\end{array}$} & No & & & & \\
\hline & Frecuencia observada & 26 & 25 & 75 & 126 \\
\hline & Porcentaje de columna & $40,63 \%$ & $54,35 \%$ & $58,59 \%$ & $52,94 \%$ \\
\hline & Frecuencia observada - esperada & $-7,88$ & 0,65 & 7,24 & \\
\hline & Contribución a chi-cuadrado & 1,83 & 0,02 & 0,77 & \\
\hline & $\begin{array}{l}\text { Sí, lo pensé pero no lo he tenido } \\
\text { en cuenta }\end{array}$ & & & & \\
\hline & Frecuencia observada & 18 & 13 & 37 & 68 \\
\hline & Porcentaje de columna & $28,13 \%$ & $28,26 \%$ & $28,91 \%$ & $28,57 \%$ \\
\hline & Frecuencia observada - esperada & $-0,29$ & $-0,14$ & 0,43 & \\
\hline & Contribución a chi-cuadrado & 0 & 0 & 0,01 & \\
\hline & Sí & & & & \\
\hline & Frecuencia observada & 20 & 8 & 16 & 44 \\
\hline & Porcentaje de columna & $31,25 \%$ & $17,39 \%$ & $12,50 \%$ & $18,49 \%$ \\
\hline & Frecuencia observada - esperada & 8,17 & $-0,5$ & $-7,66$ & \\
\hline & Contribución a chi-cuadrado & 5,64 & 0,03 & 2,48 & \\
\hline \multicolumn{6}{|l|}{ Total columna } \\
\hline & Frecuencia observada & 64 & 46 & 128 & 238 \\
\hline & Porcentaje de fila & $26,89 \%$ & $19,33 \%$ & $53,78 \%$ & $100,00 \%$ \\
\hline
\end{tabular}

Estadístico $\chi^{2}=10,79 ;$ Grados de libertad $=4$; P-valor $=0,029$

La prueba resulta significativa ( $p$-valor $<0,05$ ), por lo que puede afirmarse que la consideración de la problemática ambiental al montar el invernadero está asociada en mayor o menor medida a la zona donde se sitúa el invernadero (Tabla 4.11).

Resultado del contraste de independencia entre las variables interés por generalizar la lucha biológica y zona se presenta la Tabla 4.12 donde se 
obtiene un estadístico $\chi^{2}$ significativo, por lo que se puede rechazar la hipótesis nula de independencia entre dichas variables para un grado de confianza del $90 \%$. Por tanto, con un nivel de significación del $10 \%$ se puede afirmar que existe relación entre las dos variables.

Tabla 4.12. Frecuencias cruzadas de las variables interés por generalizar la lucha biológica y zona

\begin{tabular}{|c|c|c|c|c|c|}
\hline & & C.Cartagena & $\begin{array}{c}\text { Zona } \\
\text { V.Guadalentín }\end{array}$ & EI Ejido & Total fila \\
\hline \multirow{10}{*}{$\begin{array}{l}\text { Interés por } \\
\text { generalizar } \\
\text { la lucha } \\
\text { biológica }\end{array}$} & \multicolumn{5}{|l|}{ No muestra interés } \\
\hline & Frecuencia observada & 0 & 3 & 9 & 12 \\
\hline & Porcentaje de columna & $0,00 \%$ & $6,52 \%$ & $7,03 \%$ & $5,04 \%$ \\
\hline & Frecuencia observada - esperada & $-3,23$ & 0,68 & 2,55 & \\
\hline & Contribución a chi-cuadrado & 3,23 & 0,2 & 1 & \\
\hline & \multicolumn{5}{|l|}{ Sí muestra interés } \\
\hline & Frecuencia observada & 64 & 43 & 119 & 226 \\
\hline & Porcentaje de columna & $100,00 \%$ & $93,48 \%$ & $92,97 \%$ & $94,96 \%$ \\
\hline & Frecuencia observada - esperada & 3,23 & $-0,68$ & $-2,55$ & \\
\hline & Contribución a chi-cuadrado & 0,17 & 0,01 & 0,05 & \\
\hline \multicolumn{6}{|c|}{ Total columna } \\
\hline & Frecuencia observada & 64 & 46 & 128 & 238 \\
\hline & Porcentaje de fila & $26,89 \%$ & $19,33 \%$ & $53,78 \%$ & $100,00 \%$ \\
\hline
\end{tabular}

Estadístico $\chi^{2}=4,67 ;$ Grados de libertad $=2 ; \mathrm{P}$-valor $=0,097$

Es de destacar que el $94,96 \%$ de los propietarios de invernaderos muestran interés por generalizar la lucha biológica, destacando el Campo de Cartagena donde la totalidad de los agricultores se muestran interesados (Tabla 4.12). Esto puede explicarse porque en esta zona comenzaron a llevarse a cabo este tipo de técnicas antes que en el resto.

\subsection{Niveles tecnológicos: Análisis cluster}

La adopción de tecnología en invernaderos, incrementando la dotación de elementos o con introducción de variaciones en las técnicas de cultivo, puede efectuarse con una planificación adecuada desde el principio o bien, a partir de una instalación existente ir ampliándola agregando elementos sucesivamente. Esta agregación de elementos es muy dispersa y se deriva de las decisiones de los propietarios sobre sus inversiones, que son muy variables, sin que se adopte un crecimiento uniforme o por niveles en las mejoras. En consecuencia, para estudiar la evolución de la tecnología 
parece más conveniente la agrupación en niveles, que puede efectuarse con criterios estrictamente técnicos concebidos por profesionales muy especializados en el tema, tomando como base grupos de elementos muy relacionados entre sí para cumplir de forma más o menos perfecta las exigencias del cultivo.

En la monografía de Hernández et al. (2000), sobre equipamientos y tecnología de los invernaderos, se indica la necesidad de evolucionar en los modelos optimizando las inversiones. En el trabajo se agrupan los invernaderos en principio por las características de su estructura en tipo parral o multitúnel. A los tipos mencionados se le asignan paquetes tecnológicos que darían lugar a cuatro niveles en el tipo parral y cinco en la modalidad de multitúnel.

En el artículo de Fernández-Zamudio et al. (2006) se analizan las características de la tecnología, y evolución posible, en invernaderos dedicados con preferencia al pimiento y localizados en el Campo de Cartagena. Para ello, agrupan los invernaderos según dotación, técnicas de cultivo y calidades susceptibles de obtenerse, en cuatro niveles tecnológicos: dos sobre cultivo en suelo y dos con empleo de cultivo en sustrato. La agrupación de los elementos que caracterizan cada nivel se atiene básicamente a las características y dimensión de la estructura, existencia o no de calefacción y si es de aire o agua, con uso temporal o permanente. La instalación de riego con la fertirrigación y el grado de automatización también son importantes y, por último, en el nivel superior se considera la posibilidad de la fertilización carbónica y el reciclaje de las soluciones nutritivas. La publicación concluye con una valoración económica de los resultados del cultivo de pimiento en cada uno de los niveles analizados.

Los criterios técnicos, aunque tienen la posibilidad de efectuarse con un elevado grado de racionalidad pueden ser muy variables y hasta cierto punto tener un carácter subjetivo, por lo que, en la presente tesis se propone un análisis basado en una técnica multivariante, el análisis cluster, que permita una clasificación por grupos con individuos lo más homogéneos 140 
entre sí y de forma que exista heterogeneidad entre los grupos. En este caso, no se adopta previamente un paquete tecnológico determinado y es el algoritmo matemático el que nos forma los grupos eliminando la subjetividad. No obstante, dada la importancia de la tecnología del cultivo en sustrato, sobre la que se incide especialmente en este estudio, previamente a la aplicación del análisis cluster, se efectuó una separación de la información procedente de los cuestionarios según correspondiera al cultivo en suelo o al cultivo en sustrato.

\subsubsection{Análisis cluster: Metodología}

Es un método estadístico multivariante de interdependencia ya que todas las variables juegan el mismo papel, sin que una o varias sean explicadas por otras.

La utilidad del análisis cluster es la de clasificar individuos en categorías, pudiéndose también utilizar para clasificar variables. En nuestro caso se utiliza para agrupar explotaciones de invernaderos según su nivel de tecnología. Así, esta técnica permite formar grupos homogéneos según unas variables observadas. Los grupos de individuos que se forman, denominados "clusters", se caracterizan por ser homogéneos intra-grupos y heterogéneos entre grupos (Guisande y Vaamonde, 2006).

Para Sokal y Sneath (1963), autores destacados en el desarrollo del análisis cluster, "la clasificación es uno de los procesos fundamentales de la ciencia, ya que los fenómenos deben ser ordenados para que podamos entenderlos".

Así, cada conjunto estará compuesto por individuos con características similares (Martín-Guzmán y Martín, 1989). Las 242 explotaciones de invernaderos que conforman la muestra se agruparán por la similitud de las variables introducidas en el análisis.

Se trata de llegar a particiones exhaustivas de conjuntos de objetos, donde los grupos obtenidos agotan la posibilidad de partición, de modo que 
la varianza intraclases debe ser mínima y la varianza interclases debe ser máxima (Ortega, 1981).

El procedimiento seguido para realizar el análisis ha sido el jerárquico aglomerativo, con el cual, partiendo de tantos grupos iniciales como individuos se estudian, en los pasos siguientes los individuos más próximos son combinados en nuevos conglomerados, reduciéndose su número en cada paso del análisis. Al final todos los individuos son agrupados en un único conglomerado, dando lugar a una estructura con forma de árbol invertido, denominada dendograma, donde los resultados de las primeras etapas están anidados dentro de las posteriores. El dendograma a que dio lugar el proceso no se presenta debido al elevado número de entradas que impide que pueda verse con claridad.

El método de agrupamiento aplicado para calcular las distancias entre conglomerados ha sido el Método de Ward para datos binarios, utilizando la distancia euclídea al cuadrado como medida de proximidad. Mediante este método se calcula la media de todas las variables de cada cluster. Luego, se calcula la distancia euclídea al cuadrado entre cada individuo y la media de su grupo, y después, se suman las distancias de todos los casos (Bisquerra, 1989).

De este modo, partiendo de $k$ grupos y $m$ variables, tenemos, para cada grupo, la siguiente fórmula:

$$
S C I_{K}=\sum_{i=1}^{m} \sum_{j=1}^{n_{k}}\left(X_{i j k}-\bar{X}_{i k}\right)^{2}
$$

Donde $S C I_{K}$ es la suma cuadrática intracluster del grupo $k$.

$$
\sum_{i=1}^{m} \sum_{i=1}^{\infty}
$$

Es la suma de desviaciones en todas las variables $m$ para todos los individuos $n$ dentro del grupo $k$. 
$X_{i j k}$ Es el valor de la variable $i$ para cada sujeto $j$ perteneciente al grupo $k$.

$\bar{X}_{i k}$ Es la media de la variable $i$ en el grupo $k$.

\subsubsection{Resultados e interpretación}

Considerando el cultivo en sustrato como eje fundamental en torno al cual se van instalando los distintos elementos tecnológicos, se ha realizado una separación previa entre los individuos con cultivo en suelo y con cultivo en sustrato.

Se ha procedido a analizar, por una parte, los individuos con cultivo en suelo, obteniéndose tres grupos diferenciados, y por otra parte, los individuos con cultivo en sustrato, que han dado lugar a dos grupos. El programa informático utilizado fue el SPSS 13.0 para Windows.

Las 24 variables introducidas en el análisis, son variables dicotómicas (1 significa presencia de la característica; 0 es ausencia de la misma) y se recogen en la Tabla 4.13, junto con su descripción.

En la Tabla 4.14, se presentan los resultados de los dos análisis cluster conjuntamente, donde se muestran las proporciones de cada variable en cada uno de los cinco grupos obtenidos: los tres primeros con cultivo en suelo, y los otros dos en sustrato. 
Tabla 4.13. Descripción de las variables analizadas

\begin{tabular}{|c|c|}
\hline Variables & Descripción \\
\hline Calefacción aire & $\begin{array}{l}1=\text { sí tiene. } \\
0=\text { otro caso. }\end{array}$ \\
\hline Calefacción agua & $\begin{array}{l}1 \text { = sí tiene. } \\
0=\text { otro caso. }\end{array}$ \\
\hline Calefacción puntual & $\begin{array}{l}1=\text { sí tiene. } \\
0=\text { otro caso. }\end{array}$ \\
\hline Calefacción permanente & $\begin{array}{l}1=\text { sí tiene. } \\
0=\text { otro caso. }\end{array}$ \\
\hline Calefacción con temperatura alta & $\begin{array}{l}1=\text { sí tiene. } \\
0=\text { otro caso. }\end{array}$ \\
\hline Material estructura del invernadero & $\begin{array}{l}1=\text { acero } \\
0=\text { madera }\end{array}$ \\
\hline Plástico flexible con frontales PVC & $\begin{array}{l}1=\text { sí tiene. } \\
0=\text { otro caso. }\end{array}$ \\
\hline Todo plástico flexible & $\begin{array}{l}1 \text { = sí tiene. } \\
0 \text { = otro caso. }\end{array}$ \\
\hline Tipo de estructura del invernadero & $\begin{array}{l}1=\text { parral. } \\
0=\text { multitúnel. }\end{array}$ \\
\hline Mallas antiinsectos & $\begin{array}{l}1=\text { sí tiene. } \\
0=\text { otro caso. }\end{array}$ \\
\hline Pantallas térmicas & $\begin{array}{l}1 \text { = sí tiene. } \\
0 \text { = otro caso. }\end{array}$ \\
\hline Mallas de sombreo interiores & $\begin{array}{l}1=\text { sí tiene. } \\
0=\text { otro caso. }\end{array}$ \\
\hline Mallas de sombreo exteriores & $\begin{array}{l}1 \text { = sí tiene. } \\
0 \text { = otro caso. }\end{array}$ \\
\hline Nebulización & $\begin{array}{l}1=\text { sí tiene. } \\
0=\text { otro caso. }\end{array}$ \\
\hline Ventiladores & $\begin{array}{l}1 \text { = sí tiene. } \\
0=\text { otro caso }\end{array}$ \\
\hline Apertura de ventanas & $\begin{array}{l}1=\text { manual } \\
0=\text { automatizada }\end{array}$ \\
\hline Programación elementos de climatización & $\begin{array}{l}1 \text { = sí tiene. } \\
0 \text { = otro caso. }\end{array}$ \\
\hline Fertilización carbónica & $\begin{array}{l}1=\text { sí tiene. } \\
0=\text { otro caso. }\end{array}$ \\
\hline Programador de riego sencillo & $\begin{array}{l}1=\text { sí tiene. } \\
0=\text { otro caso. }\end{array}$ \\
\hline Programador de riego y fertirrigación & $\begin{array}{l}1=\text { sí tiene. } \\
0=\text { otro caso. }\end{array}$ \\
\hline $\begin{array}{l}\text { Programador de riego y fertirrigación } \\
\text { informatizado }\end{array}$ & $\begin{array}{l}1=\text { sí tiene. } \\
0=\text { otro caso. }\end{array}$ \\
\hline Balsa de riego & $\begin{array}{l}1=\text { sí tiene. } \\
0=\text { otro caso. }\end{array}$ \\
\hline Raíles & $\begin{array}{l}1 \text { = sí tiene. } \\
0=\text { otro caso. }\end{array}$ \\
\hline Carretillas & $\begin{array}{l}1 \text { = sí tiene. } \\
0=\text { otro caso. }\end{array}$ \\
\hline
\end{tabular}


Tabla 4.14. Proporciones de las variables en cada nivel tecnológico

\begin{tabular}{|c|c|c|c|c|c|}
\hline \multirow[t]{3}{*}{ Variables } & \multicolumn{5}{|c|}{ Niveles tecnológicos } \\
\hline & \multicolumn{3}{|c|}{ Cultivo en suelo } & \multicolumn{2}{|c|}{$\begin{array}{c}\begin{array}{c}\text { Cultivo en } \\
\text { sustrato }\end{array} \\
\end{array}$} \\
\hline & 1 & 2 & 3 & 4 & 5 \\
\hline № individuos / cluster & $\begin{array}{c}93 \\
(39 \%)\end{array}$ & $\begin{array}{c}78 \\
(33 \%)\end{array}$ & $\begin{array}{c}14 \\
(6 \%) \\
\end{array}$ & $\begin{array}{c}39 \\
(16 \%)\end{array}$ & $\begin{array}{c}14 \\
(6 \%) \\
\end{array}$ \\
\hline Calefacción aire & $1,1 \%$ & $6,4 \%$ & $0,0 \%$ & $12,8 \%$ & $14,3 \%$ \\
\hline Calefacción agua & $0,0 \%$ & $0,0 \%$ & $42,9 \%$ & $0,0 \%$ & $78,6 \%$ \\
\hline Calefacción puntual & $1,1 \%$ & $5,1 \%$ & $7,1 \%$ & $7,7 \%$ & $7,1 \%$ \\
\hline Calefacción permanente & $0,0 \%$ & $1,3 \%$ & $35,7 \%$ & $5,1 \%$ & $85,7 \%$ \\
\hline Calefacción alta temperatura & $0,0 \%$ & $0,0 \%$ & $7,1 \%$ & $0,0 \%$ & $50,0 \%$ \\
\hline $\begin{array}{l}\text { Estructura acero } \\
\text { Cubierta frontales PVC } \\
\text { Cubierta todo plástico flexible }\end{array}$ & $\begin{array}{r}90,3 \% \\
2,2 \% \\
86,0 \%\end{array}$ & $\begin{array}{r}88,5 \% \\
3,8 \% \\
93,6 \%\end{array}$ & $\begin{array}{r}100,0 \% \\
71,4 \% \\
28,6 \%\end{array}$ & $\begin{array}{r}97,4 \% \\
0,0 \% \\
100,0 \%\end{array}$ & $\begin{array}{r}100,0 \% \\
57,1 \% \\
42,9 \%\end{array}$ \\
\hline Tipo parral & $98,9 \%$ & $92,3 \%$ & $21,4 \%$ & $100,0 \%$ & $21,4 \%$ \\
\hline Mallas antiinsectos & $84,9 \%$ & $97,4 \%$ & $92,9 \%$ & $100,0 \%$ & $92,9 \%$ \\
\hline Pantallas térmicas & $1,1 \%$ & $1,3 \%$ & $50,0 \%$ & $0,0 \%$ & $85,7 \%$ \\
\hline Mallas sombreo exteriores & $1,1 \%$ & $11,5 \%$ & $0,0 \%$ & $10,3 \%$ & $14,3 \%$ \\
\hline Mallas sombreo interiores & $4,3 \%$ & $9,0 \%$ & $0,0 \%$ & $5,1 \%$ & $7,1 \%$ \\
\hline Nebulización & $1,1 \%$ & $5,1 \%$ & $7,1 \%$ & $15,4 \%$ & $14,3 \%$ \\
\hline Ventiladores & $2,2 \%$ & $5,1 \%$ & $28,6 \%$ & $15,4 \%$ & $78,6 \%$ \\
\hline \multirow{2}{*}{$\begin{array}{l}\text { Apertura ventanas manual } \\
\text { Programación elementos de } \\
\text { climatización }\end{array}$} & $92,5 \%$ & $96,2 \%$ & $0,0 \%$ & $100,0 \%$ & $7,1 \%$ \\
\hline & $5,4 \%$ & $1,3 \%$ & $42,9 \%$ & $0,0 \%$ & $64,3 \%$ \\
\hline Fertilización $\mathrm{CO}_{2}$ & $0,0 \%$ & $0,0 \%$ & $0,0 \%$ & $0,0 \%$ & $7,1 \%$ \\
\hline Programador riego sencillo & $45,2 \%$ & $0,0 \%$ & $14,3 \%$ & $5,1 \%$ & $0,0 \%$ \\
\hline Programador riego y fertirrigación & $2,2 \%$ & $92,3 \%$ & $35,7 \%$ & $74,4 \%$ & $21,4 \%$ \\
\hline Riego y fertirrigación informatizado & $10,8 \%$ & $0,0 \%$ & $42,9 \%$ & $20,5 \%$ & $78,6 \%$ \\
\hline Balsa & $83,9 \%$ & $94,9 \%$ & $92,9 \%$ & $94,9 \%$ & $85,7 \%$ \\
\hline Raíles & $0,0 \%$ & $0,0 \%$ & $0,0 \%$ & $0,0 \%$ & $7,1 \%$ \\
\hline Carretillas elevadoras & $3,2 \%$ & $3,8 \%$ & $0,0 \%$ & $2,6 \%$ & $14,3 \%$ \\
\hline
\end{tabular}




\subsubsection{Interpretación y caracterización de los niveles formados}

A primera vista, con los resultados de la Tabla 4.14, parece suficiente y adecuada la clasificación de los invernaderos estudiados en los cinco grupos. Entre las ventajas en la utilización de la técnica del cluster se aprecia, por una parte, el número de individuos asignados en cada grupo y a su vez, en cada uno de ellos, la proporción de individuos que disponen de una determinada variable o elemento.

Una vez formados los grupos, según la metodología aplicada, por el conjunto de elementos que los constituyen, se deducen las características técnicas de las diferentes combinaciones y cómo inciden en la mejora que representa el paso de un nivel a otro superior.

A continuación, se procede a la descripción de los cinco niveles tecnológicos tomando como base la composición de sus elementos y utilidad de su función.

Nivel 1: Constituye el grupo más rudimentario o menos evolucionado, formado por invernaderos de tipo parral con cubierta de plástico flexible, en su mayoría; la apertura de ventanas se realiza de forma manual y no tienen calefacción.

La proporción de invernaderos que disponen de balsa en este grupo también es elevada por lo que la disposición de este elemento no diferencia los grupos; su existencia en altas proporciones, se deriva de la necesidad de tener abastecidas las exigencias del riego y de la fertirrigación permanentemente junto con el almacenamiento del agua propio de zonas áridas donde están ubicados los invernaderos.

Aunque en general el agricultor suele dar prioridad en sus inversiones a la mejora del sistema de riego, menos de la mitad de los invernaderos de este grupo disponen de programador de riego sencillo y las proporciones de riego y fertirrigación informatizados sólo alcanzan el 10,8\%. Un aspecto muy positivo a pesar de la composición tan simple de los 146 
invernaderos de este grupo es que están dotados de mallas antiinsectos en su mayor parte, $(84,9 \%)$, por lo que es viable su orientación hacia la producción integrada con control biológico.

Nivel 2: Domina este nivel la estructura de acero, aunque aún subsiste la de madera en un $11,5 \%$. La cubierta es de plástico flexible y existe un reducido número de invernaderos cubiertos de malla. Predomina en este conjunto el tipo parral, la mayor parte de ellos con mejoras introducidas, y también se han incluido invernaderos del tipo multitúnel en un $7,7 \%$ de los casos.

Sobresale, especialmente en este nivel, la dotación asignada al sistema de riego y casi en la totalidad de las unidades disponen de balsa y el riego y la fertirrigación están programados. Hay proporciones apreciables de mallas de sombreo tanto exteriores como interiores. Es baja la proporción de elementos modificadores de la temperatura: la nebulización figura en el $5,1 \%$ de los casos y la calefacción por aire en el $6,4 \%$, si bien suele tener un uso puntual. La práctica totalidad del grupo tiene instaladas mallas antiinsectos.

Resta perfección a los invernaderos de este grupo la forma de apertura de ventanas que, casi en su totalidad, es manual.

Nivel 3: Se da en este grupo un salto tecnológico importante. Predomina el tipo multitúnel, y la estructura es de acero en la totalidad de los casos. Dispone de frontales de PVC en la mayor parte de los casos y el recubrimiento es de plástico flexible. A diferencia de los dos niveles anteriores, la mitad tienen el riego y la fertirrigación informatizados y la otra mitad disponen de un programador.

Respecto al control de temperatura, se considera con un buen nivel de dotación dado que la mitad llevan pantallas térmicas, casi un tercio ventiladores y el $42,9 \%$ tienen instalada calefacción por agua, con utilización permanente en un $36 \%$ de los casos, que en alguno de ellos llega a ser de alta temperatura. La apertura de ventanas nunca es manual y la programación de los elementos de climatización alcanza una proporción del 
$42,9 \%$. Prácticamente la totalidad de los invernaderos del grupo disponen de mallas antiinsectos.

En resumen, cabe aceptar que la evolución tecnológica en este grupo es muy aceptable. La proporción de invernaderos en multitúnel es similar al grupo 5, el más evolucionado, y parece evidente que en este grupo se incluyen propietarios que han realizado inversiones importantes, tratándose de cultivo en suelo, pero se resisten a evolucionar hacia el cultivo en sustrato.

Nivel 4: Aquí se aprecia un avance clave en la modalidad de cultivo, la adopción del sustrato, aunque con respecto al grupo 3 , en términos generales, la dotación es inferior. El tipo de invernadero es un parral mejorado con estructura de acero y cubierto al $100 \%$ de plástico flexible. Presenta un aceptable desarrollo en la instalación del riego y la fertirrigación, con programador en el $80 \%$ de los casos e informatizado en el $20,5 \%$. Es el grupo con mayor proporción de instalaciones de nebulización, si bien sólo alcanzan el $15,4 \%$ de los casos, lo que nos indica que este sistema de enfriamiento no alcanza proporciones adecuadas. Se han instalado ventiladores en la misma proporción que la nebulización. En las mallas antiinsectos se ha conseguido llegar a una proporción del 100\% de los invernaderos del grupo.

El 10,3\% tienen mallas de sombreo exteriores y el 5,1\% interiores. Existe un predominio de la calefacción por aire en el 12,8\% de los casos, y en cuanto a la calefacción permanente por agua la mayoría de los propietarios no se han mostrado inclinados a invertir en su instalación.

Nivel 5: Es sin duda el más evolucionado. En la mayoría de los casos el tipo elegido es el multitúnel con estructura de acero y recubrimiento de plástico flexible con frontales de PVC en más de la mitad de los casos. Sobresale la proporción de riego y fertirrigación informatizada con el 78,6\% de los casos.

Respecto a los elementos de control climático, una mayoría de los invernaderos disponen de pantallas térmicas y ventiladores. En menor 
proporción figuran las mallas de sombreo exteriores e interiores y la nebulización. La disposición de elementos de control se completa con las mallas antiinsectos, imprescindibles en el control biológico.

También es característico en este grupo la proporción de calefacción que alcanza el 93\% de los invernaderos, en los que el 85,7\% tiene carácter permanente y además el $50 \%$ es de alta temperatura.

La programación de elementos de climatización está instalada en el $64,3 \%$ de los invernaderos del grupo. Aunque en baja proporción, es el único grupo que tiene instalación de raíles; a pesar de ello, la proporción de carretillas elevadoras también es baja.

Una característica diferenciadora de este grupo, en relación con los otros cuatro, es la existencia de instalación de fertilización con $\mathrm{CO}_{2}$ en una proporción del 7,1\%.

Este grupo, aunque no numeroso, representa un ideal en la dotación de invernaderos hortícolas mediterráneos con el que es posible lograr buenos niveles en el control de la climatización y la fertirrigación que hoy día se exige para obtener calidad y en el cultivo de variedades selectas.

\subsubsection{Relación de los niveles tecnológicos de los invernaderos con variables de interés}

Una vez definidos y caracterizados los grupos, se cree conveniente deducir la relación de cada uno de ellos con algunas características relevantes de la explotación obtenidas en la información de los cuestionarios. Para ello, se han elaborado tablas de frecuencias cruzadas a cuyas variables se les ha aplicado el contraste de independencia, cuya teoría ha sido expuesta en el apartado 4.6.1 de este capítulo. Solamente se expresan los resultados de las variables significativas, que corresponden a: zonas de estudio, tipo de cultivo, edad de los agricultores, disposición de los propietarios al endeudamiento y subvenciones o préstamos oficiales recibidos. 


\section{Zonas de estudio}

El conjunto de explotaciones que integra cada nivel tecnológico, presenta una alta relación con las tres zonas en las que se ha realizado el estudio, dado que se obtiene un estadístico $\chi^{2}$ total muy elevado (Tabla 4.15).

Tabla 4.15. Distribución de los niveles tecnológicos de los invernaderos según zona

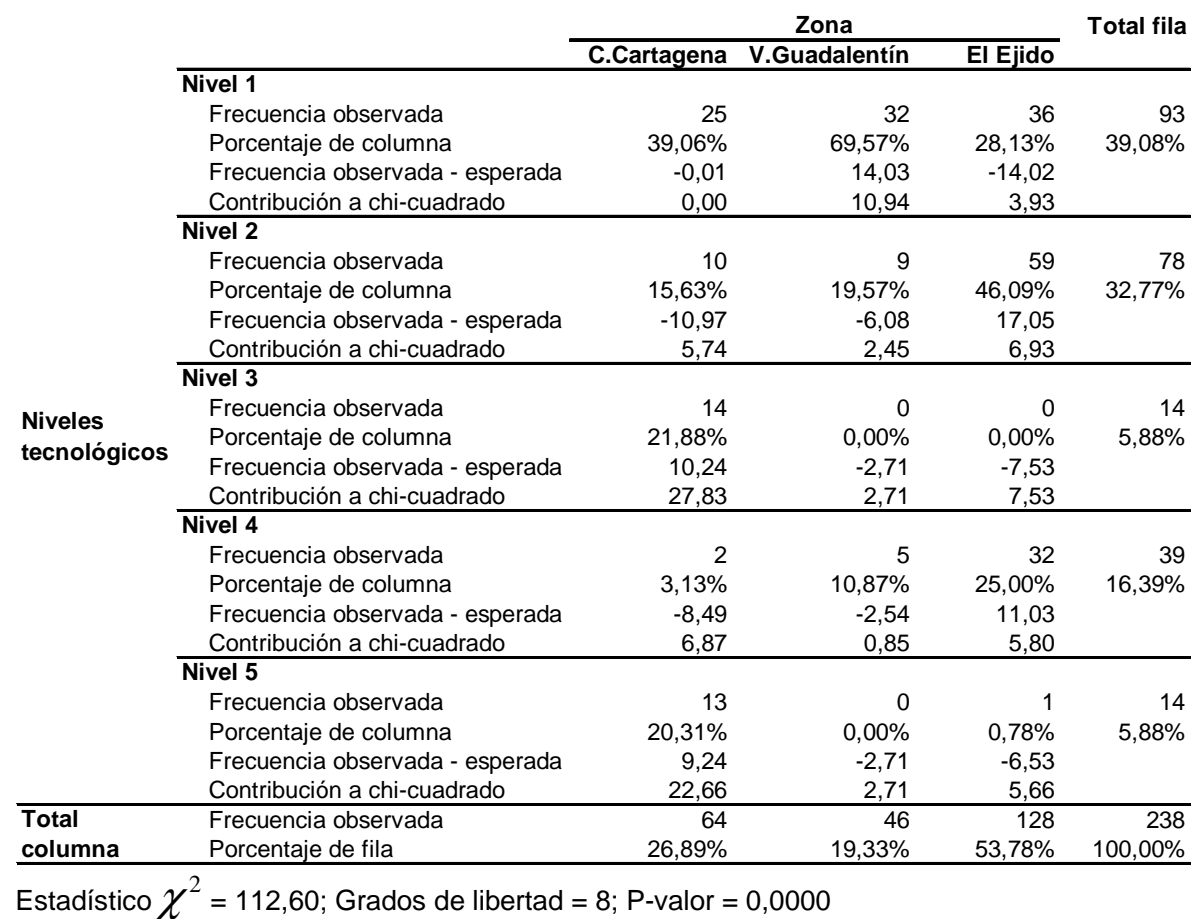

Cabe señalar que el Campo de Cartagena tiene instalaciones más completas, lo que a primera vista se deduce por los porcentajes de los grupos 3 y 5 que son superiores a los de otras zonas; también, su contribución a $\chi^{2}$ es elevada y se observa una frecuencia mayor de la que cabría esperar bajo la hipótesis de independencia.

El Valle del Guadalentín presenta una evolución menor, probablemente debido a la especialización de la zona en cultivo de tomate. 
La proporción del grupo 1, el más sencillo, es muy elevada, siendo su contribución a $\chi^{2}$ total también elevada, a lo que se añade además, una asociación positiva entre la zona y el grupo, lo que significa que la frecuencia observada en el Valle de Guadalentín para el grupo 1 es mayor que la esperada bajo la hipótesis de independencia.

Finalmente, la zona de El Ejido tiene su porcentaje más importante en el grupo 2, lo que permite afirmar que se ha registrado una evolución importante en los 15 últimos años respecto al primitivo invernadero plano. Sobresale la tendencia a incrementar la proporción de invernaderos en el grupo 4, que corresponde a la modalidad de sustrato sin llegar a completar un equipamiento adecuado. Se observa que, tanto en el grupo 2 como en el 4, la asociación entre grupo y zona es positiva, por lo que se deduce que en El Ejido la frecuencia de estos invernaderos es mayor de lo que se esperaba bajo la hipótesis de independencia.

\section{Tipo de cultivo}

Al analizar los niveles tecnológicos según el tipo de cultivo se obtiene un estadístico $\chi^{2}$ total con un p-valor muy bajo, lo que indica la existencia de dependencia entre el tipo de cultivo y el nivel tecnológico al que con más frecuencia son asignados (Tabla 4.16).

El pimiento presenta una distribución más uniforme y mayores proporciones entre los tres niveles altos en comparación con los demás cultivos, lo que se explica por la elevada exigencia del cultivo de pimiento y su mejor respuesta a las inversiones. Los resultados muestran cómo en el nivel 1, el más sencillo, la frecuencia observada es menor que la esperada bajo la hipótesis de independencia. Lo contrario, se puede observar en los niveles 3 y 5 , donde se da una asociación positiva, es decir, la frecuencia observada ha resultado mayor que la esperada, a lo que se añade una elevada contribución a $\chi^{2}$. 
El tomate es una de las especies hortícolas bajo abrigo con menores exigencias. En una elevada proporción se le asignan los invernaderos del nivel 1, presentando esta celda la mayor contribución a $\chi^{2}$ y una asociación positiva. El cultivo en sustrato sin calefacción permanente (nivel 4) es la modalidad elegida cuando al tomate se le practica un cultivo más exigente en medios.

Tabla 4.16. Distribución de los niveles tecnológicos de los invernaderos según su especialización por cultivos

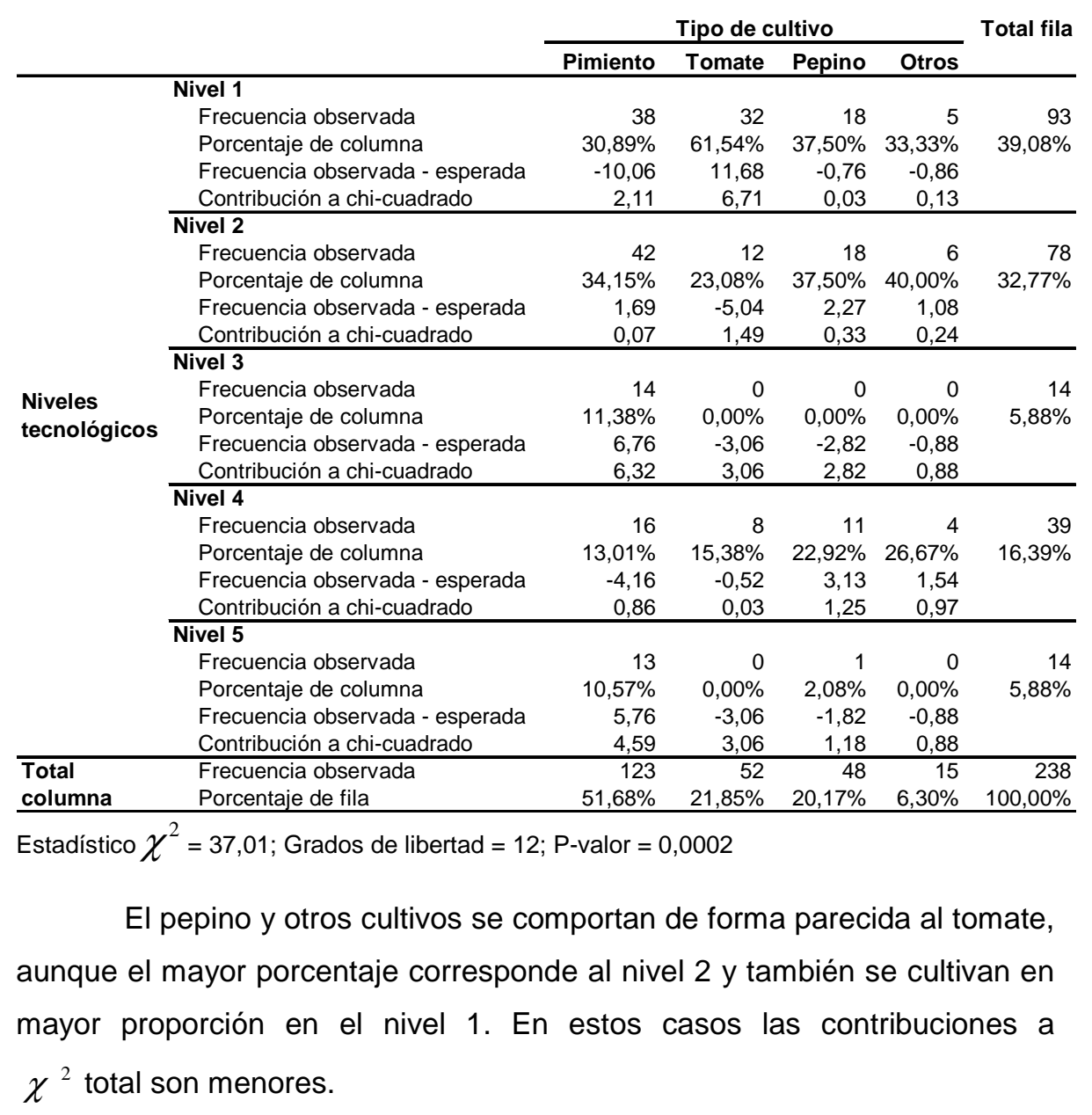




\section{Edad del agricultor}

Aunque se esperaba que la edad del agricultor y el nivel tecnológico de su invernadero estuvieran relacionados, según los resultados no hay evidencias de que haya dependencia entre las dos variables (Tabla 4.17).

Tabla 4.17. Distribución de los niveles tecnológicos de los invernaderos según intervalos de edad de los propietarios

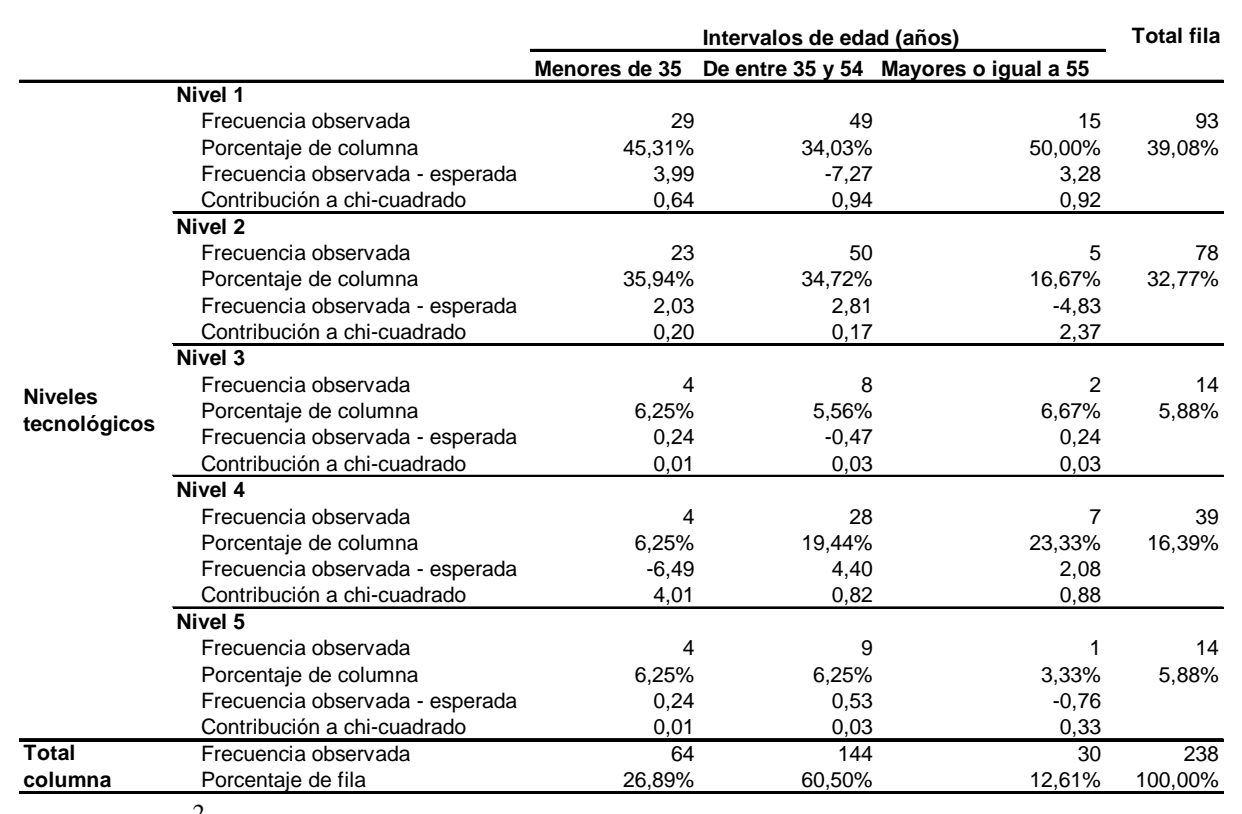

Estadístico $\chi^{2}=11,40 ;$ Grados de libertad $=8 ; \mathrm{P}$-valor $=0,1801$

\section{Disposición al endeudamiento}

En el análisis de los niveles tecnológicos de los invernaderos según la disposición al endeudamiento, se obtiene un estadístico $\chi^{2}$ total considerablemente elevado, lo que indica que existe una relación de dependencia entre la disposición al endeudamiento y el nivel tecnológico de los invernaderos (Tabla 4.18).

Cuando la disposición empresarial al endeudamiento es muy baja aparece un resultado lógico, con el $47,44 \%$ y el $25,64 \%$ en los dos primeros niveles, respectivamente. Cuando es baja, aunque se distribuyen los 
mayores porcentajes en los dos primeros niveles, sobresale la cantidad que elige el nivel 4 , un 26,47\%, con la contribución a chi-cuadrado total más elevada de la tabla y una asociación positiva, mientras que en el nivel 5 la asociación es negativa, lo cual indica que, respecto a la motivación para invertir en la modalidad de sustrato, se inclinan más por un cultivo en sustrato en frío con "exigencias bajas" en equipamiento, que por uno con calefacción permanente y elementos de control más costosos.

Tabla 4.18. Distribución de los niveles tecnológicos de los invernaderos según la disposición de los propietarios al endeudamiento

\begin{tabular}{|c|c|c|c|c|c|c|c|}
\hline & & \multicolumn{5}{|c|}{ Disposición al endeudamiento } & \multirow[t]{2}{*}{ Total fila } \\
\hline & & \multirow[t]{2}{*}{ Muy baja } & \multirow[t]{2}{*}{ Baja } & \multirow[t]{2}{*}{ Indiferente } & \multicolumn{2}{|c|}{ Alta Muy alta } & \\
\hline & Nivel 1 & & & & & & \\
\hline & Frecuencia observada & 37 & 24 & 14 & 8 & 10 & 93 \\
\hline & Porcentaje de columna & $47,44 \%$ & $35,29 \%$ & $25,00 \%$ & $50,00 \%$ & $50,00 \%$ & $39,08 \%$ \\
\hline & Frecuencia observada - esperada & 6,52 & $-2,57$ & $-7,88$ & 1,75 & 2,18 & \\
\hline & Contribución a chi-cuadrado & 1,40 & 0,25 & 2,84 & 0,49 & 0,61 & \\
\hline & Nivel 2 & & & & & & \\
\hline & Frecuencia observada & 20 & 25 & 22 & 4 & 7 & 78 \\
\hline & Porcentaje de columna & $25,64 \%$ & $36,76 \%$ & $39,29 \%$ & $25,00 \%$ & $35,00 \%$ & $32,77 \%$ \\
\hline & Frecuencia observada - esperada & $-5,56$ & 2,71 & 3,65 & $-1,24$ & 0,45 & \\
\hline & Contribución a chi-cuadrado & 1,21 & 0,33 & 0,72 & 0,29 & 0,03 & \\
\hline & Nivel 3 & & & & & & \\
\hline \multirow{14}{*}{$\begin{array}{l}\text { Niveles } \\
\text { tecnológicos }\end{array}$} & Frecuencia observada & 6 & 0 & 6 & 2 & 0 & \\
\hline & Porcentaje de columna & $7,69 \%$ & $0,00 \%$ & $10,71 \%$ & $12,50 \%$ & $0,00 \%$ & $5,88 \%$ \\
\hline & Frecuencia observada - esperada & 1,41 & $-4,00$ & 2,71 & 1,06 & $-1,18$ & \\
\hline & Contribución a chi-cuadrado & 0,43 & 4,00 & 2,22 & 1,19 & 1,18 & \\
\hline & Nivel 4 & & & & & & \\
\hline & Frecuencia observada & 10 & 18 & 8 & 1 & 2 & 39 \\
\hline & Porcentaje de columna & $12,82 \%$ & $26,47 \%$ & $14,29 \%$ & $6,25 \%$ & $10,00 \%$ & $16,39 \%$ \\
\hline & Frecuencia observada - esperada & $-2,78$ & 6,86 & $-1,18$ & $-1,62$ & $-1,28$ & \\
\hline & Contribución a chi-cuadrado & 0,61 & 4,22 & 0,15 & 1,00 & 0,5 & \\
\hline & Nivel 5 & & & & & & \\
\hline & Frecuencia observada & 5 & 1 & 6 & 1 & 1 & 14 \\
\hline & Porcentaje de columna & $6,41 \%$ & $1,47 \%$ & $10,71 \%$ & $6,25 \%$ & $5,00 \%$ & $5,88 \%$ \\
\hline & Frecuencia observada - esperada & 0,41 & $-3,00$ & 2,71 & 0,06 & $-0,18$ & \\
\hline & Contribución a chi-cuadrado & 0,04 & 2,25 & 2,22 & 0,00 & 0,03 & \\
\hline \multirow{2}{*}{$\begin{array}{l}\text { Total } \\
\text { columna }\end{array}$} & Frecuencia observada & 78 & 68 & 56 & 16 & 20 & 238 \\
\hline & Porcentaje de fila & $32,77 \%$ & $28,57 \%$ & $23,53 \%$ & $6,72 \%$ & $8,40 \%$ & $100,00 \%$ \\
\hline
\end{tabular}

Los empresarios que se manifestaron como indiferentes muestran una distribución algo más regular, siendo éste el grupo más dispuesto a elegir el mayor nivel de tecnología.

La disposición alta y muy alta no han inducido una mayor dedicación al sustrato y resulta algo contradictorio que solamente un $12,5 \%$ y un $15 \%$ 
respectivamente se sitúen en los niveles 4 y 5 , dado que son precisamente los que requieren más inversión.

\section{Subvenciones o préstamos oficiales}

Al analizar los niveles tecnológicos de los invernaderos en relación a si han recibido o no subvenciones o préstamos oficiales, se obtiene un estadístico $\chi^{2}$ total elevado, lo que significa que existe relación del nivel tecnológico del invernadero con el hecho de haber recibido algún préstamo o subvención (Tabla 4.19).

Tabla 4.19. Distribución de los niveles tecnológicos de los invernaderos según las subvenciones o préstamos del Gobierno recibidos por los propietarios

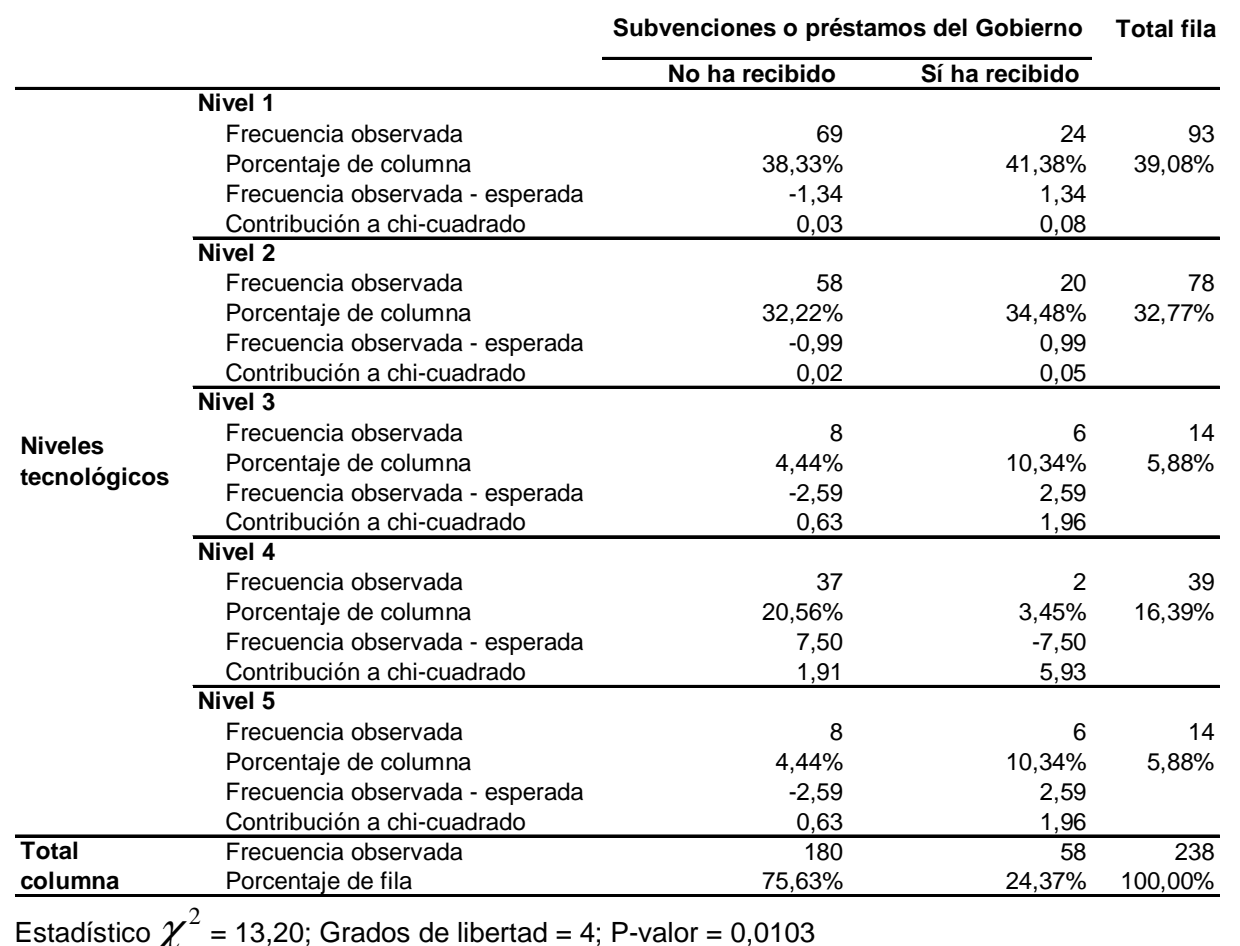

En ambas situaciones los porcentajes de distribución son similares en los dos primeros niveles; en cambio, en los tres últimos, las diferencias son evidentes: cuando no ha recibido subvenciones el nivel más elegido es 
el 4 y si las ha recibido se distribuyen en los niveles con mayor dotación de elementos, el 3 y el 5. Señalar también que el caso de mayor contribución a la $\chi^{2}$ total es el nivel 4 cuando ha recibido subvenciones, pero con una asociación negativa, esto es, se han detectado menos casos de los esperados bajo la hipótesis de que las variables fueran independientes.

\subsubsection{Relación de los niveles tecnológicos con los factores que afectan al proceso de adopción}

Con los grupos obtenidos como resultado del análisis cluster, se ha creído conveniente deducir la relación de cada uno de ellos con los factores que afectan al proceso de adopción, entre los cuales se han considerado las vías a través de las cuales el agricultor obtuvo la información inicial sobre el cultivo en sustrato (o en su defecto el cultivo en suelo), a través de quién se formó en este tema, y quién le suele asesorar en los problemas técnicos.

Para realizar este análisis, al igual que en el apartado anterior, se han elaborado tablas de frecuencias cruzadas a cuyas variables se les ha aplicado el contraste de independencia. Solamente se expresan los resultados de las variables marcadas como primera opción, ya que las tablas en las que se consideraban las variables señaladas como segunda opción no resultaron significativas.

Se obtuvieron resultados válidos respecto a la información inicial, a la formación y al asesoramiento. Las opciones de Internet, revistas y centros de investigación, que se proponían en el cuestionario, no resultaron elegidas en ningún caso como primera opción, y por tanto, no se incluyeron en los análisis posteriores.

Según los resultados obtenidos (Tabla 4.20), las fuentes de información iniciales más frecuentes son otros agricultores $(39,66 \%)$ y familiares $(36,29 \%)$, seguidos de los técnicos de cooperativas $(8,02 \%)$.

Al analizar los niveles tecnológicos de los invernaderos según las fuentes de información inicial, se obtiene un estadístico chi-cuadrado total muy elevado, lo que significa que existe relación entre los niveles 156 
tecnológicos y las fuentes prioritarias de información utilizadas por los propietarios (Tabla 4.20). La celda con mayor contribución a chi-cuadrado es la del grupo 5 cruzada con técnicos de cooperativas, que da una desviación (frecuencia observada-esperada) de signo positivo, lo cual indica que en este grupo se informan sensiblemente más a través de técnicos de cooperativas de lo que cabía esperar bajo la hipótesis de independencia.

Tabla 4.20. Frecuencias cruzadas de los niveles tecnológicos con las

\section{fuentes de información inicial}

\begin{tabular}{|c|c|c|c|c|c|c|c|c|}
\hline Niveles tecnológicos & $\begin{array}{l}\text { Técn. } \\
\text { Coop. }\end{array}$ & $\begin{array}{r}\text { Prov. Mat. } \\
\text { y Prod. }\end{array}$ & $\begin{array}{r}\text { Of.Capac. } \\
\text { Agraria }\end{array}$ & $\begin{array}{l}\text { Ing. y Técn. } \\
\text { Indptes }\end{array}$ & $\begin{array}{r}\text { Otros } \\
\text { Agricultores }\end{array}$ & $\begin{array}{r}\text { Cursos } \\
\text { Técnicos }\end{array}$ & Familiares & Total fila \\
\hline \multicolumn{9}{|l|}{ Nivel 1} \\
\hline Frecuencia observada & 8 & 3 & 4 & 3 & 48 & 3 & 23 & \\
\hline Porcentaje de fila & $8,70 \%$ & $3,26 \%$ & $4,35 \%$ & $3,26 \%$ & $52,17 \%$ & $3,26 \%$ & $25,00 \%$ & $38,82 \%$ \\
\hline Frecuencia observada - esperada & 0,62 & $-2,82$ & 0,89 & 0,28 & 11,51 & $-0,11$ & $-10,38$ & \\
\hline Contribución a chi-cuadrado & 0,05 & 1,37 & 0,26 & 0,03 & 3,63 & 0,00 & 3,23 & \\
\hline \multicolumn{9}{|l|}{ Nivel 2} \\
\hline Frecuencia observada & 3 & 8 & 1 & 2 & 23 & 4 & 37 & 78 \\
\hline Porcentaje de fila & $3,85 \%$ & $10,26 \%$ & $1,28 \%$ & $2,56 \%$ & $29,49 \%$ & $5,13 \%$ & $47,44 \%$ & $32,91 \%$ \\
\hline Frecuencia observada - esperada & $-3,25$ & 3,06 & $-1,63$ & $-0,30$ & $-7,94$ & 1,37 & 8,70 & \\
\hline Contribución a chi-cuadrado & 1,69 & 1,90 & 1,01 & 0,04 & 2,04 & 0,71 & 2,67 & \\
\hline \multicolumn{9}{|l|}{ Nivel 3} \\
\hline Frecuencia observada & 2 & 0 & 2 & 0 & 9 & 1 & 0 & 14 \\
\hline Porcentaj & $14,29 \%$ & $0,00 \%$ & $14,29 \%$ & $0,00 \%$ & $64,29 \%$ & $7,14 \%$ & $0,00 \%$ & $5,91 \%$ \\
\hline Frecuencia observada - esperada & 0,88 & $-0,89$ & 1,53 & $-0,41$ & 3,45 & 0,53 & $-5,08$ & \\
\hline Contribución a chi-cuadrado & 0,69 & 0,89 & 4,94 & 0,41 & 2,14 & 0,59 & 5,08 & \\
\hline \multicolumn{9}{|l|}{ Nivel 4} \\
\hline Frecuenc & 2 & 4 & 0 & 1 & 8 & 0 & 24 & \\
\hline Porcentaje de fila & $5,13 \%$ & $10,26 \%$ & $0,00 \%$ & $2,56 \%$ & $20,51 \%$ & $0,00 \%$ & $61,54 \%$ & $16,46 \%$ \\
\hline Frecuencia observada - esperada & $-1,13$ & 1,53 & $-1,32$ & $-0,15$ & $-7,47$ & $-1,32$ & 9,85 & \\
\hline Contribución a chi-cuadrado & 0,41 & 0,95 & 1,32 & 0,02 & 3,61 & 1,32 & 6,85 & \\
\hline \multicolumn{9}{|l|}{ Nivel 5} \\
\hline Frecuencia observada & 4 & 0 & 1 & 1 & 6 & 0 & 2 & 14 \\
\hline Porcentaje de fila & $28,57 \%$ & $0,00 \%$ & $7,14 \%$ & $7,14 \%$ & $42,86 \%$ & $0,00 \%$ & $14,29 \%$ & $5,91 \%$ \\
\hline Frecuencia observada - esperada & 2,88 & $-0,89$ & 0,53 & 0,59 & 0,45 & $-0,47$ & $-3,08$ & \\
\hline Contribución a chi-cuadrado & 7,38 & 0,89 & 0,59 & 0,83 & 0,04 & 0,47 & 1,87 & \\
\hline Total columna & $\begin{array}{r}19 \\
8,02 \%\end{array}$ & $\begin{array}{r}15 \\
6,33 \%\end{array}$ & $\begin{array}{r}8 \\
3,38 \%\end{array}$ & $\begin{array}{r}7 \\
2.95 \%\end{array}$ & $\begin{array}{r}94 \\
39,66 \%\end{array}$ & $\begin{array}{r}8 \\
3,38 \%\end{array}$ & $\begin{array}{r}86 \\
36,29 \%\end{array}$ & $\begin{array}{r}237 \\
100,00 \%\end{array}$ \\
\hline
\end{tabular}

Estadístico $\chi^{2}=59,900 ;$ Grados de libertad $=24 ; \mathrm{P}$-valor $=0,000$

Como se deduce de los resultados (Tabla 4.21), las vías de formación más frecuentes son familiares $(31,36 \%)$ y otros agricultores $(30,08 \%)$, seguidos de los técnicos de cooperativas $(17,80 \%)$.

Del análisis de la distribución de los niveles tecnológicos según las vías de formación más frecuentemente utilizadas, se obtiene un estadístico chi-cuadrado total muy elevado, lo que indica que los niveles tecnológicos de los invernaderos están relacionados con las vías de formación utilizadas por los propietarios. 
Sobresalen los técnicos de cooperativas y los familiares ya que presentan las casillas con la mayor contribución a chi-cuadrado total, en los grupos 5 y 2 respectivamente, que además al ser una asociación positiva indica que estos grupos utilizan sensiblemente más estas vías para formarse en materia del cultivo en sustrato, de lo que se esperaba según la hipótesis de independencia.

\section{Tabla 4.21. Frecuencias cruzadas de los niveles tecnológicos con las}

\section{fuentes de formación}

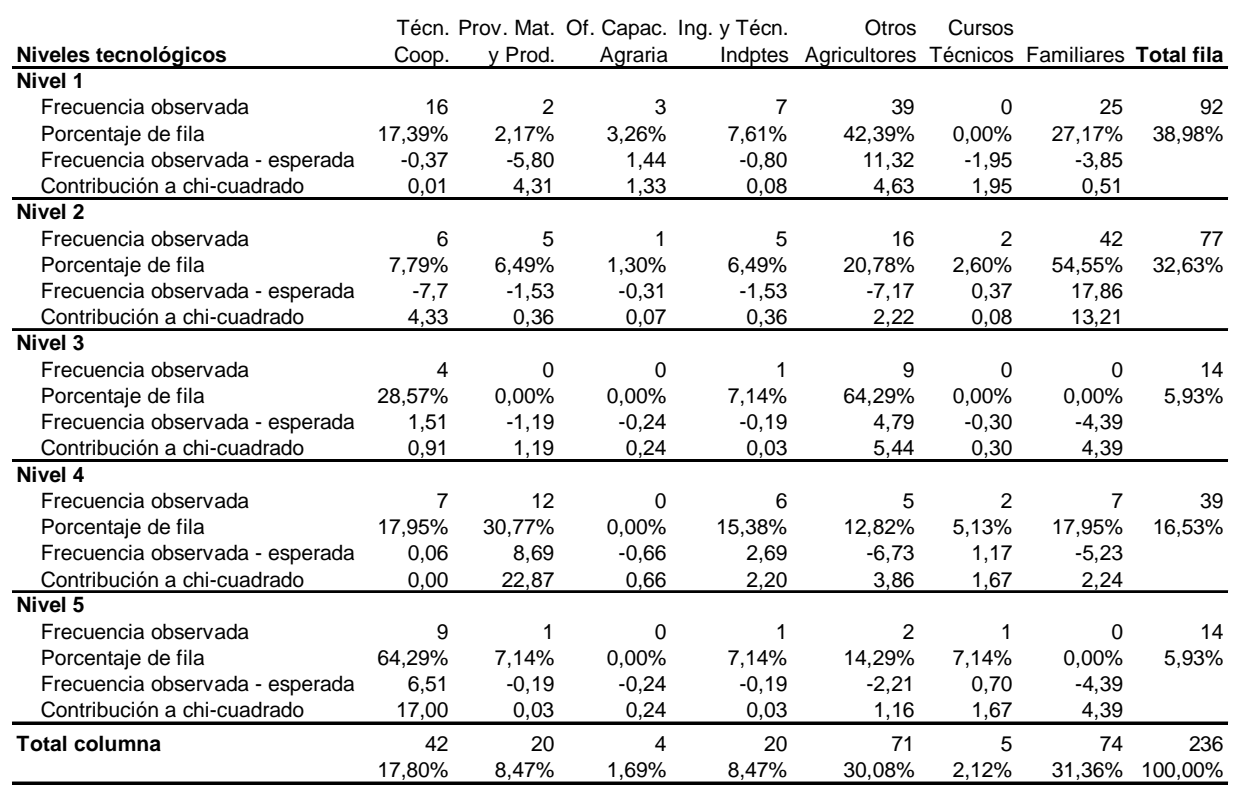

Estadístico $\chi^{2}=103,960 ;$ Grados de libertad $=24 ; \mathrm{P}$-valor $=0,000$

Como se deduce de los resultados (Tabla 4.22), las vías de asesoramiento más frecuentes son, en primer lugar, los técnicos de cooperativas $(39,41 \%)$, seguidos de los proveedores de materiales y productos $(27,97 \%)$ y de los ingenieros o técnicos independientes $(26,69 \%)$.

Del análisis de la distribución de los niveles tecnológicos según las vías de asesoramiento más frecuentemente utilizadas, se obtiene un estadístico chi-cuadrado total elevado ( $p$-valor $=0,018$ ), lo que indica que los niveles tecnológicos de los invernaderos guardan una relación de 
dependencia con las vías de asesoramiento más frecuentemente utilizadas por los propietarios.

Poniendo atención a las celdas con mayor contribución a chicuadrado, destacan el asesoramiento a través de otros agricultores y de ingenieros o técnicos independientes, en los grupos 1 y 3 , respectivamente. Además, tienen una asociación positiva, lo que indica que en el grupo 1 se asesoran más de lo esperado a través de otros agricultores. Lo mismo ocurre con el grupo 3, que se asesoran más de lo esperado, en este caso, a través de los ingenieros o técnicos independientes.

\section{Tabla 4.22. Frecuencias cruzadas de los niveles tecnológicos con las}

\section{fuentes de asesoramiento}

\begin{tabular}{|c|c|c|c|c|c|c|}
\hline Niveles tecnológicos & $\begin{array}{l}\text { Técn. } \\
\text { Coop. }\end{array}$ & $\begin{array}{r}\text { Prov. Mat. } \\
\text { y Prod. }\end{array}$ & $\begin{array}{l}\text { Ing. y Técn. } \\
\text { Indptes }\end{array}$ & $\begin{array}{r}\text { Otros } \\
\text { Agricultores } \\
\end{array}$ & Familiares & Total fila \\
\hline \multicolumn{7}{|l|}{ Nivel 1} \\
\hline Frecuencia observada & 29 & 22 & 30 & 10 & 1 & 92 \\
\hline Porcentaje de fila & $31,52 \%$ & $23,91 \%$ & $32,61 \%$ & $10,87 \%$ & $1,09 \%$ & $38,98 \%$ \\
\hline Frecuencia observada - esperada & $-7,25$ & $-3,73$ & 5,44 & 4,93 & 0,61 & \\
\hline Contribución a chi-cuadrado & 1,45 & 0,54 & 1,21 & 4,80 & 0,96 & \\
\hline \multicolumn{7}{|l|}{ Nivel 2} \\
\hline Frecuencia observada & 34 & 27 & 14 & 2 & 0 & 77 \\
\hline Porcentaje de fila & $44,16 \%$ & $35,06 \%$ & $18,18 \%$ & $2,60 \%$ & $0,00 \%$ & $32,63 \%$ \\
\hline Frecuencia observada - esperada & 3,66 & 5,47 & $-6,56$ & $-2,24$ & $-0,33$ & \\
\hline Contribución a chi-cuadrado & 0,44 & 1,39 & 2,09 & 1,18 & 0,33 & \\
\hline \multicolumn{7}{|l|}{ Nivel 3} \\
\hline Frecuencia observada & 3 & 2 & 8 & 1 & 0 & 14 \\
\hline Porcentaje de fila & $21,43 \%$ & $14,29 \%$ & $57,14 \%$ & $7,14 \%$ & $0,00 \%$ & $5,93 \%$ \\
\hline Frecuencia observada - esperada & $-2,52$ & $-1,92$ & 4,26 & 0,23 & $-0,06$ & \\
\hline Contribución a chi-cuadrado & 1,15 & 0,94 & 4,86 & 0,07 & 0,06 & \\
\hline \multicolumn{7}{|l|}{ Nivel 4} \\
\hline Frecuencia observada & 20 & 13 & 6 & 0 & 0 & 39 \\
\hline Porcentaje de fila & $51,28 \%$ & $33,33 \%$ & $15,38 \%$ & $0,00 \%$ & $0,00 \%$ & $16,53 \%$ \\
\hline Frecuencia observada - esperada & 4,63 & 2,09 & $-4,41$ & $-2,15$ & $-0,17$ & \\
\hline Contribución a chi-cuadrado & 1,40 & 0,40 & 1,87 & 2,15 & 0,17 & \\
\hline \multicolumn{7}{|l|}{ Nivel 5} \\
\hline Frecuencia observada & 7 & 2 & 5 & 0 & 0 & 14 \\
\hline Porcentaje de fila & $50,00 \%$ & $14,29 \%$ & $35,71 \%$ & $0,00 \%$ & $0,00 \%$ & $5,93 \%$ \\
\hline Frecuencia observada - esperada & 1,48 & $-1,92$ & 1,26 & $-0,77$ & $-0,06$ & \\
\hline Contribución a chi-cuadrado & 0,40 & 0,94 & 0,43 & 0,77 & 0,06 & \\
\hline Total columna & 93 & 66 & 63 & 13 & 1 & 236 \\
\hline & $39,41 \%$ & $27,97 \%$ & $26,69 \%$ & $5,51 \%$ & $0,42 \%$ & $100,00 \%$ \\
\hline
\end{tabular}

Estadístico $\chi^{2}=30,030$; Grados de libertad $=16$; P-valor $=0,018$ 


\subsection{Resumen y comentarios}

El nivel de tecnología que existe en la producción hortícola española en invernadero es función de:

- Una situación ajena a la explotación, condicionada por los mercados, precios, globalización, competencia directa, especialmente de los países mediterráneos, y evolución en la calidad y seguridad sanitaria de los alimentos exigida por los consumidores. Todo ello repercute en unas perspectivas en los precios que determinan las expectativas empresariales $\mathrm{y}$, por tanto, la disposición del empresario a realizar inversiones.

- Una situación relacionada directamente con las características propias de la explotación, entre las que cabe considerar: la edad de los propietarios, si existe sucesión en la explotación, la extensión de la explotación y el nivel tecnológico con el que el agricultor está dispuesto a trabajar.

- En las diferentes áreas también es importante, respecto a la oferta de tecnología, la existencia abundante de suministros, de empresas especializadas con técnica solvente para mecanismos, montajes y mantenimiento, y el nivel alcanzado por las empresas de asesoramiento.

- También sobresale la existencia de unas estructuras comerciales bien desarrolladas, a nivel de mayoristas (cooperativas y SAT, alhóndigas y otros mayoristas), con proporciones variables en las tres zonas; esta facilidad de entrada en los canales comerciales es muy útil a efectos de la seguridad en las inversiones.

De la documentación existente sobre la evolución temporal de la tecnología, se deducen implantaciones rápidas en los primeros años pero, 
actualmente, con una visión completa de los resultados del análisis realizado, se detecta una cierta lentitud. Por ejemplo, se reduce al $6 \%$ la proporción de las explotaciones con tecnología más completa en los invernaderos, aceptando esta situación cuando disponen de estructura bien dimensionada, calefacción permanente, climatización, riego y fertirrigación programados junto a otras dotaciones de elementos también importantes. Incluso hay explotaciones que no han superado el invernadero de madera (7,4\%). Aún permanece el parral clásico en un $24 \%$ de las explotaciones, correspondiendo la proporción mayor al tipo parral modificado, que con frecuencia está más tecnificado, pero con una instalación de bajo coste, es decir, los niveles más bajos de tecnología son los que incluyen conjuntos más numerosos, lo que confirma la lentitud en los cambios. La estructura en multitúnel, idónea para todo tipo de mejoras y equipamiento, sólo alcanza una proporción del $11,2 \%$.

Respecto a la mecanización del invernadero (material móvil y auxiliar de tratamientos y recolecciones), si se tiene en cuenta la información resultante del total de las explotaciones, se le puede atribuir un nivel relativamente bajo. Es muy escaso el uso de raíles, carretillas elevadoras y tratamientos fitosanitarios automatizados. Cabe admitir que en la generalización de la mecanización con material móvil queda un amplio camino por recorrer cuando, por otra parte, las inversiones en este capítulo no son elevadas e inciden decisivamente en la eficiencia de la mano de obra.

Por ser el agua un factor limitante, en el riego y en la fertirrigación es donde se han realizado más inversiones para elevar el nivel de tecnología; por tanto, es la actuación a la que otorgan los agricultores una preferencia mayor.

El enarenado, modalidad de cultivo en invernadero propia de Almería, constituye un sistema productivo muy arraigado, no sólo en cuanto a las características de la producción, sino también por la amplitud de superficie y especialización de servicios. No se le suelen asignar las 
estructuras que se consideran más completas ni la calefacción. Un sistema así es estable y con resistencia a los cambios.

Examinando las actitudes de los empresarios hacia el cultivo en sustrato podría deducirse que actualmente hay un escaso margen de crecimiento puesto que sólo un $27,7 \%$ lo considera importante o imprescindible, proporción que sólo supera en un 5,7\% a la proporción de empresarios que lo han instalado. Para un posible aumento en la aceptación de esta técnica por un número mayor de empresarios, se precisa actuar más en la transferencia de tecnología sobre un $47 \%$ de propietarios que sólo la consideran "una técnica más", sin distinguirla en su opinión. Un aspecto muy positivo para la difusión del cultivo en sustrato es la opinión de los agricultores que la han adoptado, que ha resultado ser claramente satisfactoria en un $51 \%$ e indiferente, sin rechazo, en un $29,3 \%$.

En relación con la disposición hacia las inversiones hay una actitud empresarial bastante favorable a la aceptación del riesgo propio del endeudamiento. Respecto a las fuentes de financiación, en primer lugar figuran los bancos y cajas rurales o de ahorro. La opción de emplear recursos propios es importante y afecta al $56,6 \%$ de los propietarios, lo cual indica una elevada proporción de explotaciones donde es importante el ahorro familiar. Las cajas rurales tienen una relación muy directa y próxima, tanto en las funciones financieras como en las de asesoramiento técnico.

No parecen favorables, dentro de la evolución tecnológica de esta actividad, los resultados de la cuestión sobre la intención de modificar el invernadero por parte de los propietarios, dado que sólo un $10 \%$ están dispuestos a una modificación inmediata, y un 35\% a medio o largo plazo, mientras que el $50 \%$ no tiene intención de efectuar mejoras. Ya se ha visto que estas contestaciones mantenían una relación directa con la existencia de sucesión y a su vez, la relación no es significativa con la edad del empresario ni el tipo de invernadero disponible.

Se ha evidenciado la aptitud del análisis cluster para establecer niveles tecnológicos en grupos de invernaderos de los sistemas agrarios 
estudiados. La formación de grupos con sus niveles tecnológicos, por medio de un procedimiento matemático como el cluster, tiene la ventaja de distinguir las características de cada uno, los elementos que los integran con la distribución por porcentajes y, además, la posibilidad de conocer la evolución de la tecnología por niveles, y cuáles son los componentes a los que los empresarios dan prioridad en la instalación y se van agregando para pasar de un nivel a otro superior. En la formación de los grupos se detecta que, respecto a sus componentes, no forman compartimentos estancos, sino que hay elementos que figuran en proporciones variables en más de un nivel o en todos.

Con los niveles establecidos, la tecnología va en orden creciente en las dos modalidades. Normalmente, los grupos de cultivo en sustrato debieran tener una dotación tecnológica mayor, pero esta hipótesis sólo se cumple con el nivel 5; el nivel 3 , en la mayor parte de elementos e instalaciones tiene mejor dotación que el nivel 4. Parece evidente que en el nivel 3 se incluyen los agricultores que están dispuestos a tener instalaciones de buen nivel, pero sin adoptar el cultivo en sustrato.

Respecto a la relación de los niveles tecnológicos con la edad de los agricultores, no se ha deducido el resultado que se esperaba, ya que no se ha manifestado la dependencia entre las dos variables, cuando parecería lógico que los niveles más elevados se correspondieran con agricultores más jóvenes.

En cuanto al comportamiento de los agricultores en el momento de decidirse por un nivel de tecnología en relación con su disposición al endeudamiento, existe una tendencia a la inversión en los niveles más bajos de tecnología en los que su disposición es baja; en cambio, cuando la disposición es alta o muy alta, no se han inclinado por los niveles 4 y 5 que corresponden al cultivo en sustrato.

Las mallas antiinsectos no marcan diferencias entre los niveles puesto que su instalación afecta a la totalidad de los invernaderos, con excepción de los que están recubiertos de malla. A pesar de que las mallas 
reducen la ventilación, y es un elemento más a tener en cuenta en el manejo, se han considerado imprescindibles para el control biológico, especialmente en los últimos años cuando se impone la reducción de plaguicidas, las prácticas de la producción integrada y la introducción de la producción ecológica.

La proporción de invernaderos con calefacción es relativamente baja, y sólo alcanza porcentajes elevados en los niveles 3 y 5 que comprenden el $12 \%$ del total de la muestra. Predomina la calefacción de agua, en la que hay mayor proporción de calefacción permanente; la calefacción por aire suele ser puntual y de apoyo.

Una visión global de los elementos que favorecen el control climático (mallas de sombreo, pantallas, nebulización y desestratificadores) muestra sus reducidas proporciones, lo que induce a pensar que el conjunto de titulares de explotaciones de invernaderos no ha encontrado una clara y eficaz justificación económica a la instalación de estos elementos, que deberá relacionarse con las posibilidades de repercusión en la calidad de los productos y en el calendario de venta. No obstante, en las condiciones actuales, hay una manifiesta necesidad de incrementar la calidad mejorando el control climático de los invernaderos lo que implica un aumento de su nivel tecnológico (Castilla, 2005).

Para estimar los factores predominantes que afectan al proceso de adopción, o que han sido elegidos con más frecuencia, se han relacionado dichos factores con los cinco niveles tecnológicos obtenidos.

Con el análisis de las variables elegidas como primera opción se obtuvieron resultados significativos para:

- Vías de obtención de la información inicial.

- $\quad$ A través de quién se ha formado.

- Quién le asesora en los problemas técnicos. 
A través del estadístico chi-cuadrado se ha probado la existencia de una relación entre los niveles tecnológicos y cada una de las variables analizadas separadamente con niveles de significación elevados.

Respecto a la primera variable, el resultado sobre las fuentes de información inicial ha dado un predominio total a otros agricultores $y$ familiares, y a gran distancia de técnicos de cooperativas. En la segunda variable el orden fue parecido.

En cuanto a las fuentes de asesoramiento el orden es diferente de los dos casos anteriores; se le concede el primer lugar a los técnicos de cooperativas, y a continuación figuran los proveedores y los técnicos independientes en proporciones muy cercanas.

Las variables tomadas en segunda opción no resultaron significativas y tampoco las opciones de Internet, revistas y centros de investigación.

Sorprende la escasa influencia que los agricultores han atribuido a las Oficinas de Capacitación Agraria en la transferencia de tecnología. 



\section{Capítulo V}

\section{Evolución hacia niveles}

superiores de tecnología: el cultivo

en sustrato 



\section{Capítulo V. Evolución hacia niveles superiores de tecnología: el cultivo en sustrato}

Como ya se ha indicado en el Capítulo IV, una vez distribuido el conjunto total de invernaderos de la muestra en sus niveles tecnológicos, el nivel 5, que presenta mayor dotación, corresponde al cultivo en sustrato; también está bien dotado el nivel 3, que aún mantiene el cultivo en suelo; y respecto al nivel 4, aunque lleva sustrato, no es frecuente en éste el uso de la calefacción.

El salto técnico y económico que representa la implantación del cultivo en sustrato es muy elevado pero en esta actividad, cuando se eleva la capitalización en equipo y tecnología, el beneficio marginal del capital es inferior al que se produce en los niveles más bajos. No obstante, para mantener una posición competitiva basada en mejores rendimientos y condición comercial de los productos, son precisas mayores inversiones en el equipamiento, al que ha de acompañar la existencia de técnicas de producción solventes y una comercialización ágil con canales bien establecidos.

Con la información reseñada en el Capítulo IV, se puede deducir que hay una gran variabilidad en la tecnología de los invernaderos hortícolas españoles y, sobre todo, un predominio de los grupos de tecnología más elemental, por lo que es urgente su mejora y reconversión cuando, por otra parte, la rentabilidad en las explotaciones presenta una tendencia descendente por la disminución de los precios.

El desarrollo de este capítulo, se va a centrar en analizar la actitud de los titulares de explotaciones con invernaderos hortícolas hacia la adopción del cultivo en sustrato, con todo lo que implica su implantación, tanto en técnica como en equipamiento. 
Para el desarrollo del capítulo, se ha utilizado la información procedente de la encuesta (Epígrafe 4.4.1) desarrollada para este trabajo a través de las cuestiones que tenían más relación con los objetivos del capítulo.

Como metodología de análisis se han empleado:

- El análisis de componentes principales para la determinación de un número menor de nuevas variables (combinaciones lineales de las anteriores) con la finalidad de resumir la información recogida en las variables originales de las "ventajas e inconvenientes del cultivo en sustrato". A continuación se ha tratado de ver cómo influyen estas nuevas variables, llamadas componentes principales (CP) en la actitud de los agricultores hacia el cultivo en sustrato y en función de las variables no tecnológicas (cultivo, edad, zona, superficie explotación, sucesión y tenencia de sustrato).

- La regresión multinomial ordinal (RMO) con la cual se ha tratado de obtener la importancia que le da el agricultor al cultivo en sustrato en función de las ventajas e inconvenientes que éste presenta.

\subsection{Los cultivos sin suelo. El sustrato}

Cuando las técnicas de cultivo no utilizan suelo natural para el desarrollo de las plantas emplean, con menor frecuencia, el agua como solución nutritiva, o bien un sustrato que retiene el agua y los nutrientes; estas técnicas se denominan cultivo sin suelo. Otro concepto empleado es el de la hidroponía con el cual se designan procedimientos de cultivo sin suelo, en soluciones nutritivas aireadas, o en sustratos artificiales. Las instalaciones de cultivo hidropónico más conocidas son el NFT (Nutrient Film Technique) con su modificación el NGS (New Growing System) en los que se emplea agua recirculante. Hay sistemas hortícolas muy 
especializados a base de bancadas flotantes. La aeroponía no parece que tenga ventajas y se ha extendido menos.

Hoy día, la superficie ocupada por el cultivo en sustrato está estabilizada en torno al $20 \%$ de la extensión total de invernaderos, localizada en Almería, Murcia y Alicante. El crecimiento más importante tuvo lugar a mediados de los 90, y actualmente en Almería se registra una mayor implantación en los invernaderos de reciente construcción debido a que la inversión inicial es menor que en el cultivo en enarenado, elevándose el porcentaje a un $35,4 \%$ de cultivo en sustrato en los invernaderos de dos años o menos (Pérez et al., 2002).

Desde el punto de vista técnico, la adopción del cultivo sin suelo representa una modificación muy drástica para el agricultor, quien deberá tener una adecuada formación y realizar una fuerte inversión en el equipamiento del invernadero, ya que su introducción requiere la utilización de un invernadero más completo en sus componentes.

A la correcta gestión técnica del cultivo en sustrato, también hay que añadir la económica, incluyendo las inquietudes medioambientales que hoy día rigen la producción de alimentos (Fernández-Zamudio et al., 2006a).

A lo largo del capítulo se van a considerar cultivos en sustrato a los que se desarrollan sobre lana de roca, perlita y fibra de coco, que son los tres más importantes. Además de la arena, que fue el primer sustrato utilizado, se emplean también mezclas de turbas y con el debido estudio y adaptación, es posible el cultivo en muy variados productos y subproductos.

La implantación del cultivo en sustrato supone liberarse de la necesidad de aplicar desinfectantes en el suelo y, en este sentido, parecía una opción casi imprescindible, cuando se planteó la prohibición del uso del bromuro de metilo desde el año 2005.

No obstante, a partir de las experiencias realizadas se han ido obteniendo soluciones para cultivar en suelo natural, con empleo de técnicas de solarización, sola o incluyendo productos químicos y materia 

orgánica, o la incorporación al suelo de plantas para abono en verde. Entre las alternativas de naturaleza química se ha empleado el Telone C-35, que es muy efectivo. En general, lo aconsejable es alternar sobre una parcela diversos procedimientos de desinfección, y últimamente, se van encontrando soluciones efectivas con plantas injertadas.

De momento, para los productores que cultivan en suelo, las alternativas químicas como el Telone C-35, y otras que se van aplicando como las formulaciones a base de 1,3 dicloropropeno y cloropicrina son las de mayor sencillez y seguridad, con independencia de su coste, si bien el riesgo que presenta la dependencia de las técnicas basadas en productos químicos es la amenaza de su prohibición por parte de la UE. Desde que se anunció la prohibición del Bromuro de Metilo y, aunque se han encontrado productos químicos que lo han sustituido, continuamente se plantea la cuestión de si el agricultor se inclinará por el cultivo en sustrato eliminando así la dependencia del suelo. A esta cuestión se tratará de dar respuesta a partir de la encuesta realizada para este trabajo.

\subsection{Características del cultivo en sustrato}

Los efectos técnicos y económicos derivados de la implantación del cultivo en sustrato no pueden contemplarse aisladamente considerando sólo la técnica en sí misma, sino que es preciso analizar también las consecuencias debidas al resto de los elementos que configuran el invernadero y que forman un paquete tecnológico, casi siempre más completo y de mayor complejidad que en el cultivo en suelo. Se habrá de atribuir a todo el conjunto las inversiones necesarias, los cambios en la tecnología de su utilización y los resultados en rendimientos y calidad.

Las principales ventajas que presenta el cultivo en sustrato con la tecnología asociada, son las siguientes:

- Rendimientos más elevados, que se derivan no sólo del mayor desarrollo de las plantas con condiciones de cultivo más 
controladas; también tiene importancia la amplitud del periodo de cultivo. Por ejemplo, en el pimiento, con experiencias en cuatro tipos de invernaderos en los que se controlaban las cantidades y la fecha de recolección, el calendario de venta de los productos en el cultivo en sustrato superó en tres meses a los cultivados en suelo (Fernández-Zamudio et al., 2008). Si se trata del tomate, el periodo de cultivo se alarga considerablemente, incluso con la ventaja de poder efectuar entreplantado para reducir las semanas improductivas.

- La calidad de los productos obtenidos es más elevada, si se tiene en cuenta la condición comercial, calibre, forma, uniformidad de tamaño y brillo. Existen vías de comercialización y países donde se considera que los productos procedentes del sustrato aportan mayor seguridad alimentaria, una condición que ha llegado a ser obsesiva por parte de minoristas y consumidores.

- Se pueden planificar las ventas con calendarios de recolección que tengan más en cuenta la elevación de precios atribuible a la precocidad que se logra con mayor facilidad dada la mayor calidad y dotación del invernadero que puede incluir diversos niveles de calefacción.

- El cultivo efectuado sin desinfectantes del suelo tiene buena imagen, y más aún después de toda la literatura negativa vertida sobre el bromuro de metilo.

- Como consecuencia de la mejor calidad y equipamiento de los invernaderos, es posible llevar a cabo diversas formas de Producción Integrada o Certificada. Indicando que en las zonas donde se desarrolla este estudio, se están consiguiendo elevados niveles en el control biológico con la utilización de mallas y empleo de fauna útil. 
- La eficiencia del empleo de los factores de producción es muy superior a la del cultivo en suelo; ciertamente, se emplean mayores cantidades de insumos por hectárea, pero esta técnica, más perfecta en el manejo, repercute en un consumo menor por unidad producida. En el empleo del nitrógeno, la reducción estimada es del $20 \%$ respecto a cultivos al aire libre o en invernadero con suelo natural. Si se consigue un nivel elevado en el reciclaje de las soluciones, para lo que presenta más facilidad el tomate, el ahorro de fertilizantes puede superar el $40 \%$.

- El volumen de agua de riego por unidad producida desciende significativamente. Así, en el tomate la cantidad de agua para producir un kilogramo se reduce en un $34 \%$ respecto al cultivo en suelo y cuando hay posibilidad de reutilización del agua de drenaje la economía puede ser del $40 \%$. La evapotranspiración dentro del invernadero es menor que en el exterior y la lámina de plástico que recubre el sustrato limita la evaporación del agua.

- El empleo de la mano de obra tiene una eficiencia mayor, con más regularidad en su utilización y periodos más amplios. En las operaciones culturales, sobre todo en la recolección, los rendimientos son mayores y la eficiencia se eleva considerablemente cuando el invernadero dispone de raíles y carretillas eléctricas elevadoras.

Entre los principales inconvenientes cabe señalar:

- Inversiones más elevadas por la estructura y dotación del invernadero. Es preciso un suministro continuo de energía eléctrica y se exige una calidad mayor en el agua de riego, lo que obliga en algunos casos a la instalación de desaladoras.

- La preparación técnica de los productores debe ser mayor que en el cultivo en suelo, con una actualización constante, ya que 
cualquier fallo en el manejo da lugar a pérdidas difíciles de evitar.

- La técnica exigible y los capitales utilizados requieren la dependencia de técnicos y empresas de asesoramiento y suministro de las que sí hay disponibilidad.

- Es importante el incremento de residuos y vertidos por los restos de sustratos artificiales, materiales plásticos, agua de drenaje y fertilizantes y desechos de material vegetal. No obstante, la mayor parte de este material tiene fácil reciclaje si el servicio está organizado.

- Si bien la calidad comercial y visual es mayor, para cierto tipo de consumidores los productos hortícolas procedentes de cultivos sin suelo tienen una imagen más bien artificial, aunque este criterio va disminuyendo.

\subsection{Necesidades tecnológicas en el cultivo en sustrato}

La adopción del cultivo en sustrato requiere de instalaciones muy completas en el invernadero de forma que esté asegurado un buen nivel de regulación ambiental en cuanto a temperatura, humedad y ventilación. Es preciso elevar el grado de automatización y control, tanto de la climatización como de los factores de producción, para lo cual la electrónica y la informática ofrecen gran número de soluciones (Caballero y FernándezZamudio, 2006). Ya existe una proporción de instalaciones en las que se puede contemplar el elevado nivel de control y automatización conseguidos, pero la investigación y desarrollo en este punto ofrece posibilidades muy amplias, tendentes al incremento de la gestión a distancia.

En las condiciones de las regiones mediterráneas españolas, un invernadero tipo para la realización del cultivo en sustrato, puede 

considerarse apto con un modelo multitúnel con estructura de acero galvanizado y una altura mínima en la canal de 3,5 a 4 metros y de 5 a 5,5 en el centro. El techo se cubre de film de plástico y los laterales con plástico o PVC; estará dotado de suficiente ventilación lateral y cenital con mallas antiinsectos instaladas. Llevará un sistema de riego localizado con fertirrigación automatizados que se completará con una balsa de regulación.

Cuando se cultiva pimiento, especialmente con variedades exigentes en temperatura, ha de tener instalada una calefacción permanente capaz de mantener la temperatura en un intervalo determinado, que normalmente es de tipo radiativo-convectivo de agua caliente.

Los factores a tener en cuenta en el control ambiental son temperatura, humedad y composición del aire. En la regulación de temperatura resulta imprescindible considerar, en el caso de España, tener en cuenta la reducción de temperaturas máximas.

La regulación de temperaturas mínimas es función de la necesidad de evitar el riesgo de heladas, o mantener la temperatura óptima para el desarrollo de la variedad elegida. Cuando no se dispone de calefacción, se instalan pantallas térmicas y dobles cámaras.

En caso de disponer de calefacción, y debido a los costes que representa el combustible, es preciso reflexionar sobre los objetivos y nivel de temperatura deseado.

\subsubsection{Fertilización carbónica}

La posibilidad de este tipo de fertilización con $\mathrm{CO}_{2}$ es una ventaja derivada de la calidad tecnológica exigida al invernadero, y constituye una de las innovaciones de más interés en invernaderos bien dotados para mantener niveles de $\mathrm{CO}_{2}$ al menos equivalentes a los del aire exterior dado que, con ventilación insuficiente, pueden descender en el interior del invernadero a niveles inadecuados cuando la actividad fotosintética es muy alta. 
Al elevar el nivel de $\mathrm{CO}_{2}$ en el invernadero se consigue un aumento de fotosíntesis y por tanto un crecimiento de la producción, efecto que se observa más claramente en unas especies que en otras.

De todas formas, la excesiva concentración de este gas en el interior del invernadero también puede tener efectos negativos que, según Maroto (2002), serían: el síndrome de hoja corta o enrollado de la hoja en el caso del tomate; la clorosis foliar; la adaptación de las plantas a la sobreconcentración de $\mathrm{CO}_{2}$, puede no generar los incrementos productivos deseados; la inhibición de la fotosíntesis inducida y el aumento del área específica foliar.

El aporte de $\mathrm{CO}_{2}$ puro puede realizarse de forma artificial, programando el momento y la concentración conforme a las necesidades del cultivo. El $\mathrm{CO}_{2}$ también puede proceder del aprovechamiento de los gases de la combustión en los sistemas de calefacción, pero para esto los gases deben estar exentos de componentes nocivos como el azufre, por lo que se deben utilizar como combustible el gas natural, la parafina o el propano. La fertilización carbónica pura tiene como mayor desventaja su coste, ya que es mayor que el de la obtenida después de un proceso de combustión.

El control de la dosificación del $\mathrm{CO}_{2}$ se realiza tomando en consideración las condiciones exteriores de radiación solar y velocidad del viento, así como la apertura y cierre de las ventanas y la humedad relativa del invernadero (Pujante, 2001). No sería lógico, dadas las necesidades de ventilación de los invernaderos mediterráneos, mantener altas concentraciones de $\mathrm{CO}_{2}$; lo deseable sería mantener los niveles existentes en el aire exterior como mínimo ya que, en condiciones de alta actividad fotosintética y ausencia de movimiento de aire, la concentración del $\mathrm{CO}_{2}$ disminuye de manera importante.

Según experiencias desarrolladas en La Mojonera (Almería) por Sánchez-Guerrero (1999), los resultados obtenidos indican que con una concentración de $\mathrm{CO}_{2}$ de 700 ppm con las ventanas cerradas, y similar a la 

existente fuera del invernadero con las ventanas abiertas, la producción de pepino de invierno aumentó entre el 12 y el $26 \%$. En el cultivo de judía de invierno el rendimiento creció el $17 \%$ y en el ciclo de primavera el $12 \%$.

Las opiniones de los técnicos no coinciden en cuanto a las ventajas económicas, especialmente cuando es preciso tener con frecuencia las ventanas abiertas por la necesidad de ventilación. El conocimiento de esta técnica ha sido rápido, no obstante en el caso del tomate su empleo se ha ido reduciendo en los últimos años.

\subsubsection{Recirculación de soluciones nutritivas}

A pesar de que a menudo se señala a los cultivos en sustrato con características desfavorables con respecto a los criterios ecológicos, una de las ventajas en lo concerniente a los cultivos tradicionales es la recuperación de las aguas de drenaje, si el sistema está dotado de bandejas situadas bajo la línea de las bolsas o contenedores del sustrato.

Tanto desde el punto de vista económico como ecológico tiene interés el reempleo para su aplicación a otros cultivos extensivos, o bien recirculando las soluciones, y con el proceso técnico necesario, introduciéndolas de nuevo en el riego del invernadero.

No obstante, la recirculación presenta, fundamentalmente, dos problemas a resolver: que el agua de riego recupere la misma composición inicial y que su estado sanitario sea satisfactorio y esté libre de gérmenes que ofrezcan peligro de infección al cultivo.

En el primer caso, influye decisivamente la calidad inicial de las aguas. En la solución drenada puede subir el nivel de cloro y sodio, con aumento de la conductividad y además necesitar más nutrientes. Cuando se llega a un valor de la conductividad que el cultivo no admite, es preciso prescindir de una parte de las aguas de drenaje o disponer de una desaladora (Sédilot et al., 2002).

El agua de drenaje debe ser canalizada hacia un depósito, para lo cual el suelo ha de tener una pendiente del 5 por 1000, y a continuación, 178 
filtrada e introducida en el circuito cerrado, corrigiendo la composición de forma automatizada. El sistema debe tener sensores de conductividad y $\mathrm{pH}$ y procedimiento de desinfección (Baixauli y Aguilar, 2002).

Además de las dificultades propias de la composición química del agua, los cultivadores estiman que el riesgo sanitario es una de las principales limitaciones para la puesta en marcha del reciclado. Para evitar el riesgo de infecciones se recomiendan diversos procedimientos de desinfección, entre los que se incluyen: La termodesinfección, radiación ultravioleta, ozonización, desinfecciones con productos químicos y la biofiltración.

La termodesinfección es eficaz, pero es el procedimiento más caro. La biofiltración está dando resultados satisfactorios, dependiendo de los microorganismos a eliminar, y tiene buena consideración desde la óptica medioambiental.

Las causas de que no se hayan generalizado instalaciones completas de reciclado tienen en muchos casos respuestas sencillas: no parece fácil y no se ve rentable por parte de los empresarios; no hay incentivo económico, puesto que la producción no aumenta recirculando. Por otra parte, aunque en el agua y los fertilizantes han subido los precios, no son tan elevados como para que resulte atractivo el ahorro y la reutilización de los drenajes. En resumen, no es previsible que la situación cambie salvo por exigencias de la legislación. Por otro lado, es difícil una ley que obligue a reciclar la solución lixiviada precisamente a los cultivos sin suelo, cuando no existen apenas limitaciones en el cultivo en suelo natural.

En situación experimental y con instalaciones de dimensión aceptable, varios autores han desarrollado trabajos sobre recirculación en España. Entre estos mencionamos el de Lorenzo et al. (2000) en el que se plantea la recirculación en cultivo de pepino. Los autores indican que el sistema de reutilización tiene viabilidad técnica, con una producción similar al sistema de drenaje libre disponiendo de agua con CE de $0,4 \mathrm{mS} \mathrm{cm}^{-1}$. 
En la obra de Marfá (2000) se expone un detallado análisis económico para un cultivo en sustrato de flor cortada con recirculación, aplicando el análisis de inversión, en un invernadero de $560 \mathrm{~m}^{2}$. El autor concluye que la rotación clavel-gerbera en cultivo sin suelo, con recirculación, es económicamente viable.

\subsection{La adopción del cultivo en sustrato con la tecnología asociada. Planteamiento del análisis}

Como se ha indicado en el Capítulo II, apartado 2.1., cuando la innovación tiene lugar a través de la introducción en el aparato productivo de nuevos elementos (por ejemplo pantallas térmicas), máquinas (p.e., desestratificadores) o sistemas de funcionamiento (p.e., fertirrigación) la adopción puede ser gradual, si se van agregando en diferentes periodos de tiempo elementos que perfeccionan el manejo del invernadero, o drástica, en cuyo caso el cambio en la actividad productiva es total y la inversión es de gran alcance.

Cuando el titular de la explotación toma la decisión de introducir el sustrato puede calificarse de una adopción drástica; no obstante, como la tecnología que le acompaña presenta cierta complejidad y es difícil llegar a un alto grado de perfección, normalmente a esta adopción drástica le sucede un amplio periodo de adopción gradual. La decisión del cambio a sustrato es muy radical, en la medida que se deja de depender del suelo con la amplitud de sus funciones, y hace falta una elevada inversión, lo que en conjunto para el empresario representa elevar los niveles de riesgo.

En las tres áreas estudiadas, parecía una aventura iniciar esta actividad a mediados de los años 80 , pero a principios de los 90 ya tuvieron lugar las primeras adopciones e instalaciones experimentales por parte de cooperativas y centros de investigación. Actualmente, en la adopción del cultivo en sustrato, las etapas relativas al conocimiento y valoración real por 
medio de instalaciones próximas están al alcance de cualquier agricultor, además de la existencia de una amplia disposición tanto de técnicos especializados como de empresas.

Una vez expuesta en el Capítulo IV la situación actual de la tecnología en los invernaderos de las tres zonas estudiadas, la finalidad principal de este Capítulo V es el desarrollo de la línea de trabajo planteada en el objetivo cinco, que se identifica con la actitud de los empresarios hacia la adopción del cultivo en sustrato con las variables que afectan al proceso de adopción.

Como corresponde a un trabajo que toma como base los datos obtenidos por encuesta realizada en un periodo de tiempo relativamente breve, se trata de un estudio de sección cruzada, y por tanto, medirá las características de la tecnología existente y las características de la adopción referidas al periodo de la realización de la encuesta.

En relación con la información solicitada en el cuestionario (Anexo 3), y de acuerdo con la finalidad de este capítulo, se incluyeron para su análisis los factores que afectan al proceso de adopción, señalados en el apartado 2.1.4., de los cuales los grupos 1, 2 y 3 comprendían las características del agricultor, los factores económicos y las características de la explotación. En el grupo 4 se agregan los factores que podían incidir en la actitud hacia la adopción del cultivo en sustrato, como son la importancia que el titular le asignaba y la experiencia de su manejo. El grupo 5 lo forman los factores externos de los cuales se han considerado los canales de información y asesoramiento especializados, vías de comercialización de los productos y fuentes de financiación.

El desarrollo de la encuesta se ha descrito en el Capítulo IV, apartados 4.4.1. y 4.4.2., donde se indican los objetivos, zonas elegidas, representatividad y tamaño de la muestra. De la información codificada se han extraído los datos que se consideraban necesarios para la explicación de los aspectos que caracterizan la adopción de tecnología. 
Para el tratamiento de la información se ha elegido como metodología más adecuada el Análisis de Componentes Principales (ACP) y la Regresión Multinomial Ordinal (RMO). Se ha completado la obtención de resultados mediante un análisis bivariante para determinar la relación entre los conceptos de más interés.

El ACP fue realizado con el programa estadístico Statgraphics Plus versión 5.1. y para el RMO se utilizó el SPSS 13.0 para Windows.

El esquema de análisis y resultados es el siguiente:

- ACP. Resultados:

- Relación de las dos primeras CP con variables no tecnológicas.

- Relación de las variables "ventajas del cultivo en sustrato" con variables no tecnológicas.

- Relación de las variables "inconvenientes del cultivo en sustrato" con variables no tecnológicas.

- RMO. Previo cálculo del Coeficiente de correlación por rangos de Spearman. Resultados: Niveles de influencia de las variables "Ventajas e inconvenientes del cultivo en sustrato".

Es preciso hacer hincapié en que la información tratada para los temas de este capítulo, corresponde a respuestas de opinión relacionadas con la actitud de los titulares hacia la adopción del cultivo en sustrato y con su valoración respecto a los factores que le afectan. Así las técnicas de análisis miden las relaciones entre diversas respuestas de opinión, lo que diferencia esta parte del análisis del realizado en el Capítulo IV donde se trataba de variables correspondientes a datos de explotación y a elementos relacionados con el nivel de tecnología del invernadero más tecnificado. 


\subsubsection{Análisis de Componentes Principales: Metodología}

El análisis de componentes principales (ACP), desarrollado por Hotelling (1933), permite examinar la estructura subyacente en el conjunto de variables, con el fin de resumir la información en un número menor de nuevas variables que recojan la mayor parte de variabilidad de las variables originales.

Las nuevas variables, llamadas componentes principales, son obtenidas como combinación lineal de las variables originales de forma que la primera componente principal es la combinación lineal de variables con mayor varianza explicada y la segunda componente principal (con la condición de que sea ortogonal a la primera) explica la mayor parte de variabilidad restante, y así sucesivamente, habiendo tantas componentes como variables.

Por tanto, si partimos de $p$ variables observadas, las condiciones que se han de cumplir son las siguientes (Cuadras, 1996; Jobson, 1992; Pérez, 2001):

- Las componentes $y_{1}, y_{2}, \ldots, y_{p}$ son variables aleatorias con varianzas decrecientes:

$$
\operatorname{Var}\left(\mathrm{y}_{1}\right) \geq \operatorname{Var}\left(\mathrm{y}_{2}\right) \geq \ldots \geq \operatorname{Var}\left(\mathrm{y}_{\mathrm{p}}\right)
$$

- Las componentes $y_{j}$ han de ser ortogonales:

$$
\mathrm{E}\left(\mathrm{y}_{\mathrm{j}}, \mathrm{y}_{\mathrm{j}^{\prime}}\right)=0 ; \forall j \neq j^{\prime}
$$

- Los coeficientes o pesos $u_{h j}$ han de cumplir la restricción:

$$
\sum_{j=1}^{p} u_{h j}^{2}=1 ; \forall j=1,2, \ldots, p
$$

sería:

En general, para $i$ observaciones, la primera componente principal

$$
\mathrm{y}_{1 i}=\mathrm{u}_{11} \mathrm{x}_{1 i}+\mathrm{u}_{12} \mathrm{x}_{2 i}+\ldots+\mathrm{u}_{1 \mathrm{p}} \mathrm{x}_{\mathrm{p} i}
$$



que se obtiene calculando la máxima varianza y cumpliendo las condiciones arriba indicadas. El valor de la $y_{p}$, es decir, el que toma cada uno de los individuos para cada componente, se conoce como "score".

La varianza de la componente $h$ es igual al valor propio de la matriz $\overline{\bar{V}}$ al que va asociada, como se expresa a continuación:

$$
\operatorname{Var}\left(y_{h}\right)=\vec{u}_{h}^{\prime} \overline{\bar{V}} \vec{u}_{h}=\lambda_{h}
$$

La primera componente es la de mayor valor propio. La segunda componente y siguientes se calculan por el mismo procedimiento con la condición de que el vector asociado sea ortogonal al anterior (o anteriores).

El vector propio $\vec{u}_{h}$ asociado a $\lambda_{h}$ define los coeficientes de cada variable en la componente $h$.

La proporción de la variabilidad total que sintetiza una componente se expresa de la siguiente forma:

$$
\frac{\lambda_{h}}{\operatorname{Traza}(\overline{\overline{\mathrm{V}}})}=\frac{\lambda_{h}}{\sum_{h=1}^{p} \lambda_{h}}
$$

La correlación entre las variables iniciales y las componentes viene dada por $r_{j h}=\frac{u_{h j} \sqrt{\lambda_{h}}}{s_{j}}$

En el caso del ACP estandarizado, que se utiliza cuando las variables tienen distintas unidades de medida, la expresión anterior sería:

$$
r_{j h}=u_{h j} \sqrt{\lambda_{h}}
$$

Una condición esencial para aplicar correctamente este tipo de análisis es que todas las variables a analizar tengan una determinada homogeneidad temática y que formen un conjunto susceptible de ser captado mediante unas dimensiones comunes (Díaz de Rada, 2002). Por ello, antes de determinar las variables a incluir en esta pregunta se procedió 
a un análisis de la literatura relevante sobre el tema con el fin de conocer los resultados de investigaciones similares sobre las actitudes de los agricultores hacia la adopción de tecnología o innovaciones.

En cuanto al cuestionario, según Manheim y Rich (1988) las afirmaciones son más útiles que las preguntas, por ello se optó por elaborar una serie de situaciones que responden a las ventajas e inconvenientes del cultivo en sustrato, donde el agricultor ha de mostrar su grado de acuerdo con esas afirmaciones (si le parece poco importante, que sería totalmente en desacuerdo, hasta si lo considera muy importante).

\subsubsection{Resultados del Análisis de Componentes Principales (ACP)}

\subsubsection{Resultados del ACP para las variables "Ventajas" e "Inconvenientes" del cultivo en sustrato}

Las variables que se han considerado en el ACP son las que se recogen en la Tabla 5.1. y se trata de dar respuestas obtenidas sobre las ventajas e inconvenientes de la implantación del cultivo en sustrato. 
Tabla 5.1. Variables utilizadas en el ACP y su identificación

\begin{tabular}{|c|c|}
\hline Variables & Identificación \\
\hline \multicolumn{2}{|l|}{ Ventajas: } \\
\hline Rendimientos (por $\mathrm{m}^{2}$ ) más elevados & A12a_Rd \\
\hline Mayor calidad comercial de los productos & A12b_CaC \\
\hline Más seguridad de obtener buenos resultados & A12c_Se \\
\hline $\begin{array}{l}\text { El periodo de producción y comercialización es } \\
\text { más amplio }\end{array}$ & A12d_Ca \\
\hline Al disponer de mejor instalación: & A12e_CCl \\
\hline \multicolumn{2}{|l|}{-Se controla mejor el clima } \\
\hline -Se aplica mejor el riego & A12f_Ri \\
\hline -Se recolectan más $\mathrm{Kg} / \mathrm{hora}$ & A12g_Rec \\
\hline -Se puede reciclar el agua de drenaje & A12h_Dre \\
\hline $\begin{array}{l}\text {-Teniendo en cuenta que no se podrá usar el } \\
\text { B.Metilo, se evita la desinfección del suelo }\end{array}$ & A12i_EDe \\
\hline $\begin{array}{l}\text { Si además se aplica la lucha biológica se reduce } \\
\text { considerablemente la cantidad de fitosanitarios }\end{array}$ & A12j_RF \\
\hline \multicolumn{2}{|l|}{ Inconvenientes: } \\
\hline Es más caro en todo & A12m_Car \\
\hline Lo veo muy arriesgado & A12n_Arr \\
\hline Es más difícil de manejar & A120_DMa \\
\hline $\begin{array}{l}\text { Se depende de empresas o técnicos que } \\
\text { asesoren }\end{array}$ & A12p_DET \\
\hline
\end{tabular}

Estas variables están medidas en una escala de 1 a 3 , donde 1 significa poco importante, 2 es igual a importante y 3 sería muy importante. Al estar todas las variables medidas en la misma unidad, no es necesario utilizar el ACP estandarizado. 
Al realizar el ACP con las variables de ventajas e inconvenientes del cultivo en sustrato, detalladas en la Tabla 5.1 (Anexo 3, pregunta 12 del cuestionario), se observa que con las dos primeras componentes ya se alcanza una cifra de 49,48 en el porcentaje acumulado de varianza (Tabla 5.2).

Tabla 5.2. Autovalores y porcentaje de varianza de las componentes para las variables ventajas e inconvenientes

\begin{tabular}{cccc}
$\begin{array}{c}\text { Número de } \\
\text { componentes }\end{array}$ & Autovalor & $\begin{array}{c}\text { Porcentaje de } \\
\text { varianza }\end{array}$ & $\begin{array}{c}\text { Porcentaje } \\
\text { acumulado }\end{array}$ \\
\hline 1 & 1,98365 & 29,617 & 29,617 \\
2 & 1,33034 & 19,863 & 49,480 \\
3 & 0,66794 & 9,973 & 59,453 \\
4 & 0,42752 & 6,383 & 65,836 \\
5 & 0,38365 & 5,728 & 71,564 \\
6 & 0,31381 & 4,685 & 76,249 \\
7 & 0,27212 & 4,063 & 80,312 \\
8 & 0,25094 & 3,747 & 84,059 \\
9 & 0,24452 & 3,651 & 87,710 \\
10 & 0,20022 & 2,989 & 90,699 \\
11 & 0,18021 & 2,691 & 93,389 \\
12 & 0,16104 & 2,404 & 95,794 \\
13 & 0,15221 & 2,273 & 98,066 \\
14 & 0,12950 & 1,934 & 100 \\
\hline
\end{tabular}

La componente 1 , con un $29,62 \%$, es la que explica el mayor porcentaje de varianza y le sigue la componente 2 con un 19,86\% de la varianza explicada. Por lo tanto, con estas dos primeras componentes principales en conjunto se explica prácticamente el $50 \%$ de la variabilidad total de los datos y permiten una interpretación clara del resultado.

Las diferencias entre explotaciones debidas a las distintas percepciones por parte de los agricultores sobre las ventajas y los inconvenientes del cultivo en sustrato, corresponden a los resultados recogidos para las dos componentes en la Tabla 5.3. 
Tabla 5.3. Pesos y coeficientes de correlación de las componentes $\mathbf{C} 1$ y C2 para las variables ventajas e inconvenientes

\begin{tabular}{lcr}
\multicolumn{1}{c}{ Variables } & Componente 1 & \multicolumn{1}{c}{ Componente 2 } \\
\hline A12a_Rd & $0,372(r=0,748)$ & $0,028(r=0,047)$ \\
A12b_CaC & $0,432(r=0,800)$ & $0,119(r=0,181)$ \\
A12c_Se & $0,296(r=0,659)$ & $0,158(r=0,288)$ \\
A12d_Ca & $0,265(r=0,603)$ & $-0,010(r=-0,019)$ \\
A12e_CCl & $0,364(r=0,758)$ & $-0,088(r=-0,150)$ \\
A12f_Ri & $0,332(r=0,741)$ & $0,117(r=0,213)$ \\
A12g_Rec & $0,166(r=0,431)$ & $0,145(r=0,309)$ \\
A12h_Dre & $0,278(r=0,584)$ & $-0,002(r=-0,004)$ \\
A12i_EDe & $0,205(r=0,462)$ & $-0,003(r=-0,006)$ \\
A12j_RF & $0,286(r=0,567)$ & $0,024(r=0,038)$ \\
A12m_Car & $0,182(r=0,337)$ & $-0,352(r=-0,533)$ \\
A12n_Arr & $0,016(r=0,028)$ & $-0,567(r=-0,849)$ \\
A120_DMa & $0,069(r=0,123)$ & $-0,586(r=-0,851)$ \\
A12p_DET & $0,081(r=0,177)$ & $-0,357(r=-0,637)$ \\
\hline
\end{tabular}

Así pues, la C1 separa, con valores más elevados, a los agricultores que dan mayor importancia a las ventajas del cultivo en sustrato de los que dan menos importancia a esas ventajas, que aparecen con valores más bajos. Respecto a la C2, figuran con valores más elevados los agricultores que dan menos importancia a los inconvenientes, y con valores más bajos aquellos que dan mayor importancia a esos inconvenientes.

En el Gráfico 5.1. se pueden observar los valores de las componentes principales por cada individuo ("scores"). De este modo, quedarían situados en la esquina superior derecha los agricultores que otorgan una mayor importancia a las ventajas y menos a los inconvenientes del sustrato, que responden a una mentalidad más optimista en este criterio. En la situación opuesta (parte inferior izquierda) están los que se manifiestan más preocupados por los inconvenientes y le dan menos valor a las ventajas, una posición pesimista y poco inclinada a los cambios.

Las otras dos situaciones más distantes entre sí, serían los agricultores que dan mayor valor a las ventajas y mayor valor a los inconvenientes, que se sitúan en la parte inferior derecha; y en la posición opuesta (la parte superior izquierda), estarían los que dan poca importancia 
a las ventajas y a los inconvenientes, postura que no es optimista pero sí equilibrada, propia de los que son más cautos a la hora de efectuar modificaciones e invertir.

El Gráfico 5.1, en el que se contempla la situación de los scores de las explotaciones encuestadas, muestra un estado de total diseminación sin que existan concentraciones que rompan la homogeneidad de la distribución; únicamente se aprecia una mayor inclinación de la población hacia el vértice que indica la posición menos inclinada a los cambios.

\section{Gráfico 5.1. Diagrama de dispersión}

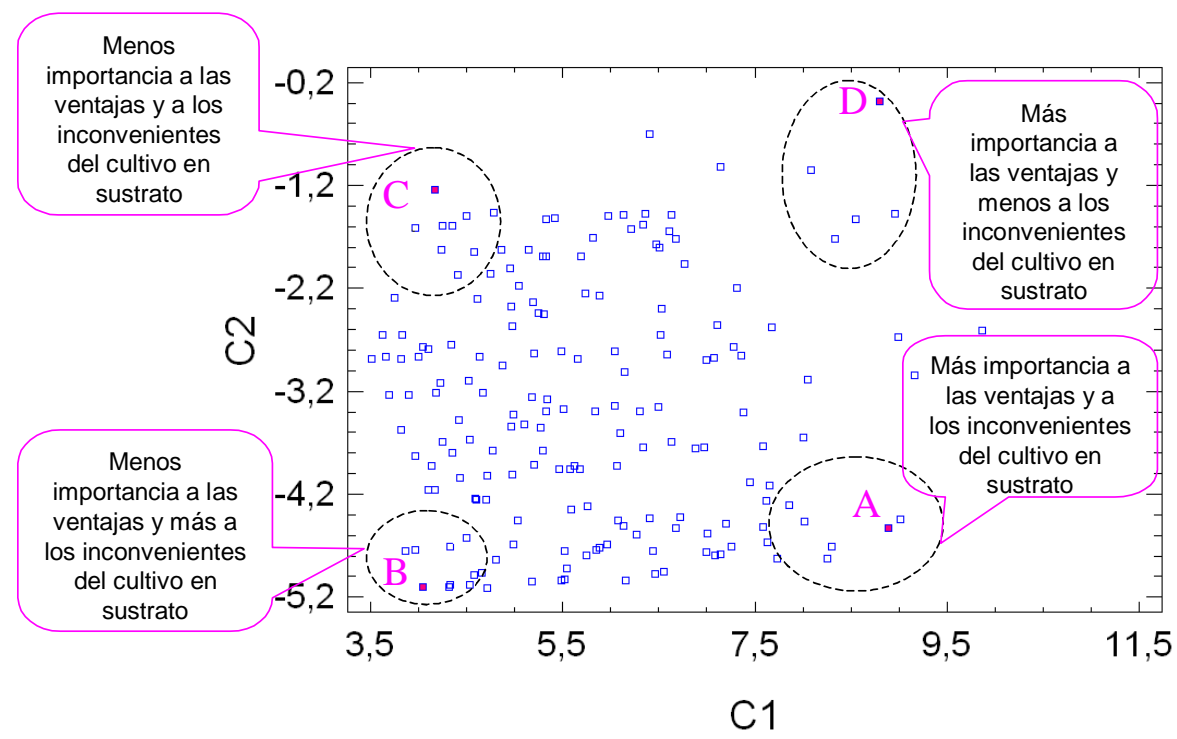

Si el Gráfico 5.1 se divide en cuatro cuadrantes, cada uno comprendiendo un vértice del rectángulo formado, se obtiene la proporción de explotaciones situadas en cada cuadrante, que se recoge en la Tabla 5.4 . 
Tabla 5.4. Proporción de explotaciones según la apreciación de los titulares respecto a las ventajas e inconvenientes del cultivo en sustrato

\begin{tabular}{lcc}
\hline \multicolumn{1}{c}{ Descripción del cuadrante } & $\begin{array}{c}\text { Número de } \\
\text { explotaciones }\end{array}$ & $\%$ \\
\hline Menos importancia a las ventajas y a los inconvenientes & 52 & 21,5 \\
Más importancia a las ventajas y menos a los inconvenientes & 8 & 3,3 \\
Más importancia a las ventajas y a los inconvenientes & 15 & 6,2 \\
Menos importancia a las ventajas y más a los inconvenientes & 167 & 69,0 \\
\hline
\end{tabular}

Considerando las explotaciones individualmente, se puede elegir como ejemplo de agricultor que da más importancia a las ventajas del cultivo en sustrato el que se sitúa más a la derecha en el Gráfico 5.1. y señalado como A) que respondió valorando las ventajas y los inconvenientes, en la mayoría de los casos, con las máximas puntuaciones y corresponde a un agricultor con una edad de 45 años del Campo de Cartagena que cultiva pimiento en suelo. El individuo señalado como B) contestó a las preguntas sobre las ventajas con la valoración más baja y los inconvenientes los valoró con la puntuación más alta; corresponde a un agricultor de 51 años, de la zona de El Ejido con un cultivo de tomate en suelo. Los agricultores A y B tienen el mismo modo de cultivo, por lo que la edad, la zona y el cultivo son las características que están influyendo en las respuestas tan diferentes.

El individuo C) sirve de ejemplo de agricultor que da poca importancia tanto a las ventajas como a los inconvenientes; se trata de una persona de 40 años, de El Ejido y con pimiento en sustrato.

Por último, para dar un ejemplo de agricultor que otorga una menor importancia a los inconvenientes, se indica el D) que respondió con la valoración más alta, en general, para las ventajas y con la puntuación más baja a todas las preguntas sobre los inconvenientes, tiene 45 años y cultiva pepino en sustrato en la zona de El Ejido. Probablemente dicha respuesta 
se deba a los menores problemas que el pepino presenta en el cultivo en sustrato y a la disponibilidad de agua de calidad en la zona.

Con objeto de determinar si las características de las explotaciones están más o menos relacionadas con estas variables $\mathrm{C} 1$ y $\mathrm{C} 2$, se ha realizado un análisis descriptivo de los "scores" de los individuos en cada componente extraída, considerando el tipo de cultivo, la edad del agricultor, la zona, la superficie del invernadero, si tiene suelo o sustrato y si tiene o no la sucesión asegurada.

Hay que tener en cuenta que la $\mathrm{C} 1$ es la que explica mayor variabilidad, por lo que conviene poner atención en ella en la mayor parte de los casos; la C2 se considera en las situaciones que pueda aportar información relevante.

\section{Tipo de cultivo}

En el Gráfico 5.2, se presentan los diagramas de Caja y Bigotes de la C1 (Gráfico 5.2.a) y de la C2 (Gráfico 5.2.b), frente a los dos niveles de la variable cultivo ("Tomate y pimiento" y "Otros").

\section{Gráfico 5.2. Diagramas de Caja y Bigotes para la C1 a) y para la C2 b) según tipo de cultivo, para ventajas e inconvenientes}

a)

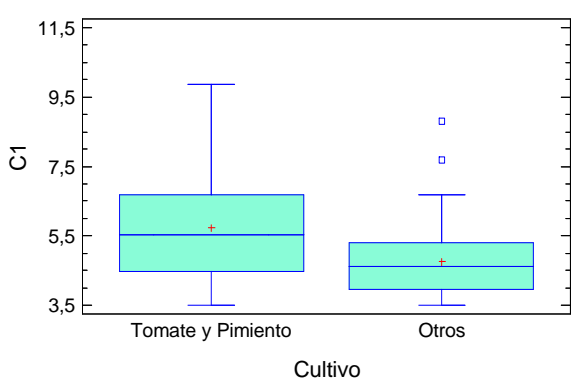

b)

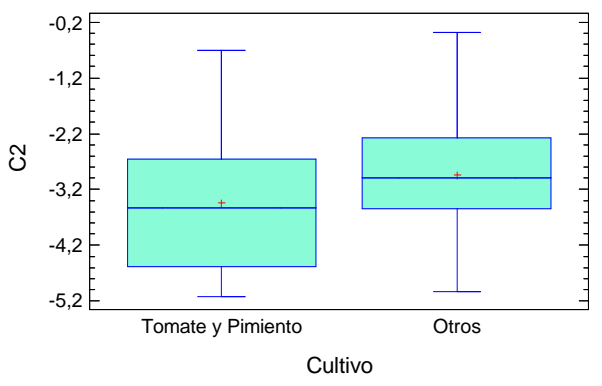

${ }^{1}$ Otros: comprende los cultivos de pepino, calabacín, berenjena, sandía, melón y judía. 
El Gráfico 5.2.a indica que la media en tomate y pimiento es más alta y existe mayor dispersión que en los otros cultivos. Una de las razones por las que los agricultores podrían pensar en una mayor ventaja del cultivo en sustrato para el tomate podría ser porque este cultivo soporta muy bien el agua de conductividad alta, por tanto, admite la reutilización del agua de drenaje, que se puede recircular en los cultivos sin suelo. En el caso del pimiento, es un cultivo que técnica y económicamente responde muy bien a las mejoras tecnológicas que necesariamente acompañan al cultivo en sustrato.

Junto a éste, se presentan los diagramas de Caja y Bigotes para la C2, que indica la importancia de los inconvenientes (Gráfico 5.2.b). Se observa que en los cultivos de tomate y pimiento se da más peso a las ventajas, pero también a los inconvenientes, en comparación a los otros cultivos.

\section{Edad del agricultor}

Tanto la C1 como la C2 (Gráfico 5.3. a y b) presentan valores muy dispersos para la edad de los agricultores; en ambos gráficos, el $87 \%$ de las respuestas pertenecen a titulares de explotación con edades comprendidas entre los 29 y los 59 años. Del grado de dispersión se desprende que la edad no parece decisiva en la valoración de las ventajas e inconvenientes.

Gráfico 5.3. Gráficos de dispersión para la $\mathrm{C} 1$ a) y para la $\mathrm{C2}$ b) según edad, para ventajas e inconvenientes

a)

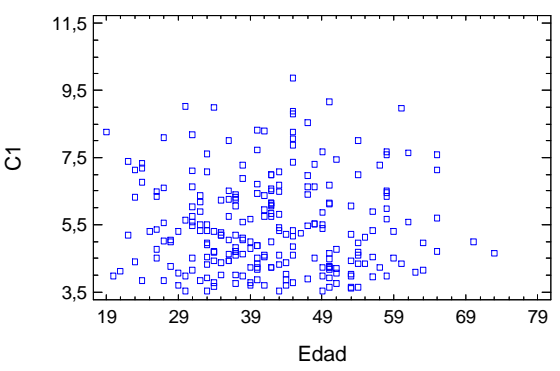

b)

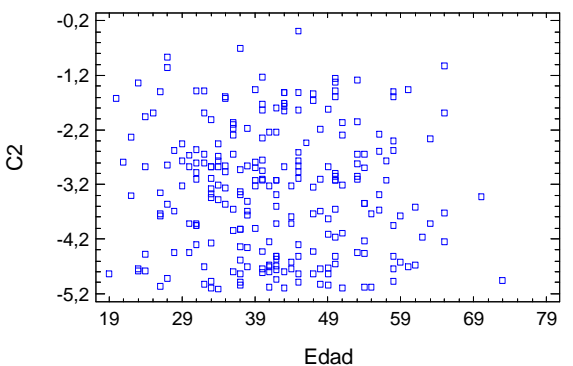


Zona

A priori podría parecer evidente un efecto significativo de la variable zona en relación con la actitud y opinión de los agricultores. Los resultados del Gráfico 5.4, con sus diagramas para ambas componentes frente a los tres niveles de la variable zona (Campo de Cartagena, Valle del Guadalentín y El Ejido) confirman la suposición.

Gráfico 5.4. Diagramas de Caja y Bigotes para la C1 a) y para la C2 b) según zona, para ventajas e inconvenientes

a)

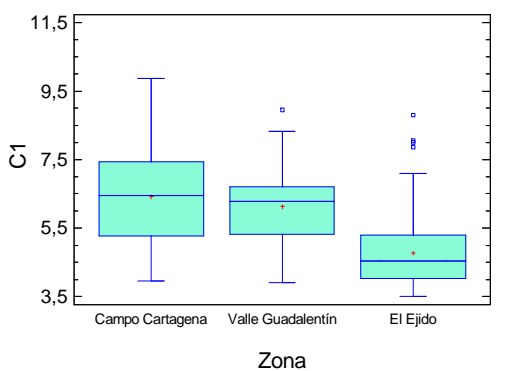

b)

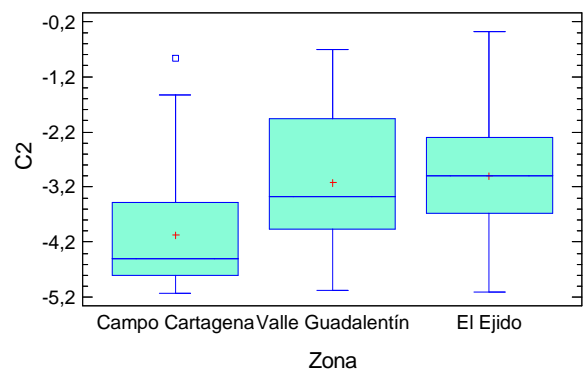

En el Gráfico 5.4.a se observa que la media más alta se registra en el Campo de Cartagena para la $\mathrm{C} 1$, lo que significa que es en esta zona donde se da mayor importancia a las ventajas del cultivo en sustrato. Esto es atribuible a:

- Predominio del cultivo de pimiento, que se trata de una especie más exigente a la que se aporta más capital en las instalaciones y más precisión en nutrientes y calidad del agua.

- También el pimiento tiene una imagen de mejores precios, ya que los descensos acusados de los precios le han afectado un menor número de campañas; por otra parte, este producto retribuye bien las diferencias de calidad que presentan las variedades más exigentes.

- En esta zona es general la opinión de que la producción en sustrato proporciona más calidad y condición comercial. 
- Además, las explotaciones presentan más diversificación, no en especies pero sí en sistemas de cultivo, tipos de invernadero y cultivos al aire libre.

En la zona del Valle del Guadalentín están más especializados en tomate, en el que el sustrato da imagen de aumento de la producción, de alargar el ciclo con más calidad y permitir una mayor reutilización del agua.

En la zona de El Ejido se dan las siguientes condiciones:

- De acuerdo con los calendarios de comercialización por especies, en esta zona siempre han tenido más importancia los periodos de invierno y primavera y menos la tendencia a producir durante largos periodos de la campaña.

- Hay mayor costumbre en alternar cultivos, y es muy general la realización de dos cultivos por campaña.

- Aún con el elevado coste del cultivo en enarenado, el empresario lo emplea y maneja con seguridad. Todo ello se lo proporciona un medio natural (temperatura y luminosidad) y técnico, que le aporta material y servicios suficientes.

- Explotaciones sólo con superficie de invernadero y con una tradición de producción intensiva con su comercialización en bastantes años. La comercialización (alhóndigas y cooperativas) responde bien a ese sistema.

Tanto las condiciones naturales como socioeconómicas proporcionan una clara estabilidad a la forma de cultivo más común en la zona y la introducción del sustrato llama menos la atención.

En el Gráfico 5.4.b se refleja la importancia de los inconvenientes (C2). En este caso, manifiestan mayores inconvenientes en la zona del Campo de Cartagena, a bastante distancia respecto al Valle del Guadalentín y El Ejido. 


\section{Superficie}

El Gráfico 5.5 resultante del análisis no permite deducir la existencia de un efecto importante de la superficie total de invernaderos en la explotación sobre las ventajas o inconvenientes del cultivo en sustrato. Se observa que mayores superficies no corresponden con mayores ventajas 0 inconvenientes.

\section{Gráfico 5.5. Gráficos de dispersión para la $\mathrm{C} 1$ a) y para la $\mathrm{C2}$ b) según superficie, para ventajas e inconvenientes}

a)

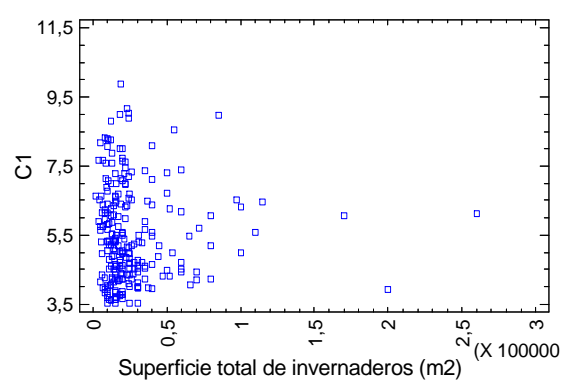

b)

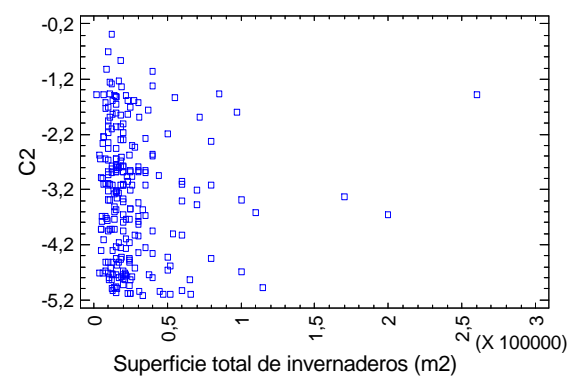

Sucesión

Contrariamente a lo que cabría esperar, la diferencia en las respuestas entre los titulares de explotación con sucesión asegurada y no asegurada es escasa, incluso algo inferior respecto a las ventajas para los que la tienen asegurada, y muy similar en los inconvenientes (Gráfico 5.6). Todo ello significa que la sucesión no está jugando un papel clave en la percepción tanto de las ventajas como de los inconvenientes del cultivo en sustrato, lo que en cierto modo es una contradicción, puesto que las explotaciones con sucesión debieran presentar una tendencia más favorable a la innovación y a las inversiones. 
Gráfico 5.6. Diagramas de Caja y Bigotes para la C1 a) y para la C2 b) según sucesión, para ventajas e inconvenientes

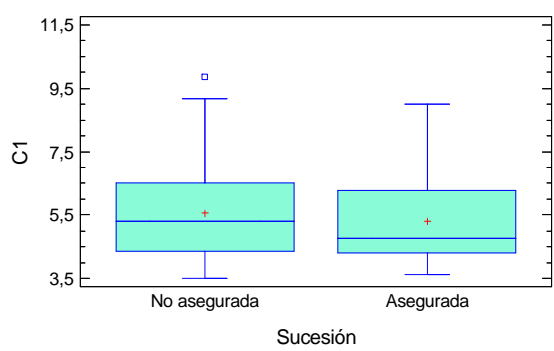

b)

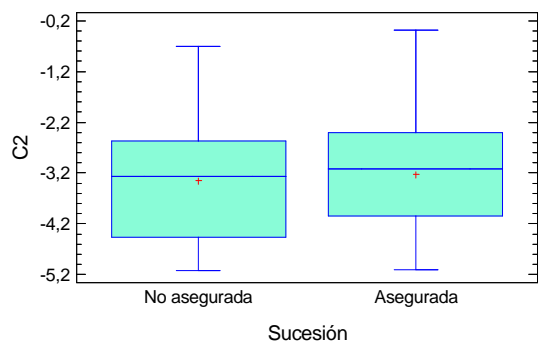

Tenencia de sustrato

El Gráfico 5.7 muestra los diagramas de Caja y Bigotes de la C1 (Gráfico 5.7.a) y de la C2 (Gráfico 5.7.b), frente a la variable sustrato.

Gráfico 5.7. Diagramas de Caja y Bigotes para la $\mathrm{C} 1$ a) y para la $\mathrm{C2}$ b) según tenencia de sustrato, para ventajas e inconvenientes

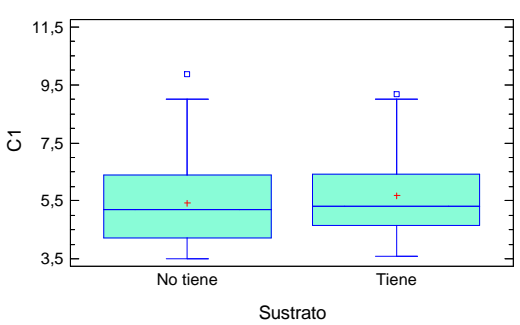

b)

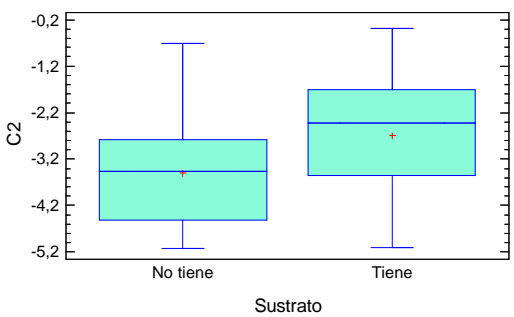

En el Gráfico 5.7.a se presenta cómo valoran los agricultores las ventajas del sustrato según lo tengan o no instalado. El grado de información técnica y económica en el momento de la decisión de cambiar la modalidad de cultivo puede ser similar en los dos conjuntos de agricultores, si bien en los que poseen sustrato parece algo superior, y la opinión sobre las ventajas presenta menos dispersión, porque ya han vivido cierta experiencia. 
La escasa diferencia entre los dos grupos se debe a que la información técnica sobre el sustrato tiene una difusión amplísima por parte de casas suministradoras de material, técnicos de empresas de asesoramiento, técnicos de cooperativas, y las propias cooperativas y alhóndigas, aparte del material gráfico (como revistas y folletos), las demostraciones y experiencias de cooperativas. También juega un papel importante la posibilidad de visitar en cualquier momento los invernaderos con cultivo en sustrato de agricultores vecinos, con la ventaja para esta innovación de estar presentes durante todo el ciclo de cultivo.

El agricultor que no cultiva en sustrato no se ve necesariamente obligado al cambio. La acentuada diferencia de costes entre las modalidades de suelo y sustrato, la relación de precios de productos según calidades y las características de la demanda, no le imponen un cambio tan acentuado hacia un nivel técnico que multiplica por cuatro las inversiones necesarias (Fernández-Zamudio et al., 2006). El cultivador tradicional (sin sustrato) aún tiene asegurados unos niveles mínimos de ingresos con menores riesgos e inmovilizaciones de capital.

En cuanto al Gráfico 5.7.b que presenta los criterios de los agricultores respecto de los inconvenientes que presenta el uso del sustrato, separando los agricultores con y sin sustrato, parece evidente la diferencia de apreciación de uno y otro grupo. El cultivador en sustrato valora esta modalidad con menor grado de negatividad que el cultivador en suelo. En consecuencia, cabe deducir que la experiencia en la gestión de invernaderos con la modalidad de sustrato proporciona a los empresarios menores temores $\mathrm{y}$, por tanto, menor sensación de riesgo para asumir los inconvenientes que se atribuyen a esta modalidad, que la manifestada por los agricultores que no tienen una experiencia directa con el cultivo en sustrato. 


\subsubsection{Resultados del ACP para las variables "Ventajas" del cultivo en sustrato}

Una vez analizadas las variables ventajas e inconvenientes del cultivo en sustrato conjuntamente, se procede a tratarlas por separado. Aquí es donde se centra el máximo interés del análisis, al permitir examinar con mayor profundidad la estructura que subyace a las variables.

En las Tablas 5.5 y 5.6 se recogen los resultados del análisis de las variables correspondientes a las ventajas.

Tabla 5.5. Autovalores y porcentaje de varianza de las componentes para las variables ventajas

\begin{tabular}{cccc}
$\begin{array}{c}\text { Número de } \\
\text { componentes }\end{array}$ & Autovalor & $\begin{array}{c}\text { Porcentaje de } \\
\text { varianza }\end{array}$ & $\begin{array}{c}\text { Porcentaje } \\
\text { acumulado }\end{array}$ \\
\hline 1 & 1,93126 & 43,089 & 43,089 \\
2 & 0,64142 & 14,311 & 57,400 \\
3 & 0,36401 & 8,122 & 65,522 \\
4 & 0,33982 & 7,582 & 73,104 \\
5 & 0,26680 & 5,953 & 79,056 \\
6 & 0,24799 & 5,533 & 84,589 \\
7 & 0,20545 & 4,584 & 89,173 \\
8 & 0,18869 & 4,210 & 93,383 \\
9 & 0,15731 & 3,510 & 96,893 \\
10 & 0,13926 & 3,107 & 100 \\
\hline
\end{tabular}

Tabla 5.6. Pesos y coeficientes de correlación de las componentes $\mathbf{C} 1$ y $\mathrm{C} 2$ para las variables ventajas

\begin{tabular}{lcr}
\multicolumn{1}{c}{ Variables } & Componente 1 & Componente 2 \\
\hline A12a_Rd & $0,379(r=0,752)$ & $-0,191(r=-0,218)$ \\
A12b_CaC & $0,447(r=0,816)$ & $-0,327(r=-0,344)$ \\
A12c_Se & $0,310(r=0,682)$ & $-0,179(r=-0,227)$ \\
A12d_Ca & $0,267(r=0,599)$ & $-0,104(r=-0,134)$ \\
A12e_CCl & $0,360(r=0,738)$ & $0,165(r=0,195)$ \\
A12f_Ri & $0,345(r=0,758)$ & $0,176(r=0,223)$ \\
A12g_Rec & $0,186(r=0,475)$ & $0,153(r=0,226)$ \\
A12h_Dre & $0,279(r=0,580)$ & $-0,405(r=-0,485)$ \\
A12i_EDe & $0,210(r=0,467)$ & $0,531(r=0,681)$ \\
A12j_RF & $0,290(r=0,567)$ & $0,534(r=0,602)$ \\
\hline
\end{tabular}


En la Tabla 5.6 se observa que en la componente 1 existe un mayor peso de las ventajas de los rendimientos por $\mathrm{m}^{2}$ más elevados (A12a_Rd), de la mayor calidad comercial de los productos (A12b_CaC) y de mejor control sobre el clima (A12e_CCl) y la aplicación del riego (A12f_Ri). La primera componente tiene, por tanto, un sentido económico, por un lado, y un sentido de manejo técnico, por otro.

La segunda componente da mayor peso a las variables evitar la desinfección del suelo (A12i_EDe) y, si se aplica la lucha biológica, se reduce la cantidad de fitosanitarios (A12j_RF). En esta segunda componente se separan los agricultores que tienen una mayor concienciación medioambiental de los que tienen menos en consideración los temas medioambientales, como la reducción de la utilización de productos químicos.

\section{Tipo de cultivo}

En el Gráfico 5.8, se presentan en el lado izquierdo los diagramas de Caja y Bigotes de la $\mathrm{C} 1$ frente a la variable cultivo, que tiene dos niveles (Gráfico 5.8.a). Se observa que la valoración media de las ventajas económicas y de manejo técnico del cultivo en sustrato es más elevada en Tomate y Pimiento que para la variable "Otros" que recoge al resto de cultivos. Esta apreciación se puede deber a que el pimiento, al ser un cultivo muy exigente, responde muy bien a las mejoras de manejo técnico que incorpora el cultivo en sustrato; y en el tomate la producción se considera de mayor calidad y mejores condiciones comerciales, y por tanto, aporta ventajas económicas en cuanto al precio de liquidación de la cosecha. 
Gráfico 5.8. Diagramas de Caja y Bigotes para la C1 a) y para la C2 b) según cultivo, para ventajas

a)

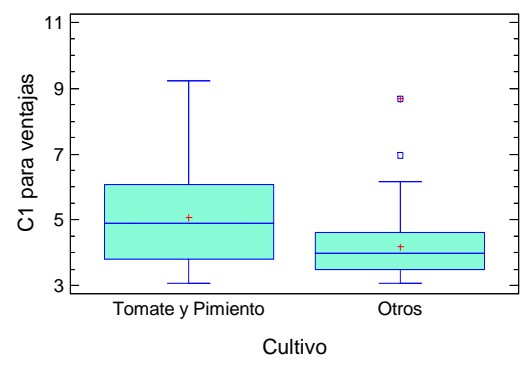

b)

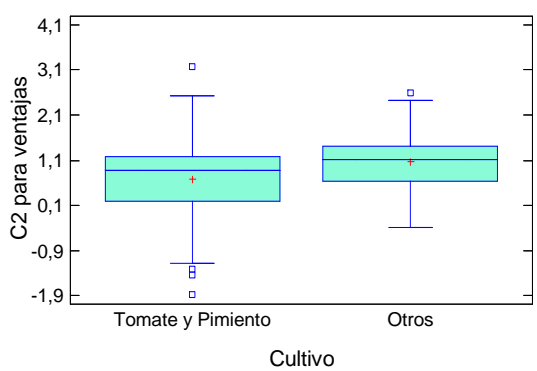

En el lado derecho, se presentan los diagramas de Caja y Bigotes para la $\mathrm{C} 2$, que indican la mayor o menor preocupación medioambiental según el cultivo (Gráfico 5.8.b). No se aprecia apenas diferencia entre las medias de Tomate y Pimiento y de Otros cultivos, aunque sí se registra en el segundo grupo una menor dispersión (tanto en el Gráfico 4.8.a, como en el Gráfico 4.8.b), lo que indica que los agricultores con cultivos diferentes del tomate y pimiento, ya sea en un único cultivo al año o en rotación, tienen una apreciación más parecida entre sí en cuanto a las consideraciones medioambientales, que los cultivadores de tomate y pimiento.

\section{Edad del agricultor}

La manifestación de la influencia de la edad en la apreciación de las ventajas del cultivo en sustrato, se refleja en el Gráfico 5.9 donde se observa que los "scores" se reparten por igual a lo largo de todas las edades. 
Gráfico 5.9. Gráficos de dispersión para la $\mathrm{C} 1$ a) y para la $\mathrm{C2}$ b) según edad, para ventajas

a)

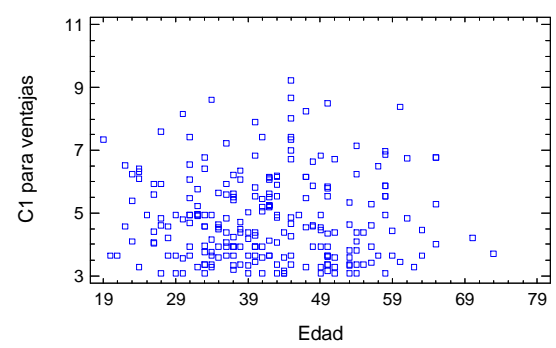

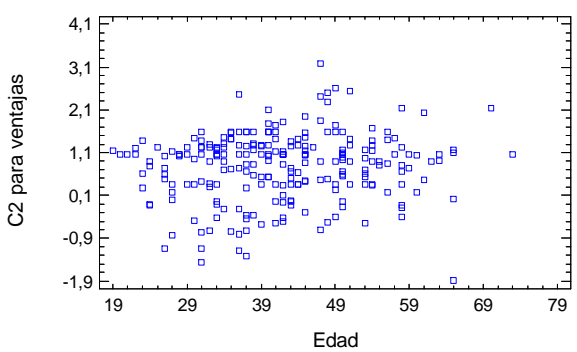

Zona

Como se puede observar en el Gráfico 5.10.a, tanto en el Campo de Cartagena como en el Valle del Guadalentín la valoración media de las ventajas económicas y de manejo técnico del cultivo en sustrato es mayor que en la zona de El Ejido. Sin embargo, en el Gráfico 5.10.b se aprecia una valoración media más alta en cuanto a la preocupación medioambiental en la zona de El Ejido. Al menos en el momento de la encuesta, parece que es mayor la sensibilización de esta zona, lo que puede tener cierta relación con la conocida crisis en la comercialización del pimiento, acontecida en diciembre de 2006, por la aparición de residuos que se debían al empleo de pesticidas no autorizados. Últimamente los productores almerienses se han volcado hacia métodos de cultivo más respetuosos con el medio ambiente, incluyendo la producción con lucha biológica.

En relación con el Campo de Cartagena, la incorporación de la lucha biológica comenzó antes que en la zona de El Ejido y se ha ido efectuando de manera gradual. 
Gráfico 5.10. Diagramas de Caja y Bigotes para la C1 a) y para la C2 b) según zona, para ventajas

a)

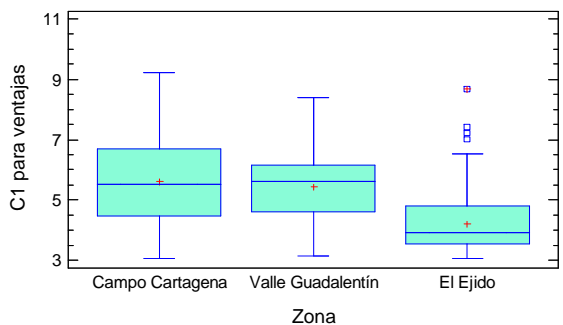

b)

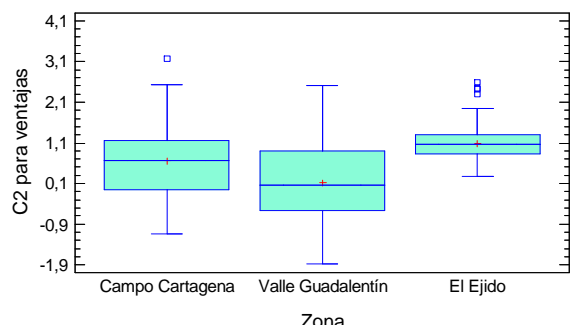

Superficie

No se observa ninguna relación entre los scores correspondientes a cada una de las dos componentes y la superficie (Gráficos 5.11.a y b).

Gráfico 5.11. Gráficos de dispersión para la $C 1$ a) y para la $C 2$ b) según superficie, para ventajas

a)

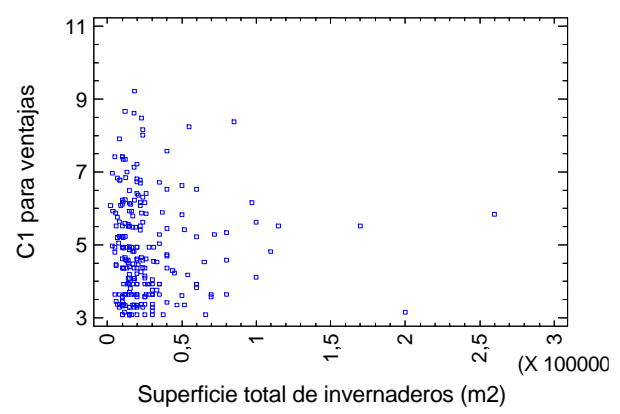

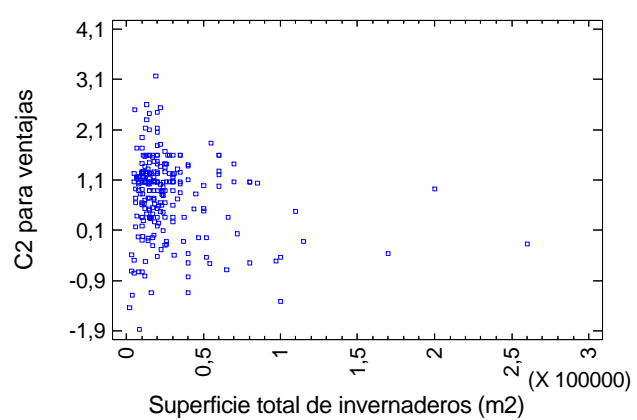

\section{Sucesión}

En el Gráfico 5.12.a se puede apreciar una opinión muy similar en cuanto a las ventajas económicas y de manejo técnico del cultivo en sustrato, según el agricultor cuente o no con sucesión en su explotación. Para la apreciación medioambiental (Gráfico 5.12.b), la valoración media también es muy similar, aunque la dispersión es menor entre los agricultores que tienen la sucesión asegurada. 
Gráfico 5.12. Diagramas de Caja y Bigotes para la C1 a) y para la C2 b) según sucesión, para ventajas

a)

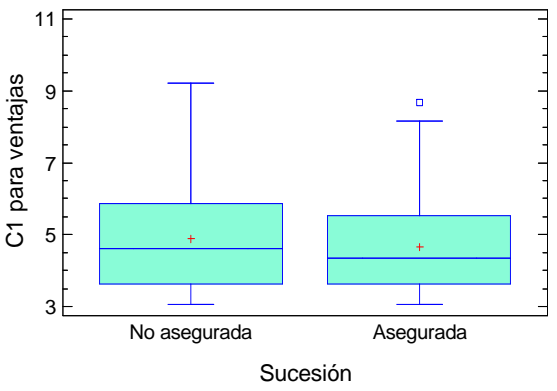

b)

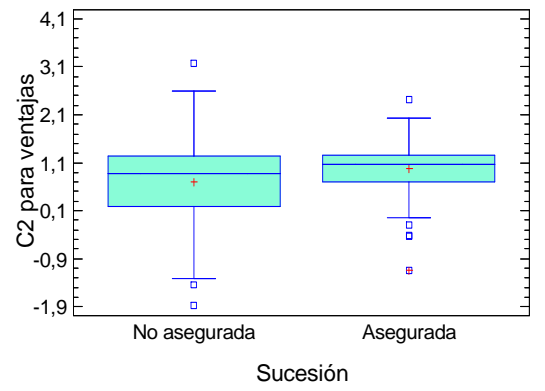

Tenencia de sustrato

La valoración de las ventajas del sustrato en la C1, según tengan ya instalada esta modalidad de cultivo o no, se contempla en el Gráfico 4.13.a donde la media es algo más alta en las ventajas económicas y de manejo técnico entre los agricultores con sustrato, ya que por otra parte, pueden haber sido las razones que hayan motivado a estos agricultores a cultivar sin suelo. El Gráfico 4.13.b muestra la apreciación de las ventajas medioambientales, y no se observan apenas diferencias entre las dos categorías de agricultores, lo que significa que los agricultores sin sustrato no ven mayores ventajas en cuanto a lo medioambiental; sí hay menor dispersión entre los que lo tienen, lo que da a entender que están más de acuerdo en la valoración de las ventajas medioambientales de esta modalidad de cultivo. 
Gráfico 5.13. Diagramas de Caja y Bigotes para la C1 a) y para la C2 b) según tenencia de sustrato, para ventajas

a)

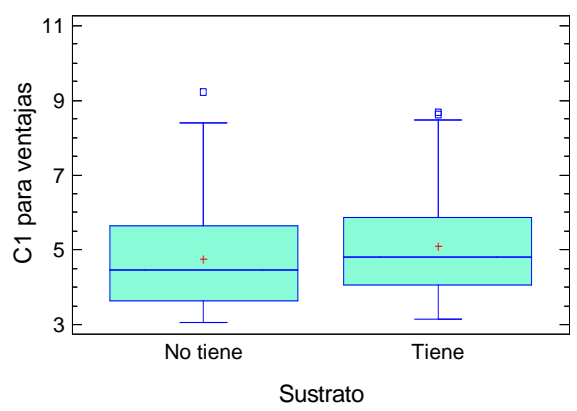

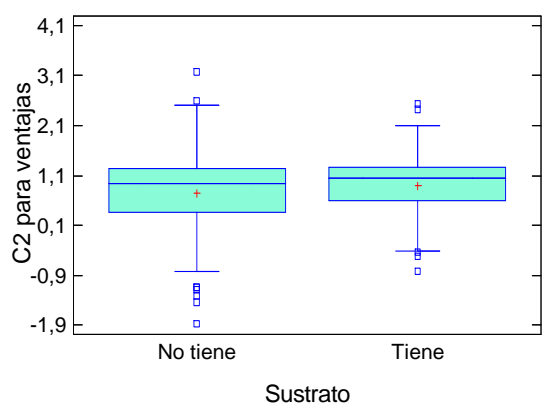

5.4.2.3. Resultados del ACP para las variables "Inconvenientes" del cultivo en sustrato

A continuación se presentan los resultados del análisis de las variables correspondientes a los inconvenientes del cultivo en sustrato. En la Tabla 5.7, se muestran los autovalores, el porcentaje de varianza y el porcentaje acumulado de cada una de las componentes principales.

Tabla 5.7. Autovalores y porcentaje de varianza de las componentes para las variables inconvenientes

\begin{tabular}{cccc}
$\begin{array}{c}\text { Número de } \\
\text { componentes }\end{array}$ & Autovalor & $\begin{array}{c}\text { Porcentaje de } \\
\text { varianza }\end{array}$ & $\begin{array}{c}\text { Porcentaje } \\
\text { acumulado }\end{array}$ \\
\hline 1 & 1,32010 & 59,366 & 59,366 \\
2 & 0,42098 & 18,932 & 78,297 \\
3 & 0,27355 & 12,302 & 90,599 \\
4 & 0,20904 & 9,401 & 100 \\
\hline
\end{tabular}


Tabla 5.8. Pesos y coeficientes de correlación de las componentes $\mathbf{C} 1$ y C2 para las variables inconvenientes

\begin{tabular}{lcr} 
Variables & Componente 1 & \multicolumn{1}{c}{ Componente 2 } \\
\hline A12m_Car & $0,451(r=0,680)$ & $-0,809(r=-0,690)$ \\
A12n_Arr & $0,566(r=0,844)$ & $-0,067(r=-0,056)$ \\
A120_DMa & $0,580(r=0,838)$ & $0,483(r=0,394)$ \\
A12p_DET & $0,374(r=0,665)$ & $0,327(r=0,328)$ \\
\hline
\end{tabular}

En la Tabla 5.8, se recogen los pesos y coeficientes de correlación para las dos primeras componentes principales, las cuales acumulan el $78,33 \%$ de la varianza. Se observa que con la $\mathrm{C} 1$ se identifican las variables "lo veo muy arriesgado" y "es más difícil de manejar" (A12n_Arr y A12o_DMa), mientras que con la componente 2 se asocia negativamente la variable "es más caro en todo" (A12m_Car).

La C1 da mayor peso a las variables que miden la desventaja de que los agricultores lo vean muy arriesgado y más difícil de manejar. Por tanto, esta componente está explicando el nivel de riesgo y de dificultad percibidos en el manejo técnico.

La C2 separa a los agricultores más preocupados por el hecho de que el cultivo en sustrato sea más caro que el cultivo en suelo de aquellos que le dan menos importancia a esta desventaja.

\section{Tipo de cultivo}

En el Gráfico 5.14 a, se observa que para la $\mathrm{C} 1$, en tomate y pimiento la media es más alta que en el resto de cultivos. Esto significa que el nivel de riesgo y de dificultad de manejo técnico del cultivo en sustrato es percibido en mayor medida para los cultivos de tomate y pimiento, aunque con la elevada dispersión resultante, parece débil la coincidencia en el grado de opinión.

En lo que respecta al Gráfico 5.14 b, la media más elevada se encuentra en Otros cultivos, aunque con escasa diferencia comparada con 
Capítulo V Evolución hacia niveles superiores de tecnología: el cultivo en sustrato la media de tomate y pimiento. Por consiguiente, la dedicación de las explotaciones a cualquiera de los mencionados cultivos no influye para considerar más caro el cultivo en sustrato.

Gráfico 5.14. Diagramas de Caja y Bigotes para la C1 a) y para la C2 b) según cultivo, para inconvenientes

a)

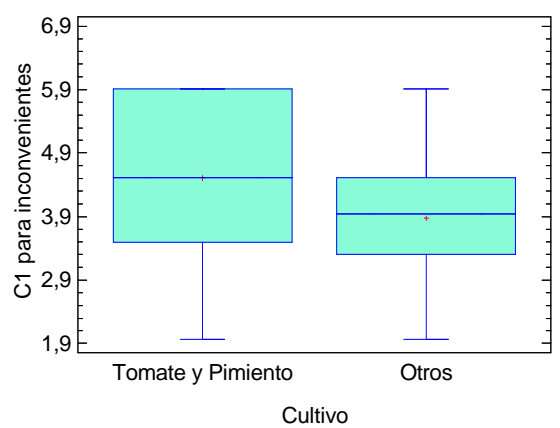

b)

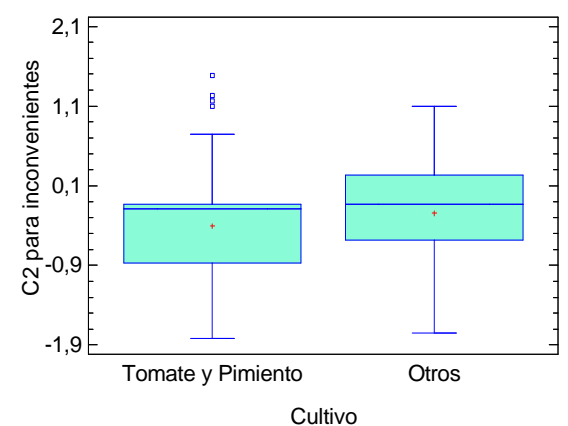

Edad del agricultor

En el Gráfico 5.15 se observa que para las dos componentes las valoraciones de los inconvenientes se encuentran muy dispersas, y por tanto parece que no existe relación entre la edad de los agricultores y los inconvenientes, representados por las $\mathrm{C} 1$ y $\mathrm{C} 2$.

Gráfico 5.15. Gráficos de dispersión para la $\mathrm{C} 1$ a) y para la $\mathrm{C2}$ b) según edad, para inconvenientes
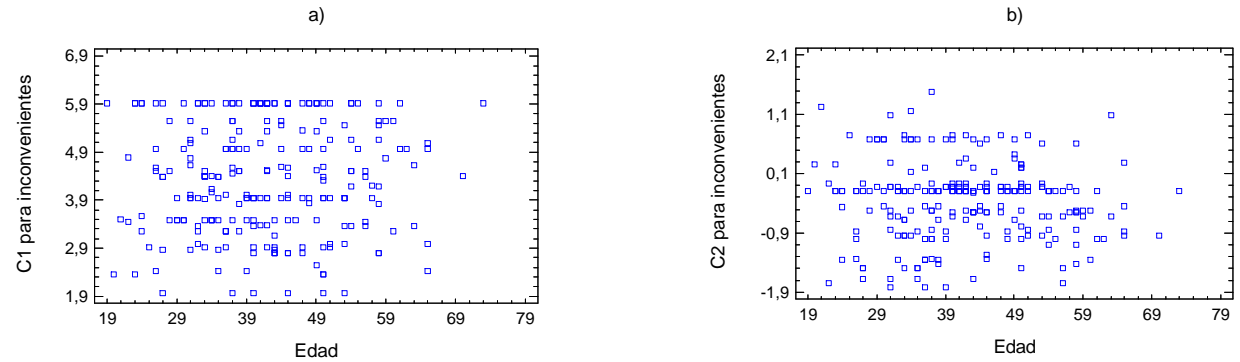
Zona

En cuanto a la valoración de los inconvenientes del sustrato, incluidos en la $\mathrm{C} 1$, según la zona donde se sitúa la explotación, en el Gráfico 5.16.a, se muestra el gradiente de mayor a menor valoración media que aparece entre los agricultores de Campo de Cartagena, Valle de Guadalentín y El Ejido, lo cual no contradice el comportamiento expresado en el Gráfico 5.10 e indica que si en una zona se pueden valorar en mayor medida las ventajas también puede suceder lo mismo con los inconvenientes.

En el Gráfico 5.16.b se distinguen las evaluaciones del inconveniente "es más caro en todo", con diferencias muy escasas entre zonas, y un valor algo más elevado en la de El Ejido. En esta zona, al tratarse de un sistema agrario más antiguo y especializado, es probable que los titulares hayan tenido en cuenta no sólo el elevado importe de la instalación, sino también lo que supone el cambio en los procesos de producción y comercialización.

Gráfico 5.16. Diagramas de Caja y Bigotes para la C1 a) y para la C2 b) según zona, para inconvenientes

a)

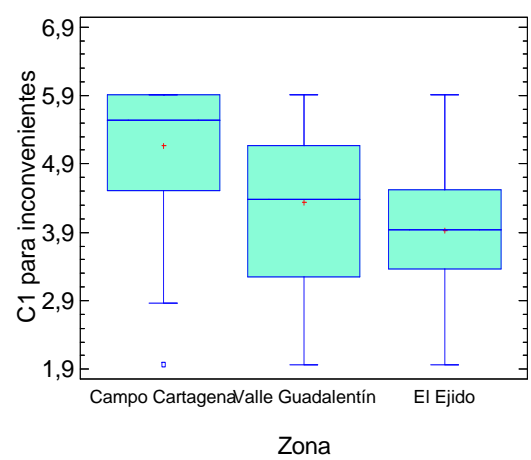

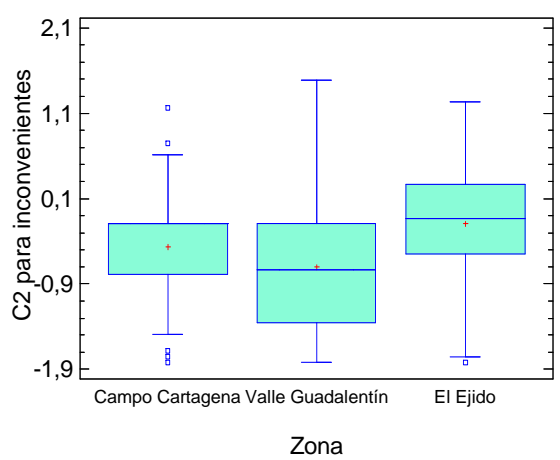




\section{Superficie}

No se encuentra ningún efecto de la superficie de las explotaciones de invernaderos sobre la importancia manifestada con respecto a las ventajas o inconvenientes de cultivar en sustrato (Gráficos 5.17. a y b).

Gráfico 5.17. Gráficos de dispersión para la $\mathrm{C} 1$ a) y para la $\mathrm{C2}$ b) según superficie, para inconvenientes

b)

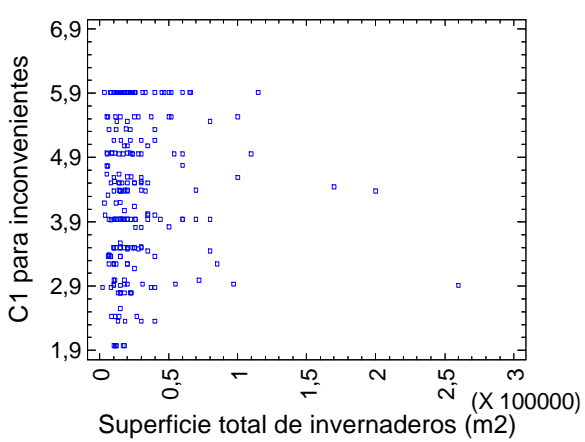

b)

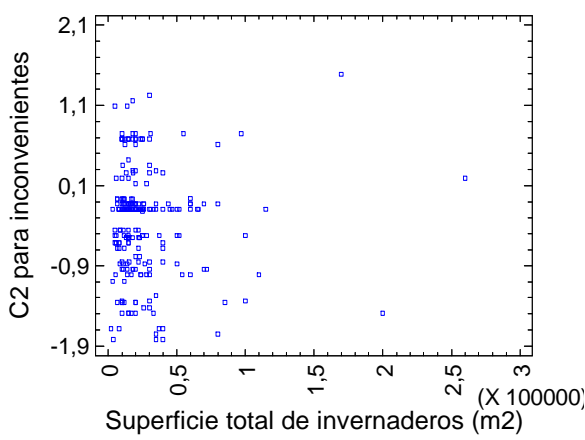

\section{Sucesión}

En la valoración de los inconvenientes para la C1 (Gráfico 5.18.a) presenta un nivel mayor entre los agricultores que no tienen asegurada la sucesión y, aunque la diferencia no es muy acusada, este comportamiento tiene cierta lógica. En cambio los niveles son muy similares para los valores medios de la C2, según el Gráfico 5.18.b. 
Gráfico 5.18. Diagramas de Caja y Bigotes para la C1 a) y para la C2 b) según sucesión, para inconvenientes

a)

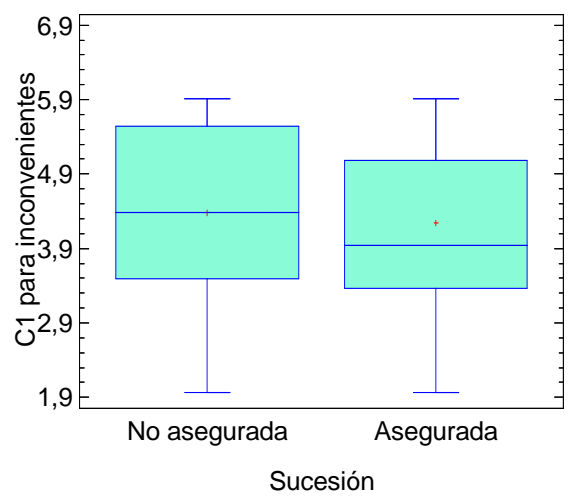

b)

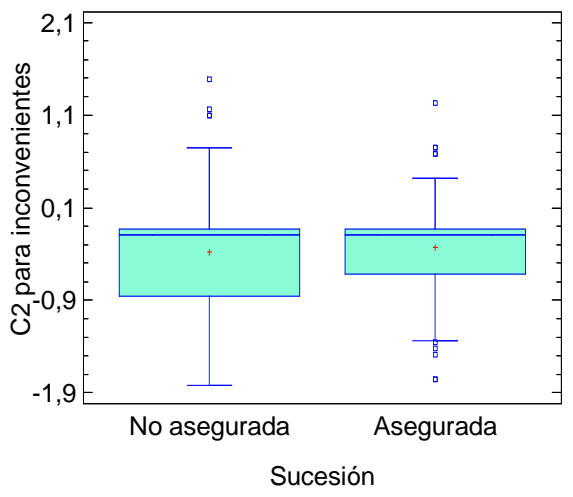

\section{Tenencia de sustrato}

Según la representación de los resultados que figura en el Gráfico 5.19.a, los agricultores que no tienen sustrato dan más importancia a los inconvenientes arriesgado y difícil manejo, con una diferencia que parece significativa.

Respecto al inconveniente "es más caro" incluido en la C2 (Gráfico 5.19.b) se deduce que los agricultores que no tienen sustrato dan más importancia a este inconveniente, pero a escasa distancia de los que lo tienen, lo que puede interpretarse como que el que lo tiene sí experimenta alguna ventaja económica aunque sea más caro, pero no espectacular. La distancia entre ambos sería mayor si los resultados de Beneficio/Inversión fueran muy diferentes entre las dos modalidades de cultivo. 
Gráfico 5.19. Diagramas de Caja y Bigotes para la C1 a) y para la C2 b) según tenencia de sustrato, para inconvenientes
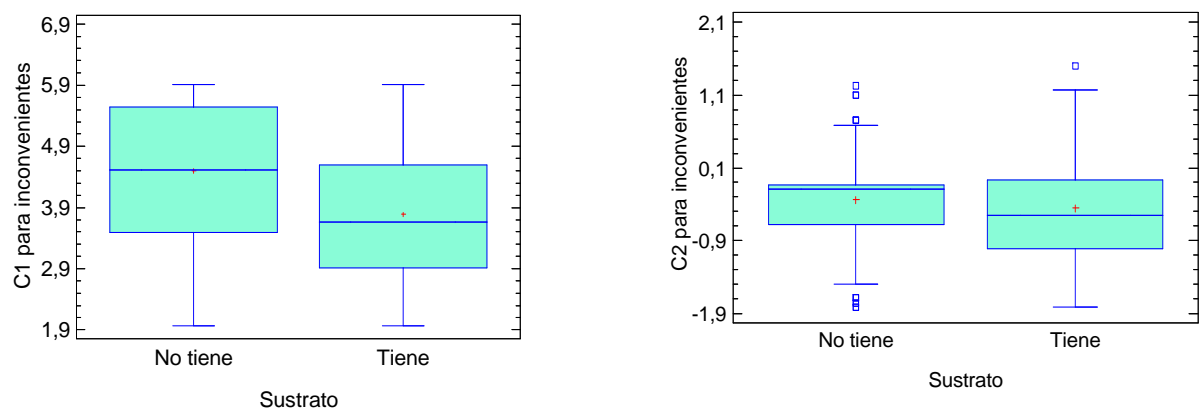

Hay que diferenciar entre los conocimientos técnicos y de resultados económicos de carácter experimental que posee el cultivador en sustrato y el bagaje de información, en conjunto, al alcance de cualquier cultivador en suelo, que en un momento determinado da lugar a un tipo de opinión cercano al que cultiva en sustrato, pero con una actitud menos favorable respecto a la decisión de invertir.

\subsubsection{Influencia de las variables en la actitud hacia la adopción: Regresión Multinomial Ordinal (RMO)}

En los apartados anteriores se han evaluado, mediante el Análisis de Componentes Principales, el efecto de las distintas variables que intervienen en la adopción de la tecnología del cultivo en sustrato y su relación con otras características no tecnológicas.

La finalidad del presente apartado es determinar la importancia relativa que cada titular de explotación asigna a las variables que se identifican con las ventajas e inconvenientes del cultivo en sustrato.

Para ello se ha aplicado la RMO en la que se han considerado las siguientes variables:

La variable respuesta "Nivel de importancia del cultivo en sustrato" consta de las categorías "Imprescindible", "Importante", "Una técnica más", 210 
"Poco interesante" y "Nada interesante", que siguen un orden natural, tomando los valores $5,4,3,2$ y 1 , respectivamente. Puesto que esta variable es ordinal, el modelo de regresión multinomial ordinal es el más adecuado.

Las variables independientes "Ventajas e Inconvenientes de los invernaderos con cultivo en sustrato" con las categorías "Muy importante", "Importante" y "Poco importante" también siguen un orden, tomando los valores 3,2 y 1 , respectivamente; y se incluyen en el modelo con las correspondientes variables dummy asociadas.

En general, si llamamos $y$ a la variable respuesta, con $j$ categorías que toman valores $j=1,2, \ldots,(J-1)$, y se quiere estimar la proporción de situaciones en que se supera el nivel $j$-ésimo, el modelo que se establece es el siguiente:

$$
P[y>j]=\frac{e^{\beta_{0}+\beta_{1} D_{1}+\beta_{2} D_{2}}}{1+e^{\beta_{0}+\beta_{1} D_{1}+\beta_{2} D_{2}}}
$$

para $P[y>J]=0$

siendo $\beta_{0,} \beta_{1,}$ y $\beta_{2}$ los coeficientes del modelo y $D_{1}$ y $D_{2}$ las dos variables dummy asociadas al concepto de ventajas o inconvenientes.

\subsubsection{Coeficiente de correlación por rangos de Spearman}

Antes de iniciar la aplicación de la Regresión Multinomial Ordinal es aconsejable comprobar la existencia de colinealidad entre las variables independientes, por lo que procede en principio determinar los coeficientes de correlación por rangos de Spearman. Se aplica este coeficiente de correlación porque las variables que se analizan no son continuas, sino de rango.

La medida de correlación de Spearman es un índice que refleja la correlación en el rango entre cada par de variables. Sea $r_{s}$ el coeficiente de 
Capítulo V Evolución hacia niveles superiores de tecnología: el cultivo en sustrato correlación por rangos de Spearman que toma valores entre -1 y 1 , se calcula como:

$$
r_{s}=1-\frac{6 \sum d^{2}}{n\left(n^{2}-1\right)}
$$

donde $d$ es la diferencia entre los rangos de las variables; y $n$ es el número de observaciones.

Como resultado de este análisis se pone de manifiesto la existencia de colinealidad entre las variables independientes dada la alta significación entre la mayoría de las variables, a pesar de presentar coeficientes de correlación no muy cercanos a 1, dada la naturaleza cualitativa de las variables (Tabla 5.9). 


\section{Tabla 5.9. Matriz de correlación por rangos de Spearman}

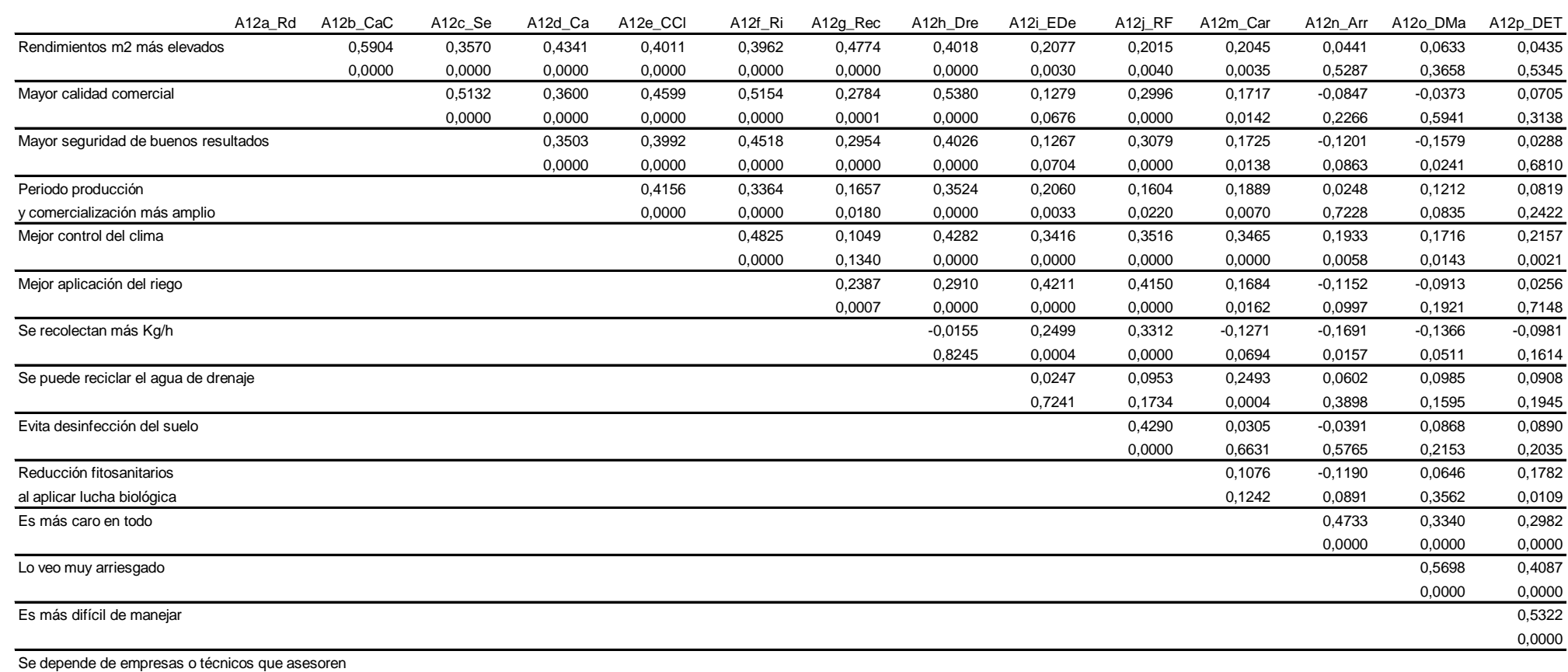

Se depende de empresas o técnicos que asesoren

Contenido de cada celda: Coeficiente de correlación

Tamaño muestral: 205 


\subsubsection{Resultados e interpretación}

Con objeto de explicitar una cierta gradación de la importancia que adquieren para el agricultor las variables que expresan las ventajas e inconvenientes del cultivo en sustrato, se utiliza el modelo de regresión multinomial ordinal, alternativo al modelo de regresión tradicional cuando la variable respuesta no es cuantitativa.

Dada la existencia de colinealidad entre las variables independientes como figura expuesto en el Tabla 5.9, el modelo ha sido aplicado sucesivamente para cada una de ellas de forma individual (Anexo 5). De este modo, se obtiene la magnitud del estadístico chi-cuadrado asociado a la variable explicativa incorporada en cada modelo. El mayor valor del estadístico indica que la importancia del cultivo en sustrato está más influenciada por esa variable y viceversa (Tabla 5.10).

Tabla 5.10. Resultados del ajuste de los modelos de regresión multinomial ordinal

\begin{tabular}{lrr} 
Variables & Chi-Cuadrado & P-valor \\
\hline A12a_Rd & 29,714 & 0,000 \\
A12b_CaC & 41,489 & 0,000 \\
A12c_Se & 39,045 & 0,000 \\
A12d_Ca & 12,100 & 0,002 \\
A12e_CCl & 6,479 & 0,039 \\
A12f_Ri & 48,826 & 0,000 \\
A12g_Rec & 33,422 & 0,000 \\
A12h_Dre & 11,318 & 0,003 \\
A12i_EDe & 3,888 & 0,143 \\
A12j_RF & 17,344 & 0,000 \\
A12m_Car & 5,129 & 0,077 \\
A12n_Arr & 42,931 & 0,000 \\
A12o_DMa & 22,930 & 0,000 \\
A12p_DET & 13,589 & 0,001 \\
\hline
\end{tabular}

Con estos resultados se pueden observar cuatro niveles de asociación de las ventajas e inconvenientes que los titulares de explotación 
dan al cultivo en sustrato, en los que queda reflejado el grado de importancia de cada variable (Tabla 5.11).

Tabla 5.11. Niveles de importancia relativa de las variables ventajas e inconvenientes del cultivo en sustrato

\begin{tabular}{|c|c|c|c|}
\hline $1^{\mathrm{er}}$ nivel & $2^{\circ}$ nivel & $3^{\mathrm{er}}$ nivel & $4^{\circ}$ nivel \\
\hline $\begin{array}{l}\text { Mayor calidad } \\
\text { comercial de los } \\
\text { productos }[\mathrm{CaC}]\end{array}$ & $\begin{array}{c}\text { Rendimientos (por } \\
\text { m2) más elevados } \\
{[R d]}\end{array}$ & $\begin{array}{c}\text { El periodo de } \\
\text { producción y } \\
\text { comercialización es } \\
\text { más amplio [Ca] }\end{array}$ & $\begin{array}{l}\text { Al disponer de mejor } \\
\text { instalación, se } \\
\text { controla mejor el } \\
\text { clima [CCl] }\end{array}$ \\
\hline $\begin{array}{l}\text { Más seguridad de } \\
\text { obtener buenos } \\
\text { resultados [Se] }\end{array}$ & $\begin{array}{l}\text { Al disponer de mejor } \\
\text { instalación, se } \\
\text { recolectan más } \\
\text { Kg/hora [Rec] }\end{array}$ & $\begin{array}{c}\text { Al disponer de mejor } \\
\text { instalación, se } \\
\text { puede reciclar el } \\
\text { agua de drenaje } \\
\text { [Dre] }\end{array}$ & $\begin{array}{l}\text { Teniendo en cuenta } \\
\text { que no se podrá } \\
\text { usar el B.Metilo, se } \\
\text { evita la desinfección } \\
\text { del suelo [EDe] }\end{array}$ \\
\hline $\begin{array}{c}\text { Al disponer de mejor } \\
\text { instalación, se } \\
\text { aplica mejor el riego } \\
\text { [Ri] }\end{array}$ & $\begin{array}{c}\text { Es más difícil de } \\
\text { manejar [DMa] }\end{array}$ & $\begin{array}{c}\text { Si se aplica la lucha } \\
\text { biológica, se reduce } \\
\text { la cantidad de } \\
\text { fitosanitarios [RF] }\end{array}$ & $\begin{array}{l}\text { Es más caro en todo } \\
\text { [Car] }\end{array}$ \\
\hline $\begin{array}{l}\text { Lo veo muy } \\
\text { arriesgado [Arr] }\end{array}$ & & $\begin{array}{c}\text { Se depende de } \\
\text { empresas o técnicos } \\
\text { que asesoren [DET] }\end{array}$ & \\
\hline
\end{tabular}

Un aspecto importante en cuanto a la utilidad que proporciona la Tabla 5.11, es la posibilidad de examinar, de forma global, el grado que los titulares de las explotaciones dan a la influencia de las variables, con independencia de sus características.

En el primer nivel han situado una variable económica, que es la obtención de mayor calidad [CaC], lo que prueba que su percepción es muy frecuente por un número amplio de titulares de explotación. Otra variable de tipo técnico es la ventaja de disponer de mejor sistema de riego [Ri].

El valor que le asignan a una utilización más perfecta de la instalación de riego refuerza lo dicho anteriormente respecto a la importancia concedida al uso del agua y la prioridad en las inversiones. 
Se completa este primer nivel, con otras dos variables, una es la seguridad de obtener buenos resultados [Se] y otra, su posición ante el riesgo $[$ Arr].

De las tres variables que forman el segundo nivel, dos son económicas, rendimientos más elevados [Rd] y mayor eficiencia en la recolección [Rec]; la tercera variable es de tipo técnico relativa a la dificultad de manejo [DMa].

En el tercer nivel aparecen cuatro variables, de las cuales una es de carácter económico, muy evidente, que es periodo de producción y comercialización más amplio [Ca]. Otra variable fundamental de tipo técnico, se refiere a la dependencia de empresas y técnicos por parte de las explotaciones [DET], cuya situación en el tercer nivel se debe a que si bien los titulares perciben, con evidencia, la exigencia técnica, al mismo tiempo, conocen la existencia de suficiente número de empresas y técnicos para el asesoramiento, lo que disminuye los inconvenientes del problema.

En este tercer nivel, hay dos variables que se pueden calificar de predominio ecológico; una se refiere a la posibilidad de reciclar el agua de drenaje [Dre], y otra a la reducción de las cantidades de producto fitosanitario [RF] mediante la aplicación de la lucha biológica. Ambas indican que el agricultor va tomando conciencia de la problemática ecológica, aunque, para él, no son las variables más importantes, ya que las sitúa en el tercer nivel. Su actitud ha evolucionado, en los últimos años, por un lado influido por la publicidad a favor del medioambiente y la sostenibilidad de las producciones y además, por la agresividad de las instituciones de la Unión Europea en reducción de plaguicidas; también encuentra positiva la reducción de problemas y la mejora de imagen del producto en la comercialización, aunque no siempre retribuida.

Las variables del cuarto nivel tienen carácter económico dos de ellas, y la otra es de tipo ecológico, aunque también relativa a un problema técnico. 
Sorprende la menor importancia relativa concedida a la variable "más caro en todo" [Car] probablemente porque, aunque es patente, al mismo tiempo consideran superable este aspecto. También la situación en este nivel de la variable que concierne al mejor control climático del invernadero [CCl], se corresponde con la idea de que en las explotaciones no han percibido, de forma generalizada, la importancia de los resultados económicos que proporciona el capital invertido en elementos de climatización.

Finalmente, no parecía previsible, la asignación de la variable "evitar desinfección del suelo" [EDe] a este nivel ya que desde el 2000 hasta el 2005, el bromuro de metilo se consideraba imprescindible, y por otra parte, estaba anunciada su incuestionable supresión a partir de enero de 2005. Actualmente, las desinfecciones con bromuro han sido sustituidas por procedimientos naturales (solarización), químicas (Telone + Cloropicrina) y mixtos (estiércol con solarización o productos químicos con solarización). En esta variable es importante resaltar su interés en cualquiera de las tres situaciones de cultivo posibles, es decir, para el cultivador en suelo que quiere continuar, para el cultivador en suelo que quiere cambiar, y para el cultivador en sustrato como perceptor de una ventaja.

El orden de las variables asignadas, según niveles de influencia en las ventajas e inconvenientes, puede parecer más o menos racional, pero es evidente su importancia en la actitud hacia el cultivo en sustrato y su comportamiento en la realización de inversiones ante la adopción de esta modalidad de cultivo, junto con el resto de elementos que perfeccionan las funciones del invernadero. Un ejemplo claro se manifiesta con la variable "Al disponer de mejor instalación se aplica mejor el riego" [Ri], la cual ha tenido una influencia muy elevada en las inversiones de los sistemas de riego. En la Tabla 4.14 , tienen instalación de riego programada (el $58,2 \%$ ) ya en el nivel más bajo, mientras que en los otros cuatro niveles prácticamente afecta a la totalidad de los invernaderos de cada grupo. Otro ejemplo de la relación entre la importancia asignada a las variables en la Tabla 5.10 y el 
comportamiento en las inversiones por parte de los titulares de las explotaciones, se encuentra en la variable "Al disponer de mejor instalación se controla mejor el clima" [CCl], puesto que en la Tabla 4.14 en las instalaciones de calefacción por agua y elementos de control climático la dotación es buena en los niveles 3 y 5 , inferior en el 4 y deficiente en los grupos más numerosos, el 1 y el 2.

\subsection{Resumen y Comentarios}

Pasar del cultivo en suelo al cultivo en sustrato representa el principal salto tecnológico en la horticultura intensiva, e implica una mayor utilización de la técnica, factores de producción e inversiones.

Desde los años 90 el modelo holandés de horticultura superintensiva siempre ha sido el paradigma pendiente. No obstante, en España se han instalado muy pocos invernaderos tipo Venlo de vidrio. De los invernaderos mejor dotados la mayor parte corresponden al nivel 5 (Tabla 4.14) con estructura en multitúnel y cubierta de plástico.

La cuestión de si existe límite en la tecnología y dotación de los invernaderos hortícolas parece que ha tenido algunas respuestas (Mesas y Valero, 2006; Magán et al., 2007) en las que se ha probado que, en el clima de las zonas de este estudio, invernaderos de vidrio no han superado en producción y calidad a los que tenían cubierta de plástico, por tanto, de menor coste.

En el primer caso, la comparación se efectuó entre tres invernaderos con cultivo de pimiento en idénticas fechas, uno de cristal, un multicapilla y un multitúnel, ambos de plástico. Tanto el invernadero multicapilla como el multitúnel tuvieron una productividad del 12 al 17\% superior al de cristal.

En el segundo, se comparaba un tipo multitúnel con cubierta de plástico y otro Venlo de cristal, ambos con el mismo equipamiento para el control del clima y se dedicaron al tomate en ramillete. Según los autores 
los resultados obtenidos no mostraron mayor productividad del invernadero Venlo respecto al multitúnel.

De todas formas, aun aceptando como meta los invernaderos con cubierta de plástico, (nivel 5, Tabla 4.14), y bien dotados, hasta alcanzar la superficie deseable, son precisas elevadas inversiones, probablemente sin ayuda oficial, por lo que el esfuerzo inversor deberá correr a cargo de los empresarios.

Realmente, a la situación del sector hortícola intensivo español deberían corresponder invernaderos mejor equipados. El problema es que los descensos de los precios en términos reales no permiten la actitud inversora de épocas pasadas.

La información tomada para este capítulo son respuestas de opinión por parte de los titulares de las explotaciones, y en la elección de la metodología de análisis, se ha tenido en cuenta que se trata de variables no cuantitativas.

Como metodologías más adecuadas se eligieron el Análisis de Componentes Principales (ACP) y la Regresión Multinomial Ordinal (RMO).

En la primera aplicación del ACP se consideraron conjuntamente las variables que representan ventajas e inconvenientes. De las componentes obtenidas se tomaron para el análisis las dos primeras $\mathrm{C} 1$ y C2 que explican el $50 \%$ de la varianza. La C1 separa, con valores más elevados, a los agricultores que dan mayor importancia a las ventajas del cultivo en sustrato de los que le atribuyen un peso menor, que aparecen con valores más bajos. En la C2 figuran con valores más elevados los agricultores que dan menor alcance a los inconvenientes y con valores más bajos los que dan más importancia.

En el análisis bivariante, realizado a continuación, se han relacionado las componentes $\mathrm{C} 1$ y $\mathrm{C} 2$ con el tipo de cultivo, edad de los titulares de explotación, zona, superficie de las explotaciones, existencia o falta de sucesión y si la explotación tiene cultivo en sustrato. 
En una breve descripción de las principales deducciones se señala:

- Que en el pimiento y el tomate se valoran las ventajas del cultivo en sustrato más que en otros cultivos, lo que parece una consecuencia de la mayor utilización de esta práctica cultural, en extensión y antigüedad en ambas especies que técnica y económicamente responden muy bien a las mejoras que acompañan al cultivo sin suelo.

- La edad de los agricultores no influye en su valoración sobre las ventajas e inconvenientes del cultivo en sustrato.

- En cuanto a la valoración de las ventajas, según zonas, figura en primer lugar la comarca del Campo de Cartagena, lo que puede atribuirse a un predominio del pimiento en los invernaderos de esta zona, con el $92 \%$ de la superficie. Se trata de una especie exigente, con respuesta adecuada al aumento de la tecnología, y obtiene retribuciones según diferencias de calidad.

- La comarca del Valle del Guadalentín tiene un predominio del tomate, que cuando se cultiva en sustrato, amplía el periodo de producción-comercialización, aumenta los rendimientos y calidad y permite cierto grado de reutilización del agua y de los fertilizantes.

- En la zona de El Ejido valoran el cultivo en sustrato menos que en las otras dos comarcas, por las características de su sistema agrario en el que hay costumbre de alternar cultivos y disponer de dos cultivos por campaña. Por otra parte, aunque el cultivo con enarenado tiene un coste de instalación elevado, el empresario lo emplea con la seguridad que proporciona una dilatada experiencia y la disponibilidad de factores de producción, asistencia técnica y vías de comercialización.

- La superficie en invernadero de las diferentes explotaciones no tiene influencia en el criterio sobre ventajas e inconvenientes del 
cultivo en sustrato. Del mismo modo, sucede con la existencia de sucesión en la explotación.

- Una de las condiciones que, de forma más clara, puede influir en la actitud de los agricultores hacia el cultivo en sustrato es el hecho de tener o no tener esta modalidad de cultivo en la explotación. Respecto a la valoración de las ventajas es muy parecida en ambos grupos, algo superior en los que cultivan en sustrato; respecto a los inconvenientes, el que cultiva en sustrato lo valora con menor grado de negatividad. De todo ello, se deduce que esta técnica también es muy conocida por los que no la han adoptado, y para los que la practican, la sensación de riesgo es menor que en los cultivadores en suelo.

Los resultados del ACP, cuando se analizan por separado las ventajas y los inconvenientes del cultivo en sustrato, son:

- Para las variables ventajas. Una vez calculadas las componentes se comprobó que las dos primeras acumulaban el $57,4 \%$ de la varianza.

- En la primera de las componentes, el mayor peso corresponde a las variables de las ventajas de los "rendimientos más elevados" [Rd], "mejor control del clima" [CCl] y "aplicación del riego" [Ri] que proporcionan un sentido económico y resaltan el manejo técnico.

- La segunda componente asigna el mayor peso a las variables "evitar la desinfección del suelo" [EDe] y "reducción de plaguicidas por aplicación del control biológico" [RF], separando a los agricultores que han expresado una mayor concienciación medioambiental, de los que tienen una consideración inferior hacia estas acciones que favorecen el medioambiente. 
Se realizó un análisis bivariante para relacionar las componentes calculadas con los mismos conceptos que en el anterior análisis conjunto de ventajas e inconvenientes. Como resultados más relevantes se señalan:

- Los cultivadores del tomate y pimiento valoran, más que los que se dedican a otras especies, las ventajas económicas y de gestión técnica del cultivo en sustrato. En este caso la diferencia es bastante importante.

- La valoración de las ventajas, desde el punto de vista medioambiental, parecen muy similares entre los diferentes cultivos.

- La edad de los titulares no ha influido en la valoración de las ventajas económicas ni de los efectos medioambientales.

- Respecto a valoración de ventajas económicas y de gestión, considerando las tres zonas del estudio, son similares entre el Campo de Cartagena y el Valle del Guadalentín, y en ambos casos superiores a la zona de El Ejido. En cambio, la preocupación medioambiental ha resultado superior en El Ejido, con menor dispersión en las contestaciones, lo que coincide en esta zona con una aceptación muy rápida en los últimos años de prácticas culturales respetuosas con el medioambiente.

- La valoración de las ventajas económicas no parece depender de la extensión de la explotación, y sobre todo, para las superficies menores, el grado de dispersión es elevado. Tampoco influye en la consideración de las variables medioambientales.

- La existencia o la falta de sucesión asegurada no tienen efecto sobre la actitud hacia las variables contenidas en ambas componentes.

- Tanto la tenencia como la carencia del cultivo en sustrato, influyen muy poco en la estimación de las ventajas económicas 
y de gestión y en las que inciden en el medioambiente. En ambos casos la apreciación es algo superior en los que tienen sucesión.

Para las variables inconvenientes, se procedió a la aplicación de la metodología del ACP como en los casos anteriores, y el análisis se centró en las dos primeras componentes que contenían combinaciones de las variables de los inconvenientes y acumulaban el $78,3 \%$ de la varianza.

En la C1 obtienen mayor peso las variables "lo veo arriesgado" [Arr] y "es más difícil de manejar" [DMa], es decir, miden la desventaja del riesgo y la dificultad de manejo técnico.

La C2 se asocia con la variable "es más caro en todo" [Car], y por tanto, separa a los agricultores más preocupados por el coste del cultivo en sustrato de los que conceden menos importancia este inconveniente.

Realizado un análisis bivariante de forma similar al practicado en las ACP anteriores, se ha deducido:

- El tipo de cultivo tiene una influencia escasa en las opiniones sobre los inconvenientes.

- La edad no influye en la valoración de los inconvenientes.

- Sobre el riesgo y el manejo, en Campo de Cartagena y Valle del Guadalentín resulta una calificación más elevada que en El Ejido. La apreciación de la variable "es más caro" [Car] es mayor en El Ejido.

- La influencia de la superficie de las explotaciones en las opiniones sobre los inconvenientes no se manifiesta.

- Los agricultores que no tienen sucesión asegurada asignan un grado mayor a la estimación de los inconvenientes relativos al riesgo y práctica de las operaciones culturales. Respecto al inconveniente caro el criterio es similar. 
- La tenencia de sustrato sí condiciona el juicio emitido sobre la importancia del riesgo y la gestión del cultivo, que es más elevada en los que no tienen sustrato.

La importancia relativa atribuida por los titulares de las explotaciones a las diferentes variables, se ha determinado a través de una RMO con la variable respuesta "nivel de importancia del cultivo en sustrato" y 14 variables independientes que corresponden a las ventajas e inconvenientes del cultivo en sustrato. El interés de la ordenación resultante radica en el orden establecido entre las 14 variables de acuerdo con el estadístico chi-cuadrado y su significación.

El orden marcado por los titulares de explotación puede tener cierto grado de subjetividad, pero es un reflejo de su actitud ante la posible adopción del cultivo en sustrato, y la tendencia en las inversiones en equipamiento de los invernaderos.

Aunque se trata de una muestra amplia, en el orden fijado no predomina un tipo de criterio, y en los niveles establecidos se sitúan variables de diferentes características; por ejemplo, en el primer nivel formado, figura una variable económica ("mayor calidad comercial" [CaC]), otra técnica ("mejor aplicación del riego" [Ri]) y dos de opinión ("seguridad de buenos resultados" [Se] y "lo veo arriesgado" [Arr]).

En la población analizada parece que hay un cierto grado de conciencia medioambiental; no obstante, el orden de prioridad asignado a las variables relacionadas con el medio ambiente es secundario.

Sobresale la menor relevancia concedida a la variable "evita la desinfección del suelo" [EDe] que, vista objetivamente, tiene interés no sólo económico sino también técnico. En el periodo de realización de la encuesta ya se había prohibido el uso del bromuro de metilo; no obstante, es posible que existiera alguna esperanza de paliar el problema con los usos críticos. Los procedimientos de solarización hace tiempo que aportan soluciones y la alternativa al bromuro de metilo más probada, aunque su generalización ha sido reciente, han sido las formulaciones a base de 1,3 dicloropropeno y 
Capítulo V Evolución hacia niveles superiores de tecnología: el cultivo en sustrato

cloropicrina (Cebolla y Serrano, 2008). De todas formas, las alternativas, aunque sean eficaces, no inspiran al agricultor la confianza que tenía en el bromuro de metilo. 

Capítulo VI

Conclusiones finales 



\section{Capítulo VI. Conclusiones finales}

El grado de cumplimiento de los objetivos ha sido elevado, y con notables aportaciones en la aplicación de la metodología. Entre ellas señalamos:

- El cálculo de los índices estacionales aporta una información de interés para el desarrollo de los calendarios de producción y comercialización. La consideración, según épocas, de la variación en los precios, permite una primera estimación en la dotación y uso de la calefacción en el invernadero.

- La elección de los modelos ARIMA se ha mostrado muy válida a corto plazo, una campaña. Tienen la ventaja de predecir los precios según la periodicidad de la serie y, por tanto, son de utilidad en la previsión de la campaña en cuanto a la variedad, técnicas productivas y uso de los factores de producción.

- Con la aplicación del análisis cluster se ha puesto de manifiesto su aptitud para establecer niveles tecnológicos en grupos de invernaderos de los sistemas agrarios estudiados, con la posibilidad de conocer los elementos que los integran, la distribución por porcentajes y la evolución de la tecnología según los conjuntos formados.

- Con el Análisis de Componentes Principales se modelizó el tratamiento de un número elevado de variables para expresar su variabilidad en un número menor de nuevas variables que explican la mayor parte de la variabilidad del conjunto inicial. Con las componentes extraídas, se efectuó un análisis bivariante relacionándolas con otras variables de interés distintas del conjunto inicial. 
- La aplicación de la Regresión Multinomial Ordinal fue conveniente debido a la naturaleza de las variables, que eran de tipo ordinal. Resultó una clasificación de dichas variables asociando su importancia relativa según el valor del estadístico chi-cuadrado obtenido.

A continuación se relacionan las principales conclusiones:

1. Relacionadas o derivadas del primer objetivo. Análisis en capítulo III:

> La posición competitiva del tomate y pimiento como principales productos hortícolas, de acuerdo con la evolución de precios y exportaciones durante el periodo 1985-2006, muestra que la situación no presenta amenazas graves pero sí una cierta estabilización con mercados saturados y precios con tendencia decreciente.

> El análisis de tendencia aplicado a series actualizadas de precios en origen ha permitido deducir que el tomate liso muestra un estancamiento o suave descenso en las zonas de mayor producción, Murcia y Almería. Para este tipo de producto la tendencia en Alicante es positiva, en lo que influye el proceso de comercialización.

> Para productos diferenciados los precios presentan una tendencia positiva; tal es el caso de los tomates acostillado, de ramillete, tipo Cherry con diversos colores y pimientos con colores distintos de los habituales. Sin embargo la obtención de productos con menor oferta suele exigir mejoras en la dotación de los invernaderos.

> En la evolución de las series de precios en el pimiento rojo y verde se refleja una tendencia descendente que no es muy acusada, pero sí característica de los productos que han tenido niveles de precios altos. 
> La situación económica del pimiento es más favorable que la del tomate y da mayores opciones en la elección de los niveles de tecnología para su producción. Un ejemplo es el tipo Wonder con elevada cotización pero muy exigente en la técnica productiva.

> La pérdida gradual de poder adquisitivo en las rentas de los cultivadores de invernaderos ha inducido en algunos casos a la utilización del capital fijo a menores niveles; tal es el caso de los invernaderos de malla.

$>$ Los principales efectos de la calefacción son la prevención ante los riesgos de bajas temperaturas, la anticipación en el calendario de producción, variación en la estacionalidad de los productos y aumento de la calidad. La elevada repercusión de los costes del combustible exige un control técnico y económico muy riguroso.

$>$ El cultivo en Producción Integrada con técnicas de control biológico mejora la imagen comercial del producto $y$, aunque son difíciles de cuantificar las diferencias económicas respecto al cultivo convencional, la prioridad en la elección en el momento de la venta siempre representa alguna ventaja.

> Cuando el productor de pimiento ecológico encuentra un canal adecuado, el aumento de precio le compensa ampliamente la disminución de la producción, puesto que ha superado, durante tres campañas, en un $40 \%$ a la calidad Wonder.

> La Producción Ecológica presenta como ventaja fundamental la claridad de su normativa y el escaso o nulo riesgo de residuos. Es una forma efectiva de diversificar la producción y abrir huecos en los mercados; no obstante, situar la PE en el mercado con precios satisfactorios para el productor resulta difícil, especialmente para el agricultor individual. 
2. Relacionadas o derivadas de los objetivos 2,3 y 4 . Análisis en capítulo IV:

> Respecto a la evolución temporal de la tecnología, de la documentación existente se deducen implantaciones rápidas en los primeros años, pero actualmente, con una visión completa de los resultados del análisis, se detecta una cierta lentitud. Por ejemplo, se reduce al $6 \%$ la proporción de las explotaciones con tecnología más completa en los invernaderos, aceptando esta situación cuando disponen de estructura bien dimensionada, calefacción permanente, climatización, riego y fertirrigación programados junto a otras dotaciones de elementos también importantes. Incluso hay explotaciones que no han superado el invernadero de madera $(7,4 \%)$.

> Aún permanece el parral clásico en un $24 \%$ de las explotaciones, y la proporción mayor corresponde al tipo parral modificado, que con frecuencia está más tecnificado, pero manteniendo una instalación con bajo coste; es decir, los niveles más bajos de tecnología son los que incluyen conjuntos más numerosos, lo que confirma la lentitud en los cambios. La estructura en multitúnel, idónea para todo tipo de mejoras y equipamiento, sólo alcanza una proporción del 11,2\%.

De la información resultante del total de las explotaciones, se le puede atribuir un nivel relativamente bajo a la mecanización del invernadero en material móvil, auxiliar de tratamientos y recolecciones. Es muy escaso el uso de raíles, carretillas elevadoras y tratamientos fitosanitarios automatizados. En la generalización de la mecanización con material móvil queda un amplio camino por recorrer cuando, por otra parte, las inversiones en este capítulo no serían elevadas.

> Por lo necesario, y lo que tiene de efectivo, la dotación de mallas antiinsectos para lucha biológica se ha extendido al $100 \%$ de los 
invernaderos, un aspecto muy positivo no sólo en el desarrollo del cultivo, sino también en la imagen de los productos.

$>$ El enarenado, modalidad de cultivo en invernadero propia de Almería, constituye un sistema productivo muy arraigado, no sólo en cuanto a las características de la producción, sino también por la amplitud de superficie y especialización de servicios. No cuenta con las estructuras que se consideran más completas ni suele tener calefacción. Un sistema así es estable y con resistencia a la evolución.

> Respecto a las actitudes de los empresarios hacia el cultivo en sustrato podría deducirse que, actualmente, existe un escaso margen de crecimiento puesto que sólo un $27,7 \%$ lo considera importante o imprescindible, proporción que sólo supera en un 5,7\% a la proporción de empresarios que lo han instalado. Para un posible aumento en la aceptación de esta técnica por un número mayor de empresarios, se precisa actuar más en la trasferencia de tecnología sobre un $47 \%$ de propietarios que sólo la consideran "una técnica más", sin distinguirla en su opinión. Un aspecto muy positivo para la difusión del cultivo en sustrato es la opinión de los agricultores que la han adoptado, que ha resultado ser claramente satisfactoria en un $51 \%$ e indiferente, sin rechazo, el $29,3 \%$.

> Parece existir una actitud empresarial bastante favorable a la aceptación del riesgo propio del endeudamiento. Respecto a las fuentes de financiación figuran en primer lugar los bancos y cajas rurales o de ahorro. La opción de emplear recursos propios es importante y afecta al $56,6 \%$ de los propietarios, lo cual indica una elevada proporción de explotaciones donde es importante el ahorro familiar. Las cajas rurales tienen una relación muy directa y próxima, tanto en las funciones financieras como en las de asesoramiento técnico. 
> No parecen favorables, dentro de la evolución tecnológica de esta actividad, los resultados de la cuestión sobre la intención de modificar el invernadero por parte de los propietarios, dado que sólo un 10\% están dispuestos a una modificación inmediata, y un 35\% a medio o largo plazo, mientras que el $50 \%$ no tiene intención de efectuar mejoras. Se ha comprobado que estas contestaciones mantenían una relación directa con la existencia de sucesión y, a su vez, la relación no es significativa con la edad del empresario ni el tipo de invernadero disponible.

$>$ En la formación de los grupos se detecta que, respecto a sus componentes, no forman compartimentos estancos, sino que hay elementos que figuran en proporciones variables en más de un nivel o en todos. Esta característica se adapta más a la realidad que en el caso de formarse los grupos por criterio de expertos.

> La proporción de invernaderos con tecnología más completa se reduce al $6 \%$ del total de la muestra, si se consideran dotaciones de elementos amplias con cultivo en sustrato; para el cultivo en suelo, la proporción de invernaderos dotados aceptablemente corresponde al grupo 3 que comprende el $6 \%$ del total de la muestra. La estructura en multitúnel, idónea para todo tipo de mejoras y equipamiento, sólo alcanza una proporción del 11,2\%. El parral clásico aún figura en un $24 \%$ de las explotaciones y, aunque la mayor proporción en el tipo de estructura corresponde al parral modificado, que suele estar más tecnificado, los niveles más bajos de tecnología son los que incluyen conjuntos más numerosos, lo que confirma la lentitud en los cambios.

> Considerando los cinco niveles tecnológicos establecidos en la población analizada, se comprueba que la tecnología lleva un orden creciente; sin embargo, hay excepciones, y así en los niveles 4 y 5 que llevan cultivo en sustrato se cumple la norma en el 5; en cambio en el nivel 3 la mayor parte de sus elementos e instalaciones están mejor dotadas que en el nivel 4. Parece evidente que en el nivel 3 
se incluyen los agricultores dispuestos a tener buenas instalaciones, pero sin adoptar el cultivo en sustrato.

> Respecto a la relación de los niveles tecnológicos con la edad de los agricultores, no se ha deducido el resultado que se esperaba, ya que no se ha manifestado la dependencia entre las dos variables, cuando parecería lógico que los niveles más elevados se correspondieran con agricultores más jóvenes.

$>$ La proporción de invernaderos con calefacción es relativamente baja, y sólo alcanza porcentajes elevados en los niveles 3 y 5 que comprenden el $12 \%$ del total de la muestra. Predomina la calefacción de agua, en la que hay mayor proporción de carácter permanente; la calefacción por aire suele ser puntual y de apoyo.

> Una visión global a los elementos que favorecen el control climático (mallas de sombreo, pantallas, nebulización y desestratificadores) muestra sus reducidas proporciones, lo que induce a pensar que el conjunto de titulares de explotaciones de invernaderos no ha encontrado una clara y eficaz justificación económica a su instalación, que deberá relacionarse con las posibilidades de repercusión en la calidad de los productos y en el calendario de venta.

> Para estimar los factores predominantes que afectan al proceso de adopción, o que han sido elegidos con más frecuencia, se han relacionado dichos factores con los cinco niveles tecnológicos obtenidos. Con el análisis de las variables elegidas como primera opción se obtuvieron resultados significativos para vías de información inicial, de formación y de asesoramiento. Respecto a la primera y segunda vías mencionadas, las respuestas han dado un mayor predominio a otros agricultores y familiares, y a gran distancia de técnicos de cooperativas. En cuanto a las fuentes de asesoramiento el orden ha sido diferente de los dos casos anteriores; se le concede el primer lugar a los técnicos de 
cooperativas, y a continuación figuran los proveedores y los técnicos independientes en proporciones muy cercanas.

$>$ En el análisis de factores predominantes no resultaron significativas las variables tomadas en segunda opción y tampoco las variables de Internet, revistas y centros de investigación.

Sorprende la escasa influencia que los agricultores han atribuido a las Oficinas de Capacitación Agraria en la transferencia de tecnología.

$>$ La innovación tecnológica en los invernaderos es fundamental para fortalecer la posición competitiva en la horticultura española, lo que resulta imprescindible teniendo en cuenta los cambios previsibles en los mercados debido al Acuerdo Euromediterráneo y a los efectos de la globalización.

3. Relacionadas o derivadas del objetivo 5. Análisis en capítulo V:

$>$ Con el ACP sobre el conjunto de variables correspondientes a la valoración por parte de los titulares de explotación de las ventajas e inconvenientes del cultivo en sustrato, se obtiene un diagrama de dispersión en el que no se aprecian núcleos de mayor concentración. Únicamente se observa un desplazamiento general hacia el vértice inferior izquierdo que marca una tendencia a conceder menos importancia a las ventajas y más a los inconvenientes, que es la posición más desfavorable, es decir, menos inclinada a los incrementos de tecnología.

> Dividida la superficie del diagrama en cuatro cuadrantes, una tendencia conformista que no ve ventajas y sí inconvenientes a las modificaciones en la tecnología, se manifiesta en un $69 \%$ de los propietarios, que sería la parte de la población reacia a la adopción. Le sigue en importancia el cuadrante superior izquierdo, en el que están situados los titulares de explotación con comportamiento más cauto en la realización de nuevas inversiones, que comprende un $21,5 \%$ del total. Los dos cuadrantes situados a la derecha, muestran 
los titulares que pueden estar más convencidos de efectuar inversiones en nueva tecnología y que dan más importancia a las ventajas; ambos grupos comprenden el 9,5\% del total.

$>$ En lo referente a la valoración conjunta de ventajas e inconvenientes del cultivo en sustrato, la relación de las componentes principales, $\mathrm{C} 1$ y $\mathrm{C} 2$, con las variables consideradas de interés, solamente se ha manifestado de forma evidente en las variables cultivo, zona y tenencia o carencia de cultivo en sustrato. La existencia o carencia de sucesión asegurada no ha influido en la opinión sobre las ventajas e inconvenientes. Esta situación no responde a la lógica de las previsiones, puesto que tener sucesión suele implicar un mayor incentivo hacia la adopción de niveles técnicos superiores.

> La evaluación independiente de las ventajas a través del ACP ha mostrado las características de las dos componentes principales extraídas, en función de las variables que en cada una de ellas han resultado con un mayor coeficiente de correlación. En consecuencia, la primera componente contiene dos sentidos, uno económico, y otro técnico. En la segunda componente se separan los agricultores, con mayor conciencia medioambiental de los que son menos sensibles a los temas medioambientales.

> En la relación de las componentes extraídas con las variables de interés, se ha podido obtener información de utilidad con el tipo de cultivo, zona y tenencia de sustrato. Se destaca en la segunda componente la influencia de las zonas en las que El Ejido presenta una valoración media más alta en la preocupación medioambiental.

Las variables con incidencia medioambiental que caracterizan la segunda componente son la desinfección del suelo y la reducción de fitosanitarios a través de la lucha biológica. El papel de estas variables ya se había detectado en las respuestas a las cuestiones planteadas sobre la percepción medioambiental (Capítulo IV, 
epígrafe 4.5). En dichas respuestas las variables mencionadas tenían opinión favorable en casi la totalidad de los agricultores; en menor proporción figuraba la necesidad de optimizar el control climático.

> En los temas medioambientales parece que se registra un notable avance en la toma de conciencia por parte de los agricultores. Hay una proporción aceptable que de forma general los tienen en cuenta y cada vez es más patente la necesidad de adaptarse a las exigencias de la UE y a la demanda de los mercados.

> En la evaluación independiente de los inconvenientes a través del ACP se extraen las dos primeras componentes principales: la componente 1 se identifica con las variables que expresan las dificultades percibidas en el manejo técnico; y la componente 2 separa a los agricultores más preocupados por la inversión más elevada que exige el cultivo en sustrato de los que no conceden importancia a este inconveniente.

> La tenencia o carencia del cultivo en sustrato en la explotación proporciona respuestas similares en los tres planteamientos de ACP expuestos anteriormente. Solamente hay una diferencia apreciable en la menor valoración de los inconvenientes, por parte de los que tienen cultivo en sustrato respecto a los que no lo tienen. Por el contrario, la apreciación de las ventajas es insignificante, lo que se debe principalmente al amplio conocimiento técnico y económico que existe en los dos grupos, aportado por empresas de suministros y asesoramiento y técnicos de cooperativas. A todo ello, se unen las experiencias en cooperativas y centros oficiales, así como la posibilidad de visitar en cualquier momento los invernaderos de los agricultores vecinos.

> Con la aplicación de la Regresión Multinomial Ordinal se ha deducido la importancia relativa del conjunto de variables que expresan las ventajas e inconvenientes del cultivo en sustrato, que 
son un reflejo de la actitud de los titulares de explotación hacia la posible adopción de esta técnica y de la tendencia en las inversiones en equipamiento de los invernaderos.

> Con el orden resultante, se han agrupado por niveles variables de características muy distintas. Así, la variable de mayor significación es la que expresa la calidad $[\mathrm{CaC}]$ y en su mismo nivel figuran también la mejor aplicación del riego [Ri] (de carácter técnico), a la que de forma general, siempre le han dado prioridad en las inversiones, y dos de opinión ("seguridad de obtener buenos resultados" [Se] y "lo veo muy arriesgado" [Arr]).

> Los agricultores han dado menor importancia a la variable rendimientos más elevados [Rd] que a la de mayor calidad y, entre las económicas, aún sitúan a menor nivel "periodo de producción y comercialización más amplio" [Ca].

> Aunque en la población analizada se ha comprobado un cierto grado de conciencia medioambiental, el orden asignado a las variables relacionadas con temas medioambientales ha sido secundario.

> Llama la atención la escasa prioridad asignada a la variable "evita la desinfección del suelo" [EDe] situada en los últimos lugares, cuando el cultivo en sustrato es la solución total y definitiva a los problemas propios de la desinfección del suelo, más preocupantes con la prohibición del bromuro de metilo. 


\subsection{Líneas de investigación futuras}

Una vez cerrada y concluida la presente tesis, de la experiencia en su realización, se pueden deducir otras líneas de investigación que a continuación se indican:

- Aceptando que los trabajos de investigación en adopción de tecnología representados por el análisis de duración, de carácter temporal, y los estudios de sección cruzada no son excluyentes, sino complementarios, el panorama de la adopción de tecnología en invernaderos se completaría con otra investigación que tendría un carácter muy amplio, basada en el análisis de duración aplicado a la tecnología del cultivo en sustrato.

- Conociendo los niveles tecnológicos, realizar evaluaciones económicas para las producciones y variedades más aptas para cada nivel, con introducción de precios y optimización de los capitales invertidos. Estimación de los límites en la tecnología y equipamiento en los invernaderos españoles.

- Ampliar el campo de análisis medioambiental que únicamente se ha esbozado en esta tesis. El estudio comprendería la actitud y compromiso de los agricultores por los temas medioambientales. Efectos técnicos y económicos de la Producción Integrada y las posibilidades técnicas y económicas de la Producción Ecológica. Estudio de los canales de comercialización de estas producciones.

Ampliar el ámbito de actuación a otros sectores. La elección de los cítricos parece adecuada por la información disponible, de carácter histórico y actual. Han existido en este sector continuas innovaciones varietales y de técnicas de cultivo. Por tanto, cabría la realización de una investigación sobre adopción de tecnología, completando un análisis de sección cruzada con otro de duración. 
Bibliografía 



\section{Bibliografía}

Abadi, A.K. \& Panell, D.J. 1999, "A conceptual framework of adoption of an agricultural innovation", Agricultural Economics, vol. 21, no. 2, pp. 145-154.

Abdulai, A. \& Huffman, W.E. 2005, "The diffusion of new agricultural technologies: The case of crossbred-cow technology in Tanzania", American Journal of Agricultural Economics, vol. 87, pp. 645-659.

Alarcón, A. 2003, "Innovación y tecnología en la producción agrícola murciana" in Libro Blanco de la Agricultura y el Desarrollo Rural. Ed. MAPA, Madrid (España).

Alarcón, A.L. 2006, Cultivos sin suelo, Ediciones de Horticultura, S.L., Reus (España).

Albisu, L.M., Vallés, J. \& Alonso, P. 1984, "Comportamiento de los precios del vino en España", An INIA/Ser Econ Sociol Agr, vol. 9, pp. 11-27.

Alcón, F., De-Miguel, M.D. \& Burton, M. 2008, "Adopción de tecnologías de distribución y control del agua en las comunidades de regantes de la Región de Murcia", Economía Agraria y Recursos Naturales, vol. 8, no. 1, pp. 83-102.

Alcón, F.J. 2007, Adopción y difusión de las tecnologías de riego: aplicación en la agricultura de la Región de Murcia. Tesis Doctoral. Universidad Politécnica de Cartagena (España).

Alpi, A. \& Tognoni, F. 1991, Cultivo en invernadero, $3^{\text {a }}$ edn. Ed. Mundi-Prensa, Madrid (España).

Althaus, R.L., Torres, A., Montero, A., Balasch, S. \& Molina, M.P. 2003, "Detection Limits of Antimicrobials in Ewe Milk by Delvotest Photometric Measurements", J. Dairy Sci., vol. 86, pp. 457-463.

Álvarez, A. \& Pérez, J.A. 2007, "Factores condicionantes de la viabilidad económica de la producción de leche ecológica", Actas del VI Congreso de Economía Agraria, Albacete (España). pp. 63-77.

Amorós, J.A., Júdez, L., Pérez, C., Bravo, S., \& Pinies, M. 2005, "Comparación de explotaciones convencionales y ecológicas de viñedo en la provincia de Ciudad Real", Porto (Portugal). 22 al 27 de mayo, 2005. Ed. Asociación Portuguesa de Horticultura.

Aparicio, V., Casado, E., Lastres, J. \& Belda, J.E. 2001, "Producción integrada en los cultivos hortícolas bajo abrigo en Almería" in El Sector Agrario y Agroalimentario de Almería ante el S.XXI, ed. J.A. Salinas. Ed. Instituto de Estudios Almerienses, Almería (España), pp. 183-191. 


\section{$\underline{\text { Referencias bibliográficas }}$}

Aramyan, L.H., Oude-Lansink, A.G.J.M. \& Verstegen, J.A.A.M. 2007, "Factors underlying the investment decision in energy-saving systems in Dutch horticulture", Agricultural Systems, vol. 94, pp. 520-527.

Arias, P. 2002, "Análisis temporal de las ventas y estimación del valor residual de tractores en España", Estudios Agrosociales y Pesqueros, vol. 192, pp. 195-222.

Arias, P. \& Alonso, R. 2000, "Análisis de las variables que inciden en la superficie a sembrar de remolacha en Castilla-León", Actas del VII Congreso de Economía Regional de Castilla y León, pp. 784-800.

Asturiano, J.F., Marco-Jiménez, F., Pérez, L., Balasch, S., Garzón, D.L., Peñaranda, D.S., Vicente, J.S., Viudes-de-Castro, M.P. \& Jover, M. 2006, "Effects of hCG as spermiation inducer on European eel semen quality", Theriogenology, vol. 66, pp. 1012-1020.

Avellà, L., Segura, P., Calafat, C. \& García, M. 2001, "Cambios del uso del suelo. Aplicación del método de análisis multivariante", Actas del IV Congreso Nacional de Economía Agraria, Pamplona (España).

Baerenklau, K.A. \& Knapp, K.C. 2007, "Dynamics of Agricultural Technology Adoption: Age Structure, Reversibility, and Uncertainty ", vol. 89, no. 1, pp. 190201.

Baille, A., Boulard, T. \& Gary, C. 1990, "Les critères d'optimisation dans la gestion du climat et de la production sous serre", C.R. Acad. Agric. Fr., vol. 76, no. 5, pp. 25-30.

Baille, A. \& González-Real, M. 2001, "Modelos de simulación en materia de control y de ayuda a la decisión" in Incorporación de Tecnología al Invernadero. Ed. Cajamar, Almería (España), pp. 73-90.

Baixauli, C. \& Aguilar, J.M. 2002, Cultivo sin suelo de hortalizas. Aspectos prácticos y experiencias. Ed. Generalitat Valenciana, Valencia (España).

Bakker, G.P.A., Challa, H. \& Van-De-Braak, N.J. (eds) 1995, Greenhouse climate control: an integrated approach, Ed. Elsevier, Wageningen (The Netherlands).

Barceló, V. 1987, "La posición competitiva de los productos mediterráneos españoles", Revista de Estudios Agrosociales, no. 140, pp. 203-227.

Barham, B.L., Foltz, J.D., Jackson-Smith, D. \& Moon, S. 2004, "The Dynamics of Agricultural Biotechnology Adoption: Lessons from series rBST Use in Wisconsin, 1994-2001", American Journal of Agricultural Economics, vol. 86, no. 1, pp. 61-72.

Barreiro, J., Ruzo, E. \& Losada, F. 2004, "Modelo logit multinomial y regresión con variables ficticias: Una aplicación regional al sector lácteo", Working Paper Series Economic Development, vol. 81, pp. 1-24. 


\section{$\underline{\text { Referencias bibliográficas }}$}

Benedicto, J.L. \& Caballero, P. 1983, "Las cámaras frigoríficas en la comercialización de los agrios", An INIA: Ser Econ Sociol Agrar, vol. 7, pp. 209300.

Berbel, J. 1989, "Analysis of Protected Cropping: an Application of Multiobjective Programming to Spanish Horticulture", European Review of Agricultural Economics, vol. 16, no. 2, pp. 203-216.

Bisquerra, R. 1989, Introducción conceptual al análisis multivariable. Ed. Promociones y Publicaciones Universitarias, Barcelona (España).

Blanque, M. 2007, "Equipamientos para invernaderos", Horticultura, , no. 201, pp. 10-19.

Booz, E., Allen, J. \& Hamilton, C. 1968, Management of New Products, Booz-Allen \& Hamilton, New York.

Botey, M. \& Arias, P. 2007, "La evolución de la parcelación en las explotaciones de Castilla y León", Actas del VI Congreso de Economía Agraria, Albacete (España), pp. 213-231.

Box, G.E.P., \& Jenkins, G.M. 1976, Time series analysis. Forecasting and control, 2nd edn. Ed. Holden Day, San Francisco (USA).

Burton, M., Rigby, D. \& Young, T. 2003, "Modelling the adoption of organic horticultural technology in the UK using Duration Analysis", Australian Journal of Agricultural \& Resource Economics, vol. 47, pp. 29-54.

Burton, M., Rigby, D. \& Young, T. 1999, "Analysis of the Determinants of Adoption of Organic Horticultural Techniques in the UK", Journal of Agricultural Economics, vol. 50, no. 1, pp. 48-63.

Caballero, P., De Miguel, M.D. \& Fernández, M.A. 2001, "La tecnología en los invernaderos", Agrícola Vergel, vol. 239, pp. 604-613.

Caballero, P., De-Miguel, M.D. \& Juliá, J.F. 1992, Costes y precios en hortofruticultura. Ed. Mundi-Prensa, Madrid (España).

Caballero, P. \& Fernández-Zamudio, M.A. 2006, "Valoración económica de la implantación del cultivo en sustrato" in Cultivos sin suelo. Ediciones Horticultura, S.L., Reus, pp. 55-69.

Caballero, P. \& Fernández-Zamudio, M.A. 2003, "Loquat, production and market", Seminaires Mediterraneens, pp. 11-20.

Caballero, P., García-Martínez, M.C., De-Miguel, M.D., Alcón, F. \& FernándezZamudio, M.A. 2009, "Rentabilidad de la producción ecológica del pimiento en invernadero", eds. A. Pardo, M.L. Suso \& N. Vázquez. VI Congreso Ibérico. Sociedad Española de Ciencias Hortícolas, Logroño, pp. 994-999. 
Cabrera, F.J., López, J.C., Baeza, E.J. \& Pérez-Parra, J.J. 2006, "Efficiency of antiinsect screens placed in the vents of Almería greenhouses", International Symposium on Greenhouse Cooling. International Society for Horticultural Science, ed. B.J. Bailey, Acta Horticulturae, pp. 605-614.

Callejón, A.J., Fernández, E.J. \& Gómez, V. 2003, "Caracterización fitoclimática de invernaderos mediterráneos" in Innovaciones tecnológicas en cultivos de invernaderos, ed. E.J. Fernández. Ed. Agrotécnicas, S.L., Madrid (España).

CAP 2006, Notas Agrarias Semanales. Ed. Conselleria de Agricultura, Generalitat Valenciana, Valencia (España).

CAPA 2006, Boletines Semanales de Información Agraria. Ed. Consejería de Agricultura y Pesca, Junta de Andalucía, Sevilla (España).

Carbonell, F., Blanes, V., Embuena, C., Calvet, S., Estellés, F., Martí, J.V., Puchades, L., Villagrá, A., Balasch, S. \& Torres, A. 2004, "Cluster analysis for pig farm agrupation according to its pig slurry treatment", AgEng, Leuven (Bélgica), pp. 736-737.

Carey, J.M. \& Zilberman, D. 2002, "A Model of Investment under Uncertainty: Modern Irrigation Technology and Emerging Markets in Water", American Journal of Agricultural Economics, vol. 84, no. 1, pp. 171-183.

CARM 2006, Informe Semanal Agrario. Ed. Consejería de Agricultura y Agua, Comunidad Autónoma de la Región de Murcia, Murcia (España).

Cases, B. 1994, "La predicción de cosechas en cítricos. Comparación entre diferentes métodos", Investigación Agraria. Economía, vol. 9, no. 3, pp. 411-446.

Castilla, N. 2005, Invernaderos de plástico. Tecnología y manejo, Ed. MundiPrensa, Madrid (España).

Castilla, N. 2004, "Infraestructuras y equipos. Opciones para el Invernadero", I Congreso Internacional de Agricultura Intensiva. Ed. Fundación Ruralcaja, Valencia (España), pp. 56-62.

Castilla, N. 1994, "Greenhouses in the Mediterranean areas: Technological level and strategic management", International Symposium on new cultivation systems in greenhouse, Cagliari (Italia), eds. G. Serra, F. Tognoni \& S. Leoni, pp. 44-56.

Castilla, N., Hernández, J., Quesada, F.M., Morales, M.I., Guillén, A., Soriano, T., Escobar, I., Antón, A. \& Montero, J.I. 2001, "Comparison of asymmetrical greenhouse types in the Mediterranean area of Spain", V International Symposium on protected cultivation in mild winter climates: Current trends for sustainable technologies, Cartagena (España), eds. J.A. Fernández, P.F. Martínez \& N. Castilla, pp. 183-186.

Chambers, W. 2004, "Forecasting feed grain prices in a changing environment", Electronic Outlook, vol. 4, no. 1, pp. 1-18. 


\section{$\underline{\text { Referencias bibliográficas }}$}

Cebolla, V. \& Serrano, F. 2008, "Mejora de la eficacia de los tratamientos de desinfección del suelo con 1,3-dicloropropeno y cloropicrina, en condiciones de bajas temperaturas, para cultivos de pimiento y plantas madre de fresón.", XI Jornadas Grupo Horticultura SECH. Ed. Fundación Ruralcaja, Valencia (España), pp. 256-264.

Chebil, A. \& Briz, J. 1999, "Analyse de la compétitivité du secteur des légumes espagnols", New Medit, no. 3, pp. 4-10.

Colman, D., Burton, M., Rigby, D. \& Franks, J. 2002, "Structural change and policy reform in the UK dairy sector", Journal of Agricultural Economics, vol. 53, pp. 645663.

Cuadras, C.M. 1996, "Análisis de componentes principales" in Métodos de análisis multivariante. Capítulo 3.

Dadi, L., Burton, M. \& Ozanne, A. 2004, "Duration analysis of technological adoption in Ethiopian agriculture", Journal of Agricultural Economics, vol. 55, pp. 613-631.

De-Cock, L. 2005, "Determinants of organic farming conversion", The Future of Rural Europe in the Global Agri-Food System. XIth International Congress of the $E A A E$, Copenague (Dinamarca).

D'Emben, F.H., Llewellyn, R.S. \& Burton, M.P. 2006, "Adoption of conservation tillage in Australian cropping regions: An application of duration analysis", Technological Forecasting and Social Change, vol. 73, pp. 630-647.

De-Miguel, M.D., Cases, B. \& Moya, I. 1994, "La variación de las rentas en producciones hortofrutícolas mediterráneas", Investigación Agraria: Economía, vol. 9, no. 1, pp. 96-110.

Douvelis, G. 1994, "Forecasting sunflowerseed prices in the United States: the case of an ARIMA model", Oil Crops, vol. 40, pp. 13-15.

Dridi, C. \& Khanna, M. 2005, "Irrigation Technology Adoption and Gains from Water Trading under Asymmetric Information ", American Journal of Agricultural Economics, vol. 87, no. 2, pp. 289-301.

Feder, G., Just, R.E. \& Zilberman, D. 1985, "Adoption of Agricultural Innovations in Developing Countries: A Survey", Economic Development \& Cultural Change, vol. 33, pp. 255.

Fernández, A., Rodríguez, L., Parejo, J.A. \& García, L. 1983, Progreso tecnológico en agricultura. Ed. Banco de Crédito Agrícola, Madrid (España).

Fernández-Sierra, C. 2001, "Producción integrada. Protocolos de inspección y auditorías", VII Simposio nacional de sanidad vegetal. Ed. Consejería de Agricultura y Pesca de Andalucía, Junta de Andalucía, Sevilla (España). 


\section{$\underline{\text { Referencias bibliográficas }}$}

Fernández-Sierra, C. \& Pérez, J. 2004, Caracterización de los invernaderos de la provincia de Almería, Ed. Fundación Cajamar, Almería (España).

Fernández-Zamudio, M.A. \& Caballero, P. 2006, "La necesidad de cuantificar la sostenibilidad de los invernaderos", Vida rural, , no. 239, pp. 49-54.

Fernández-Zamudio, M.A., Pérez, A. \& Caballero, P. 2006, "Análisis económico de la tecnología de los invernaderos mediterráneos: aplicación en la producción del pimiento", ITEA, vol. 102, no. 3, pp. 260-277.

Fernández-Zamudio, M.A., Torró, F., De Miguel, M.D. \& Caballero, P. 2002, "Efectos económicos de la producción integrada en los invernaderos de pimiento", Phytoma España, no. 135, pp. 198-200.

Fernández-Zamudio, M.A., Jover, S., García-Martínez, M.C. \& Caballero, P. 2008, "Economía vs tecnología en los invernaderos mediterráneos", Horticultura, vol. XXVI, no. 3, pp. 14-23.

Freeman, C. 1975, "The National System of Innovation in Historical-Perspective", Cambridge Journal of Economics, no. 19, pp. 5-24.

García-Azcarate, T. \& Mastrostefano, M. 2006, "Las relaciones euromediterráneas y las consecuencias de la reforma de la Política Agrícola Común", Monografías mediterráneas, pp. 55-65.

García-Martínez, M.C., Fernández-Zamudio, M.A. \& Caballero, P. 2008, "Price trends in greenhouse tomato and pepper and choice of adoptable technology", Spanish Journal of Agricultural Research, vol. 6, no. 3, pp. 320-332.

García-Sanz, J. 1865, Guía práctica de labradores y hortelanos, Ed. Villaverde, L.P. , Madrid (España).

Gatignon, H. \& Robertson, T.S. 1991, "Innovative Decision Processes" in Handbook of Consumer Behaviour, eds. T.S. Robertson \& H.H. Kassarjian, Ed. Prentice-Hall, Englewood Cliffs, NJ, pp. 316-348.

Gázquez, J.C., López, J.C., Cabrera, F.J., Meca, D.E., Pérez-Parra, J. \& Baeza, E. 2005, "Estrategias de calefacción en invernadero con cultivo de pimiento", V Congreso Ibérico de Ciencias Hortícolas, Actas de Horticultura, vol. 3, Ed. Asociación Portuguesa de Ciencias Hortícolas.

Gázquez, J.C., Pérez, C., López, J.C., Soler, A., Cabrera, F., Meca, D., Pérez-Parra, J. \& Navarro, I. 2006, "Invernaderos de malla: incidencia de plagas y productividad de un cultivo de tomate", X Jornadas Grupo Horticultura SECH, Actas de Horticultura, Granada (España).

Gellynck, X., Van-Huylenbroeck, G. \& Rogiers, G. 2005, "Greenhouse concentration and sustainable horticulture in densely populated areas", International Journal of Agricultural Resources. Governance and Ecology, vol. 4, no. 1, pp. 2444. 


\section{$\underline{\text { Referencias bibliográficas }}$}

Gentile, N. \& Rodríguez, E. 2004, "El mercado argentino de los alimentos orgánicos", Estudios Económicos, vol. 21, no. 42, pp. 1-20.

Goncharova, N., Oskam, A., Oude-Lansink, A.G.J.M., Van-Der-Vlist, A. \& Verstegen, J.A.A.M. 2008, "Investment spikes in dutch greenhouse horticulture", Journal of Agricultural Economics, vol. 59, no. 3, pp. 516-536.

Gorini, F. 1962, "I requisiti constructtivi delle serre rispetto alla necesita di illuminazione, aereazione e di riscaldamento", Rev. Dell'Orto Florofrutt, vol. 3.

Guàrdia, M.D., Estany, J., Balasch, S., Oliver, M.A., Gispert, M. \& Diestre, A. 2004, "Risk assessment of PSE condition due to pre-slaughter conditions and RYR1 gene in pigs", Meat Science, vol. 67, pp. 471-478.

Guàrdia, M.D., Estany, J., Balasch, S., Oliver, M.A., Gispert, M. \& Diestre, A. 2005, "Risk assessment of DFD meat due to pre-slaughter conditions in pigs", Meat Science, vol. 70, pp. 709-716.

Guigó, M.A. 2004, "La estacionalidad en los precios agrarios durante la primera mitad del S.XIX. Un caso especial: la cebada", Cuadernos de Estudios Empresariales, vol. 14, pp. 207-218.

Guisande, C. \& Vaamonde, A. 2006, "Análisis multivariante" in Tratamiento de datos, Ed. Díaz de Santos, Madrid (España), pp. 207-220.

Hernández, J., Escobar, I. \& Castilla, N. 2000, Nivel tecnológico de los invernaderos de la costa andaluza, Ed. Caja Rural de Granada, Granada (España).

Hinojosa, V., Stoian, D. \& Somarriba, E. 2003, "Los volúmenes de negocio y las tendencias de precios en los mercados internacionales de cacao y banano orgánico", Agroforestaria en las Américas, vol. 10, no. 37/38, pp. 63-68.

Hotelling, H. 1933, "Analysis of a complex of statistical variables into principal components", J.Educ.Psych., vol. 24, pp. 417-441.

Isik, M. \& Khanna, M. 2003, "Stochastic Technology, Risk Preferences, and Adoption of Site-Specific Technologies", American Journal of Agricultural Economics, vol. 85, no. 2, pp. 305-317.

Jobson, J.D. 1992, "Principal Components, Factors and Correspondence Analysis" in Categorical and multivariate methods. Ed. Springer, vol. 2, pp. 345-469.

Jordao, J., Cambero, I., López-García, J.L. \& Briz, J. 2005, "El análisis factorial de Componentes Principales aplicado al estudio de la calidad sensorial de la Pera Rocha portuguesa", V Congreso Ibérico de Ciencias Hortícolas, pp. 547-558.

Jungklaus, S.O. \& Happe, K. 2007, "Non-adoption of conservation tillage because of knowledge gaps? a case study from north-east Bulgaria", $16^{\text {th }}$ Farm Management Congress. Ed. IFM Association, Cork (Irlanda). 


\section{$\underline{\text { Referencias bibliográficas }}$}

Junta de Andalucía 2007, Valoración de la campaña hortícola almeriense 2006/2007. Ed. Secretaría General de Agricultura, Ganadería y Desarrollo Rural, Sevilla (España).

Kalbfleisch, J.D. \& Prentice, R.L. 1980, The statistical analysis of failure time data, Ed. Wiley, New York (USA).

Karshenas, M. \& Stoneman, P.L. 1995, "Technological Diffusion" in Handbook of the economics of innovation and technological change, ed. P. Stoneman. Ed. Blackwell Handbook in Economics, Oxford, pp. 265-296.

Kiefer, N.M. 1988, "Economic duration data and hazard functions", Journal of Economic Literature, vol. 26, pp. 646-679.

Koundouri, P., Nauges, C. \& Tzouvelekas, V. 2006, "Technology Adoption under Production Uncertainty: Theory and Application to Irrigation Technology ", American Journal of Agricultural Economics, vol. 88, no. 3, pp. 657-670.

Krause, M.A. \& Black, J.R. 1995, "Optimal adoption strategies for no-till technology in Michigan", Review of Agricultural Economics, no. 17, pp. 299-310.

Kurkalova, L., Kling, C. \& Zhao, J. 2006, "Green Subsidies in Agriculture: Estimating the Adoption Costs of Conservation Tillage from Observed Behavior", Canadian Journal of Agricultural Economics, no. 54, pp. 247-267.

Lange, O. 1974, Introducción a la econometría, Ed. Fondo de Cultura Económica.

Lidner, R. 1987, "Adoption and diffusion of technology: an Overview." in Technological change in postharvest handling and transportation of grain in the humid tropic, eds. B.R. Champ, E. Highly \& J.V. Remenyi. Ed. Australian Centre for International Agricultural Research, Bangkok, Tailand, pp. 144-151.

López, J.C., Baille, A., Bonachela, S., Montero, J.I., González-Real, M.M. \& PérezParra, J. 2003a, "Consumos de energía en invernaderos multitúnel en la región de Almería. Comparación de dos sistemas de calefacción". Ed. Sociedad Española de Agroingeniería, Córdoba (España).

López, J.C., Pérez, C., Pérez-Parra, J.J. \& Cabrera, F.J. 2003b, "Evaluación de dos sistemas de ahorro de energía para un cultivo de pepino en invernadero parral", $\mathrm{X}$ Congreso Nacional de Ciencias Hortícolas. Actas de Horticultura, Pontevedra (España).

Lorenzo, P., Medrano, E. \& Sánchez-Guerrero, M.C. 2000, "Recirculación en cultivo sin suelo de pepino en Almería", Horticultura, Ed. Horticultura, S.L., pp. 7380 .

Macedo, R., Galina, M.A., Zorrilla, J.M., Palma, J.M. \& Pérez Guerrero, J. 2003, "Análisis de un sistema de producción tradicional en Colima, México", Archivos de Zootecnia, vol. 52, pp. 463-474. 


\section{$\underline{\text { Referencias bibliográficas }}$}

Magán, J.J., López, J.C., Escudero, A. \& Pérez-Parra, J. 2007, "Comparación de dos estructuras de invernadero (cristal vs. plástico) equipadas con sistemas de control activo del clima", XI Congreso de Ciencias Hortícolas, Albacete (España), pp. 880883.

Mahajan, V., Muller, E. \& Bass, F.N. 1990, "New products diffusion model in marketing: a review and directions for research", Journal of Marketing, vol. 54, pp. $1-26$.

Makridakis, S. \& Wheelwright, S.C. 1978, Interactive forecasting, 2nd edn. Ed. Holden Day, S. Francisco (USA).

Manheim, J.B. \& Rich, R.C. 1988, "The Research Process" in Análisis político empírico: métodos de investigación en ciencia política. Alianza Editorial, Madrid (España).

MAPA 2007, Anuario de Estadística Agroalimentaria [Homepage of Ministerio de Agricultura, Pesca y Alimentación], [Online]. Available: http://www.mapa.es/es/estadistica/pags/anuario/introduccion.htm [2008].

MAPA 2006, Anuario de Estadística Agroalimentaria [Homepage of Ministerio de Agricultura, Pesca y Alimentación], [Online]. Available: http://www.mapa.es/es/estadistica/pags/anuario/introduccion.htm [2007].

Marco-Jiménez, F., Viudes-de-Castro, M.P., Balasch, S., Mocé, E., Silvestre, M.A., Gómez, E.A. \& Vicente, J.S. 2006, "Morphometric changes in goat sperm heads induced by cryopreservation", Cryobiology, vol. 52, pp. 295-304.

Marfá, O. 2000, Recirculación en cultivo sin suelo, Ed. Horticultura S.L., Reus (España).

Maroto, J.V. 2008, Elementos de horticultura general, $3^{\mathrm{a}}$ edn. Ed. Mundi-Prensa, Madrid (España).

Maroto, J.V. 2002, Horticultura herbácea especial, 5ª edn. Ed. Mundi-Prensa, Madrid (España).

Marra, M., Pannell, D.J. \& Abadi, A.K. 2003, "The economics of risk, uncertainty and learning in the adoption of new agricultural technologies: where are the learning curve?", Agricultural Systems, vol. 75, pp. 215-234.

Martín, J.P. 2001, "El futuro de los invernaderos", Horticultura, vol. 150, pp. 28-40.

Martínez, P.F., Roca, D., Suay, R., Martínez, M., Blasco, X., Herrero, J.M. \&

Ramos, C. 2002, "Avances en el control de los factores del clima para el cultivo en invernadero", Comunitat Valenciana Agraria. Ed. Generalitat Valenciana, no. 20, pp. 29-47. 
Martínez, M., Marín, C., Torres, A. \& Laínez, M. 2008, Caracterización de las explotaciones de pollos de engorde de la Comunitat Valenciana. Ed. Fundación Agroalimed, Valencia (España).

Martínez-Caldevilla, E. \& García-Lozano, M. 1993, Cultivos sin suelo: Hortalizas en clima mediterráneo. Ed. Horticultura S.L, Reus (España).

Martínez-Paz, J.M. 2003, Economía y gestión del agua en la Horticultura intensiva de Almería. Un enfoque desde la teoría de la decisión. Tesis Doctoral. Universidad de Murcia (España).

Martín-Guzmán, P. \& Martín, J. 1989, Curso básico de estadística económica, $3^{\text {a }}$ edn. Editorial AC, Madrid (España).

Matallana, A. \& Montero, J.I. 2001, Invernaderos. Diseño, Construcción y Ambientación, $2^{\mathrm{a}}$ edn. Ed. Mundi-Prensa, Madrid (España).

Matuschke, I. \& Qaim, M. 2008, "Seed Market Privatisation and Farmers' Access to Crop Technologies: The Case of Hybrid Pearl Millet Adoption in India", Journal of Agricultural Economics, vol. 59, no. 3, pp. 498-515.

Mesas, A.B. \& Valero, L.M. 2006, "Ensayo de invernaderos alta tecnología para cultivo de pimiento en otoño", eds. Generalidad Valenciana \& Fundación ruralcaja, Valencia (España), pp. 66.

Millán, J.A. \& Ruiz, P. 1987, "Modelos logit de adopción de innovaciones en invernaderos de Almería", Revista Investigación Agraria, vol. 2, no. 2, pp. 115-125.

Molina, F.D., Valera, D.L., Gil, J.A. \& Álvarez, A.J. 2003, "Evolución de los invernaderos de Almería", Riegos y Drenajes del Siglo XXI, vol. Especial Almería, pp. 58-63.

Montero, J.I., Stanghellini, C. \& Castilla, N. 2008, "Invernadero para la producción sostenible en áreas de clima de invierno suaves", Horticultura Internacional, no. 65, pp. 12-26.

Moreno, G. \& Sunding, D. 2005, "Joint estimation of technology adoption and land allocation with implications for the design of conservation policy", Amer. J. Agr. Econ., vol. 87, no. 4, pp. 1009-1019.

Muñoz, R.M. 2004, Difusión y adopción del tractor agrícola en Cataluña, Tesis Doctoral. Universidad de Lérida (España).

Najeeb, I., Khuda, B., Asif, M. \& Ahmad, A.S. 2005, "Use of the ARIMA model for forecasting wheat area and production in Pakistan", Journal of Agriculture and Social Sciences, vol. 1, no. 2, pp. 120-122.

Navarro, J.A. 2001, "Producción integrada: incidencia de las nuevas normativas de residuos de plaguicidas sobre la horticultura almeriense" in El Sector Agrario y 


\section{$\underline{\text { Referencias bibliográficas }}$}

Agroalimentario de Almería ante el S.XXI, ed. J.A. Salinas. Ed. Instituto de Estudios Almerienses. Almería (España), pp. 221-246.

Negri, D.H. \& Brooks, D.H. 1990, "Determinants of irrigation technology choice", Western Journal of Agricultural Economics, vol. 15, no. 2, pp. 213-223.

Noguera, P. 1996, "El patrón estacional de los precios y de las producciones hortofrutícolas", Revista Española de Economía Agraria, vol. 178, pp. 35-72.

Ortega, E. 1981, "La tipología" in Manual de investigación comercial. Ed. Pirámide, Madrid (España), pp. 654-668.

Oude-Lansink, A.G.J.M. \& Pietola, K. 2005, "Semi-parametric modelling of investments in heating instalations: The case of the Dutch glasshouse industry", Journal of Agricultural Economics, vol. 56, no. 3, pp. 433-448.

Panell, D.J., Marshall, G.R., Barr, N., Curtis, A., Vanclay, F. \& Wilkinson, R. 2006, "Understanding and promoting adoption of conservation practices by rural landholders", Australian Journal of Experimental Economics, no. 46, pp. 14071424.

Pearson, K. 1914, Tables for Statisticians and Biometricians.

Peña, D. 2005, Análisis de series temporales, Alianza Editorial, Madrid (España).

Pérez, C. 2001, "Componentes principales y análisis factorial" in Técnicas Estadísticas con SPSS. Ed. Prentice Hall, Madrid (España).

Pérez, J., López, J.C. \& Fernández, M.D. 2002, "La agricultura del Sureste: Situación actual y tendencias de las estructuras de producción en la horticultura almeriense" in La agricultura Mediterréanea en el S.XXI, ed. J.M. García ÁlvarezCoque. Ed. Instituto de Estudios Socioeconómicos de Cajamar, Almería (España), pp. 262-282.

Pérez, C. 2002, Estadística práctica con Statgraphics. Ed. Prentice Hall, Madrid (España).

Peterson, J.M., Cassman, K.G. \& Cantrell, R. 2002, "Changes in cultural practices of farmers in Southeast Nebraska as a Result of Their Adoption of Transgenic Crops", Journal of Extension, vol. 40, no. 1.

Pindyck, R. \& Rubinfeld, D. 1998, Econometric models and economic forecasts. Ed. McGraw Hill, New York (USA).

Pujante, F. 2001, "Control climático en invernadero" in El sector agrario y agroalimentario de Almería ante el S. XXI. Ed. Instituto de Estudios Almerienses, Almería (España), pp. 211-219.

Pulido, F., Escribano, M., Rodríguez de Ledesma, A. \& Mesías, F.J. 2001, "Segmentación de los consumidores extremeños de queso", IV Congreso Nacional 


\section{$\underline{\text { Referencias bibliográficas }}$}

de Economía Agraria. Ed. Asociación Española de Economía Agraria, Pamplona (España).

Quesada, F.M., Hernández, J., Morales, M.I., Guillén, A. \& Castilla, N. 1998, "Pendientes de cubierta en invernaderos asimétricos: respuesta de un cultivo de pepino", III Congreso Nacional de Ciencias Hortícolas, pp. 45-50.

Rahm, M.R. \& Huffman, W.E. 1984, "The adoption of reduced tillage: The role of human capital and other variables", American Journal of Agricultural Economics, no. November 1984, pp. 405-413.

Ramos, R. 2008, "Técnicas para la producción ecológica de cultivos hortofrutícolas", Vida rural, noviembre 2008, pp. 38-42.

Rapey, H., Lifran, R. \& Valadier, A. 2001, "Identifying social, economic and technical determinants of silvopastoral practices in temperature uplands: results of a survey in the Massif central region of France", Agricultural Systems, vol. 69, no. 12, pp. 119-135.

Rodríguez-Díaz, J.A., Camacho-Poyato, E., López-Luque, R. \& Pérez-Urrestarazu, L. 2008, "Benchmarking and multivariate data analysis techniques for improving the efficiency of irrigation districts: An application in Spain", Agricultural Systems, vol. 96, pp. 250-259.

Rogers, E.M. 2003, Diffusion of innovations, $5^{\mathrm{a}}$ edn, New York (USA).

Rogers, E.M. 1962, Diffusion of innovations, $1^{\mathrm{a}}$ edn, New York (USA).

Rogers, E.M. \& Shoemaker, F.F. 1971, Communication of innovations. ColliersMcMillan, New York (USA).

Romero, R. \& Balasch, S. 1986, "Evaluación de la efectividad de la lucha antigranizo en Navarra: Una aplicación del enfoque Box-Jenkins del análisis de series temporales", Inv Agrar: Prod Prot Veg, vol. 1, no. 3, pp. 360-377.

Sánchez-Guerrero, M.C. 1999, Enriquecimiento carbónico en cultivos hortícolas bajo invernadero de polietileno. Tesis Doctoral. Universidad de Murcia (España).

Scarascia, G. 1995, "Sustainable greenhouse production in mediterranean climate: A case study in Italy", Medit, no. 4, pp. 48-58.

Schumpeter, J. 1939, Business Cycles. Ed. McGraw-Hill, New York (USA).

Sédilot, C., Degas, L., Le Quillet, S., Brajeul, E. \& Grasselly, D. 2002, "La gestion des effluents des serres. L'etat des lieux en France", Infos Ctifl, vol. 181, pp. 50-53.

Serra, T., Zilberman, D. \& Gil, J.M. 2008, "Differential uncertainties and risk attitudes between conventional and organic producers: the case of Spanish arable crop farmers", Agricultural Economics, vol. 39, no. 2, pp. 219-229. 


\section{$\underline{\text { Referencias bibliográficas }}$}

Sineiro, F., Valdês, B. \& López, E. 2005, "Características productivas y familiares de las explotaciones inversoras en la producción de vacuno en Galicia", V Congreso de Economía Agraria. Ed. Sociedad Española de Economía Agraria. Santiago de Compostela (España).

Sokal, R.R. \& Sneath, P.H.A. 1963, Principles of Numerical Taxonomy. Ed. Freeman, San Francisco (USA).

Soriano, T., Morales, M.I., Hita, O. \& Romacho, I. 2006, "Cultivos estivales bajo mallas plásticas", Horticultura, vol. 192, pp. 14-18.

Sunding, D. \& Zilberman, D. 2001, "The agricultural innovation process: research and technology adoption in a changing agricultural sector" in Handbook of agricultural economics, eds. B.L. Gardner \& G.C. Rausser. Ed. Elsevier, Amsterdam, pp. 207-261.

Tan, S. 1994, "Predicting Innovation Adoption: A Choice-Based Approach", Asia Pacific Advances in Consumer Research, no. 1, pp. 72-78.

Tendero, D. 2004, "La ventilación natural y su mecanización en invernaderos", Horticultura, no. 198, pp. 26-31.

Torres, A., Albiñana, B., Balasch, S., Gallego, L., Fernández, N., Rodríguez, M. \& Molina, A. 1993, "Un ensayo de caracterización de los sistemas ovinos en CastillaLa Mancha: Aproximación mediante un modelo multivariante de componentes principales", ITEA, vol. Extra, no 12, Tomo II, pp. 672-674.

Train, K. 2003, Discrete Choice Methods with Simulation. Ed. Cambridge University Press, Cambridge (England).

Uriel, E. \& Peiró, A. 2000, Introducción al análisis de series temporales, AC, Madrid (España).

Urrestarazu, M. 2004, Tratado de cultivo sin suelo, $3^{\mathrm{a}}$ edn. Ed. Mundi-Prensa, Madrid (España).

Useche, P., Barham, B.L. \& Foltz, J.D. 2009, "Integrating Technology Traits and Producer Heterogeneity: A Mixed-Multinomial Model of Genetically Modified Corn Adoption", American Journal of Agricultural Economics, vol. 91, no. 2, pp. 444461.

Valera, D. \& Molina, F. 2008, "Gestión mecanizada de la fertirrigación, las labores culturales y el clima en invernaderos", Vida rural, no. Mayo 2008, pp. 47-52.

Verguts, V., Dessein, J. \& Lauwers, L. 2008, "Transition towards sustainability: Dutch greenhouse parks as a touschstone for Flemish clustering experiments", $12^{\text {th }}$ Congress of the EAAE, Gent (Belgium).

Wynn, G., Crabtree, B. \& Potts, J. 2001, Journal of Agricultural Economics, vol. 52, no. 1 , pp. 65-82. 

Anexos 

Anexo 1 

$\underline{\text { Anexo } 1}$

\section{Anexo 1. Series de precios}

\section{Tabla A1.1. Precios quincenales en origen del tomate acostillado en Almería (en $€ / \mathrm{kg}$, datos actualizados a Agosto de}

2006)

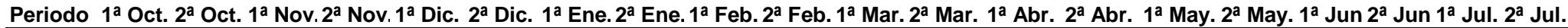
\begin{tabular}{lllllllllllllllllllll}
\hline $\mathbf{1 9 9 2 / 9 3}$ & 0,60 & 0,62 & 0,76 & 0,86 & 0,83 & 0,67 & 1,06 & 0,87 & 1,27 & 1,36 & 1,27 & 1,36 & 1,89 & 1,99 & 1,61 & 1,28 & 0,56 & 0,39 & 0,37 & 0,37
\end{tabular}

$\begin{array}{lllllllllllllllllllll}1993 / 94 & 0,89 & 1,08 & 1,38 & 1,59 & 0,88 & 0,95 & 1,12 & 1,00 & 1,11 & 1,08 & 0,85 & 1,56 & 1,60 & 1,85 & 0,84 & 0,51 & 0,45 & 0,47 & 0,58 & 0,59\end{array}$

$\begin{array}{llllllllllllllllllllll}\mathbf{1 9 9 4} / 95 & 1,31 & 0,98 & 1,20 & 0,65 & 0,93 & 1,21 & 1,40 & 1,18 & 1,03 & 1,03 & 1,53 & 1,78 & 1,10 & 2,24 & 1,99 & 1,39 & 0,61 & 0,30 & 0,18 & 0,24\end{array}$

$\begin{array}{lllllllllllllllllllllll}1995 / 96 & 0,50 & 0,49 & 0,94 & 1,06 & 1,64 & 1,50 & 1,12 & 1,15 & 1,32 & 1,64 & 2,14 & 1,73 & 1,47 & 1,85 & 1,99 & 2,12 & 1,63 & 0,71 & 0,66 & 0,55\end{array}$

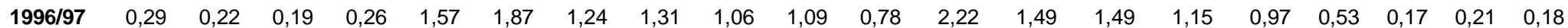

$\begin{array}{llllllllllllllllllllll}1997 / 98 & 0,33 & 0,62 & 0,84 & 1,16 & 1,32 & 1,53 & 1,37 & 1,55 & 0,33 & 1,81 & 1,91 & 2,26 & 2,10 & 1,62 & 1,28 & 0,85 & 0,27 & 0,27 & 0,16 & 0,21\end{array}$

$\begin{array}{llllllllllllllllllllll}1998 / 99 & 0,51 & 0,69 & 1,14 & 1,72 & 2,05 & 2,24 & 1,89 & 1,80 & 1,95 & 1,49 & 1,43 & 1,83 & 1,61 & 1,79 & 2,53 & 1,40 & 0,62 & 0,33 & 0,26 & 0,30\end{array}$

$\begin{array}{lllllllllllllllllllllll}\mathbf{1 9 9 9} / 00 & 0,50 & 0,97 & 1,18 & 1,52 & 2,72 & 1,09 & 0,87 & 1,34 & 1,24 & 1,30 & 1,94 & 2,30 & 2,16 & 2,33 & 1,93 & 1,22 & 0,42 & 0,16 & 0,34 & 0,29\end{array}$

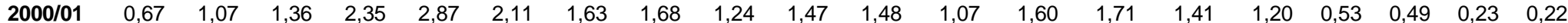

$\begin{array}{lllllllllllllllllllllll}\mathbf{2 0 0 1 / 0 2} & 0,36 & 0,07 & 0,55 & 1,05 & 2,00 & 1,98 & 0,94 & 2,27 & 2,34 & 2,32 & 1,40 & 3,50 & 2,54 & 3,80 & 1,80 & 1,13 & 1,04 & 0,72 & 0,21 & 0,36\end{array}$

$\begin{array}{lllllllllllllllllllll}\mathbf{2 0 0 2} / 03 & 0,33 & 0,31 & 0,55 & 0,57 & 3,11 & 0,71 & 0,87 & 1,41 & 1,12 & 1,13 & 1,27 & 1,56 & 2,41 & 2,58 & 2,51 & 1,81 & 0,91 & 0,77 & 0,49 & 0,59\end{array}$

$\begin{array}{lllllllllllllllllllll}\mathbf{2 0 0 3} / 04 & 1,82 & 0,65 & 1,01 & 1,79 & 1,62 & 1,78 & 1,57 & 1,58 & 1,50 & 1,55 & 1,40 & 1,65 & 1,86 & 2,64 & 2,64 & 2,61 & 1,53 & 0,71 & 0,66 & 0,46\end{array}$

$\begin{array}{llllllllllllllllllllll}\mathbf{2 0 0 4} / 05 & 0,49 & 0,69 & 1,17 & 2,70 & 2,36 & 2,19 & 1,34 & 1,05 & 1,25 & 1,52 & 2,06 & 1,83 & 1,56 & 3,00 & 2,57 & 1,40 & 0,59 & 0,32 & 0,24 & 0,44\end{array}$

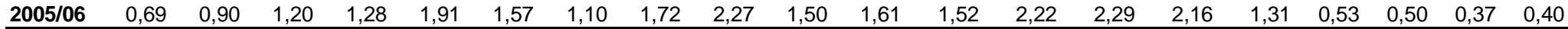

Fuente: Elaboración propia a partir de "Boletines Semanales de Información Agraria", Consejería de Agricultura Junta de Andalucía (1992-2006). 
Tabla A1.2. Precios quincenales en origen del tomate larga vida en Almería (en $€ / \mathbf{k g}$, datos actualizados a Agosto de 2006)

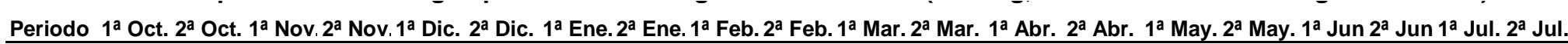

\begin{tabular}{|c|c|c|c|c|c|c|c|c|c|c|c|c|c|c|c|c|c|c|c|c|}
\hline 1997/98 & 0,78 & 0,63 & 0,71 & 0,60 & 0,64 & 0,80 & 0,77 & 0,54 & 0,58 & 0,55 & 0,82 & 0,61 & 0,71 & 0,65 & 0,34 & 0,45 & 0,22 & 0,22 & 0,36 & 0,37 \\
\hline 1998/99 & 0,67 & 1,08 & 1,08 & 0,67 & 0,87 & 1,50 & 0,95 & 0,99 & 0,64 & 0,57 & 0,58 & 0,52 & 0,54 & 0,68 & 0,64 & 0,83 & 0,34 & 0,35 & 0,41 & 0,44 \\
\hline 1999/00 & 0,76 & 0,59 & 0,76 & 0,57 & 0,88 & 0,93 & 0,65 & 0,71 & 0,72 & 0,56 & 1,05 & 1,57 & 1,46 & 1,26 & 0,72 & 0,54 & 0,26 & 0,35 & 0,61 & 0,47 \\
\hline $2001 / 02$ & 0,43 & 0,62 & 0,43 & 0,47 & 0,77 & 1,00 & 0,37 & 0,98 & 075 & 0,88 & 103 & 151 & 1,23 & 1,13 & 0,90 & 0,25 & 0,29 & 0,37 & 0,18 & 0,48 \\
\hline $2002 / 03$ & 0,86 & 0,68 & 0,53 & 0,21 & 0,73 & 0,15 & 0,49 & 0,54 & 0,72 & 0,63 & 0,77 & 0,67 & 0,83 & 0,96 & 0,64 & 0,44 & 0,44 & 0,54 & 0,48 & 0,50 \\
\hline 2003/04 & 0,57 & 0,66 & 0,97 & 0,75 & 0,58 & 0,66 & 0,62 & 0,44 & 0,58 & 0,60 & 0,75 & 0,83 & 0,52 & 0,46 & 0,49 & 0,41 & 0,36 & 0,24 & 0,30 & 0,25 \\
\hline 2005/06 & 0,45 & 0,63 & 0,46 & 0,49 & 0,45 & 0,58 & 0,50 & 0,57 & 0,52 & 0,48 & 0,58 & 0,63 & 0,70 & 0,72 & 0,79 & 0,76 & 0,26 & 0,30 & 0,42 & 0,64 \\
\hline
\end{tabular}

Fuente: Elaboración propia a partir de "Boletines Semanales de Información Agraria", Consejería de Agricultura Junta de Andalucía (1997-2006). 
$\underline{\text { Anexo } 1}$

Tabla A1.3. Precios quincenales en origen del pimiento verde en Almería (en $€ / \mathbf{k g}$, datos actualizados a Agosto de 2006)

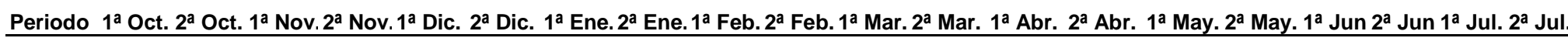

\begin{tabular}{|c|c|c|c|c|c|c|c|c|c|c|c|c|c|c|c|c|c|c|c|c|}
\hline & 82 & 77 & 0,62 & 0,47 & 0,40 & 0,43 & 0,59 & 0,70 & 1,72 & 1,29 & & 1,28 & 1,32 & 0,90 & 0,64 & 0,39 & 0,28 & 0,33 & 0,31 & \\
\hline 993/94 & & & & & & & & & & & & & & & & & & & & \\
\hline $94 / 95$ & 79 & 68 &, 57 & &, 73 &, 69 & & 33 & ,53 & 1,86 & 1,56 & & & & & ,66 &, 50 & ,76 & ,69 & \\
\hline 995/96 & 0,66 & ,55 & 0,52 & 0,58 & 0,82 & 111 & 1,34 & 001 & 0,93 & 0,85 & 1,33 & 111 & 151 & 100 & 0,77 & 0,80 & ,66 & ,66 & 0,42 & 1 \\
\hline $006 / 07$ & 0,34 &, 49 & 0 & 0,32 & 025 & ד7 0 & & 116 & & & (1,J) & & & & & & & & 0,43 & \\
\hline 97/98 &, 57 & ,71 & ,, 57 &, 44 & 0,50 & 0,87 & , 16 & 0,99 & ,88 & 0,80 & 1,36 & |,31 & 1,0 & 0,83 & 0,42 & 0,67 & , ,39 & , 39 &, 46 & \\
\hline 998/99 & 0,39 & 0,78 & 0,52 & 0,50 & 0,65 & 0,72 & 0,92 & 0,75 & 1,21 & 0,78 & 1,10 & 0,98 & 0,89 & 0,88 & 0,55 & 0,44 & 0,34 & 0,58 & 0,50 & \\
\hline ( & 1,12 & 0,67 & 0,77 & 0,75 & & 0,90 & & 0,70 & & & & & & & & & & & & \\
\hline $001 / 02$ & 1,00 & 0,87 & 0,69 & 0,55 & 0,75 & 0,99 & 0,58 & 0,76 & ,92 & 1,05 & 0,57 & 0,94 & 1,00 & 0,33 & 0,18 & 0,09 & 0,14 & 0,34 & 0,33 & \\
\hline $02 / 03$ & 65 & 0,55 & 0,47 & 18 & 0,48 & 0,32 & 0,54 & 0,52 & ,61 & 0,85 & 0,70 & 0.53 & 014 & & 0,33 & 0,47 & 0,45 & 0,64 & 0,63 & \\
\hline 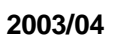 & 0,40 & 0,38 & 0,00 & 0,66 & 0,91 & 0,92 & 1,07 & 0,78 & & 1,04 & 1,43 & & & & 0,30 & & & & 0,61 & \\
\hline $004 / 05$ & ,77 & 0,73 & 0,70 & 0,67 & 0,78 & 1,03 & 0,68 & 0,88 & 0,93 & 0,88 & 1,10 & 1,14 & 0,85 & 0,26 & 0,2 & 0,31 & 0,39 & 0,47 & 0,31 & \\
\hline
\end{tabular}

Fuente: Elaboración propia a partir de "Boletines Semanales de Información Agraria", Consejería de Agricultura Junta de Andalucía (1992-2006). 
$\underline{\text { Anexo } 1}$

Tabla A1.4. Precios quincenales en origen del pimiento rojo en Almería (en $€ / \mathrm{kg}$, datos actualizados a Agosto de 2006)

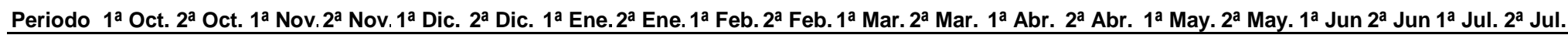

\begin{tabular}{lllllllllllllllllllll}
\hline \hline $\mathbf{1 9 9 2 / 9 3}$ & 1,31 & 1,88 & 1,14 & 0,95 & 1,14 & 1,05 & 0,55 & 0,60 & 1,01 & 1,05 & 0,80 & 0,80 & 1,75 & 1,74 & 1,39 & 0,58 & 1,14 & 0,34 & 0,32 & 0,28
\end{tabular}

$\begin{array}{llllllllllllllllllllllll}\mathbf{1 9 9 3} / 94 & 1,08 & 1,05 & 1,53 & 1,02 & 1,05 & 1,02 & 1,39 & 1,51 & 1,63 & 1,59 & 2,52 & 2,09 & 0,88 & 1,16 & 1,65 & 0,93 & 0,62 & 0,85 & 0,81 & 0,72\end{array}$

$\begin{array}{lllllllllllllllllllll}1994 / 95 & 0,85 & 0,78 & 0,76 & 0,69 & 0,85 & 0,92 & 0,91 & 1,43 & 1,67 & 1,49 & 1,42 & 1,30 & 1,20 & 1,53 & 0,93 & 0,71 & 0,74 & 0,82 & 0,93 & 0,81\end{array}$

$\begin{array}{llllllllllllllllllllllll}1995 / 96 & 0,95 & 0,66 & 0,76 & 0,57 & 0,70 & 0,75 & 0,86 & 0,82 & 1,20 & 1,82 & 2,56 & 2,05 & 1,28 & 0,86 & 1,36 & 1,39 & 0,96 & 1,04 & 0,50 & 0,71\end{array}$

$\begin{array}{llllllllllllllllllllllll}1996 / 97 & 0,65 & 0,62 & 0,46 & 0,49 & 0,42 & 0,42 & 0,84 & 0,78 & 1,23 & 1,77 & 2,15 & 2,37 & 1,75 & 0,64 & 2,57 & 1,78 & 0,54 & 0,45 & 0,60 & 0,91\end{array}$

$\begin{array}{lllllllllllllllllllll}1997 / 98 & 0,66 & 0,67 & 0,71 & 0,70 & 1,04 & 0,72 & 1,04 & 0,91 & 1,21 & 1,09 & 1,66 & 1,09 & 0,68 & 0,43 & 0,44 & 0,93 & 0,93 & 0,93 & 0,36 & 0,79\end{array}$

$\begin{array}{llllllllllllllllllllllll}1998 / 99 & 0,82 & 1,01 & 1,24 & 1,41 & 1,64 & 1,85 & 1,08 & 0,70 & 0,84 & 0,61 & 0,90 & 0,70 & 0,97 & 0,68 & 0,90 & 1,01 & 0,44 & 0,36 & 0,38 & 1,18\end{array}$

$\begin{array}{llllllllllllllllllllllll}\mathbf{1 9 9 9} / 00 & 0,71 & 0,80 & 0,77 & 0,70 & 0,88 & 0,97 & 0,94 & 1,51 & 2,16 & 1,92 & 1,27 & 1,07 & 0,67 & 0,82 & 0,80 & 0,92 & 1,25 & 1,02 & 0,83 & 0,73\end{array}$

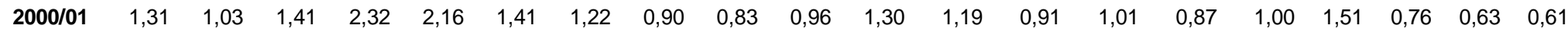

$\begin{array}{llllllllllllllllllllllll}\mathbf{2 0 0 1 / 0 2} & 0,69 & 0,68 & 0,64 & 0,63 & 1,00 & 0,99 & 0,59 & 0,83 & 1,26 & 0,95 & 0,59 & 0,79 & 0,76 & 0,37 & 0,22 & 0,26 & 0,19 & 0,17 & 0,23 & 0,58\end{array}$

$\begin{array}{lllllllllllllllllllllll}\mathbf{2 0 0 2} / 03 & 1,03 & 0,69 & 0,56 & 0,18 & 0,50 & 0,31 & 0,46 & 0,59 & 0,54 & 0,87 & 0,99 & 1,51 & 1,53 & 0,80 & 1,24 & 0,56 & 0,57 & 0,65 & 0,99 & 0,89\end{array}$

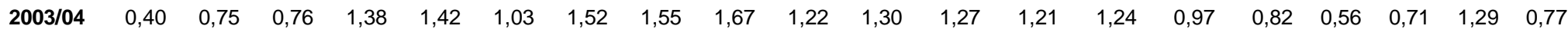

$\begin{array}{llllllllllllllllllllllll}\mathbf{2 0 0 4} / 05 & 0,45 & 0,54 & 0,80 & 1,06 & 1,36 & 1,37 & 0,77 & 1,43 & 1,58 & 1,32 & 1,17 & 0,93 & 0,68 & 0,32 & 0,46 & 0,33 & 0,37 & 0,45 & 0,25 & 0,32\end{array}$

\begin{tabular}{rrrrrrrrrrrrrrrrrrrrrrrr}
$\mathbf{2 0 0 5 / 0 6}$ & 0,54 & 0,65 & 0,49 & 0,76 & 0,31 & 0,50 & 0,63 & 0,63 & 0,73 & 0,76 & 0,82 & 0,82 & 0,47 & 0,76 & 0,39 & 0,49 & 0,24 & 0,32 & 0,70 & 0,80 \\
\hline
\end{tabular}

Fuente: Elaboración propia a partir de "Boletines Semanales de Información Agraria", Consejería de Agricultura Junta de Andalucía (1992-2006). 
Tabla A1.5. Precios quincenales en origen del tomate liso en Murcia (en $€ / \mathbf{k g}$, datos actualizados a Septiembre de 2006)

\begin{tabular}{|c|c|c|c|c|c|c|c|c|c|c|c|c|c|c|c|c|c|c|c|c|c|c|c|c|}
\hline & & & & & & & & & & & & & & & & & & & a Jul & $2^{\mathrm{a}} \mathrm{Jul}$. & & & & \\
\hline 1992/93 & 1,24 & 0,70 & 0,78 & 0,73 & 0,79 & 1,04 & 0,79 & 0,56 & 0,51 & 0,47 & 0,76 & 0,89 & 1,76 & 1,69 & 1,57 & 0,74 & 0,60 & 0,53 & 0,67 & 0,53 & 0,52 & 0,51 & 0,72 & 1,05 \\
\hline 1993/94 & 1,38 & 0,71 & 0,78 & 0,70 & 0,65 & 0,81 & 0,68 & 0,56 & 0,50 & 0,60 & 0,82 & 1,02 & 0,97 & 1,39 & 0,99 & 0,51 & 0,59 & 0,74 & 0,70 & 0,75 & 0,75 & 0,57 & 0,85 & 1,22 \\
\hline 1994/95 & 1,52 & 0,72 & 0,78 & 0,67 & 0,52 & 0,60 & 0,68 & 0,68 & 0,64 & 0,59 & 0,91 & 1,20 & 1,24 & 0,94 & 0,68 & 0,50 & 0,57 & 0,35 & 0,26 & 0,45 & 0,42 & 0,39 & 0,50 & 0,61 \\
\hline 1995/96 & 0,72 & 0,54 & 0,62 & 0,64 & 0,89 & 1,24 & 0,70 & 0,64 & 0,89 & 0,88 & 1,16 & 1,05 & 1,04 & 1,10 & 0,78 & 0,48 & 0,55 & 0,51 & 0,45 & 0,56 & 0,55 & 0,45 & 0,63 & 1,02 \\
\hline $1996 / 97$ & 1,05 & 0,59 & 0,66 & 0,62 & 0,67 & 0,88 & 0,68 & 0,55 & 0,70 & 0,55 & 0,76 & 0,84 & 1,11 & 1,18 & 0,93 & 0,64 & 0,48 & 0,47 & 0,42 & 0,45 & 0,66 & 0,78 & 0,82 & 0,88 \\
\hline 1997/98 & 0,94 & 0,79 & 0,72 & 0,76 & 0,69 & 0,99 & 0,65 & 0,59 & 0,67 & 0,90 & 1,13 & 1,07 & 0,87 & 1,11 & 0,72 & 0,49 & 0,51 & 0,62 & 0,53 & 0,51 & 0,77 & 1,11 & 1,00 & 0,64 \\
\hline 1998/99 & 0,84 & 0,98 & 0,78 & 0,91 & 0,71 & 0,80 & 0,69 & 0,65 & 0,53 & 0,56 & 0,73 & 0,86 & 0,50 & 1,05 & 1,01 & 0,76 & 0,52 & 0,50 & 0,42 & 0,62 & 0,63 & 0,61 & 0,61 & 0,61 \\
\hline 1999/00 & 0,78 & 0,98 & 1,04 & 0,91 & 0,60 & 0,73 & 0,52 & 0,54 & 0,67 & 0,94 & 1,68 & 1,61 & 1,30 & 1,30 & 0,56 & 0,37 & 0,36 & 0,72 & 0,52 & 0,48 & 0,84 & 1,50 & 1,06 & 0,62 \\
\hline 2000/01 & 0,84 & 1,11 & 0,88 & 1,09 & 0,87 & 0,74 & 0,64 & 0,51 & 0,71 & 1,05 & 0,81 & 0,57 & 0,68 & 0,80 & 0,50 & 0,28 & 0,56 & 0,55 & 0,55 & 0,35 & 0,65 & 0,92 & 0,78 & 0,75 \\
\hline $2001 / 02$ & 0,82 & 0,68 & 0,30 & 0,57 & 0,53 & 0,77 & 0,59 & 0,94 & 0,99 & 1,22 & 1,66 & 1,61 & 1,38 & 1,10 & 0,27 & 0,34 & 0,30 & 0,54 & 0,43 & 0,54 & 0,47 & 0,38 & 0,52 & 0,86 \\
\hline 2002/03 & 0,93 & 1,10 & 0,86 & 0,61 & 0,63 & 0,54 & 0,44 & 0,37 & 0,50 & 0,60 & 0,60 & 0,74 & 0,89 & 1,06 & 0,47 & 0,41 & 0,46 & 0,36 & 0,45 & 0,63 & 0,89 & 0,81 & 0,88 & 1,48 \\
\hline 2003/04 & 1,41 & 1,23 & 0,77 & 0,51 & 0,71 & 0,49 & 0,42 & 0,28 & 0,37 & 0,46 & 0,44 & 0,38 & 0,22 & 0,26 & 0,38 & 0,49 & 0,27 & 0,38 & 0,28 & 0,28 & 0,28 & 0,27 & 0,31 & 0,45 \\
\hline $2004 / 05$ & 0,58 & 0,60 & 0,55 & 0,71 & 0,80 & 0,65 & 0,68 & 0,75 & 0,69 & 0,59 & 0,54 & 0,66 & 0,70 & 0,76 & 0,84 & 0,40 & 0,24 & 0,29 & 0,28 & 0,42 & 0,62 & 0,62 & 0,70 & 0,64 \\
\hline 2005/06 & 0,58 & 0,50 & 0,39 & 0,45 & 0,39 & 0,49 & 0,29 & 0,31 & 0,23 & 0,28 & 0,38 & 0,38 & 0,49 & 0,85 & 0,68 & 0,42 & 0,36 & 0,47 & 0,70 & 0,57 & 0,66 & 0,57 & 0,60 & 0,57 \\
\hline
\end{tabular}

Fuente: Elaboración propia a partir de "Informe Semanal Agrario", Consejería de Agricultura Región de Murcia (1992-2006). 
Tabla A1.6. Precios quincenales en origen del pimiento verde en Murcia (en $€ / \mathbf{k g}$, datos actualizados a Septiembre de 2006)

\begin{tabular}{|c|c|c|c|c|c|c|c|c|c|c|}
\hline do & 2'Mar. & $1^{\mathrm{a}} \mathrm{Abr}$. & $2^{\mathrm{a}} \mathrm{Abr}$ & 1ªy. & 2ªyay. & 1ªun. & 2ª Jun. & Jul. & 2- Jul. & $\mathbf{1}^{\mathrm{a}} \mathrm{Ago}$. \\
\hline 1992 & 2,08 & 2,11 & 1,67 & 0,91 & $\overline{00,63}$ & $\overline{0,58}$ & 0,58 & 0 & $0,0,55$ & 0,57 \\
\hline 1993 & 1,86 & 1,65 & 1,27 & 0,81 & 0,80 & 0,55 & 0,60 & 0,61 & 0,64 & 0,50 \\
\hline 1994 & 1,97 & 1,68 & 0,99 & 1,10 & 1,01 & 0,91 & 1,10 & 1,10 & 1,03 & 0,74 \\
\hline 1995 & 1,11 & 0,88 & 0,89 & 0,67 & 0,82 & 0,88 & 0,89 & 0,91 & 0,82 & 0,69 \\
\hline 1996 & 1,38 & 1,46 & 1,38 & 0,77 & 0,89 & 0,55 & 0,62 & 0,58 & 0,56 & 0,47 \\
\hline 1997 & 1,95 & 1,55 & 1,04 & 0,86 & 0,74 & 0,82 & 0,90 & 0,81 & 0,71 & 0,66 \\
\hline 1998 & 1,45 & 1,26 & 1,23 & 0,96 & 0,80 & 0,84 & 0,80 & 0,81 & 0,73 & 0,60 \\
\hline 1999 & 1,06 & 1,40 & 1,56 & 0,79 & 1,04 & 0,58 & 0,67 & 0,59 & 0,52 & 0,48 \\
\hline 2000 & 2,02 & 1,50 & 1,12 & 0,69 & 0,53 & 0,78 & 0,76 & 0,59 & 0,45 & 0,62 \\
\hline 2001 & 1,78 & 1,63 & 1,55 & 1,23 & 0,80 & 0,82 & 0,72 & 0,74 & 0,66 & 0,53 \\
\hline 2002 & 1,58 & 1,45 & 0,77 & 0,51 & 0,60 & 0,51 & 0,84 & 0,42 & 0,69 & 0,52 \\
\hline 2003 & 1,36 & 1,25 & 1,43 & 0,43 & 1,18 & 1,24 & 0,89 & 1,05 & 0,94 & 0,62 \\
\hline 2004 & 1,05 & 1,48 & 1,08 & 1,18 & 1,24 & 1,29 & 1,06 & 0,58 & 0,58 & 0,61 \\
\hline 2005 & 0,82 & 1,01 & 1,03 & 1,21 & 0,69 & 0,72 & 0,53 & 0,40 & 0,38 & 0,34 \\
\hline 2006 & 0,80 & 0,89 & 0,88 & 0,81 & 0,65 & 0,60 & 0,65 & 0,69 & 0,50 & 0,50 \\
\hline
\end{tabular}

Fuente: Elaboración propia a partir de "Informe Semanal Agrario", Consejería de Agricultura Región de Murcia (1992-2006). 
Tabla A1.7. Precios quincenales en origen del pimiento rojo en Murcia (en $€ / \mathbf{k g}$, datos actualizados a Septiembre de 2006)

\begin{tabular}{|c|c|c|c|c|c|c|c|c|c|c|c|}
\hline riodo & $1^{\mathrm{a}} \mathrm{Abr}$. & Abr. & May. & 2"May. & un. & un. & Jul. & Jul. & & & \\
\hline 1992 & 1,30 & 2,23 & 2,90 & 2,01 & $\overline{0,9,98}$ & $\overline{0,73}$ & $\overline{0,99}$ & $\overline{\overline{0,96}}$ & $\overline{0,74}$ & 0,67 & $\overline{\overline{0,81}}$ \\
\hline 1993 & 2,09 & 2,29 & 1,90 & 1,56 & 1,53 & 0,88 & 0,62 & 0,76 & 0,71 & 0,72 & 0,59 \\
\hline 1994 & 2,52 & 2,45 & 2,38 & 1,14 & 1,05 & 1,30 & 1,10 & 1,03 & 1,16 & 1,13 & 0,96 \\
\hline 1995 & 1,89 & 1,39 & 0,89 & 0,79 & 0,95 & 1,26 & 1,28 & 1,13 & 0,84 & 0,86 & 0,69 \\
\hline 1996 & 1,65 & 2,02 & 1,94 & 1,47 & 1,02 & 0,71 & 0,58 & 0,74 & 1,12 & 1,19 & 1,17 \\
\hline 1997 & 2,08 & 2,19 & 2,40 & 1,33 & 0,87 & 1,14 & 0,94 & 0,89 & 0,90 & 0,87 & 0,86 \\
\hline 1998 & 2,09 & 1,83 & 1,74 & 1,33 & 0,92 & 1,02 & 1,01 & 0,91 & 0,78 & 0,77 & 0,63 \\
\hline 1999 & 0,85 & 1,17 & 1,29 & 0,91 & 0,40 & 0,38 & 0,57 & 0,76 & 1,53 & 1,66 & 1,73 \\
\hline 2000 & 1,80 & 2,06 & 2,53 & 1,55 & 0,76 & 1,04 & 0,85 & 0,81 & 0,72 & 0,68 & 0,82 \\
\hline 2001 & 2,33 & 2,27 & 1,64 & 1,19 & 0,59 & 0,54 & 0,51 & 0,48 & 0,74 & 0,71 & 0,59 \\
\hline 2002 & 1,81 & 1,46 & 1,12 & 0,53 & 0,48 & 1,11 & 0,64 & 0,58 & 0,58 & 0,51 & 0,41 \\
\hline 2003 & 2,17 & 1,85 & 2,35 & 1,59 & 0,87 & 0,71 & 0,54 & 0,66 & 0,55 & 0,52 & 0,61 \\
\hline 2004 & 2,73 & 2,25 & 1,56 & 0,61 & 0,90 & 1,47 & 1,00 & 0,75 & 0,50 & 0,68 & 0,68 \\
\hline 2005 & 1,10 & 1,53 & 1,41 & 1,21 & 1,03 & 0,63 & 0,31 & 0,31 & 0,30 & 0,28 & 0,2 \\
\hline 2006 & 0,65 & 1,34 & 1,28 & 0,91 & 0,60 & 0,60 & 0,60 & 0,63 & 0,63 & 0,62 & 0,2 \\
\hline
\end{tabular}

Fuente: Elaboración propia a partir de "Informe Semanal Agrario", Consejería de Agricultura Región de Murcia (1992-2006). 
Tabla A1.8. Precios quincenales en origen del tomate acostillado en Alicante (en $€ / \mathbf{k g}$, datos actualizados a Agosto de 2006)

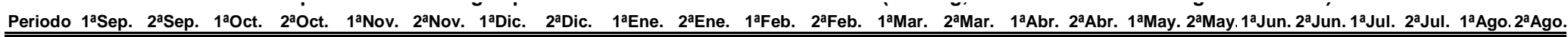
\begin{tabular}{llllllllllllllllllllllllll}
\hline \hline $1998 / 99$ & 0,59 & 0,70 & 1,00 & 0,96 & 0,96 & 0,94 & 1,01 & 1,95 & 0,85 & 0,82 & 0,81 & 0,76 & 0,73 & 0,77 & 0,89 & 1,19 & 1,04 & 0,38 & 0,62 & 0,56 & 0,57 & 0,42 & 0,57 & 0,50
\end{tabular} $\begin{array}{lllllllllllllllllllllllll}\mathbf{1 9 9 9 / 0 0} & 0,88 & 0,80 & 1,92 & 1,54 & 0,95 & 0,95 & 0,95 & 0,79 & 0,87 & 0,79 & 0,72 & 0,92 & 1,69 & 1,80 & 1,76 & 1,23 & 0,82 & 0,43 & 0,82 & 0,97 & 0,70 & 0,55 & 0,40 & 0,85\end{array}$ $\begin{array}{llllllllllllllllllllllllll}\mathbf{2 0 0 0 / 0 1} & 0,48 & 0,62 & 0,69 & 1,21 & 1,13 & 1,29 & 1,31 & 1,24 & 0,76 & 0,94 & 1,05 & 1,20 & 1,01 & 0,65 & 0,57 & 0,50 & 0,71 & 0,43 & 0,57 & 0,61 & 0,87 & 0,82 & 0,57 & 0,57\end{array}$ $\begin{array}{lllllllllllllllllllllllll}\mathbf{2 0 0 1 / 0 2} & 0,43 & 0,85 & 0,89 & 1,24 & 0,98 & 0,85 & 1,24 & 0,85 & 1,04 & 0,88 & 0,70 & 1,02 & 1,01 & 1,75 & 0,98 & 1,26 & 0,44 & 0,21 & 0,30 & 1,10 & 0,45 & 0,65 & 0,38 & 0,65\end{array}$ $\begin{array}{lllllllllllllllllllllllll}\mathbf{2 0 0 2} / 03 & 1,13 & 0,82 & 1,37 & 1,91 & 0,51 & 1,12 & 1,41 & 1,09 & 0,93 & 0,76 & 0,76 & 0,87 & 0,39 & 0,84 & 1,64 & 1,79 & 0,67 & 1,68 & 2,24 & 1,17 & 1,04 & 0,86 & 1,05 & 0,77\end{array}$ $\begin{array}{llllllllllllllllllllllllllll}\mathbf{2 0 0 3 / 0 4} & 1,66 & 3,49 & 3,60 & 3,33 & 2,05 & 1,40 & 1,71 & 2,01 & 0,90 & 0,90 & 1,05 & 1,35 & 1,84 & 1,21 & 2,15 & 0,90 & 1,11 & 1,33 & 0,59 & 1,75 & 1,19 & 1,02 & 0,32 & 0,25\end{array}$ \begin{tabular}{lllllllllllllllllllllllllll}
$\mathbf{2 0 0 4 / 0 5}$ & 0,89 & 1,24 & 1,04 & 1,71 & 2,22 & 1,95 & 1,81 & 2,07 & 1,08 & 1,29 & 2,21 & 1,80 & 1,17 & 0,98 & 1,43 & 3,02 & 1,85 & 0,85 & 0,56 & 0,68 & 0,52 & 0,76 & 0,73 & 0,39 \\
\hline
\end{tabular} \begin{tabular}{lllllllllllllllllllllllll}
$\mathbf{2 0 0 5 / 0 6}$ & 0,78 & 0,83 & 1,16 & 1,19 & 0,98 & 1,29 & 1,65 & 2,11 & 0,96 & 0,67 & 0,55 & 0,59 & 0,47 & 0,53 & 0,51 & 0,51 & 0,59 & 0,70 & 1,00 & 0,96 & 0,96 & 0,94 & 1,01 & 1,95 \\
\hline
\end{tabular}

Tabla A1.9. Precios quincenales en origen del tomate liso en Alicante (en $€ / \mathbf{k g}$, datos actualizados a Agosto de 2006)

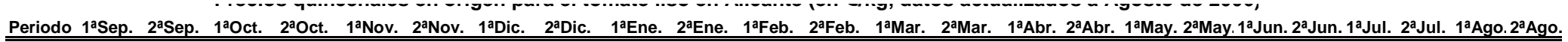

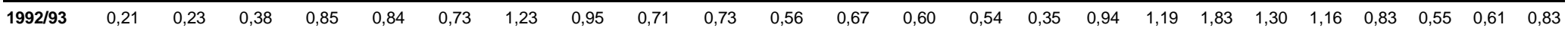
$\begin{array}{llllllllllllllllllllllllll}1993 / 94 & 0,27 & 0,27 & 0,46 & 0,50 & 0,71 & 0,57 & 0,52 & 0,41 & 0,40 & 0,47 & 0,65 & 0,47 & 0,40 & 0,71 & 0,76 & 1,11 & 0,62 & 0,51 & 0,33 & 0,82 & 0,77 & 0,57 & 0,62 & 0,50\end{array}$ $\begin{array}{lllllllllllllllllllllllll}1994 / 95 & 0,53 & 0,98 & 0,83 & 0,52 & 0,46 & 0,48 & 0,28 & 0,52 & 0,64 & 0,47 & 0,49 & 0,51 & 1,06 & 0,89 & 0,97 & 0,66 & 0,38 & 0,51 & 0,49 & 0,52 & 0,25 & 0,25 & 0,25 & 0,27\end{array}$ $\begin{array}{llllllllllllllllllllllllllll}1995 / 96 & 0,28 & 0,30 & 0,52 & 0,40 & 0,50 & 0,46 & 0,71 & 0,60 & 0,54 & 0,45 & 0,46 & 0,48 & 0,75 & 0,81 & 0,87 & 0,84 & 1,04 & 0,61 & 0,45 & 0,53 & 0,59 & 0,49 & 0,39 & 0,28\end{array}$ $\begin{array}{lllllllllllllllllllllllllll}1996 / 97 & 0,28 & 0,30 & 0,32 & 0,34 & 0,34 & 0,38 & 0,46 & 0,48 & 0,64 & 0,56 & 0,48 & 0,60 & 0,73 & 0,74 & 0,82 & 0,96 & 0,40 & 0,34 & 0,28 & 0,36 & 0,32 & 0,34 & 0,46 & 0,38\end{array}$ $\begin{array}{lllllllllllllllllllllllllllll}1997 / 98 & 0,63 & 0,48 & 0,64 & 0,64 & 0,59 & 0,69 & 0,77 & 0,73 & 0,75 & 0,67 & 0,49 & 0,71 & 0,71 & 0,67 & 0,71 & 0,59 & 0,69 & 0,47 & 0,33 & 0,41 & 0,37 & 0,33 & 0,39 & 0,31\end{array}$ $\begin{array}{lllllllllllllllllllllllllll}1998 / 99 & 0,31 & 0,38 & 0,55 & 0,84 & 0,84 & 0,61 & 0,74 & 1,25 & 0,74 & 0,66 & 0,70 & 0,31 & 0,31 & 1,00 & 0,67 & 0,81 & 0,83 & 0,38 & 0,62 & 0,35 & 0,50 & 0,36 & 0,36 & 0,38\end{array}$ $\begin{array}{llllllllllllllllllllllllllll}1999 / 00 & 0,57 & 0,55 & 0,91 & 0,82 & 0,65 & 0,61 & 0,76 & 0,51 & 0,41 & 0,64 & 0,49 & 0,55 & 1,35 & 1,43 & 1,31 & 0,78 & 0,41 & 0,52 & 0,19 & 0,59 & 0,52 & 0,44 & 0,59 & 0,55\end{array}$ $\begin{array}{llllllllllllllllllllllllll}\mathbf{2 0 0 0 / 0 1} & 0,38 & 0,49 & 0,49 & 0,88 & 0,95 & 0,89 & 0,98 & 0,69 & 0,55 & 0,55 & 0,56 & 0,83 & 0,76 & 0,54 & 0,85 & 0,68 & 0,64 & 0,50 & 0,52 & 0,57 & 0,60 & 0,39 & 0,21 & 0,25\end{array}$ $\begin{array}{lllllllllllllllllllllllllll}\mathbf{2 0 0 1 / 0 2} & 0,25 & 0,67 & 0,59 & 0,67 & 0,53 & 0,46 & 0,64 & 0,64 & 0,67 & 0,71 & 0,56 & 0,88 & 1,66 & 0,93 & 0,98 & 1,26 & 0,38 & 0,21 & 0,34 & 0,86 & 0,39 & 0,46 & 0,26 & 0,44\end{array}$ $\begin{array}{llllllllllllllllllllllllllll}\mathbf{2 0 0 2} / 03 & 0,58 & 0,37 & 1,01 & 0,91 & 0,38 & 0,83 & 0,91 & 0,91 & 0,21 & 0,23 & 0,38 & 0,85 & 0,84 & 0,73 & 1,23 & 0,95 & 0,71 & 0,73 & 0,56 & 0,67 & 0,60 & 0,54 & 0,35 & 0,94\end{array}$ $\begin{array}{lllllllllllllllllllllllllll}\mathbf{2 0 0 3 / 0 4} & 1,19 & 1,83 & 1,30 & 1,16 & 0,83 & 0,55 & 0,61 & 0,83 & 0,30 & 0,61 & 0,61 & 0,81 & 0,90 & 0,83 & 1,31 & 0,52 & 0,72 & 0,81 & 0,46 & 0,76 & 0,49 & 0,49 & 0,35 & 0,19\end{array}$ \begin{tabular}{llllllllllllllllllllllllllll}
$\mathbf{2 0 0 4 / 0 5}$ & 0,48 & 0,43 & 0,59 & 0,83 & 1,07 & 0,96 & 1,04 & 0,92 & 0,73 & 0,91 & 0,69 & 0,71 & 0,80 & 0,60 & 0,89 & 1,97 & 1,52 & 0,80 & 0,45 & 0,34 & 0,31 & 0,75 & 0,80 & 0,43 \\
\hline
\end{tabular}

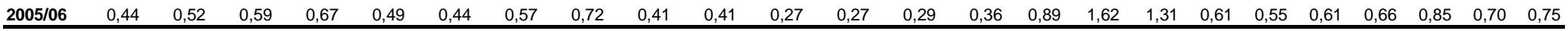

Fuente: Elaboración propia a partir de "Notas Agrarias Semanales", Conselleria de Agricultura Generalitat Valenciana (1992-2006) 
$\underline{\text { Anexo } 1}$

Tabla A1.10. Precios quincenales en origen del pimiento verde en Alicante (en $€ / \mathbf{k g}$, datos actualizados a Agosto de 2006)

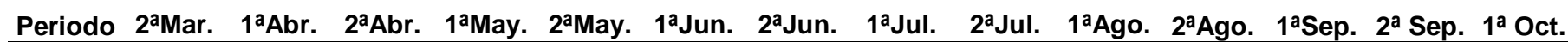

\begin{tabular}{|c|c|c|c|c|c|c|c|c|c|c|c|c|c|c|}
\hline 1990 & 2,62 & 1,90 & 0,94 & 0,72 & 0,51 & 0,54 & 0,47 & 0,41 & 0,51 & 0,32 & 0,27 & 0,35 & 0,56 & 0,56 \\
\hline 1991 & 0,50 & 1,25 & 0,93 & 0,69 & 0,53 & 0,49 & 0,66 & 0,51 & 0,75 & 0,59 & 0,53 & 0,53 & 0,49 & 0,50 \\
\hline 1992 & 1,85 & 2,00 & 0,93 & 0,60 & 0,56 & 0,54 & 0,50 & 0,53 & 0,55 & 0,38 & 0,38 & 0,52 & 0,42 & 0,45 \\
\hline 1993 & 2,03 & 1,17 & 1,31 & 0,61 & 0,62 & 0,53 & 0,51 & 0,56 & 0,52 & 0,39 & 0,52 & 0,50 & 0,27 & 0,25 \\
\hline 1994 & 1,73 & 1,07 & 0,65 & 0,95 & 1,09 & 0,90 & 0,77 & 1,04 & 1,02 & 0,98 & 0,64 & 0,57 & 0,53 & 0,39 \\
\hline 1995 & 0,93 & 0,79 & 0,59 & 0,67 & 0,58 & 0,73 & 0,68 & 0,84 & 0,74 & 0,54 & 0,50 & 0,53 & 0,55 & 0,47 \\
\hline 1996 & 1,39 & 0,71 & 0,62 & 0,84 & 0,66 & 0,69 & 0,69 & 0,53 & 0,55 & 0,30 & 0,17 & 0,27 & 0,28 & 0,25 \\
\hline 1997 & 1,84 & 1,29 & 0,85 & 0,94 & 0,79 & 0,77 & 0,62 & 0,55 & 0,55 & 0,48 & 0,52 & 0,37 & 0,30 & 0,22 \\
\hline 1998 & 1,28 & 1,10 & 1,10 & 0,81 & 0,79 & 0,53 & 0,60 & 0,53 & 0,29 & 0,47 & 0,49 & 0,43 & 0,33 & 0,33 \\
\hline 1999 & 1,09 & 0,90 & 0,69 & 0,63 & 0,53 & 0,52 & 0,62 & 0,50 & 0,37 & 0,32 & 0,39 & 0,41 & 0,37 & 0,35 \\
\hline 2000 & 1,27 & 0,92 & 0,77 & 0,47 & 0,56 & 0,97 & 0,66 & 0,55 & 0,48 & 0,55 & 0,55 & 0,48 & 0,35 & 0,35 \\
\hline 2001 & 1,62 & 1,08 & 1,08 & 0,89 & 0,55 & 0,78 & 0,53 & 0,74 & 0,62 & 0,46 & 0,30 & 0,28 & 0,21 & 0,28 \\
\hline 2002 & 1,84 & 0,75 & 0,45 & 0,49 & 0,49 & 0,40 & 0,98 & 0,43 & 0,34 & 0,38 & 0,29 & 0,27 & 0,14 & 0,21 \\
\hline 2003 & 1,46 & 1,09 & 1,34 & 0,73 & 0,86 & 1,45 & 0,95 & 0,70 & 0,52 & 0,40 & 0,33 & 0,30 & 0,22 & 0,14 \\
\hline 2004 & 1,16 & 1,36 & 0,68 & 1,25 & 1,35 & 1,19 & 1,27 & 0,51 & 0,51 & 0,43 & 0,37 & 0,34 & 0,28 & 0,21 \\
\hline 2005 & 1,65 & 1,21 & 0,95 & 0,89 & 0,74 & 0,73 & 0,52 & 0,31 & 0,37 & 0,36 & 0,37 & 0,35 & 0,32 & 0,26 \\
\hline 2006 & 1,23 & 0,81 & 1,01 & 0,76 & 0,66 & 0,55 & 0,60 & 0,60 & 0,55 & 0,55 & 0,33 & 0,36 & 0,25 & 0,28 \\
\hline
\end{tabular}

Fuente: Elaboración propia a partir de "Notas Agrarias Semanales", Conselleria de Agricultura Generalitat Valenciana (1990-2006). 
$\underline{\text { Anexo } 1}$

Tabla A1.11. Precios quincenales en origen del pimiento rojo en Alicante (en $€ / \mathrm{kg}$, datos actualizados a Agosto de 2006)

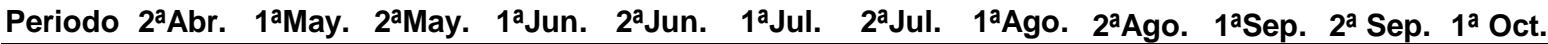

\begin{tabular}{lllllllllllll}
\hline \hline $\mathbf{1 9 9 0}$ & 3,30 & 2,54 & 0,63 & 0,69 & 0,75 & 0,81 & 0,81 & 0,53 & 0,51 & 0,63 & 0,77 & 0,68 \\
$\mathbf{1 9 9 1}$ & 1,97 & 1,79 & 1,06 & 0,57 & 0,59 & 0,77 & 1,07 & 0,97 & 1,17 & 0,76 & 0,77 & 0,60 \\
$\mathbf{1 9 9 2}$ & 2,16 & 2,51 & 1,56 & 0,58 & 0,63 & 0,92 & 0,83 & 0,58 & 0,53 & 0,76 & 0,57 & 0,43 \\
$\mathbf{1 9 9 3}$ & 2,06 & 1,56 & 1,49 & 1,53 & 0,84 & 0,60 & 0,65 & 0,49 & 0,66 & 0,73 & 0,50 & 0,41 \\
$\mathbf{1 9 9 4}$ & 1,91 & 2,10 & 1,49 & 1,06 & 1,06 & 1,38 & 1,28 & 0,47 & 1,02 & 0,93 & 0,79 & 0,73 \\
$\mathbf{1 9 9 5}$ & 0,89 & 0,71 & 0,59 & 0,60 & 0,93 & 1,15 & 1,26 & 0,92 & 0,91 & 0,75 & 0,75 & 0,67 \\
$\mathbf{1 9 9 6}$ & 1,27 & 1,36 & 1,18 & 1,40 & 0,87 & 0,57 & 0,41 & 0,45 & 0,30 & 0,30 & 0,18 & 0,40 \\
$\mathbf{1 9 9 7}$ & 2,81 & 2,33 & 0,96 & 0,53 & 0,77 & 0,84 & 0,62 & 0,55 & 0,85 & 0,66 & 0,81 & 0,61 \\
$\mathbf{1 9 9 8}$ & 1,14 & 1,00 & 1,38 & 1,06 & 0,59 & 0,61 & 0,78 & 0,70 & 0,70 & 0,65 & 0,66 & 0,47 \\
$\mathbf{1 9 9 9}$ & 1,36 & 1,58 & 0,64 & 0,41 & 0,37 & 0,94 & 1,01 & 0,93 & 0,50 & 0,57 & 0,62 & 0,54 \\
$\mathbf{2 0 0 0}$ & 1,09 & 0,82 & 0,39 & 0,52 & 0,85 & 0,22 & 0,96 & 0,53 & 0,53 & 0,55 & 0,59 & 0,57 \\
$\mathbf{2 0 0 1}$ & 2,57 & 1,64 & 1,29 & 0,94 & 0,75 & 0,74 & 0,78 & 0,70 & 0,44 & 0,46 & 0,34 & 0,46 \\
$\mathbf{2 0 0 2}$ & 1,82 & 1,07 & 1,07 & 0,38 & 0,52 & 0,52 & 0,38 & 0,51 & 0,51 & 0,48 & 0,23 & 0,34 \\
$\mathbf{2 0 0 3}$ & 2,04 & 1,85 & 1,40 & 1,11 & 1,26 & 0,58 & 0,50 & 0,51 & 0,51 & 0,49 & 0,36 & 0,34 \\
$\mathbf{2 0 0 4}$ & 1,39 & 1,35 & 1,06 & 1,19 & 1,57 & 0,97 & 0,92 & 0,34 & 0,38 & 0,44 & 0,34 & 0,32 \\
$\mathbf{2 0 0 5}$ & 0,74 & 1,28 & 0,92 & 0,99 & 0,37 & 0,37 & 0,29 & 0,44 & 0,26 & 0,28 & 0,26 & 0,31 \\
$\mathbf{2 0 0 6}$ & 0,97 & 1,21 & 1,01 & 0,45 & 0,45 & 0,60 & 0,70 & 0,57 & 0,42 & 0,35 & 0,30 & 0,31 \\
\hline
\end{tabular}

Fuente: Elaboración propia a partir de "Notas Agrarias Semanales", Conselleria de Agricultura Generalitat Valenciana (1990-2006). 
Anexo 2 



\section{Anexo 2. Cuestionario "Uso de la calefacción en invernadero"}

Persona de contacto:

Telefono:

Zona:

Datos referidos al periodo:

CULTIVO:

DESCRIPCIÓN DEL NIVEL TECNOLOGICO DEL INVERNADERO:

Dimensión del invernadero:

Variedad:

Producción media obtenida:

Fecha plantación:

Periodo de recolección:

Otras observaciones sobre cultivo:

Estructura del invernadero:

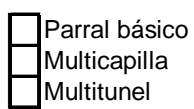

$\square$ Parral mejorado

Altura a la canal:

Modalidad de cultivo:

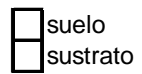

Tipo de sustrato:
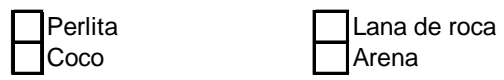

Elementos de ventilación (tipo, protegidas o no con mallas, etc..), describir:

Otras mejoras tecnológicas:

\begin{tabular}{|l} 
Equipo de fertirrigación \\
CO2 \\
Mallas de sombreo
\end{tabular}

OO (detallar los datos que recuerde):

\section{DESCRIPCIÓN DE LA CALEFACCIÓN:}

Tipo de calefacción, según T⿳a

$\square$ De minimos (indicar ${ }^{\circ} \mathrm{C}$ )

Permanente (indicar $\stackrel{\circ}{\circ}$ )

Tipo:

Por aire caliente

Forma de distribución del calor en el invernadero:

Periodo de uso de la calefacción:

Tipo de combustible:

Gasto de calefacción por campaña (Pts o euros/m2):

COSTES DE IMPLANTACIÓN DE LA CALEFACCIÓN (detallar por elementos o según recuerde):

Por del uso de la calefacción, concretamente obtuvo: Más producción Adelanto de la cosecha

Más calidad 
Gráfico A2.1. Tipo de calefacción por temperatura de los invernaderos del Campo de Cartagena

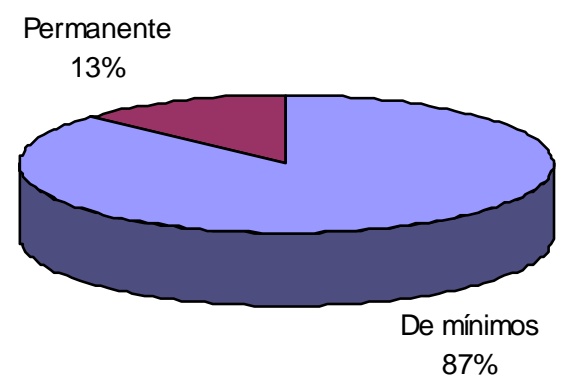

Gráfico A2.2. Tipo de calefacción de los invernaderos del Campo de Cartagena

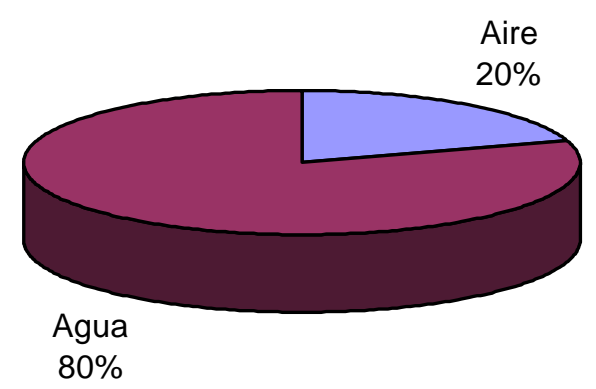


Gráfico A2.3. Distribución del calor de la calefacción de los invernaderos del Campo de Cartagena

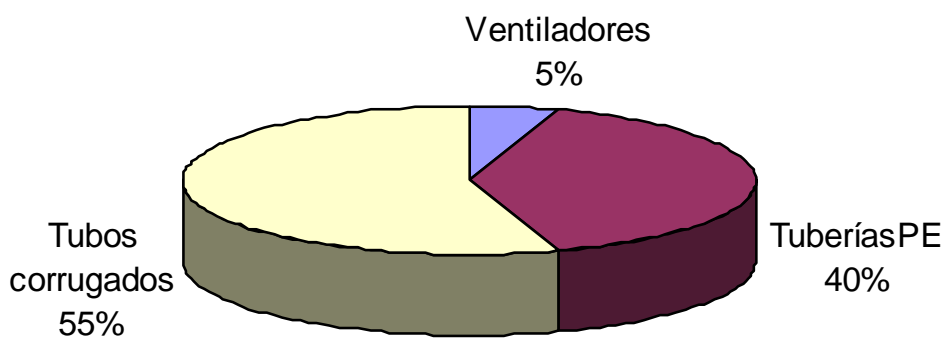

Gráfico A2.4. Tipo de combustión de la calefacción de los invernaderos del Campo de Cartagena

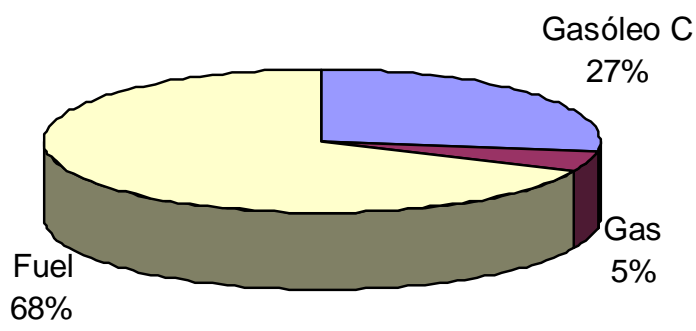


Gráfico A2.5. Distribución en porcentaje de las mejoras por el uso de la calefacción en los invernaderos del Campo de Cartagena

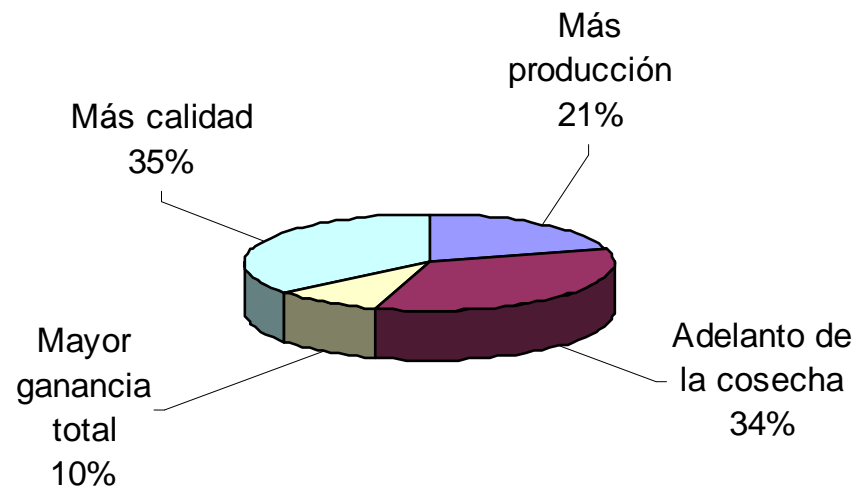

Gráfico A2.6. Mejoras por el uso de la calefacción en los invernaderos del Campo de Cartagena

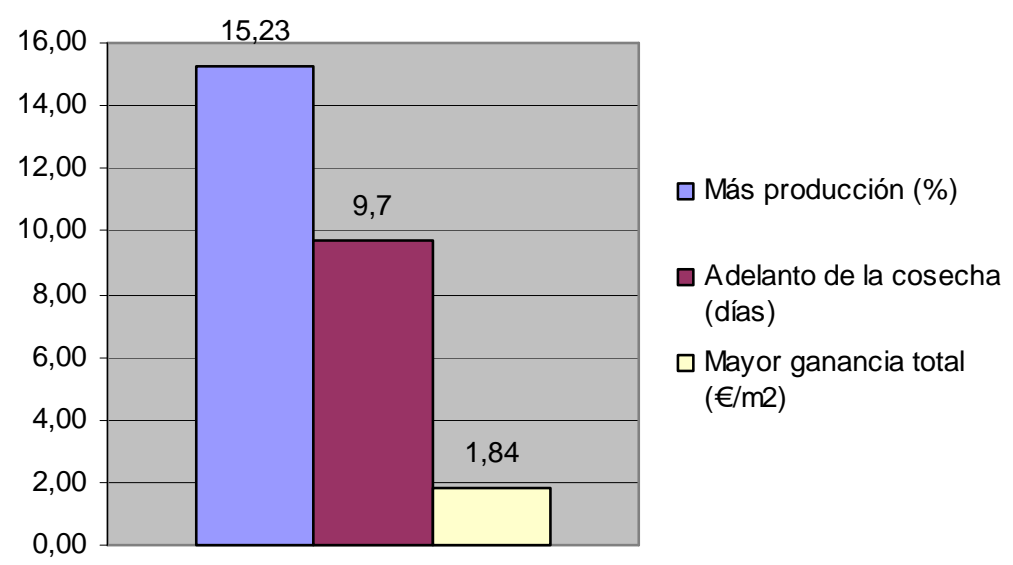


Gráfico A2.7. Distribución en porcentaje de las mejoras en la calidad por el uso de la calefacción en los invernaderos del Campo de

\section{Cartagena}

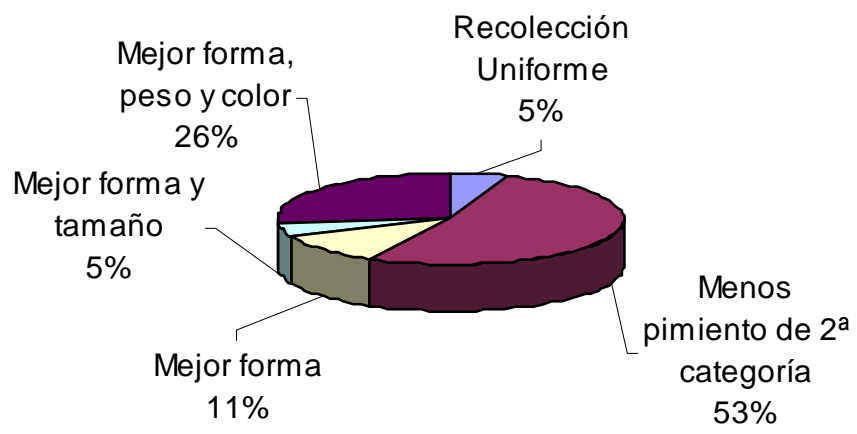



Anexo 3 



\section{Anexo 3. Cuestionario "Adopción Tecnología Invernaderos Mediterráneos"}

Fecha:

Encuestador/a:

Titular:

Teléfono:

Término municipal:

\section{DATOS DE LA EXPLOTACIÓN:}

1. Superficie total de invernaderos en la explotación: $\mathrm{m}^{2}$

2. Otros cultivos al aire libre(ha)

3. Superficie que tiene de cada tipo de invernadero:

Total en SUELO $\mathrm{m}^{2} \quad$ Total en SUSTRATO $\mathrm{m}^{2}$

- Parral básico:

- Parral mejorado: . $\mathrm{m}^{2}$

- Multitúnel: $\mathrm{m}^{2}$ $\mathrm{m}^{2}$

4. Datos del titular: Edad ....años. Dedicación a la actividad agraria: Parcial $\square$ Total $\square$ 5.¿La sucesión de la actividad está asegurada? $\square$ Sí, por ...

$$
\square \text { No, porque }
$$

6. Trabajadores en la explotación:

\begin{tabular}{|l|l|l|c|}
\hline & \multicolumn{2}{|c|}{$\mathrm{N}^{\circ}$ y dedicación } & $\begin{array}{c}\text { Parciales (indicar días o jornales } \\
\text { contratados al año) }\end{array}$ \\
\hline & Total & Parcial & \\
\hline Familiares & & & \\
\hline $\begin{array}{l}\text { Trabajadores } \\
\text { eventuales }\end{array}$ & & & \\
\hline
\end{tabular}

7. ¿Piensa modificar los tipos de invernaderos que tiene ahora?

$\square$ Sí, y lo haré pronto

$\square$ Necesitaría cambiar, pero no preveo hacerlo pronto

$\square$ No 
NIVEL DE TECNOLOGÍA DE LA EXPLOTACIÓN (conteste para su invernadero más tecnificado)

Superficie___ $\mathrm{m}^{2} \quad$ Inversión requerida para instalación

8. Aspectos básicos del invernadero con más tecnología:

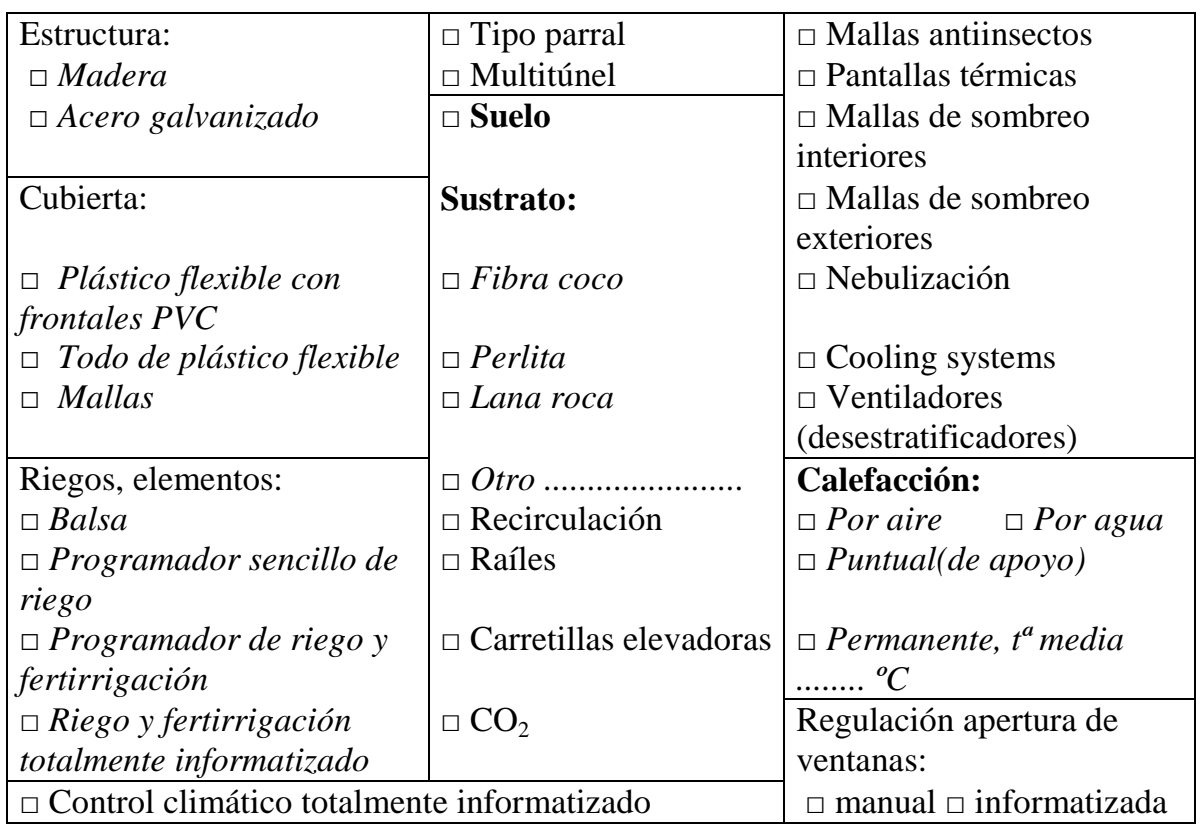

9. Cultivos y producciones:

\begin{tabular}{|l|l|}
\hline Cultivo y variedad & Rto. anual medio $\left(\mathrm{Kg} / \mathbf{m}^{2}\right)$ \\
\hline & \\
\hline
\end{tabular}


ACTITUD HACIA LA ADOPCIÓN DEL SUSTRATO

10. Año en que instaló por primera vez el sustrato $\mathrm{m}^{2}$

En el año puso $\mathrm{m}^{2}$

En el año puso $\mathrm{m}^{2}$

Actualmente suele mantener una superficie media de sustrato de $\mathrm{m}^{2}$

11. Nivel de importancia que tiene para Ud. el cultivo en sustrato (con los complementos necesarios)

\begin{tabular}{|c|c|c|c|c|}
\hline $\begin{array}{c}\text { Imprescindible o } \\
\text { totalmente } \\
\text { necesario }\end{array}$ & Importante & $\begin{array}{c}\text { Una técnica } \\
\text { más }\end{array}$ & $\begin{array}{c}\text { Poco } \\
\text { interesante }\end{array}$ & $\begin{array}{c}\text { Nada } \\
\text { interesante }\end{array}$ \\
\hline
\end{tabular}

12. Clasifique las ventajas e inconvenientes habituales en los invernaderos con cultivo en sustrato:

\begin{tabular}{|c|c|c|c|}
\hline Ventajas & $\begin{array}{c}\text { Muy } \\
\text { importante }\end{array}$ & Importante & $\begin{array}{c}\text { Poco } \\
\text { importante }\end{array}$ \\
\hline \multicolumn{4}{|l|}{ Rendimientos $\left(\right.$ por $\mathrm{m}^{2}$ ) más elevados } \\
\hline \multicolumn{4}{|l|}{ Mayor calidad comercial de los productos } \\
\hline \multicolumn{4}{|l|}{ Más seguridad de obtener buenos resultados } \\
\hline \multicolumn{4}{|l|}{$\begin{array}{l}\text { El periodo de producción y comercialización es } \\
\text { más amplio }\end{array}$} \\
\hline \multicolumn{4}{|l|}{ Al disponer de mejor instalación: } \\
\hline - $\quad$ Se controla mejor el clima & & & \\
\hline Se aplica mejor el riego & & & \\
\hline Se recolectan más $\mathrm{Kg}$ /hora & & & \\
\hline - $\quad$ Se puede reciclar el agua de drenaje & & & \\
\hline $\begin{array}{l}\text { - Teniendo en cuenta que no se podrá } \\
\text { usar el B.Metilo, se evita la desinfección del } \\
\text { suelo }\end{array}$ & & & \\
\hline \multicolumn{4}{|l|}{$\begin{array}{l}\text { Si además se aplica la lucha biológica se reduce } \\
\text { considerablemente la cantidad de fitosanitarios }\end{array}$} \\
\hline \multicolumn{4}{|l|}{ Otra ventaja: } \\
\hline Inconvenientes & $\begin{array}{c}\text { Muy } \\
\text { importante }\end{array}$ & Importante & $\begin{array}{c}\text { Poco } \\
\text { importante }\end{array}$ \\
\hline \multicolumn{4}{|l|}{ Es más caro en todo } \\
\hline \multicolumn{4}{|l|}{ Lo veo muy arriesgado } \\
\hline \multicolumn{4}{|l|}{ Es más difícil de manejar } \\
\hline \multicolumn{4}{|l|}{ Se depende de empresas o técnicos que asesoren } \\
\hline Otro inconveniente: & & & \\
\hline
\end{tabular}




\section{FACTORES QUE AFECTAN AL PROCESO DE INNOVACIÓN}

13. En cuanto a la información sobre formación y asesoramiento del cultivo en sustrato (o en su defecto cultivo en suelo), señale 2 opciones por orden de importancia en cada caso,

\begin{tabular}{|c|c|c|c|}
\hline & $\begin{array}{c}\begin{array}{c}\text { ¿Cómo } \\
\text { obtuvo la } \\
\text { información }\end{array} \\
\text { inicial? }\end{array}$ & $\begin{array}{l}\text { ¿A través } \\
\text { de quién } \\
\text { se ha } \\
\text { formado? }\end{array}$ & $\begin{array}{c}\text { ¿Quién le } \\
\text { asesora } \\
\text { con los } \\
\text { problemas } \\
\text { técnicos? }\end{array}$ \\
\hline Técnicos de Cooperativas & & & \\
\hline $\begin{array}{l}\text { Proveedores de materiales y } \\
\text { productos }\end{array}$ & & & \\
\hline Centros de Investigación & & & \\
\hline $\begin{array}{l}\text { Oficinas de Capacitación } \\
\text { Agraria (OCA) }\end{array}$ & & & \\
\hline $\begin{array}{l}\text { Ingenieros o técnicos } \\
\text { independientes }\end{array}$ & & & \\
\hline Internet & & & \\
\hline Revistas & & & \\
\hline Otros agricultores & & & \\
\hline Cursos técnicos & & & \\
\hline Otras fuentes & & & \\
\hline
\end{tabular}

14. ¿Lee publicaciones relacionadas con temas agrarios? $\square$ No Sí: $\square$ revistas $\square$ libros $\square$ folletos comerciales

15. ¿Cómo comercializa su cosecha?
$\square$ A través de la cooperativa
$\square$ A través de la alhóndiga

$\square$ A través de mayoristas compradores

$\square$ Otros

16. Si tiene cultivo en sustrato, ¿está satisfecho con él?,

\begin{tabular}{|l|l|l|l|l|l|l|}
\hline Totalmente insatisfecho & 1 & 2 & 3 & 4 & 5 & Totalmente satisfecho \\
\hline
\end{tabular}

17. Indique la importancia de los principales problemas para adoptar el sustrato usando esta escala:

\begin{tabular}{|l|l|l|l|l|l|l|}
\hline Nada importante & 1 & 2 & 3 & 4 & 5 & Muy importante \\
\hline
\end{tabular}

Elevado coste de inversión

Dificultades para manejarlo

Cualquier deficiencia puede originar la pérdida de una campaña

Exige una asistencia técnica muy puntual 


\section{FINANCIACIÓN}

18. Si le es conveniente pedir un préstamo, ¿cómo acepta el hecho de endeudarse?:

\begin{tabular}{|l|l|l|l|l|l|c|}
\hline $\begin{array}{l}\text { No me gusta nada } \\
\text { endeudarme }\end{array}$ & 1 & 2 & 3 & 4 & 5 & $\begin{array}{c}\text { No tengo ningún miedo } \\
\text { a endeudarme }\end{array}$ \\
\hline
\end{tabular}

19. Cuando realiza algún desembolso en su explotación, qué \% del dinero procede de cada una de estas fuentes (aproximadamente):

\begin{tabular}{|c|c|}
\hline & $\%$ \\
\hline Recursos propios & \\
\hline $\begin{array}{l}\text { Utilizo las facilidades de pago o de financiación de las empresas } \\
\text { suministradoras }\end{array}$ & \\
\hline Créditos de Bancos y Cajas de Ahorro & \\
\hline Préstamos o subvenciones del Ministerio o gobierno Autonómico & \\
\hline Fondos de la Unión Europea & \\
\hline Otras fuentes & \\
\hline
\end{tabular}

\section{PERCEPCIÓN AMBIENTAL}

20. Respecto al aire libre, los invernaderos pueden afectar al medio ambiente. Indique la importancia que tiene para Ud. cada uno de estos efectos:

\begin{tabular}{|l|l|l|l|}
\hline $\begin{array}{l}\text { Efecto sobre el medio } \\
\text { ambiente: }\end{array}$ & $\begin{array}{c}\text { Muy } \\
\text { importante }\end{array}$ & Importante & $\begin{array}{c}\text { Poco } \\
\text { importante }\end{array}$ \\
\hline Mayor consumo de agua & & & \\
\hline Mayor consumo de energía & & & \\
\hline Más productos químicos & & & \\
\hline Desecho de plásticos & & & \\
\hline Restos de cosechas & & & \\
\hline $\begin{array}{l}\text { Agua de drenaje con productos } \\
\text { químicos }\end{array}$ & & & \\
\hline
\end{tabular}

21. A la hora de montar un nuevo invernadero, ¿ha tenido en cuenta la problemática ambiental?

$\square$ No, ni siquiera he caído en ello.

$\square$ Sí lo pensé, pero como había ninguna normativa que me obligara, no la he tenido en cuenta.

$\square$ Sí, y he realizado las mejores actuaciones, porque me preocupa mucho el medio ambiente. 
22. Para mejorar el medio ambiente en las zonas de invernadero sería necesario realizar algunas estrategias, ordénelas según la prioridad que Ud. les daría a cada una de ellas y mencionar si tienen interés:

\begin{tabular}{|l|l|l|}
\hline Estrategia para mejorar el medio ambiente: & Interés & $\begin{array}{c}\text { Orden según } \\
\text { prioridad }\end{array}$ \\
\hline Reducir el consumo de productos químicos & & \\
\hline Generalizar la lucha biológica & & \\
\hline Reutilizar las soluciones & & \\
\hline Optimizar el control climático de los invernaderos & & \\
\hline $\begin{array}{c}\text { Controlar u ordenar las nuevas superficies } \\
\text { cubiertas }\end{array}$ & & \\
\hline $\begin{array}{c}\text { Los productores deberían responsabilizarse de la } \\
\text { eliminación de los distintos vertidos }\end{array}$ & & \\
\hline $\begin{array}{c}\text { Los productores deberían restaurar el paisaje tras } \\
\text { abandonar un invernadero }\end{array}$ & & \\
\hline
\end{tabular}


Anexo 4 



\section{Anexo 4. Análisis descriptivo de las variables}

\section{A4.1. Variables "Datos de Explotación”}

Tabla A4.1.1. Análisis descriptivo de la variable superficie de invernaderos

\begin{tabular}{|ll|r|r|}
\hline & \multicolumn{1}{|c|}{ Statistic } & Std. Error \\
\hline Superficie Invernaderos & Mean & 26545,85 & 1853,349 \\
& Median & 18500,00 & \\
& Std. Deviation & 28771,72 & \\
& Minimum & 2000,00 & \\
& Maximum & 260000,0 & \\
& Range & 258000,00 & \\
Interquartile Range & 18000,00 & \\
& Skewness & 4,274 &, 157 \\
Kurtosis & 25,401 &, 312 \\
\hline
\end{tabular}

Gráfico A4.1.1. Histograma de la variable superficie de invernaderos

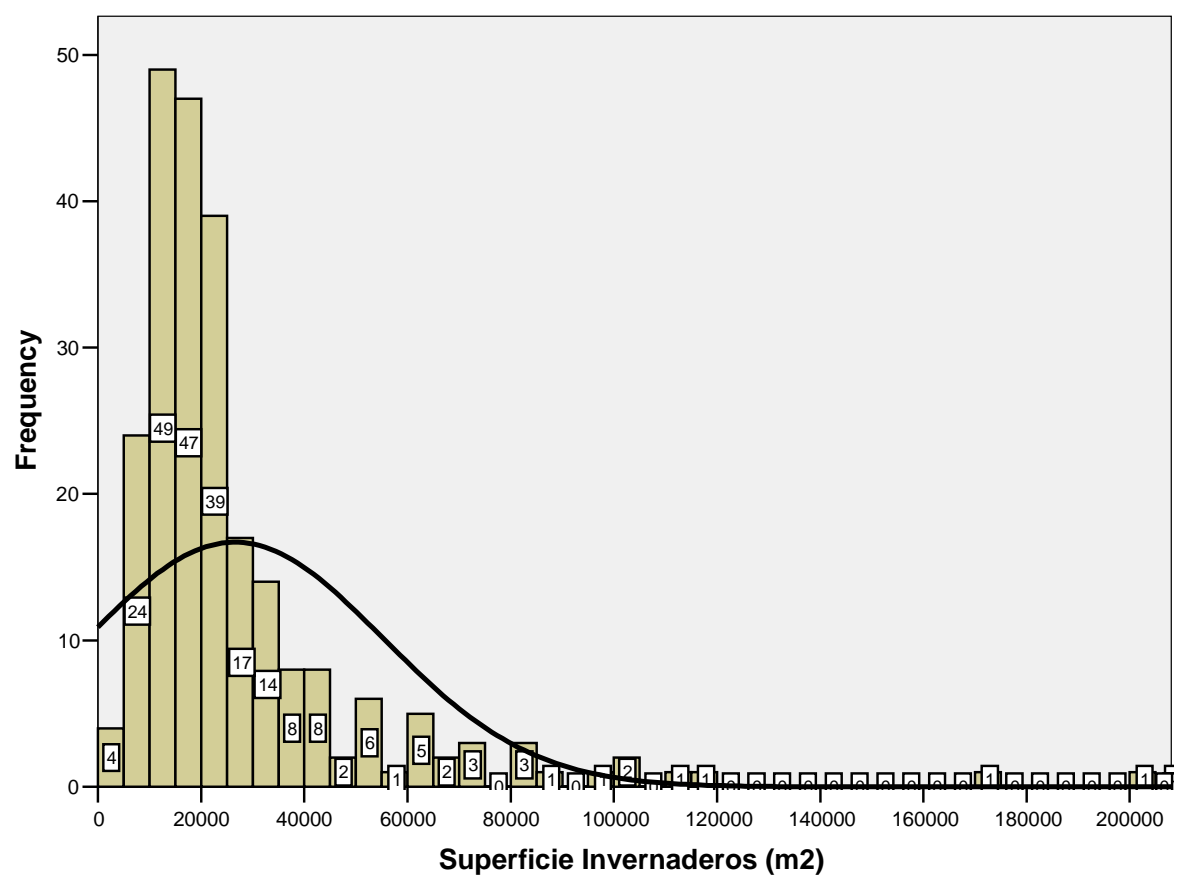


Gráfico A4.1.2. Diagrama Caja-Bigotes de la variable superficie de invernaderos

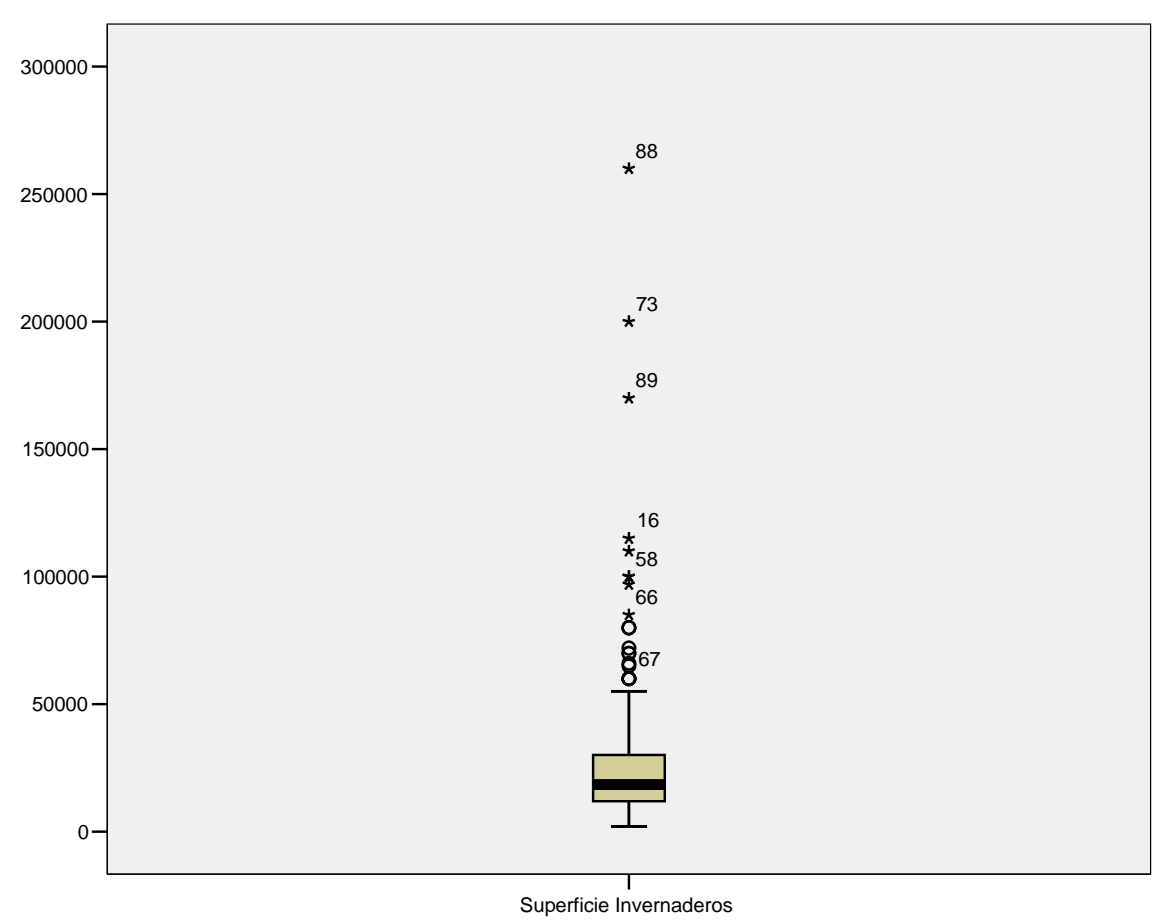

Tabla A4.1.2. Tabla análisis descriptivo de la variable superficie al aire libre (ha)

\begin{tabular}{|ll|r|r|}
\hline & \multicolumn{1}{|c|}{ Statistic } & Std. Error \\
\hline Superficie aire libre & Mean & 1,9410 &, 50857 \\
& Median &, 0000 & \\
Std. Deviation & 7,89511 & \\
Minimum &, 00 & \\
Maximum & 100,00 & \\
Range & 100,00 & \\
Interquartile Range &, 50 & \\
Skewness & 9,292 &, 157 \\
Kurtosis & 105,219 &, 312 \\
\hline
\end{tabular}


$\underline{\text { Anexo } 4}$

Gráfico A4.1.3. Histograma de la variable superficie al aire libre (ha)

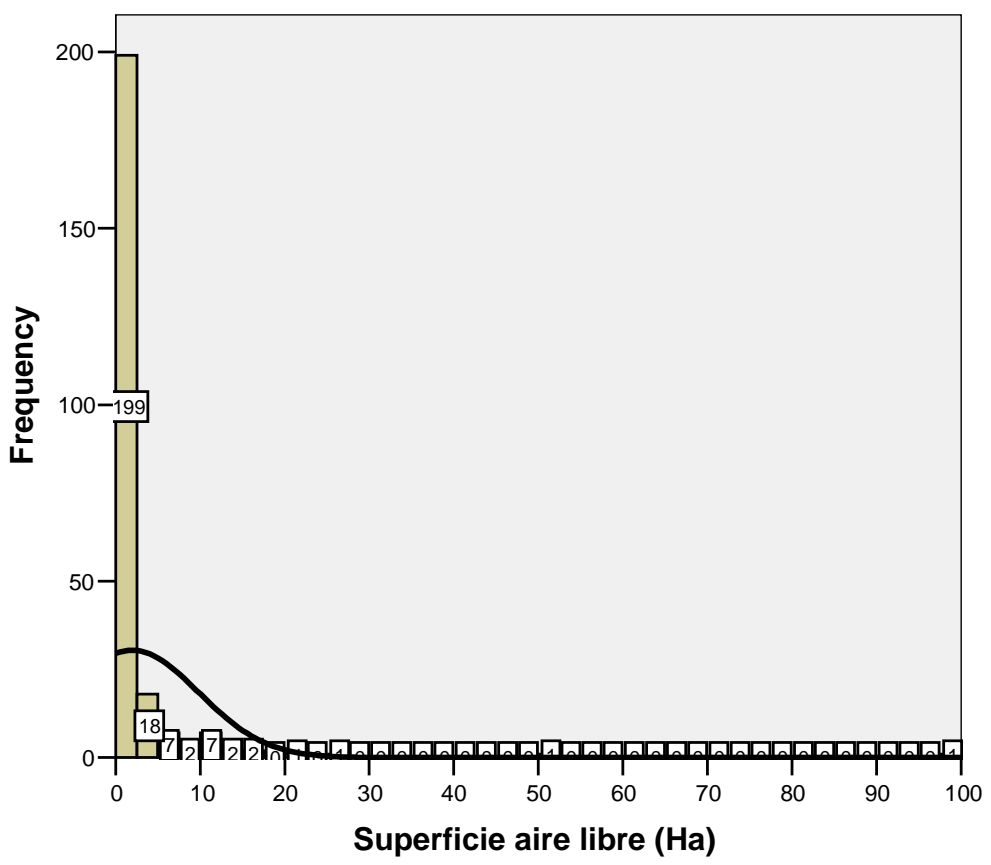

Gráfico A4.1.4. Diagrama Caja-Bigotes de la variable superficie al aire libre (ha)

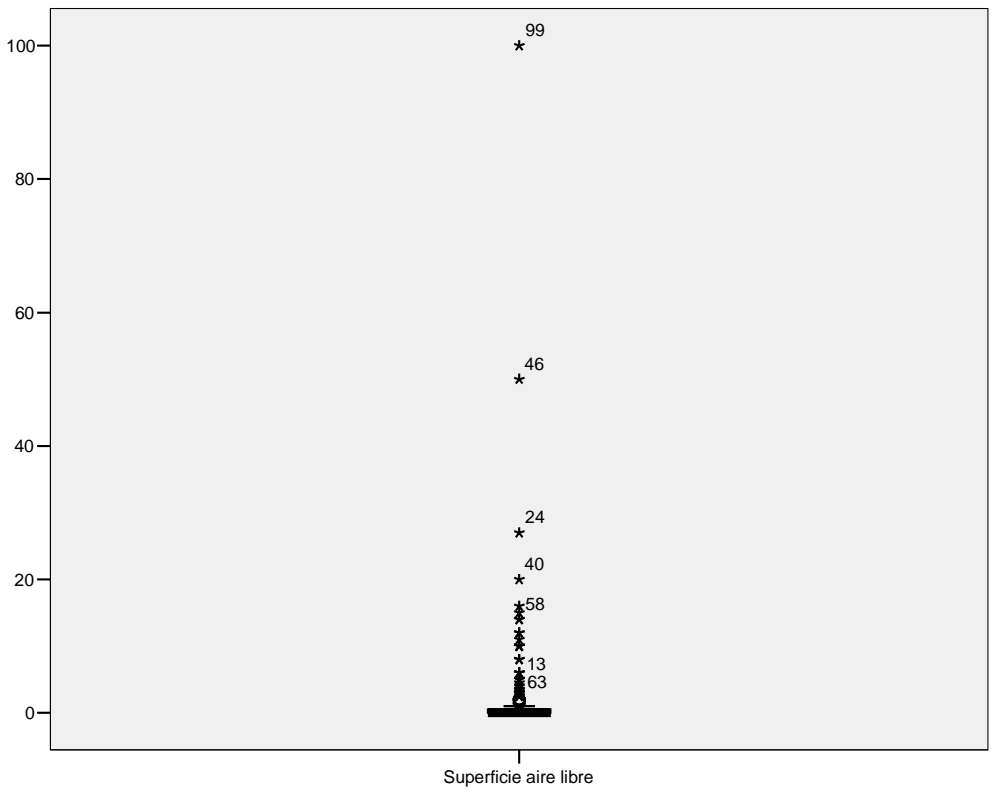


Tabla A4.1.3. Tabla análisis descriptivo de la variable superficie de invernadero en suelo

\begin{tabular}{|ll|r|r|}
\hline & & Statistic & Std. Error \\
\hline Superficie & Mean & 21472,82 & 1490,430 \\
invernadero en suelo & Median & 15000,00 & \\
& Std. Deviation & 23137,69 & \\
& Minimum &, 00 & \\
& Maximum & 200000,0 & \\
& Range & 200000,00 & \\
Interquartile Range & 15000,00 & \\
& Skewness & 3,282 &, 157 \\
& Kurtosis & 16,951 &, 312 \\
\hline
\end{tabular}

Gráfico A4.1.5. Histograma de la variable superficie de invernadero en suelo

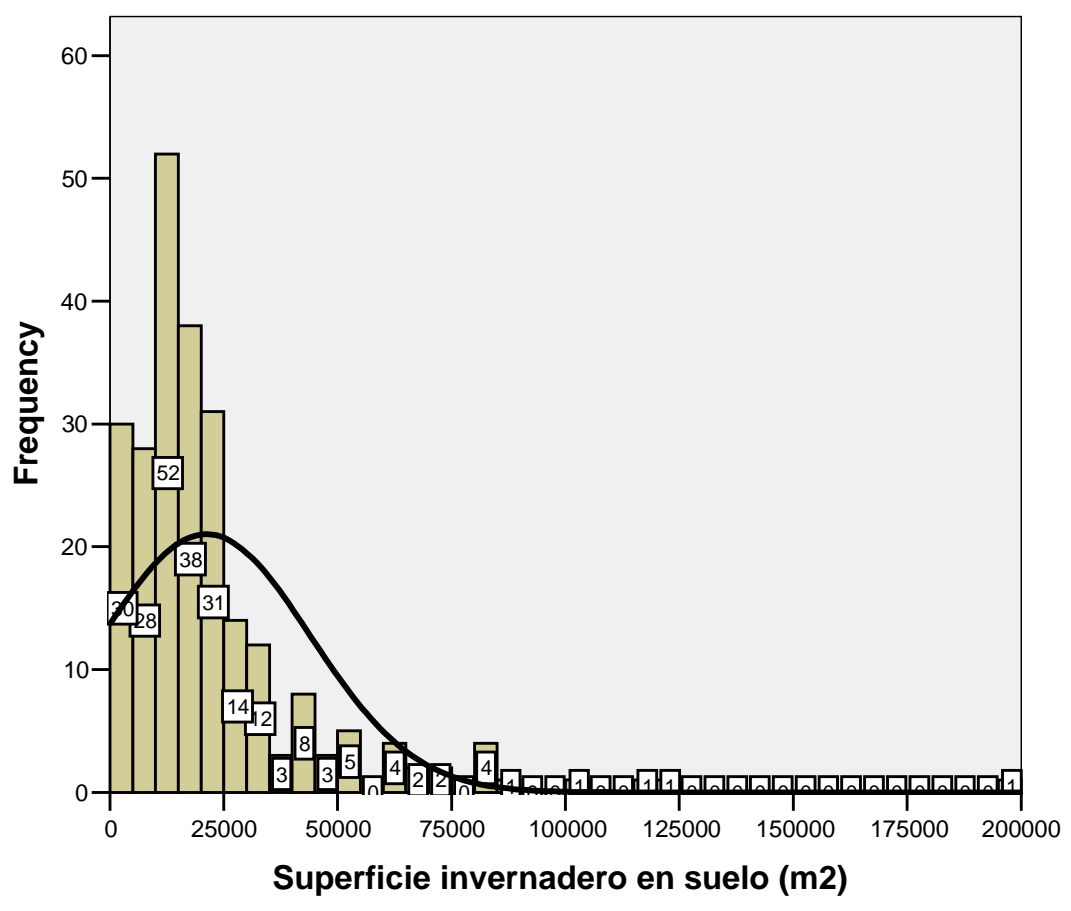


Gráfico A4.1.6. Diagrama Caja-Bigotes de la variable superficie de invernadero en suelo

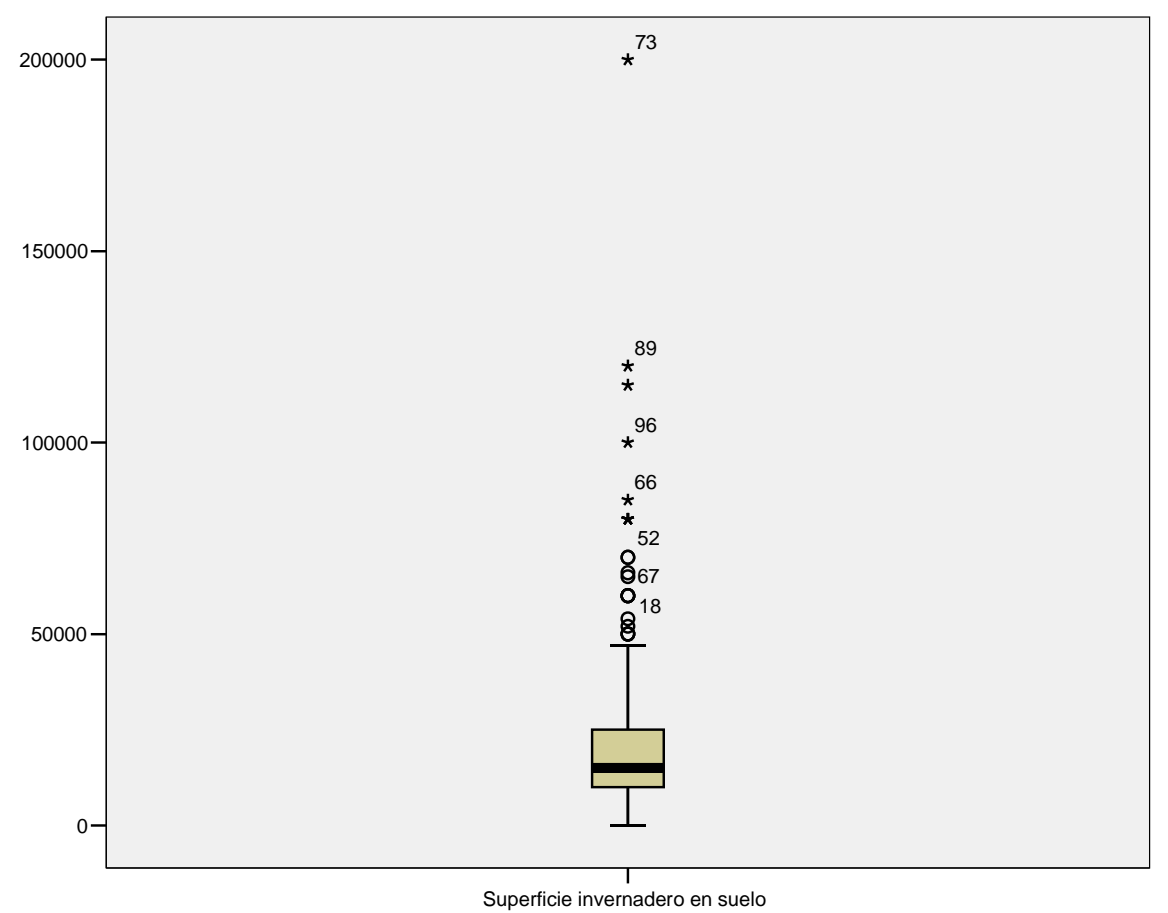

Tabla A4.1.4. Tabla análisis descriptivo de la variable superficie de invernadero en sustrato

\begin{tabular}{|ll|r|r|}
\hline & & Statistic & Std. Error \\
\hline Superficie invernadero & Mean & 5044,3983 & 1250,986 \\
en sustrato & Median &, 0000 & \\
& Std. Deviation & 19420,53 & \\
& Minimum &, 00 & \\
& Maximum & 260000,0 & \\
& Range & 260000,00 & \\
& Interquartile Range &, 00 & \\
& Skewness & 10,292 &, 157 \\
& Kurtosis & 127,730 &, 312 \\
\hline
\end{tabular}


Gráfico A4.1.7. Histograma de la variable superficie de invernadero en sustrato

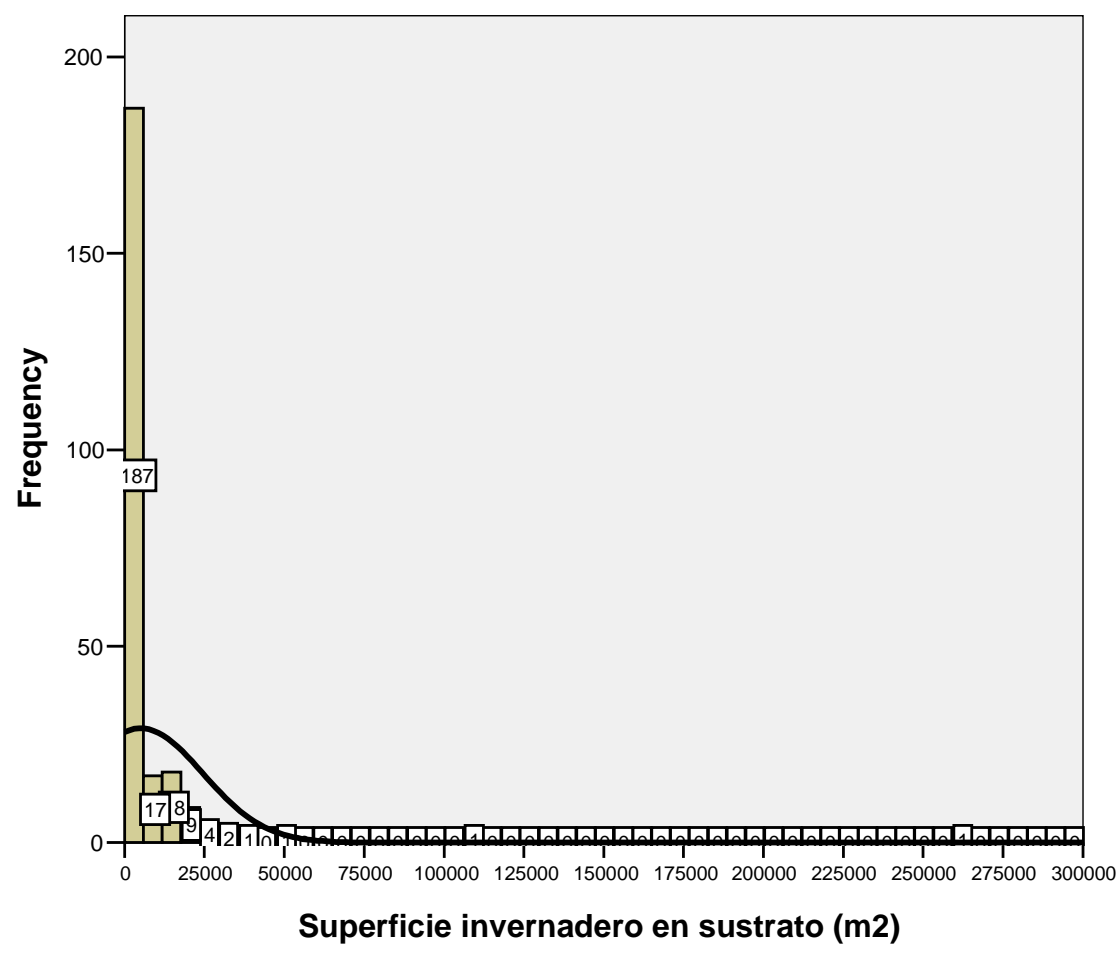


Gráfico A4.1.8. Diagrama Caja-Bigotes de la variable superficie de invernadero en sustrato

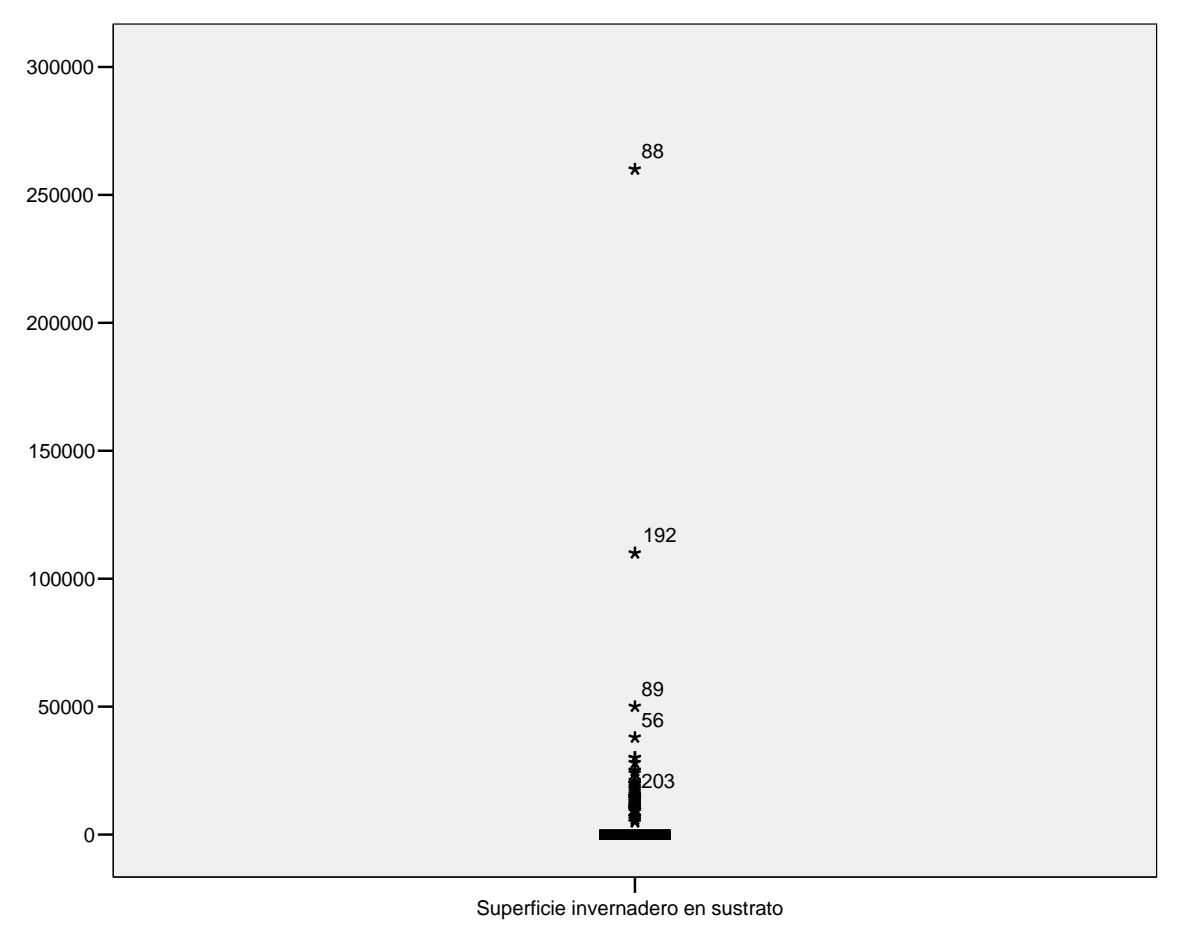

Tabla A4.1.5. Tabla análisis descriptivo de la variable superficie parral básico

\begin{tabular}{|ll|r|r|}
\hline & \multicolumn{1}{|c|}{ Statistic } & Std. Error \\
\hline Superficie parral básico & Mean & 8725,3112 & 1163,112 \\
& Median & 4000,0000 & \\
& Std. Deviation & 18056,36 & \\
& Minimum &, 00 & \\
& Maximum & 200000,0 & \\
Range & 200000,00 & \\
Interquartile Range & 10000,00 & \\
Skewness & 6,333 &, 157 \\
& Kurtosis & 56,457 &, 312 \\
\hline
\end{tabular}


Gráfico A4.1.9. Histograma de la variable superficie de parral básico

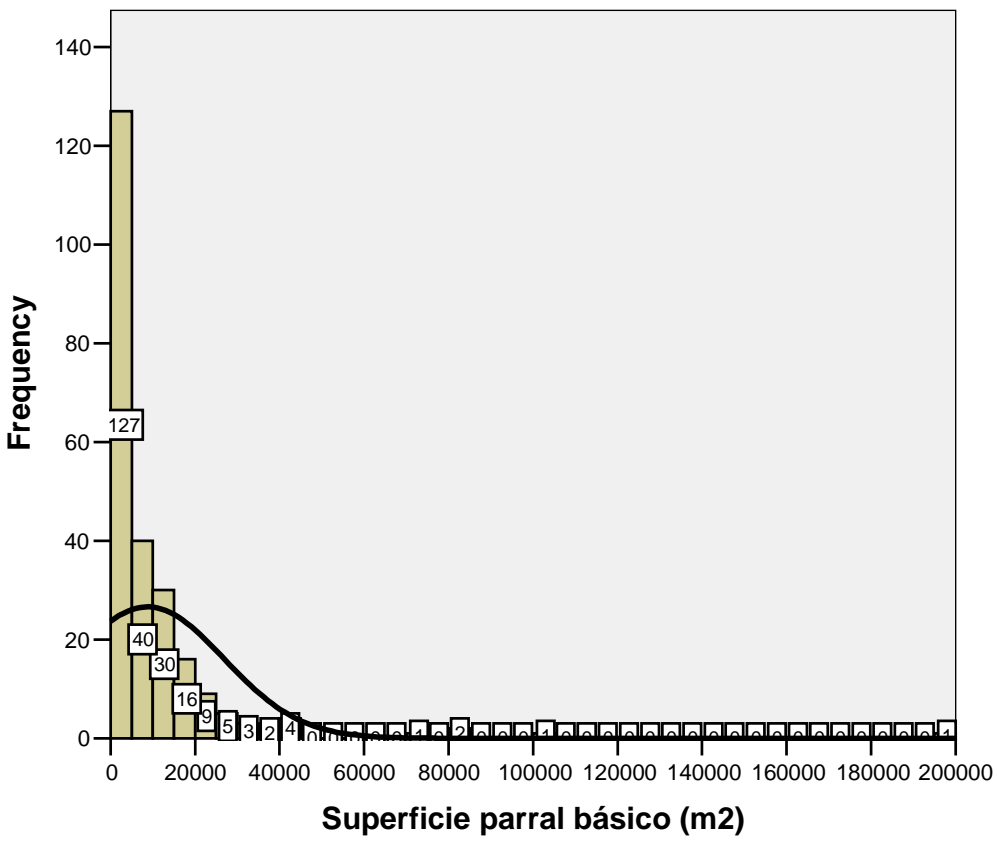

Gráfico A4.1.10. Diagrama Caja-Bigotes de la variable superficie de parral básico

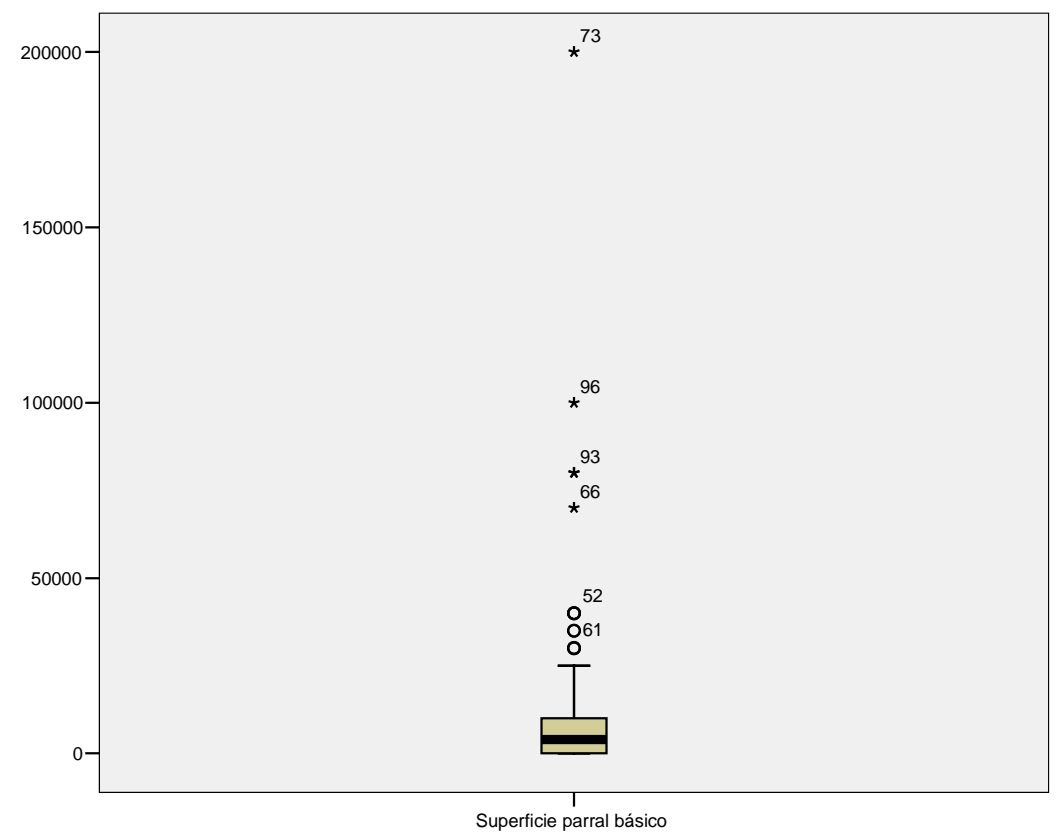


Tabla A4.1.6. Tabla análisis descriptivo de la variable superficie parral mejorado

\begin{tabular}{|ll|r|r|}
\hline & \multicolumn{1}{|c|}{ Statistic } & Std. Error \\
\hline Superficie parral & Mean & 15857,47 & 1507,385 \\
mejorado & Median & 12000,00 & \\
& Std. Deviation & 23400,91 & \\
Minimum &, 00 & \\
& Maximum & 260000,0 & \\
Range & 260000,00 & \\
Interquartile Range & 14350,00 & \\
Skewness & 6,413 &, 157 \\
Kurtosis & 57,211 &, 312 \\
\hline
\end{tabular}

Gráfico A4.1.11. Histograma de la variable superficie de parral mejorado

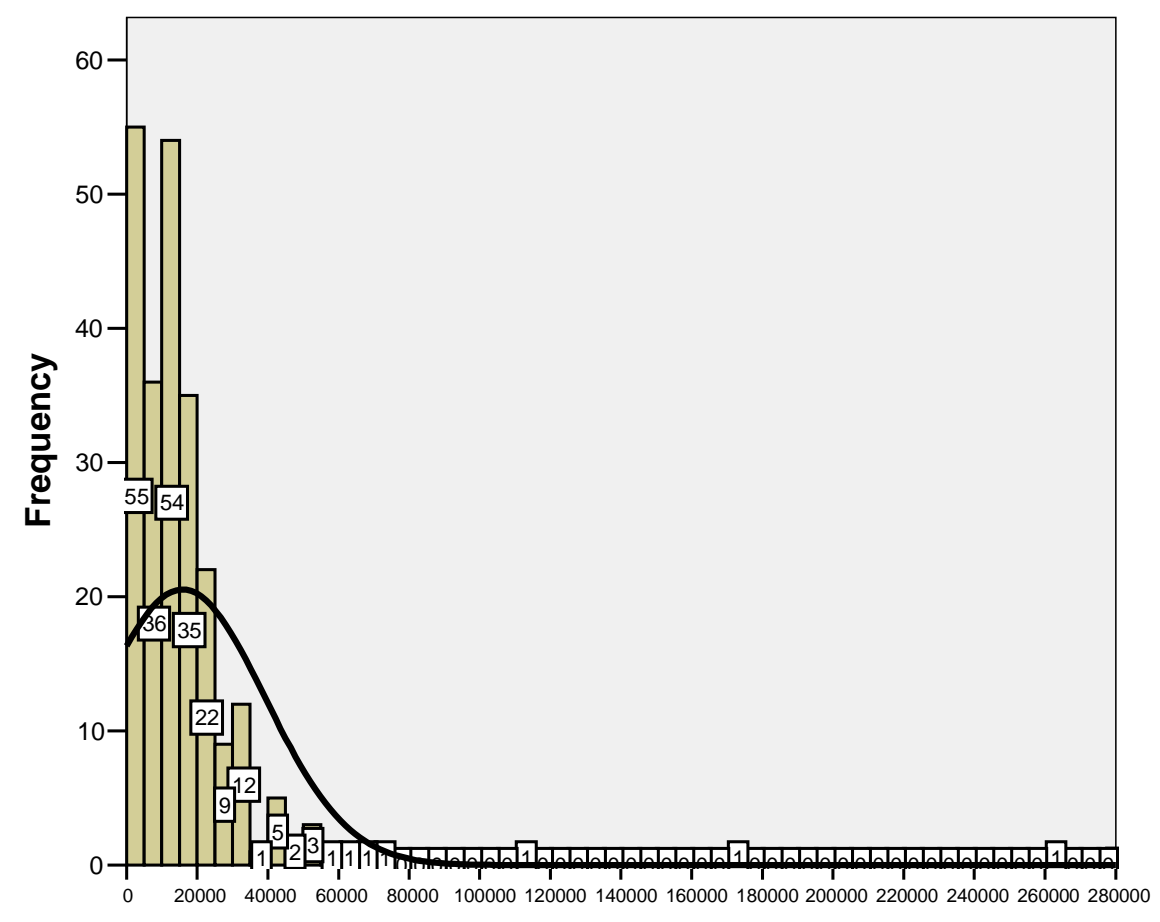

Superficie parral mejorado (m2) 
Gráfico A4.1.12. Diagrama Caja-Bigotes de la variable superficie de parral mejorado

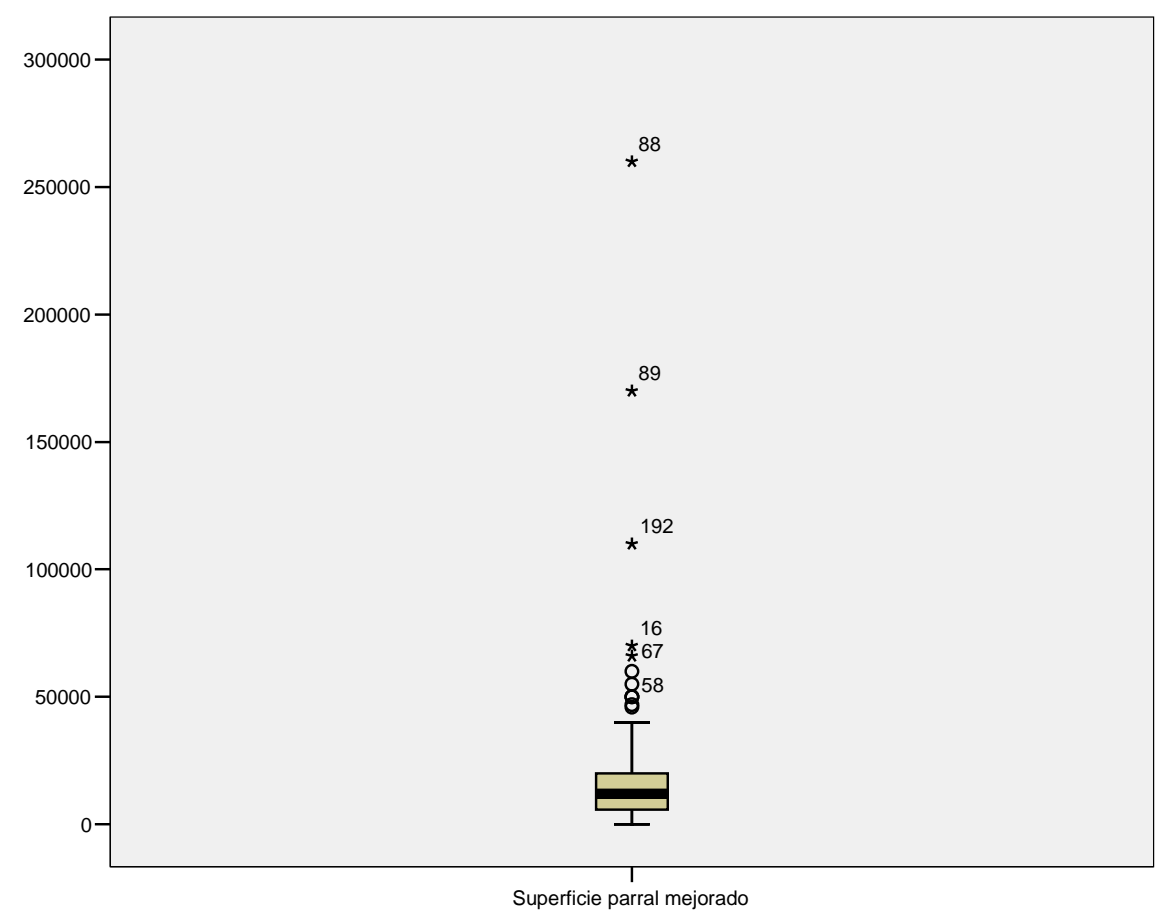

Tabla A4.1.7. Tabla análisis descriptivo de la variable superficie parral multitúnel

\begin{tabular}{|ll|r|r|}
\hline & \multicolumn{1}{|c|}{ Statistic } & Std. Error \\
\hline Superficie multitúnel & Mean & 1705,8091 & 397,16561 \\
& Median &, 0000 & \\
& Std. Deviation & 6165,668 & \\
& Minimum &, 00 & \\
& Maximum & 55000,00 & \\
& Range & 55000,00 & \\
Interquartile Range &, 00 & \\
Skewness & 5,200 &, 157 \\
& Kurtosis & 32,622 &, 312 \\
\hline
\end{tabular}


Gráfico A4.1.13. Histograma de la variable superficie de parral multitúnel

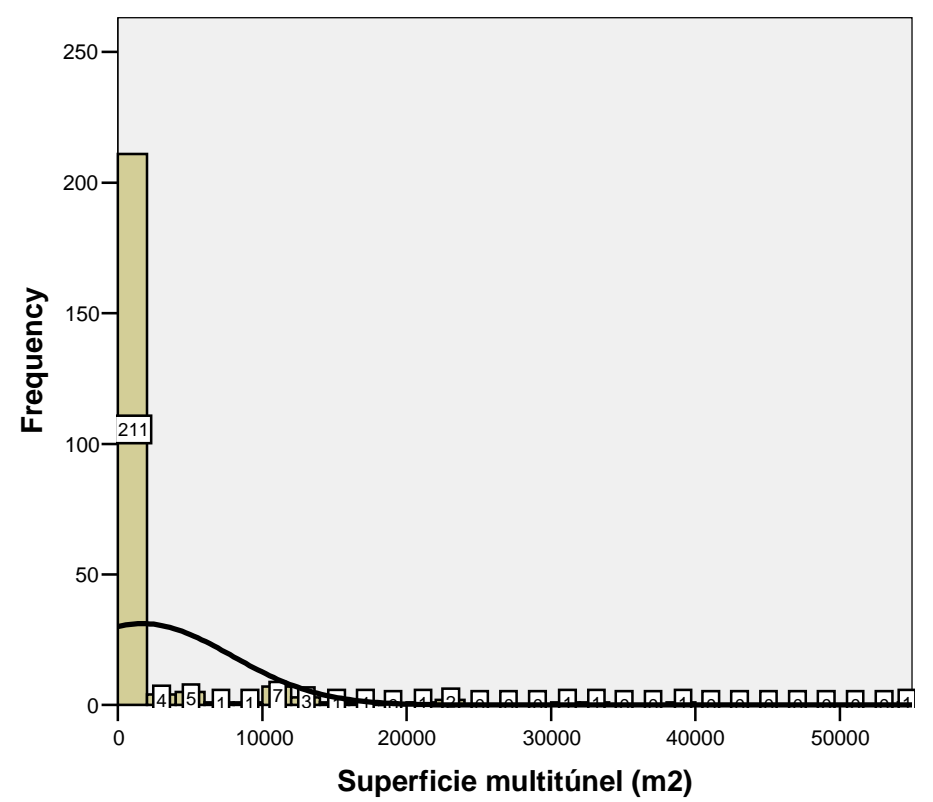

Gráfico A4.1.14. Diagrama Caja-Bigotes de la variable superficie de parral multitúnel

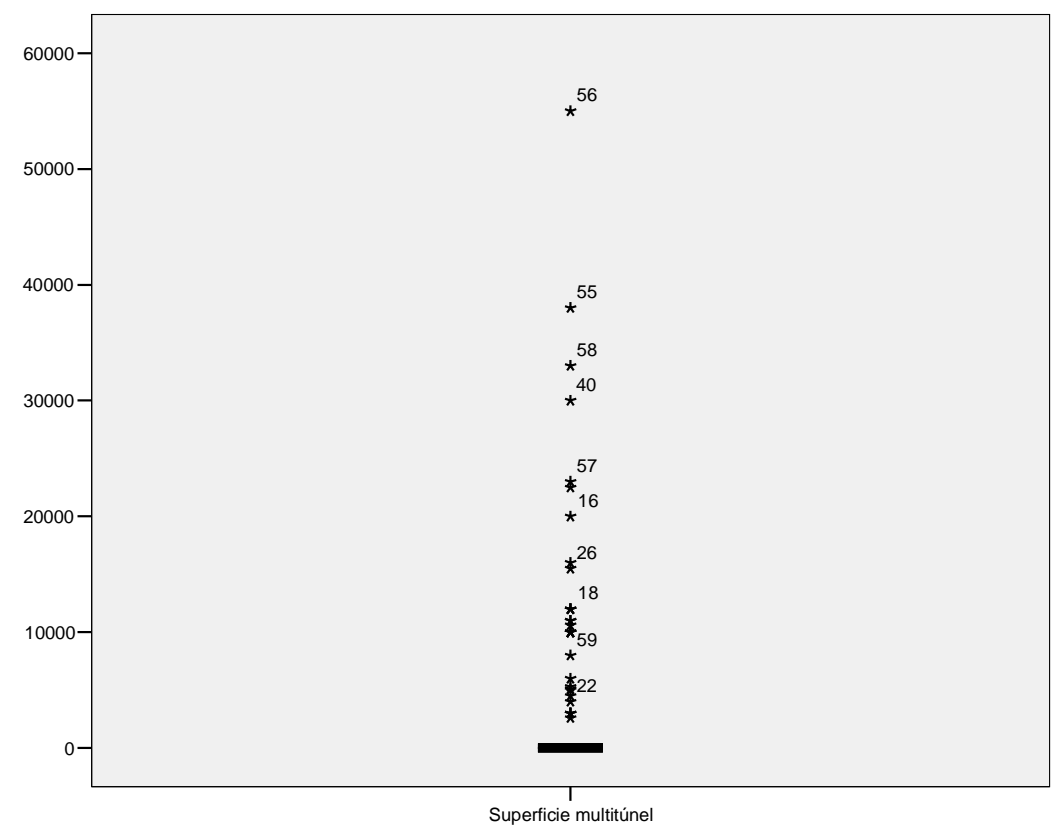


Tabla A4.1.8. Tabla distribución de frecuencias de la variable número de familiares con dedicación total

\begin{tabular}{|ll|r|r|r|r|}
\hline & & Frequency & Percent & Valid Percent & $\begin{array}{c}\text { Cumulative } \\
\text { Percent }\end{array}$ \\
\hline Valid &, 00 & 4 & 1,7 & 1,7 & 1,7 \\
& 1,00 & 103 & 42,7 & 42,7 & 44,4 \\
& 2,00 & 85 & 35,3 & 35,3 & 79,7 \\
3,00 & 33 & 13,7 & 13,7 & 93,4 \\
4,00 & 14 & 5,8 & 5,8 & 99,2 \\
& 5,00 & 2 &, 8 &, 8 & 100,0 \\
& Total & 241 & 100,0 & 100,0 & \\
\hline
\end{tabular}

Gráfico A4.1.15. Histograma de la variable número de familiares con dedicación total

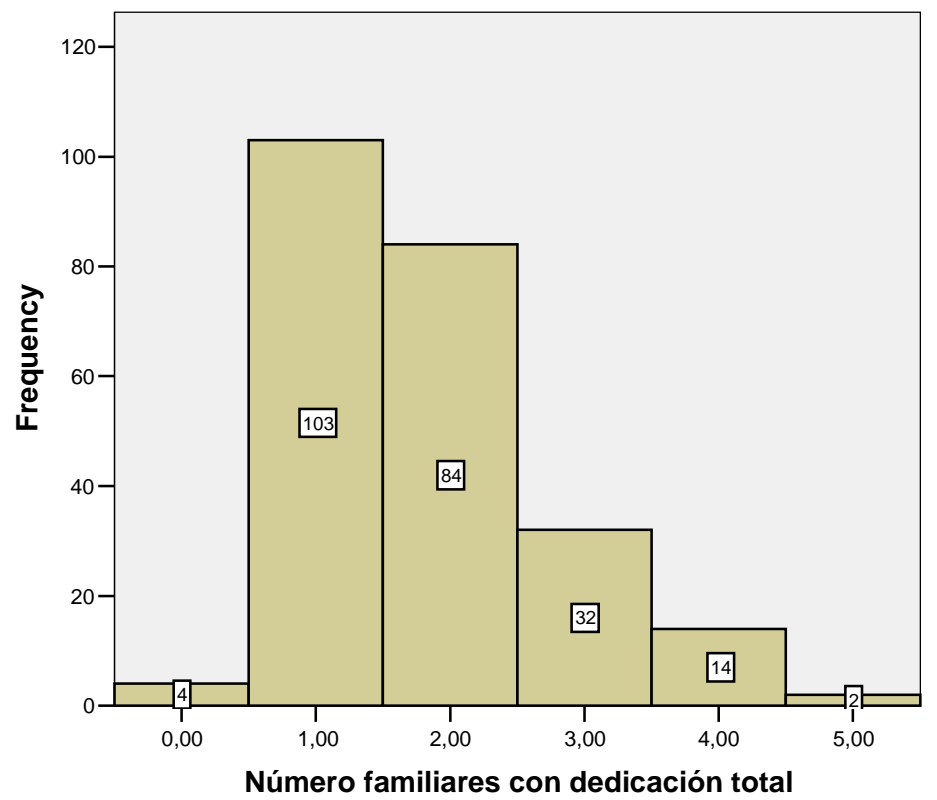


Gráfico A4.1.16. Diagrama Caja-Bigotes de la variable número de familiares con dedicación total

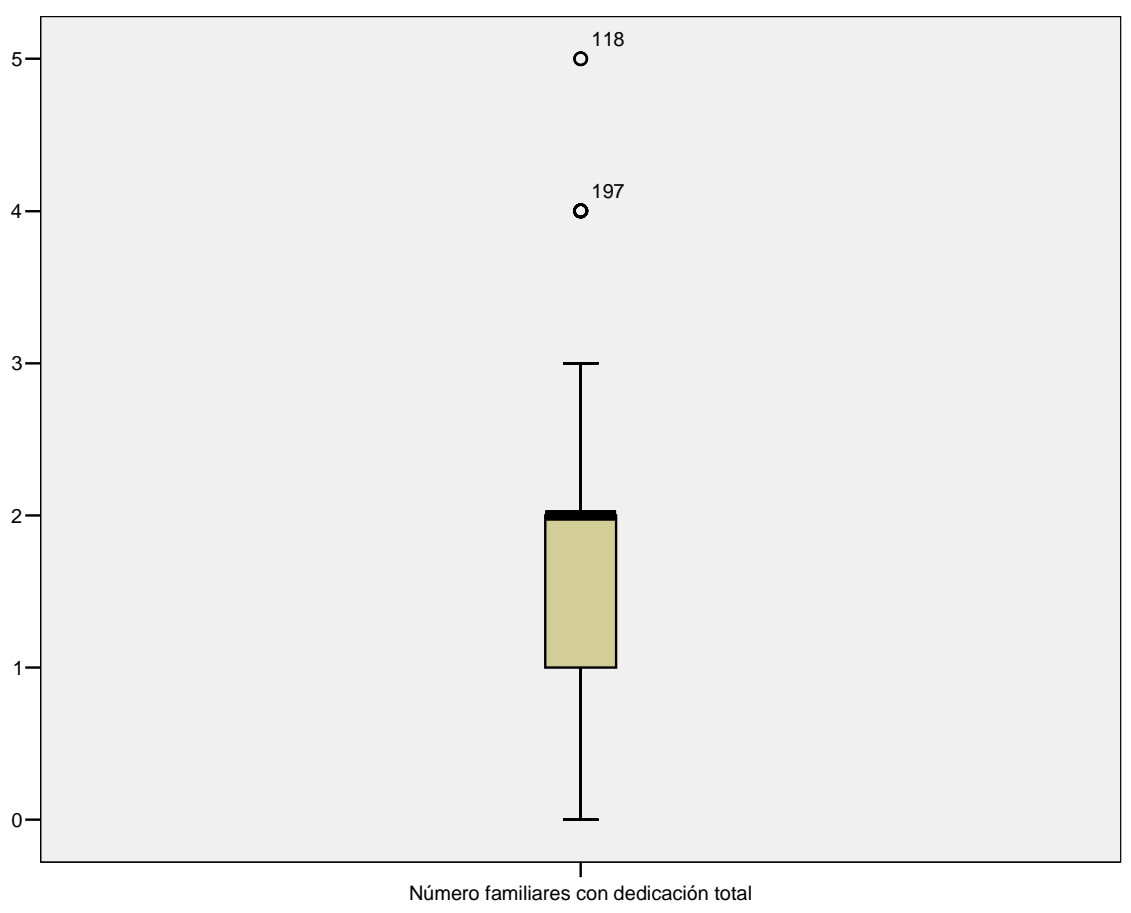

Tabla A4.1.9. Distribución de frecuencias de la variable número de familiares con dedicación parcial

\begin{tabular}{|ll|r|r|r|r|}
\hline & & & & Cumulative \\
& & Frequency & Percent & Valid Percent & Percent \\
\hline Valid &, 00 & 103 & 42,7 & 42,7 & 42,7 \\
& 1,00 & 47 & 19,5 & 19,5 & 62,2 \\
2,00 & 47 & 19,5 & 19,5 & 81,7 \\
3,00 & 13 & 5,4 & 5,4 & 87,1 \\
4,00 & 8 & 3,3 & 3,3 & 90,5 \\
5,00 & 3 & 1,2 & 1,2 & 91,7 \\
6,00 & 4 & 1,7 & 1,7 & 93,4 \\
7,00 & 1 &, 4 &, 4 & 93,8 \\
8,00 & 4 & 1,7 & 1,7 & 95,4 \\
10,00 & 3 & 1,2 & 1,2 & 96,7 \\
15,00 & 2 &, 8 &, 8 & 97,5 \\
18,00 & 1 &, 4 &, 4 & 97,9 \\
20,00 & 2 &, 8 &, 8 & 98,8 \\
25,00 & 1 &, 4 &, 4 & 99,2 \\
40,00 & 1 &, 4 &, 4 & 99,6 \\
125,00 & 1 &, 4 &, 4 & 100,0 \\
Total & 241 & 100,0 & 100,0 & \\
\hline
\end{tabular}


Gráfico A4.1.17. Histograma de la variable número de familiares con dedicación parcial

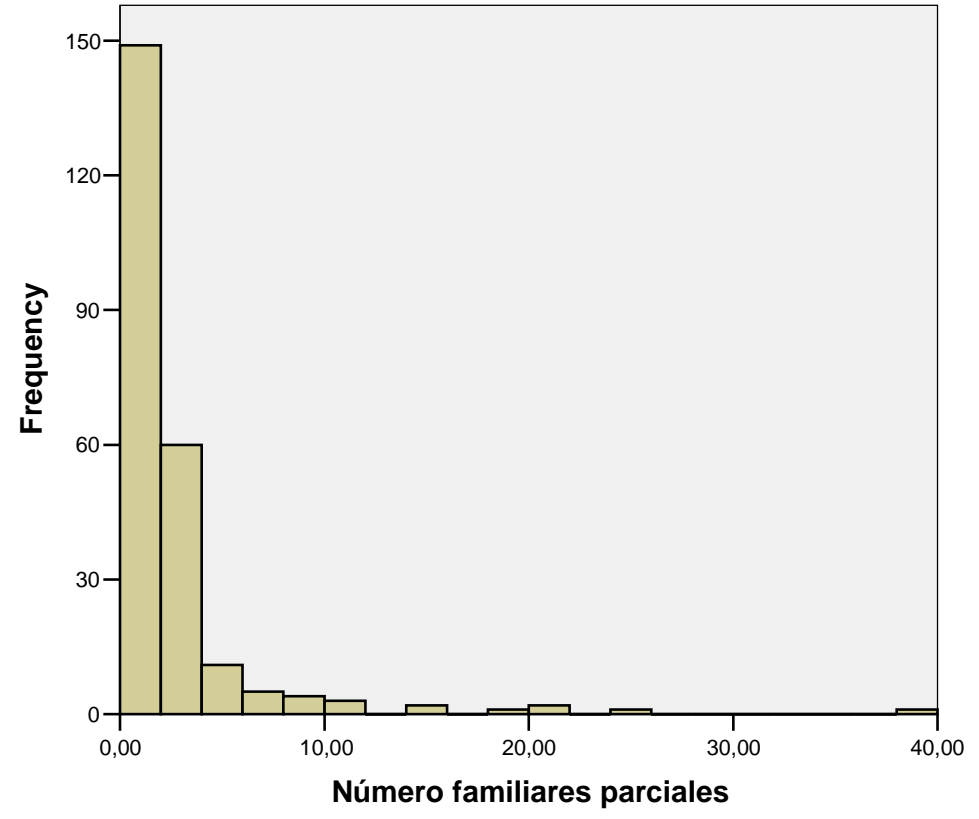

Gráfico A4.1.18. Diagrama Caja-Bigotes de la variable número de familiares con dedicación parcial

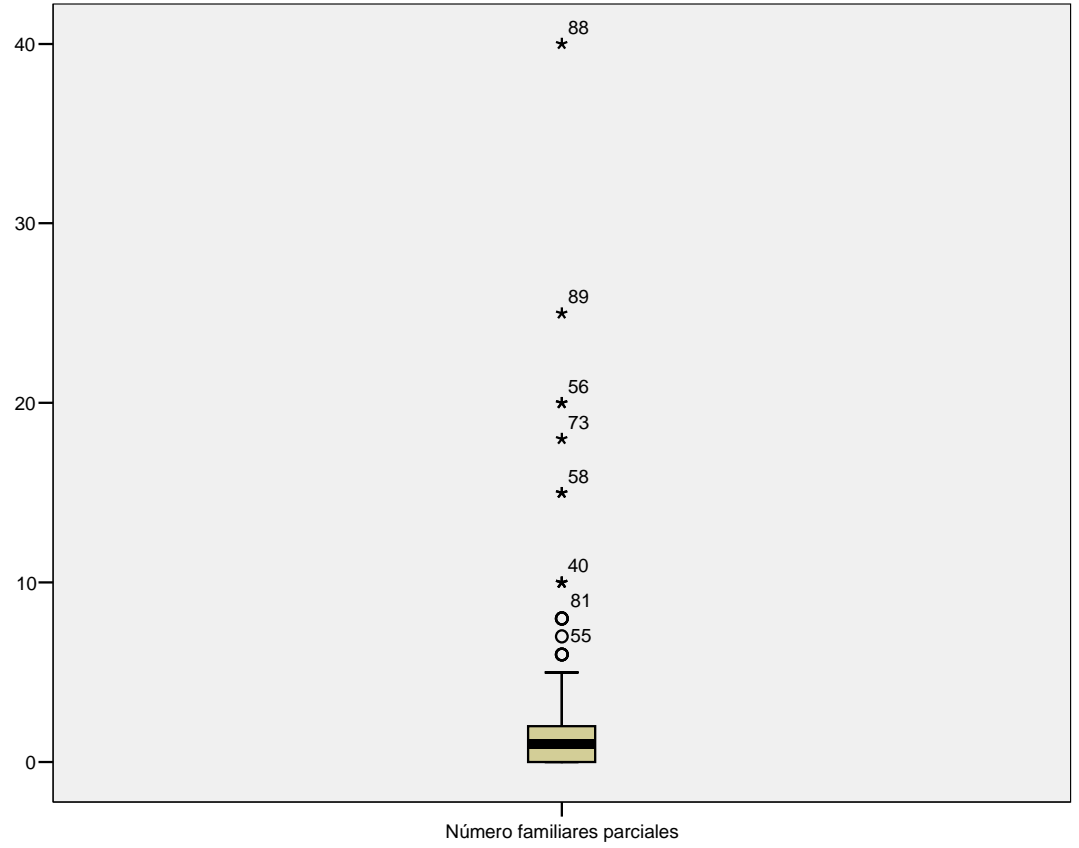


$\underline{\text { Anexo } 4}$

Tabla A4.1.10. Distribución de frecuencias de la variable número de eventuales a tiempo total

\begin{tabular}{|c|c|c|c|c|c|}
\hline & Frequency & Percent & Valid Percent & $\begin{array}{c}\text { Cumulative } \\
\text { Percent }\end{array}$ \\
\hline \multirow[t]{9}{*}{ Valid } & ,00 & 209 & 86,7 & 86,7 & 86,7 \\
\hline & 1,00 & 14 & 5,8 & 5,8 & 92,5 \\
\hline & 2,00 & 4 & 1,7 & 1,7 & 94,2 \\
\hline & 3,00 & 5 & 2,1 & 2,1 & 96,3 \\
\hline & 4,00 & 4 & 1,7 & 1,7 & 97,9 \\
\hline & 7,00 & 3 & 1,2 & 1,2 & 99,2 \\
\hline & 8,00 & 1 &, 4 & ,4 & 99,6 \\
\hline & 20,00 & 1 & ,4 & , 4 & 100,0 \\
\hline & Total & 241 & 100,0 & 100,0 & \\
\hline
\end{tabular}

Gráfico A4.1.19. Histograma de la variable número de eventuales a tiempo total

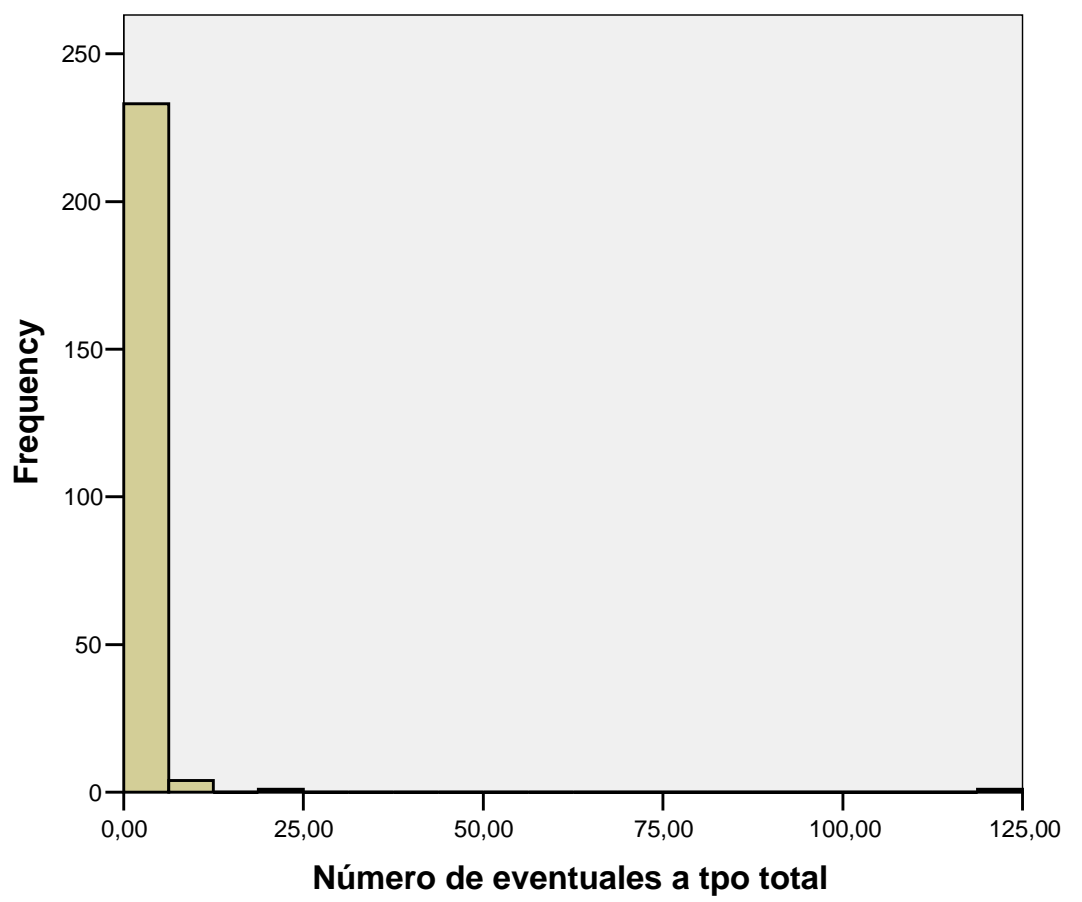


Gráfico A4.1.20. Diagrama Caja-Bigotes de la variable número de eventuales a tiempo total

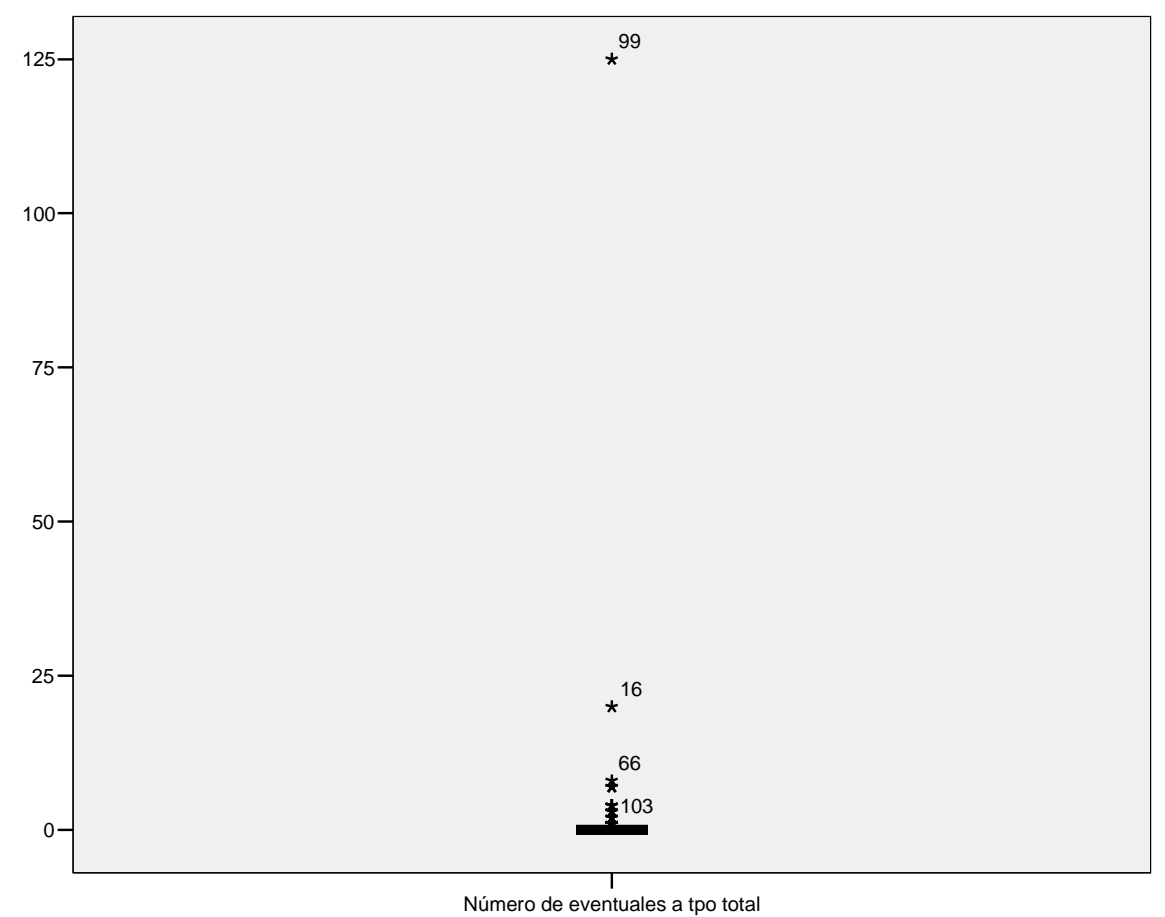

Tabla A4.1.11. Distribución de frecuencias de la variable número de eventuales a tiempo parcial

\begin{tabular}{|c|c|c|c|c|c|}
\hline & & Frequency & Percent & Valid Percent & $\begin{array}{c}\text { Cumulative } \\
\text { Percent }\end{array}$ \\
\hline \multirow[t]{16}{*}{ Valid } &, 00 & 143 & 59,3 & 59,3 & 59,3 \\
\hline & 1,00 & 21 & 8,7 & 8,7 & 68,0 \\
\hline & 2,00 & 30 & 12,4 & 12,4 & 80,5 \\
\hline & 3,00 & 12 & 5,0 & 5,0 & 85,5 \\
\hline & 4,00 & 7 & 2,9 & 2,9 & 88,4 \\
\hline & 5,00 & 10 & 4,1 & 4,1 & 92,5 \\
\hline & 6,00 & 4 & 1,7 & 1,7 & 94,2 \\
\hline & 7,00 & 1 & ,4 & ,4 & 94,6 \\
\hline & 8,00 & 1 & ,4 & ,4 & 95,0 \\
\hline & 9,00 & 1 & , 4 & , 4 & 95,4 \\
\hline & 10,00 & 5 & 2,1 & 2,1 & 97,5 \\
\hline & 13,00 & 1 & 4 & 4 & 97,9 \\
\hline & 14,00 & 1 & ,4 & ,4 & 98,3 \\
\hline & 15,00 & 2 & 8 & 8 & 99,2 \\
\hline & 20,00 & 2 & ,8 & ,8 & 100,0 \\
\hline & Total & 241 & 100,0 & 100,0 & \\
\hline
\end{tabular}


Gráfico A4.1.21. Histograma de la variable número de eventuales a tiempo parcial

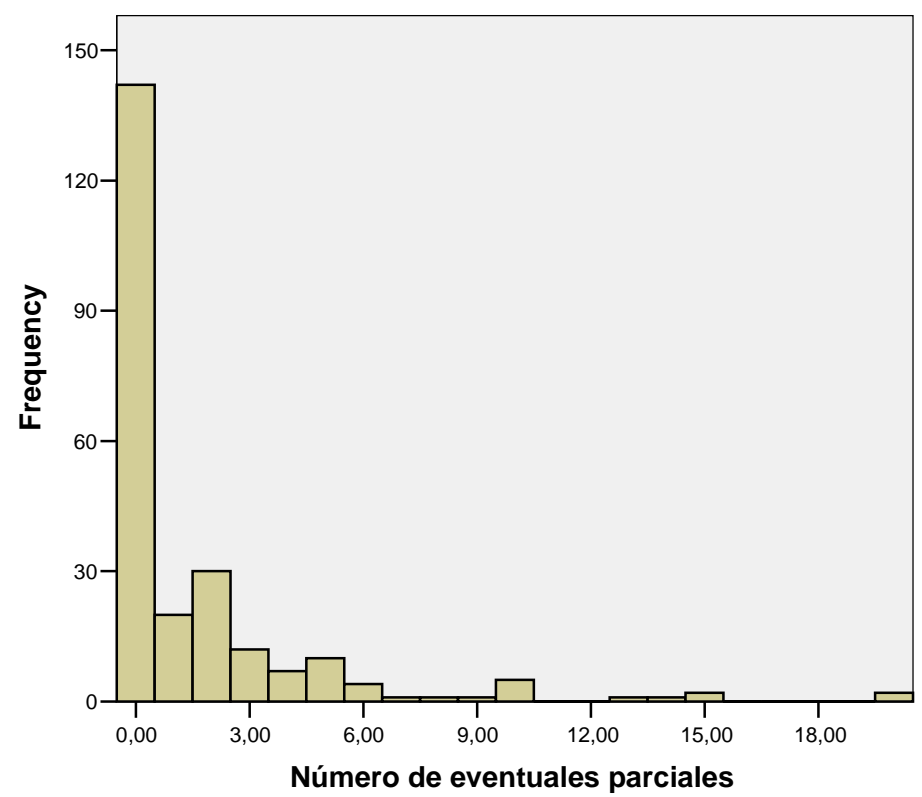

Gráfico A4.1.22. Diagrama Caja-Bigotes de la variable número de eventuales a tiempo parcial

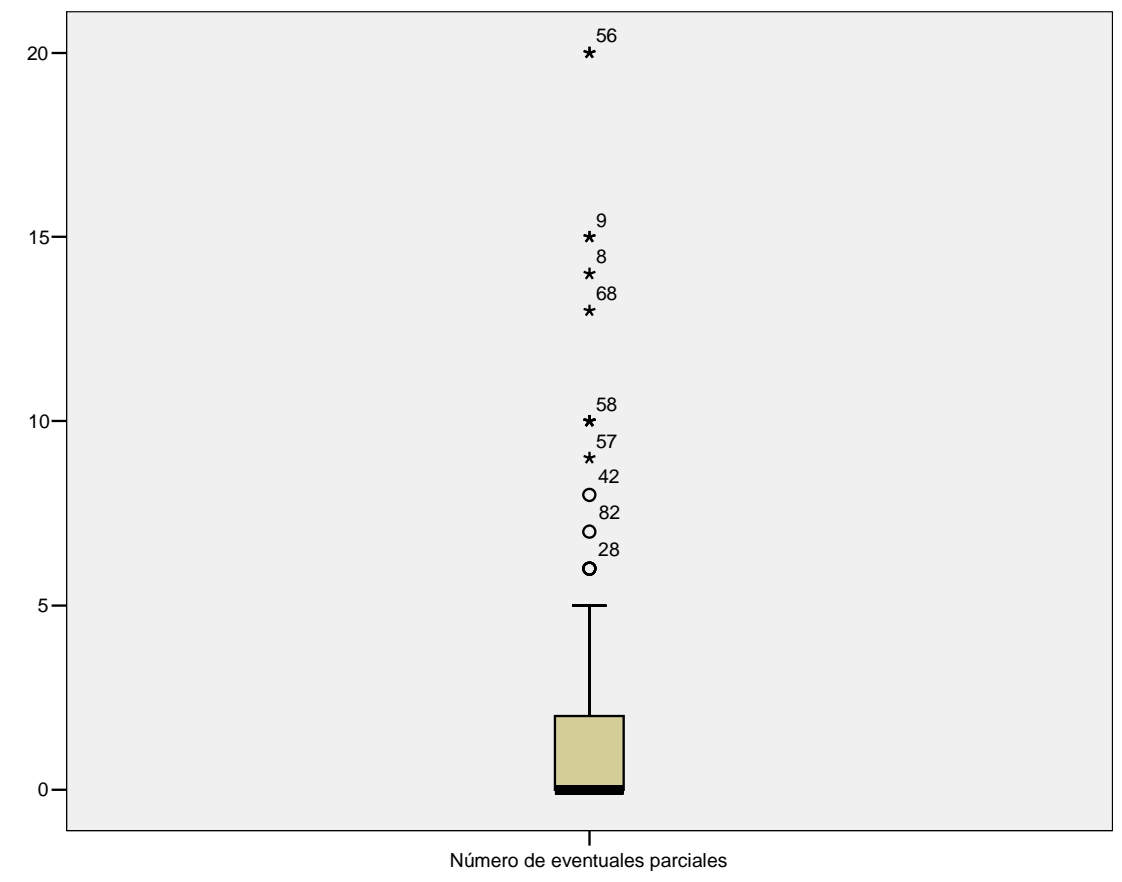


Tabla A4.1.12. Distribución de frecuencias de la variable número de jornales al año por familiares a tiempo parcial

\begin{tabular}{|c|c|c|c|c|c|}
\hline & & Frequency & Percent & Valid Percent & $\begin{array}{c}\text { Cumulative } \\
\text { Percent }\end{array}$ \\
\hline \multirow[t]{8}{*}{ Valid } &, 00 & 227 & 94,2 & 94,6 & 94,6 \\
\hline & 30,00 & 1 & ,4 & ,4 & 95,0 \\
\hline & 60,00 & 1 & ,4 & ,4 & 95,4 \\
\hline & 90,00 & 6 & 2,5 & 2,5 & 97,9 \\
\hline & 120,00 & 3 & 1,2 & 1,3 & 99,2 \\
\hline & 150,00 & 1 & , 4 & , 4 & 99,6 \\
\hline & 180,00 & 1 & ,4 & ,4 & 100,0 \\
\hline & Total & 240 & 99,6 & 100,0 & \\
\hline Missing & System & 1 & ,4 & & \\
\hline Total & & 241 & 100,0 & & \\
\hline
\end{tabular}

Gráfico A4.1.23. Histograma de la variable número de jornales al año por familiares a tiempo parcial

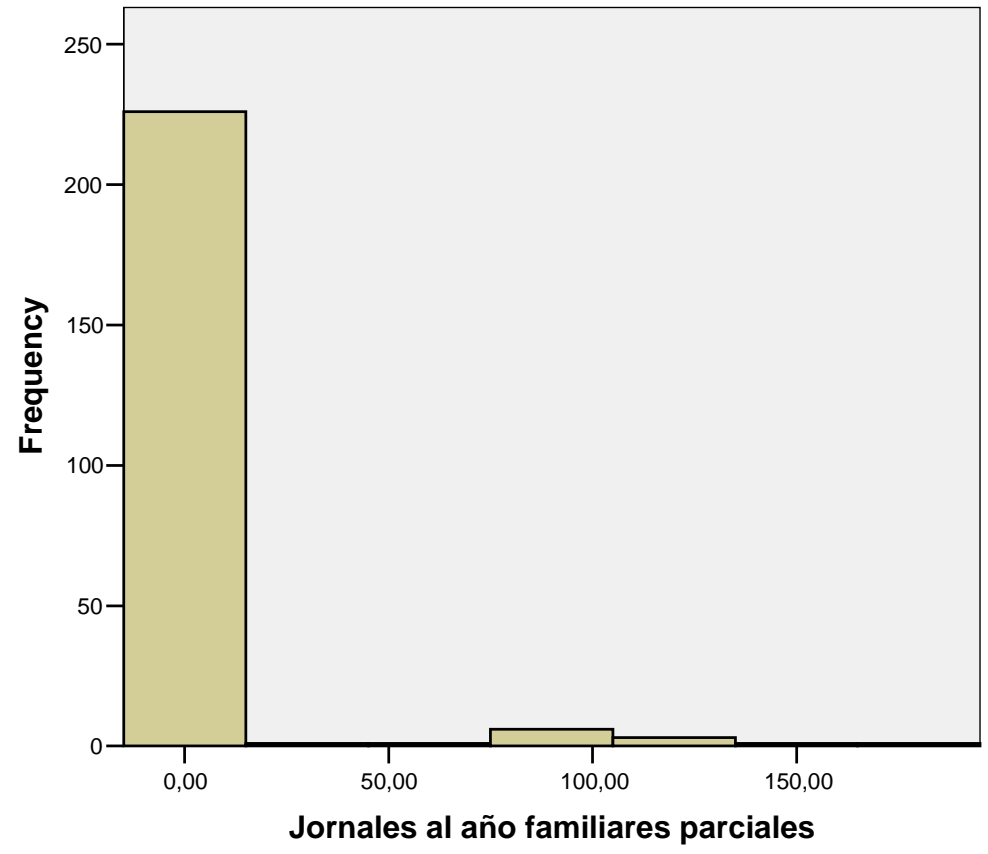


Gráfico A4.1.24. Diagrama Caja-Bigotes de la variable número de jornales al año por familiares a tiempo parcial

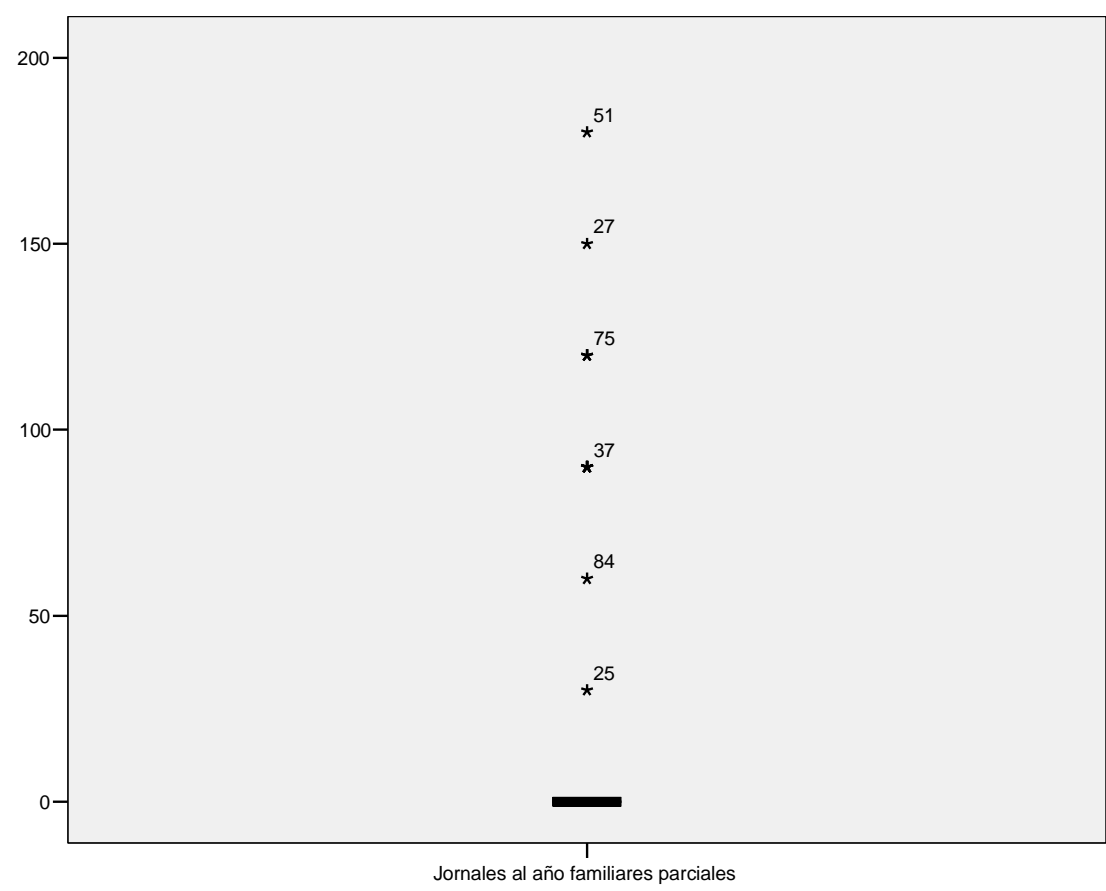

Tabla A4.1.13. Distribución de frecuencias de la variable número de jornales al año por eventuales a tiempo parcial

\begin{tabular}{|ll|r|r|r|r|}
\hline & & & & Cumulative \\
& & Frequency & Percent & Valid Percent & Percent \\
\hline Valid &, 00 & 128 & 53,1 & 53,3 & 53,3 \\
& 20,00 & 1 &, 4 &, 4 & 53,8 \\
& 40,00 & 1,7 & 1,7 & 55,4 \\
60,00 & 10 & 4,1 & 4,2 & 59,6 \\
& 90,00 & 19 & 7,9 & 7,9 & 67,5 \\
96,00 & 1 &, 4 &, 4 & 67,9 \\
& 100,00 & 1 &, 4 &, 4 & 68,3 \\
& 120,00 & 18 & 7,5 & 7,5 & 75,8 \\
& 150,00 & 13 & 5,4 & 5,4 & 81,3 \\
& 180,00 & 29 & 12,0 & 12,1 & 93,3 \\
& 210,00 & 7 & 2,9 & 2,9 & 96,3 \\
& 240,00 & 5 & 2,1 & 2,1 & 98,3 \\
& 270,00 & 3 & 1,2 & 1,3 & 99,6 \\
& 300,00 & 1 &, 4 &, 4 & 100,0 \\
& Total & 240 & 99,6 & 100,0 & \\
Missing & System & 1 &, 4 & & \\
Total & & 241 & 100,0 & & \\
\hline
\end{tabular}


Gráfico A4.1.25. Histograma de la variable número de jornales al año por eventuales a tiempo parcial

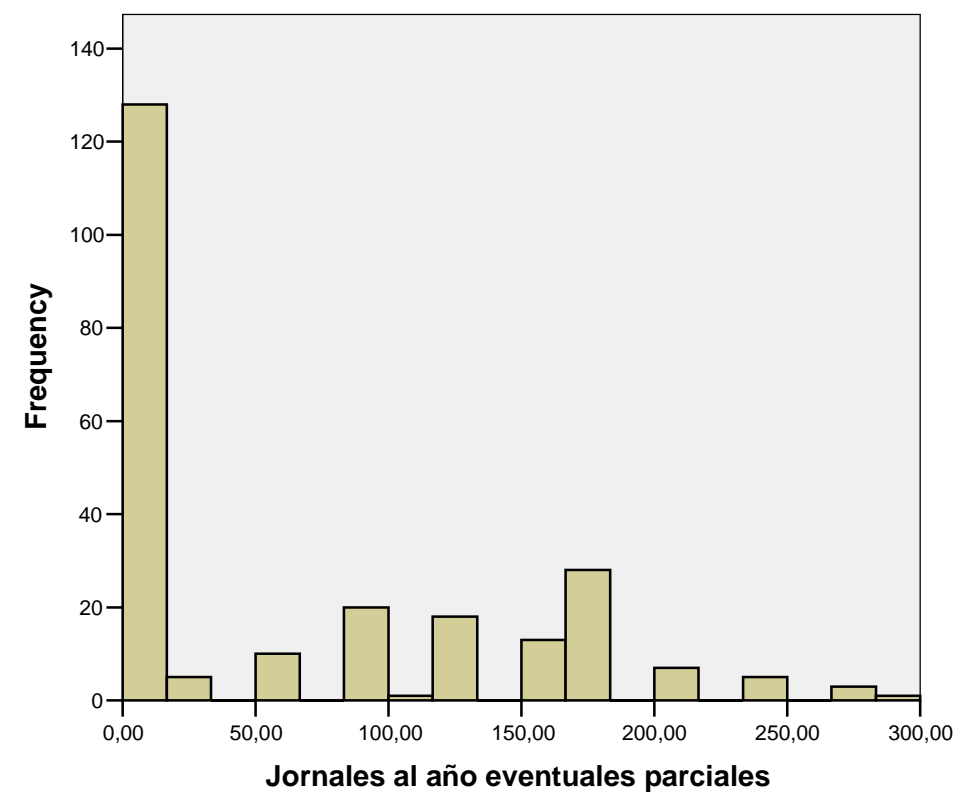

Gráfico A4.1.26. Diagrama Caja-Bigotes de la variable número de jornales al año por eventuales a tiempo parcial

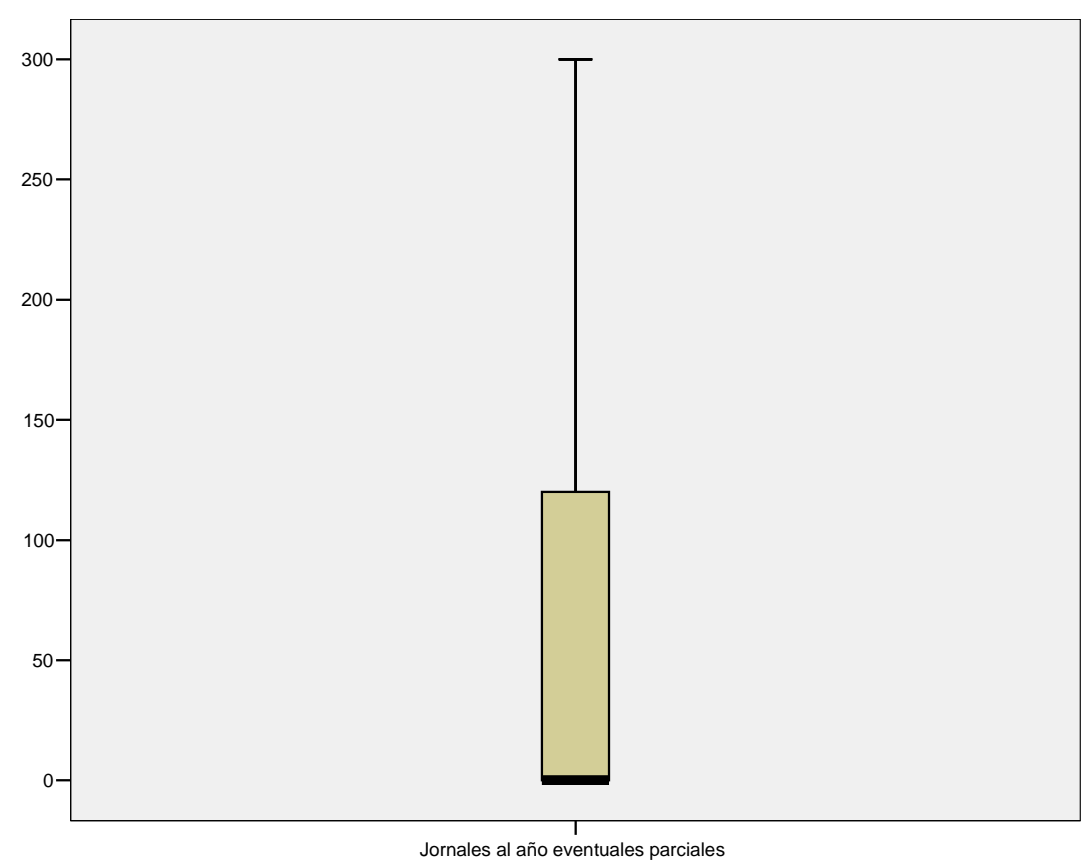


Gráfico A4.1.27. Histograma de la variable rendimiento anual medio del pimiento $\left(\mathrm{kg} / \mathrm{m}^{2}\right)$

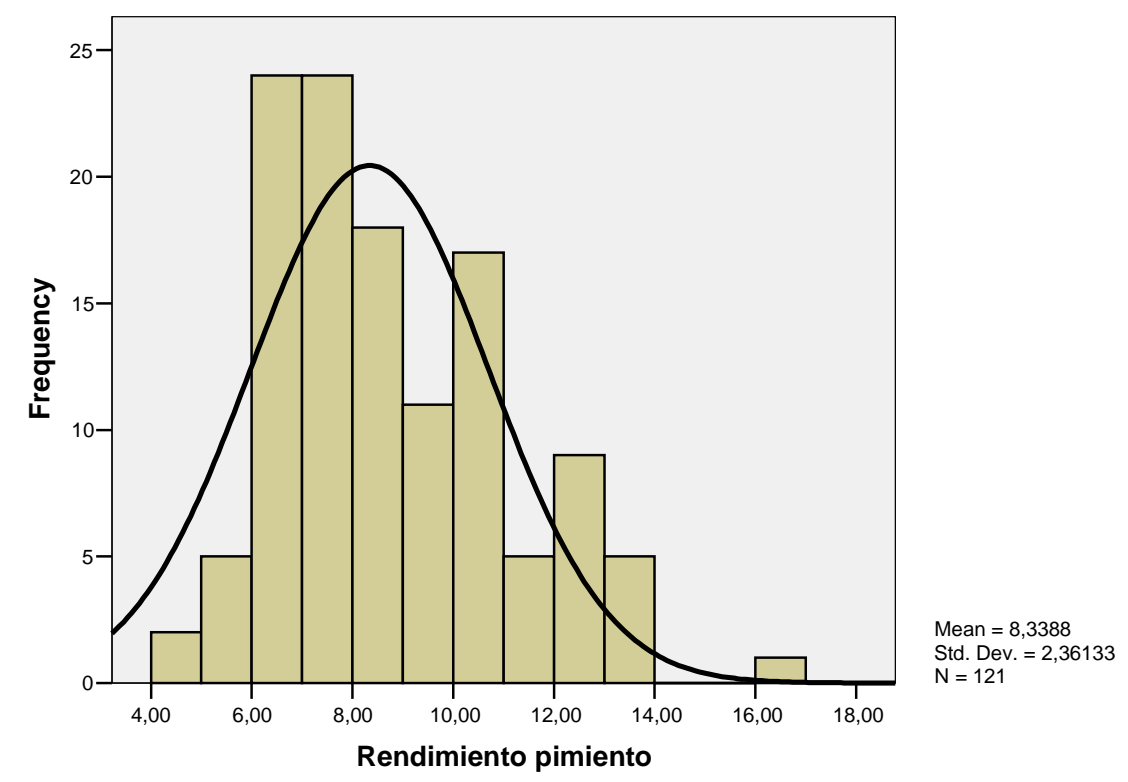

Gráfico A4.1.28. Histograma de la variable rendimiento anual medio del tomate $\left(\mathrm{kg} / \mathrm{m}^{2}\right)$

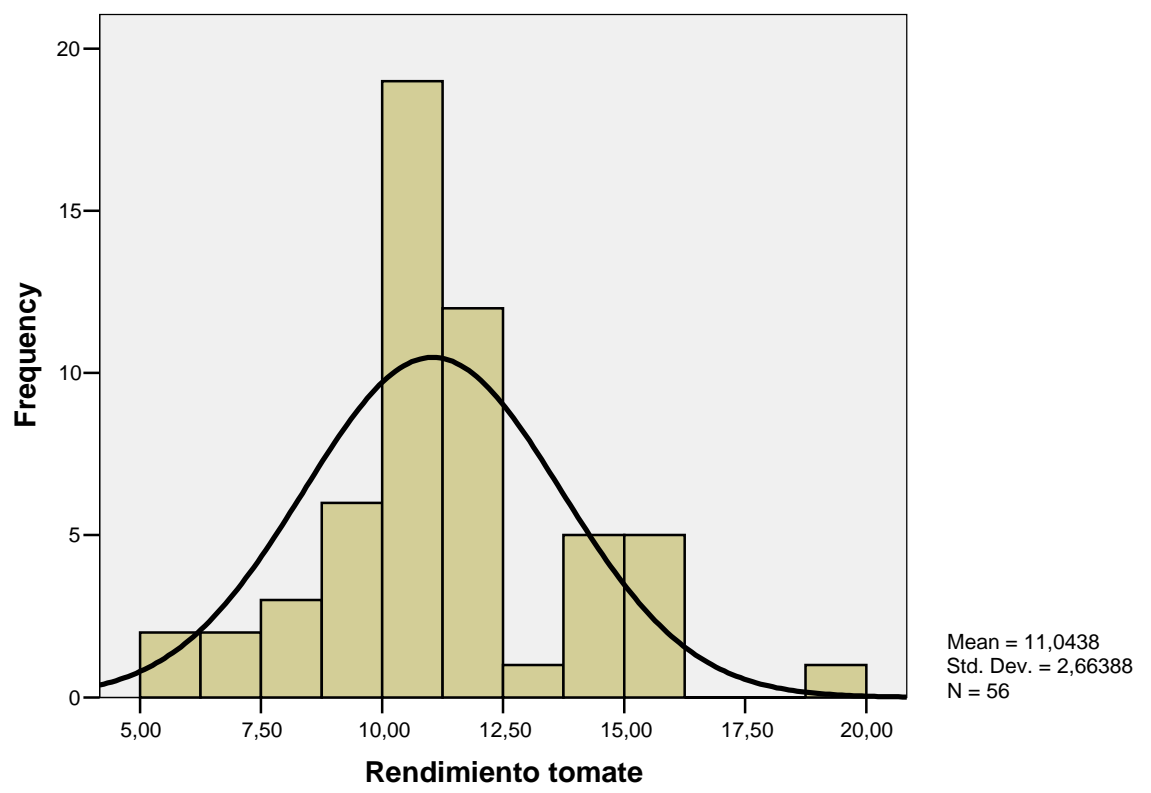


Gráfico A4.1.29. Histograma de la variable rendimiento anual medio del pepino $\left(\mathrm{kg} / \mathrm{m}^{2}\right)$

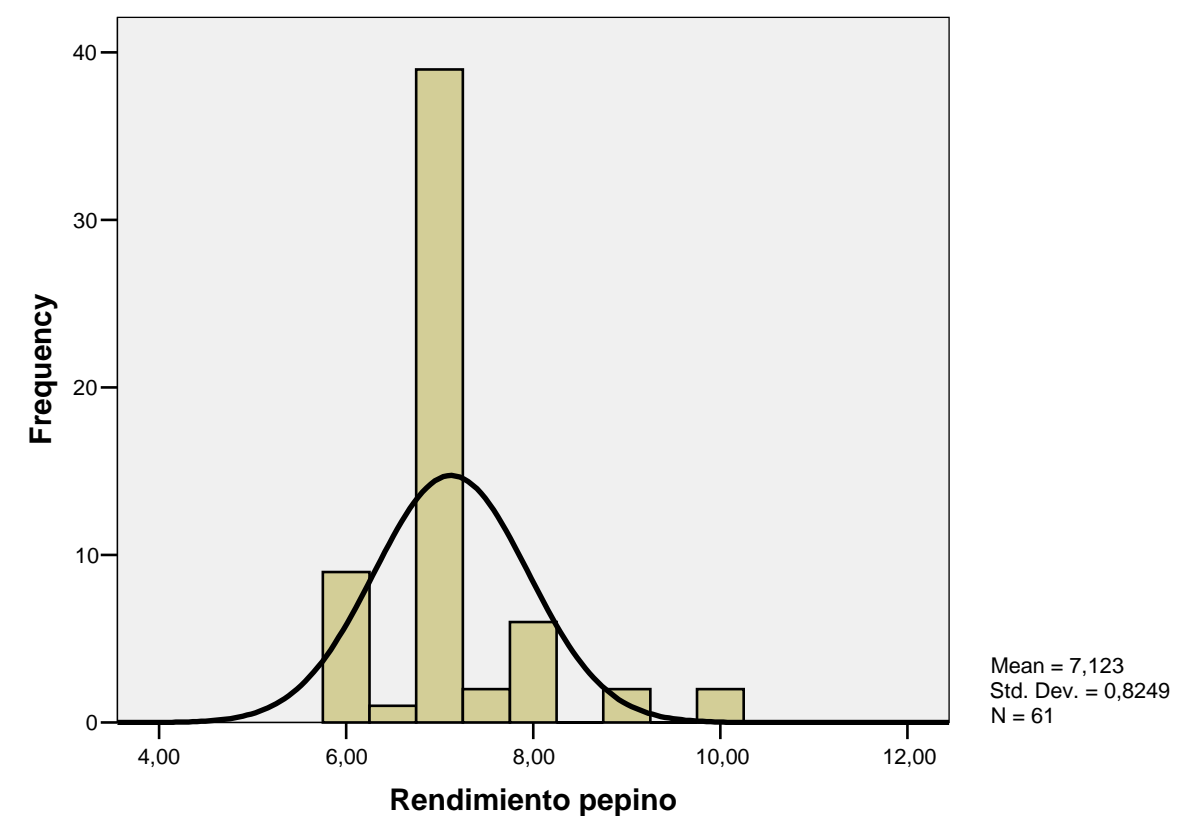

Gráfico A4.1.30. Histograma de la variable rendimiento anual medio del berenjena $\left(\mathrm{kg} / \mathrm{m}^{2}\right)$

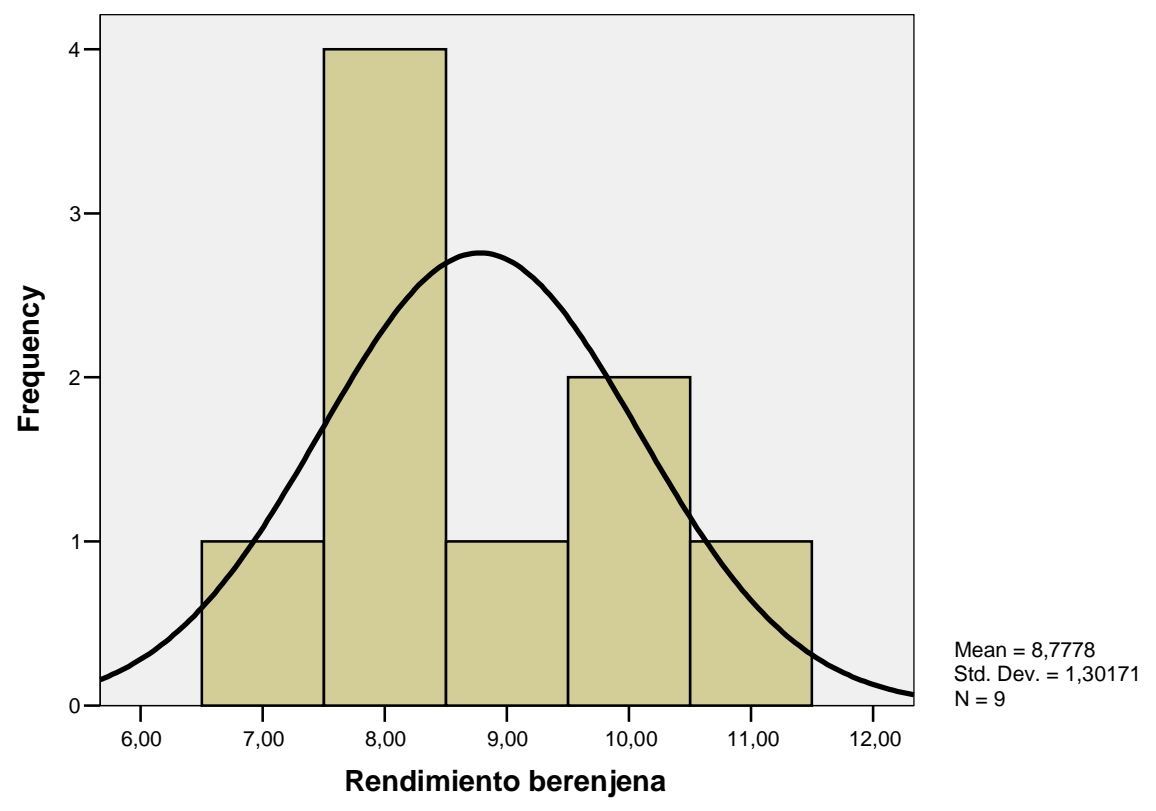


$\underline{\text { Anexo } 4}$

Gráfico A4.1.31. Histograma de la variable rendimiento anual medio del calabacín $\left(\mathrm{kg} / \mathrm{m}^{2}\right)$

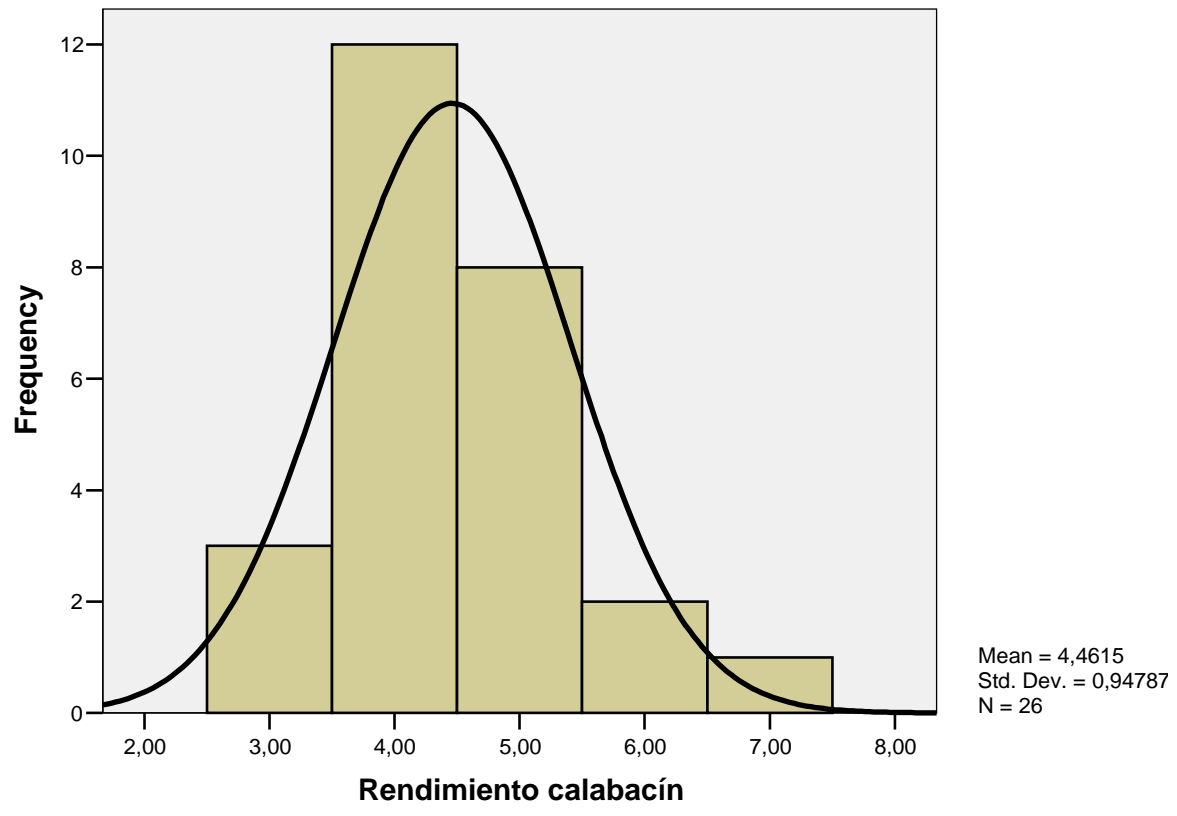




\section{A4.2. Variables "Nivel de tecnología"}

Tabla A4.2.1. Tabla análisis descriptivo de la variable superficie del invernadero más tecnificado de la explotación

\begin{tabular}{|ll|r|r|}
\hline & & \multicolumn{1}{|c|}{ Statistic } & Std. Error \\
\hline Superficie Invernadero & Mean & 9900,0000 & 932,45544 \\
más tecnificado & Median & 8000,0000 & \\
& Std. Deviation & 14445,54 & \\
& Minimum & 1000,00 & \\
& Maximum & 200000,0 & \\
& Range & 199000,00 & \\
& Interquartile Range & 5000,00 & \\
& Skewness & 10,155 &, 157 \\
& Kurtosis & 127,578 &, 313 \\
\hline
\end{tabular}

Gráfico A4.2.1. Histograma de la variable superficie del invernadero más tecnificado de la explotación $\left(\mathrm{m}^{2}\right)$

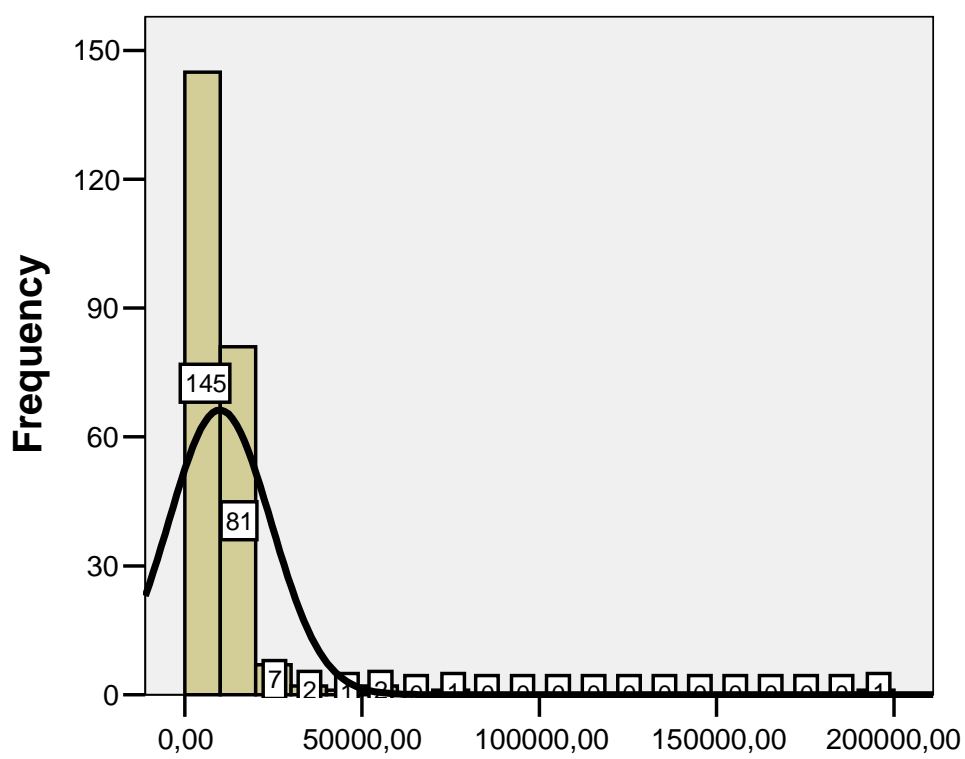

Superficie Invernadero más tecnificado 
Anexo 4

Gráfico A4.2.2. Diagrama Caja-Bigotes de la variable superficie del invernadero más tecnificado de la explotación

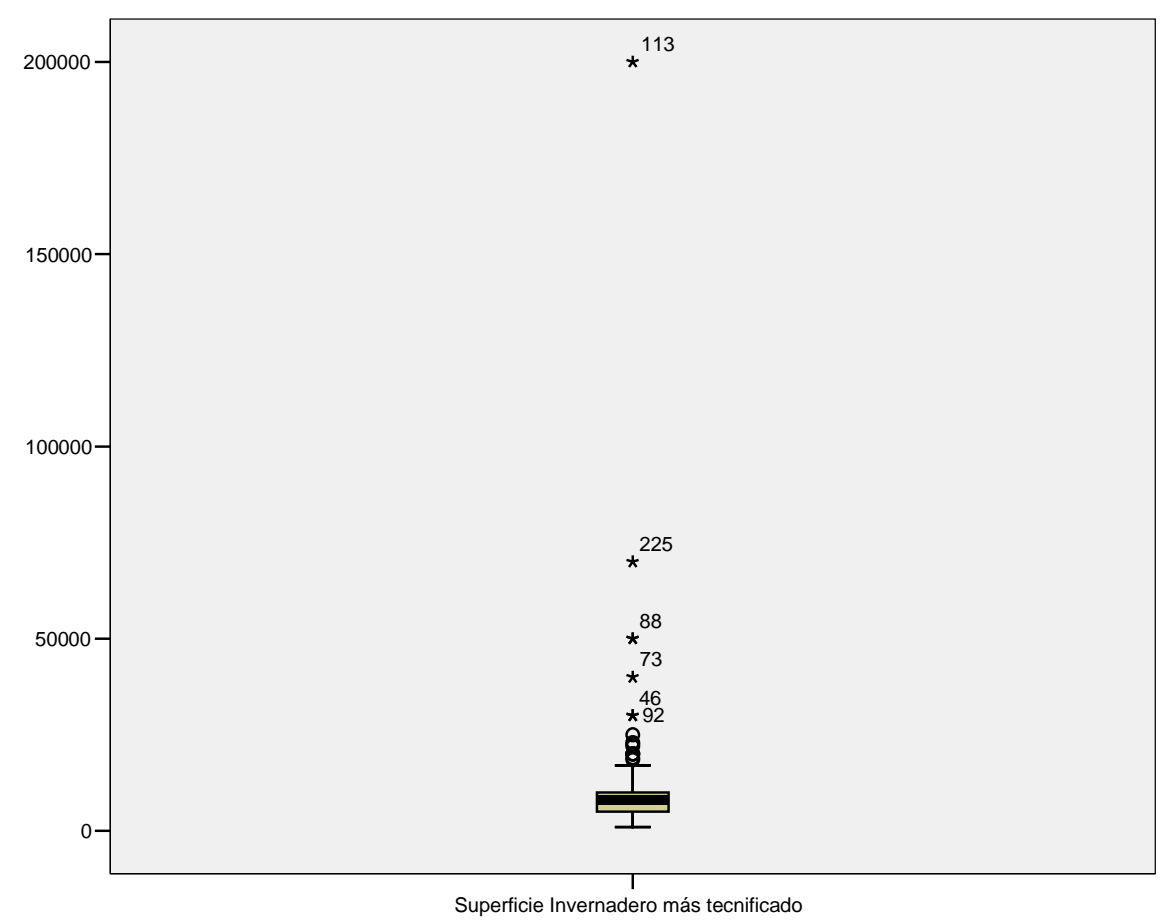

Tabla A4.2.1. Tipo estructura del invernadero

\begin{tabular}{|l|r|r|}
\hline & Frequency & Percent \\
\hline Madera & 18 & 7,5 \\
Acero & 223 & 92,5 \\
Total & 241 & 100,0 \\
\hline
\end{tabular}

Tabla A4.2.2. Tipo cubierta del invernadero

\begin{tabular}{|l|r|r|}
\hline & Frequency & Percent \\
\hline & 1 &, 4 \\
Frontal PVC & 24 & 10,0 \\
Plástico & 205 & 85,1 \\
Malla & 11 & 4,6 \\
Total & 241 & 100,0 \\
\hline
\end{tabular}


Tabla A4.2.3. Tipo de programador de riego

\begin{tabular}{|l|r|r|}
\hline & Frequency & Percent \\
\hline Ninguno & 45 & 18,7 \\
Sencillo & 46 & 19,1 \\
& 115 & 47,7 \\
Fertirrigación & & \\
Fertirrigación & 35 & 14,5 \\
informatizada & 241 & 100,0 \\
Total & &
\end{tabular}

Tabla A4.2.4. Tipo de invernadero

\begin{tabular}{|l|r|r|}
\hline & Frequency & Percent \\
\hline Parral & 215 & 89,2 \\
Multitúnel & 26 & 10,8 \\
Total & 241 & 100,0 \\
\hline
\end{tabular}

Tabla A4.2.5. Modalidad de cultivo

\begin{tabular}{|c|c|c|}
\hline & Frequency & Percent \\
\hline Ninguno & 2 &, 8 \\
Suelo & 187 & 77,6 \\
Fibra coco & 9 & 3,7 \\
Perlita & 32 & 13,3 \\
Lana roca & 11 & 4,6 \\
Total & 241 & 100,0 \\
\hline
\end{tabular}

Tabla A4.2.6. Recirculación

\begin{tabular}{|c|c|c|}
\hline & Frequency & Percent \\
\hline No & 241 & 100,0 \\
\hline
\end{tabular}

Tabla A4.2.7. Raíles

\begin{tabular}{|l|r|r|}
\hline & Frequency & Percent \\
\hline No & 240 & 99,6 \\
Sí & 1 &, 4 \\
Total & 241 & 100,0 \\
\hline
\end{tabular}


Tabla A4.2.8. Carretillas elevadoras

\begin{tabular}{|l|l|l|}
\hline & Frequency & Percent \\
\hline No & 232 & 96,3 \\
Sí & 9 & 3,7 \\
Total & 241 & 100,0 \\
\hline
\end{tabular}

Tabla A4.2.9. Fertilización carbónica

\begin{tabular}{|l|l|l|}
\hline & Frequency & Percent \\
\hline No & 240 & 99,6 \\
Sí & 1 &, 4 \\
Total & 241 & 100,0 \\
\hline
\end{tabular}

Tabla A4.2.10. Mallas antiinsectos

\begin{tabular}{|l|l|l|}
\hline & Frequency & Percent \\
\hline No & 15 & 6,2 \\
Sí & 226 & 93,8 \\
Total & 241 & 100,0 \\
\hline
\end{tabular}

Tabla A4.2.11. Mallas de sombreo interiores

\begin{tabular}{|l|l|l|}
\hline & & \\
& Frequency & Percent \\
\hline No & 225 & 93,4 \\
Sí & 16 & 6,6 \\
Total & 241 & 100,0 \\
\hline
\end{tabular}

Tabla A4.2.12. Pantallas térmicas

\begin{tabular}{|l|l|l|}
\hline & Frequency & Percent \\
\hline No & 221 & 91,7 \\
Sí & 20 & 8,3 \\
Total & 241 & 100,0 \\
\hline
\end{tabular}

Tabla A4.2.13. Mallas de sombreo exteriores

\begin{tabular}{|l|r|r|}
\hline & Frequency & Percent \\
\hline No & 227 & 94,2 \\
Sí & 14 & 5,8 \\
Total & 241 & 100,0 \\
\hline
\end{tabular}


Tabla A4.2.14. Nebulización

\begin{tabular}{|l|r|r|}
\hline & Frequency & Percent \\
\hline No & 226 & 93,8 \\
Sí & 15 & 6,2 \\
Total & 241 & 100,0 \\
\hline
\end{tabular}

Tabla A4.2.15. Cooling System

\begin{tabular}{|ll|r|r|r|}
\hline & & Frequency & Percent & Valid Percent \\
\hline Valid & No & 240 & 99,6 & 100,0 \\
Missing & System & 1 &, 4 & \\
Total & & 241 & 100,0 & \\
\hline
\end{tabular}

Tabla A4.2.16. Ventiladores (desestratificadores)

\begin{tabular}{|l|r|r|}
\hline & Frequency & Percent \\
\hline No & 212 & 88,0 \\
Sí & 29 & 12,0 \\
Total & 241 & 100,0 \\
\hline
\end{tabular}

Gráfico A4.2.3. Histograma de la variable temperatura de la calefacción

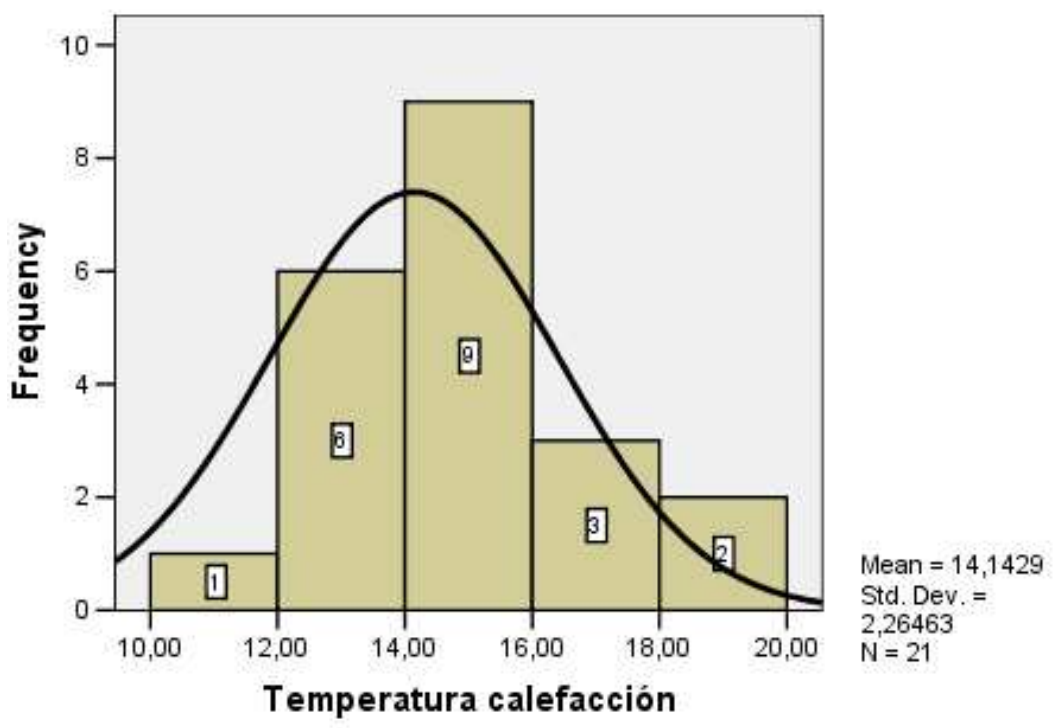


Tabla A4.2.17. Tipo calefacción

\begin{tabular}{|c|c|c|}
\hline & Frequency & Percent \\
\hline & 1 &, 4 \\
No & 210 & 87,1 \\
Por aire & 13 & 5,4 \\
Por agua & 17 & 7,1 \\
Total & 241 & 100,0 \\
\hline
\end{tabular}

Tabla A4.2.18. Forma calefacción

\begin{tabular}{|l|r|r|}
\hline & Frequency & Percent \\
\hline & 1 &, 4 \\
No & 210 & 87,1 \\
Puntual & 10 & 4,1 \\
Permanente & 20 & 8,3 \\
Total & 241 & 100,0 \\
\hline
\end{tabular}

\section{A4.3. Variables "Actitud hacia la adopción del sustrato"}

Gráfico A4.3.1. Intención de modificar el tipo de invernadero

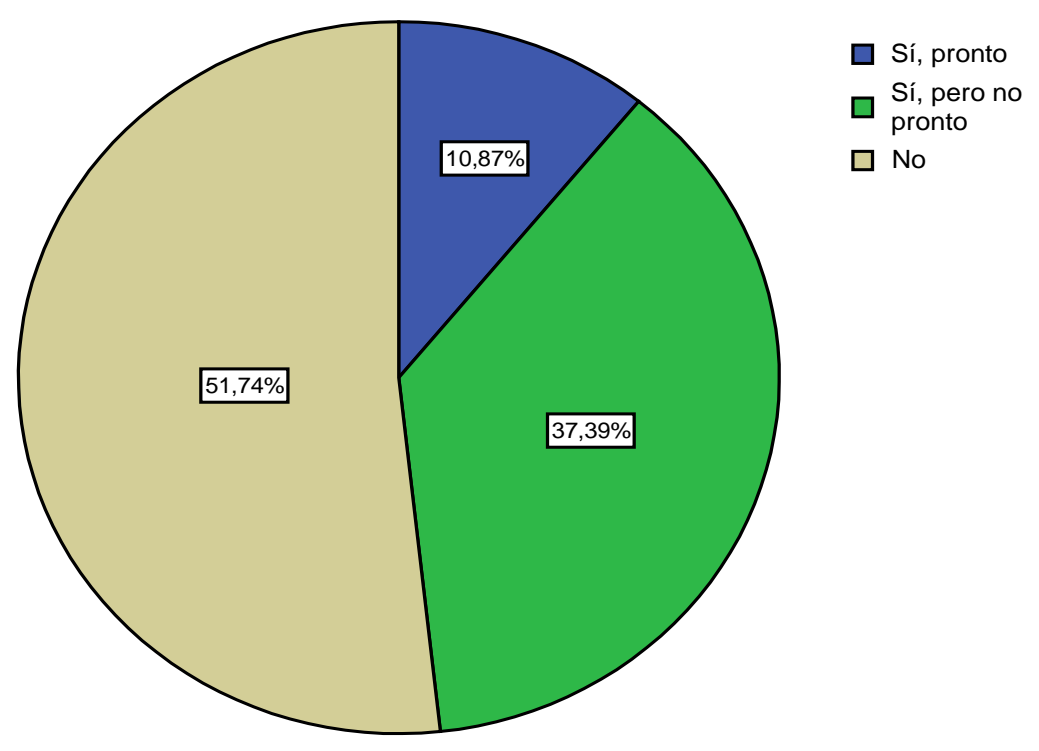




\section{A4.4. Variables "Factores que afectan al proceso de innovación"}

Tabla A4.4.1. Frecuencias de las Fuentes de Información Inicial

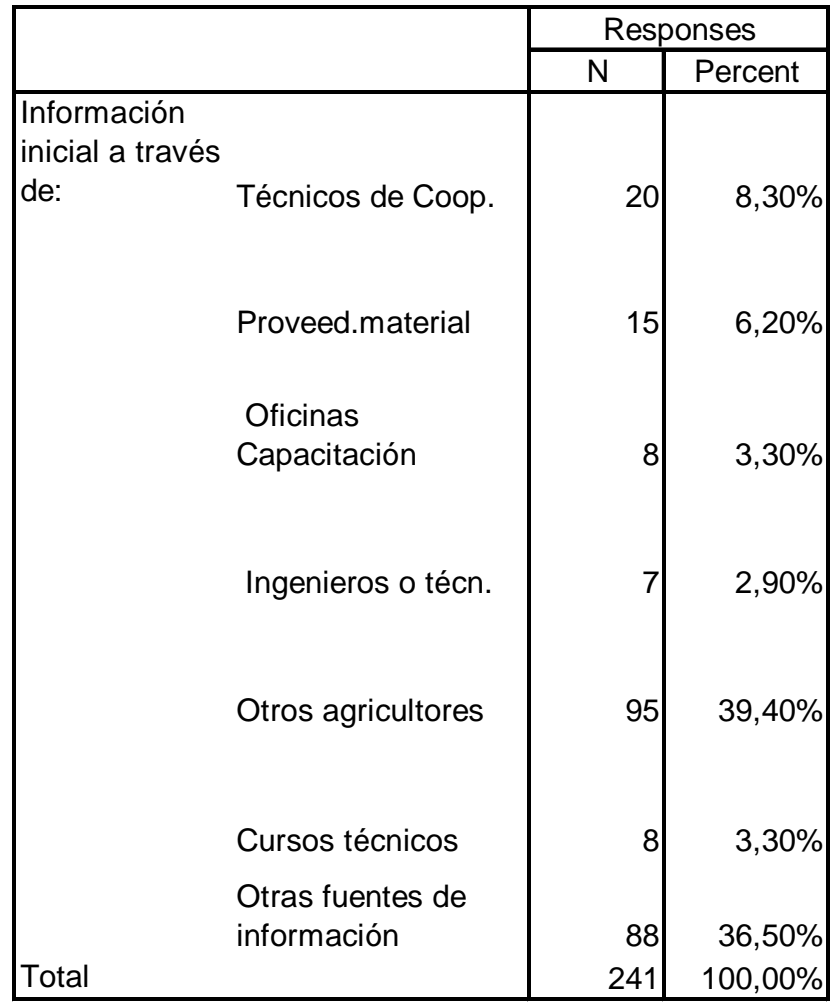

Tabla A4.4.2. Frecuencias de las vías de Formación

\begin{tabular}{|ll|r|r|}
\hline & & \multicolumn{2}{|c|}{ Responses } \\
\cline { 3 - 4 } & & $\mathrm{N}$ & \multicolumn{1}{|c|}{ Percent } \\
\hline Formación a través & & \\
de: & Técnicos de Coop. & 43 & $17,9 \%$ \\
& Proveed.materiales & 20 & $8,3 \%$ \\
& Oficinas de & & \\
& Capacitación & 4 & $1,7 \%$ \\
& & & \\
& Ingenieros o técnicos & 20 & $8,3 \%$ \\
& Otros agricultores & 72 & $30,0 \%$ \\
Total & Cursos técnicos & 5 & $2,1 \%$ \\
& Otros & 76 & $31,7 \%$ \\
& & 240 & $100,0 \%$ \\
\hline
\end{tabular}


Tabla A4.4.3. Frecuencias de las vías de Asesoramiento

\begin{tabular}{|ll|r|r|}
\hline & & \multicolumn{2}{|c|}{ Responses } \\
\cline { 3 - 4 } & $\mathrm{N}$ & \multicolumn{1}{|c|}{ Percent } \\
\hline Asesoramiento de & Técnicos de Coop. & 95 & $39,6 \%$ \\
los problemas & Proveed.materiales & 67 & $27,9 \%$ \\
técnicos a través de: & Ingenieros o técn. & 64 & $26,7 \%$ \\
& Otros agricultores & 13 & $5,4 \%$ \\
& Otras vías & 1 & $0,4 \%$ \\
Total & & 240 & $100,0 \%$ \\
\hline
\end{tabular}

Gráfico A4.4.1. Lectura de publicaciones relacionadas con temas agrarios

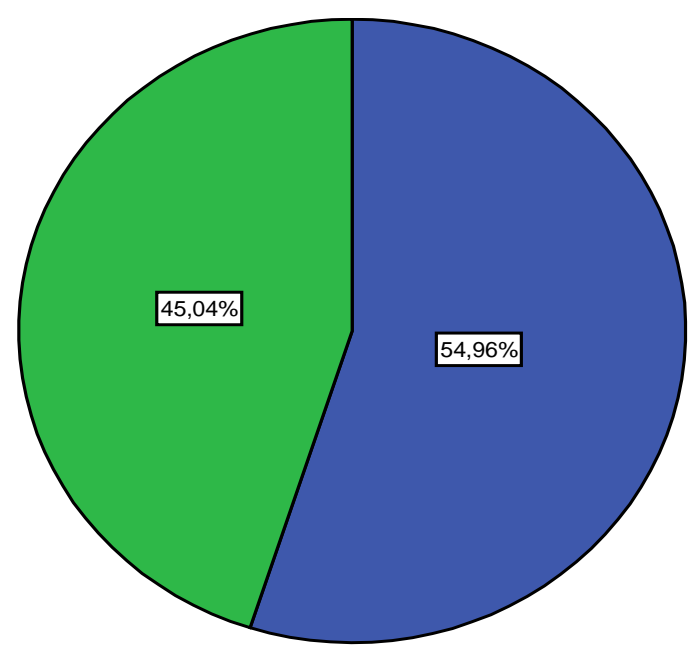

$\square$ Lee algún tipo de

publicación

$\square$ No lee

publicaciones

Tabla A4.4.4. Frecuencias de las vías de Comercialización

\begin{tabular}{|ll|r|r|}
\hline & & \multicolumn{2}{|c|}{ Responses } \\
\cline { 3 - 4 } & & $\mathrm{N}$ & Percent \\
\hline Comercializa la & & \\
producción a través & & & \\
de: & Cooperativa & 141 & $58,3 \%$ \\
& Mayorista & 3 & $1,2 \%$ \\
& Alhóndiga & 91 & $37,6 \%$ \\
& Otros canales & & \\
Total & comercialización & 7 & $2,9 \%$ \\
\hline
\end{tabular}




\section{A4.5. Variables "Percepción ambiental"}

Tabla A4.5.1. Importancia de la variable "Mayor consumo de agua" respecto al cultivo al aire libre

\begin{tabular}{|ll|r|r|r|}
\hline & & & Cumulative \\
& & Frequency & Valid Percent & Percent \\
\hline Valid & Poco importante & 156 & 64,5 & 64,5 \\
& Importante & 74 & 30,6 & 95,0 \\
& Muy importante & 12 & 5,0 & 100,0 \\
Total & 242 & 100,0 & \\
\hline
\end{tabular}

Tabla A4.5.2. Importancia de la variable "Mayor consumo de energía" respecto al cultivo al aire libre

\begin{tabular}{|ll|r|r|r|}
\hline & & & Cumulative \\
& & Frequency & Valid Percent & Percent \\
\hline Valid & Poco importante & 161 & 66,8 & 66,8 \\
& Importante & 58 & 24,1 & 90,9 \\
& Muy importante & 22 & 9,1 & 100,0 \\
& Total & 241 & 100,0 & \\
\hline
\end{tabular}

Tabla A4.5.3. Importancia de la variable "Más consumo de productos químicos" respecto al cultivo al aire libre

\begin{tabular}{|ll|r|r|r|}
\hline & & & Cumulative \\
& & Frequency & Valid Percent & Percent \\
\hline Valid & Poco importante & 89 & 36,8 & 36,8 \\
& Importante & 133 & 55,0 & 91,7 \\
& Muy importante & 20 & 8,3 & 100,0 \\
& Total & 242 & 100,0 & \\
\hline
\end{tabular}


Tabla A4.5.4. Importancia de la variable "Más desechos plásticos" respecto al cultivo al aire libre

\begin{tabular}{|c|c|c|c|c|}
\hline & & Frequency & Valid Percent & $\begin{array}{c}\text { Cumulative } \\
\text { Percent }\end{array}$ \\
\hline \multirow[t]{4}{*}{$\begin{array}{l}\text { Valid } \\
\end{array}$} & Poco importante & 22 & 9,1 & 9,1 \\
\hline & Importante & 177 & 73,1 & 82,2 \\
\hline & Muy importante & 43 & 17,8 & 100,0 \\
\hline & Total & 242 & 100,0 & \\
\hline
\end{tabular}

Tabla A4.5.5. Importancia de la variable "Más restos de cosechas" respecto al cultivo al aire libre

\begin{tabular}{|c|c|c|c|c|}
\hline & & Frequency & Valid Percent & $\begin{array}{c}\text { Cumulative } \\
\text { Percent }\end{array}$ \\
\hline \multirow[t]{4}{*}{ Valid } & Poco importante & 95 & 39,4 & 39,4 \\
\hline & Importante & 142 & 58,9 & 98,3 \\
\hline & Muy importante & 4 & 1,7 & 100,0 \\
\hline & Total & 241 & 100,0 & \\
\hline
\end{tabular}

Tabla A4.5.6. Importancia de la variable "Agua de drenaje con productos químicos"

\begin{tabular}{|c|c|c|c|c|}
\hline & & Frequency & Valid Percent & $\begin{array}{l}\text { Cumulative } \\
\text { Percent }\end{array}$ \\
\hline \multirow[t]{4}{*}{ Valid } & Poco importante & 157 & 66,0 & 66,0 \\
\hline & Importante & 67 & 28,2 & 94,1 \\
\hline & Muy importante & 14 & 5,9 & 100,0 \\
\hline & Total & 238 & 100,0 & \\
\hline
\end{tabular}

Tabla A4.5.7. Interés de la variable "Reducir el consumo de productos químicos" como estrategia prioritaria para mejorar el medio ambiente en las zonas de invernaderos

\begin{tabular}{|ll|r|r|}
\hline & & Frequency & Valid Percent \\
\hline Valid & No tiene interés & 6 & 2,5 \\
& Tiene interés & 236 & 97,5 \\
& Total & 242 & 100,0 \\
\hline
\end{tabular}


Tabla A4.5.8. Interés de la variable "Aplicar la lucha biológica" como estrategia prioritaria para mejorar el medio ambiente en las zonas de invernaderos

\begin{tabular}{|ll|r|r|}
\hline & & Frequency & Valid Percent \\
\hline Valid & No tiene interés & 12 & 5,0 \\
& Tiene interés & 230 & 95,0 \\
& Total & 242 & 100,0 \\
\hline
\end{tabular}

Tabla A4.5.9. Interés de la variable "Reutilizar las soluciones de drenaje" como estrategia prioritaria para mejorar el medio ambiente en las zonas de invernaderos

\begin{tabular}{|ll|r|r|}
\hline & & \\
& & Frequency & Valid Percent \\
\hline Valid & No tiene interés & 139 & 57,4 \\
& Tiene interés & 103 & 42,6 \\
& Total & 242 & 100,0 \\
\hline
\end{tabular}

Tabla A4.5.10. Interés de la variable "Optimizar el control climático de los invernaderos" como estrategia prioritaria para mejorar el medio ambiente en las zonas de invernaderos

\begin{tabular}{|ll|r|r|}
\hline & & \\
& & Frequency & Valid Percent \\
\hline Valid & No tiene interés & 54 & 22,3 \\
& Tiene interés & 188 & 77,7 \\
& Total & 242 & 100,0 \\
\hline
\end{tabular}

Tabla A4.5.11. Interés de la variable "Ordenar las nuevas superficies cubiertas" como estrategia prioritaria para mejorar el medio ambiente en las zonas de invernaderos

\begin{tabular}{|ll|r|r|}
\hline & & \\
& & Frequency & Valid Percent \\
\hline Valid & No tiene interés & 145 & 59,9 \\
& Tiene interés & 97 & 40,1 \\
& Total & 242 & 100,0 \\
\hline
\end{tabular}


Tabla A4.5.12. Interés de la variable "Responsabilizarse de la eliminación de los vertidos" como estrategia prioritaria para mejorar el medio ambiente en las zonas de invernaderos

\begin{tabular}{|ll|r|r|}
\hline & & \\
& & Frequency & Valid Percent \\
\hline Valid & No tiene interés & 64 & 26,4 \\
& Tiene interés & 178 & 73,6 \\
& Total & 242 & 100,0 \\
\hline
\end{tabular}

Tabla A4.5.13. Interés de la variable "Responsabilizarse de la restauración del paisaje tras abandonar un invernadero" como estrategia prioritaria para mejorar el medio ambiente en las zonas de invernaderos

\begin{tabular}{|ll|r|r|}
\hline & & Frequency & Valid Percent \\
\hline Valid & No tiene interés & 162 & 66,9 \\
& Tiene interés & 80 & 33,1 \\
& Total & 242 & 100,0 \\
\hline
\end{tabular}



Anexo 5 



\section{Anexo 5. Modelos de Regresión Multinomial Ordinal obtenidos}

Tabla A5.1. Número de casos y porcentaje marginal para cada nivel de las variables "Nivel de importancia del cultivo en sustrato" y "Rendimientos (por $\mathrm{m}^{2}$ ) más elevados"

\begin{tabular}{|ll|r|r|}
\hline & & $\mathrm{N}$ & \multicolumn{1}{c|}{$\begin{array}{c}\text { Marginal } \\
\text { Percentage }\end{array}$} \\
\hline Nivel importancia & Nada interesante & 16 & $6,6 \%$ \\
cultivo sustrato & Poco interesante & 56 & $23,1 \%$ \\
& Una técnica más & 103 & $42,6 \%$ \\
& Importante & 62 & $25,6 \%$ \\
& Imprescindible & 5 & $2,1 \%$ \\
Rdtos (por m2) & Poco importante & 127 & $52,5 \%$ \\
más elevados & Importante & 85 & $35,1 \%$ \\
& Muy importante & 30 & $12,4 \%$ \\
Valid & & 242 & $100,0 \%$ \\
Missing & 0 & \\
Total & & 242 & \\
\hline
\end{tabular}

Tabla A5.2. Coeficientes estimados, error estandar y significatividad del Modelo de Regresión Multinomial Ordinal para la variable "Rendimientos (por $\mathrm{m}^{2}$ ) más elevados" frente a "Nivel de importancia del cultivo en sustrato"

\begin{tabular}{|c|c|c|c|c|}
\hline & & Estimate & Std. Error & Sig. \\
\hline \multirow[t]{4}{*}{ Threshold } & $[\mathrm{A} 11] \mathrm{Im}=1]$ & $-4,029$ &, 444 &, 000 \\
\hline & [A11_Im = 2] & $-2,156$ & 378 & ,000 \\
\hline & [A11_Im = 3] &,- 129 & 349 & ,712 \\
\hline & {$\left[\mathrm{A} 11 \_\mathrm{Im}=4\right]$} & 2,887 & ,531 & ,000 \\
\hline \multirow[t]{2}{*}{ Location } & {$\left[\mathrm{A} 12 \mathrm{a} \_\mathrm{Rd}=1\right]$} & $-1,795$ & ,397 & ,000 \\
\hline & [A12a_Rd=2] &,- 706 & ,402 & ,079 \\
\hline
\end{tabular}

Estadístico $\chi^{2}=29,714 ;$ Grados de libertad $=2 ;$ P-valor $=0,000$ 
Tabla A5.3. Número de casos y porcentaje marginal para cada nivel de las variables "Nivel de importancia del cultivo en sustrato" y "Mayor calidad comercial de los productos"

\begin{tabular}{|ll|r|r|}
\hline & & $\mathrm{N}$ & \multicolumn{1}{|c|}{$\begin{array}{c}\text { Marginal } \\
\text { Percentage }\end{array}$} \\
\hline Nivel importancia & Nada interesante & 16 & $6,6 \%$ \\
cultivo sustrato & Poco interesante & 56 & $23,1 \%$ \\
& Una técnica más & 103 & $42,6 \%$ \\
& Importante & 62 & $25,6 \%$ \\
& Imprescindible & 5 & $2,1 \%$ \\
Mayor calidad & Poco importante & 102 & $42,1 \%$ \\
comercial de los & Importante & 91 & $37,6 \%$ \\
productos & Muy importante & 49 & $20,2 \%$ \\
Valid & & 242 & $100,0 \%$ \\
Missing & & 242 & \\
Total & & \\
\hline
\end{tabular}

Tabla A5.4. Coeficientes estimados, error estandar y significatividad del Modelo de Regresión Multinomial Ordinal para la variable "Mayor calidad comercial de los productos" frente a "Nivel de importancia del cultivo en sustrato"

\begin{tabular}{|rl|r|r|r|}
\hline & & & & \\
\hline Threshold & {$\left[\mathrm{A} 11 \_\mathrm{Im}=1\right]$} & $-4,067$ &, 393 &, 000 \\
& {$\left[\mathrm{~A} 11 \_\mathrm{Im}=2\right]$} & $-2,132$ &, 312 &, 000 \\
& {$\left[\mathrm{~A} 11 \_\mathrm{Im}=3\right]$} &,- 035 &, 274 &, 897 \\
& {$\left[\mathrm{~A} 11 \_\mathrm{Im}=4\right]$} & 2,993 &, 489 &, 000 \\
Location & {$\left[\mathrm{A} 12 \mathrm{~b} \_\mathrm{CaC}=1\right]$} & $-2,024$ &, 349 &, 000 \\
& {$\left[\mathrm{~A} 12 \mathrm{~b} \_\mathrm{CaC}=2\right]$} &,- 767 &, 336 &, 023 \\
\hline
\end{tabular}

Estadístico $\chi^{2}=41,489$; Grados de libertad $=2$; $\mathrm{P}$-valor $=0,000$ 
Tabla A5.5. Número de casos y porcentaje marginal para cada nivel de las variables "Nivel de importancia del cultivo en sustrato" y "Más seguridad de obtener buenos resultados"

\begin{tabular}{|ll|r|r|}
\hline & & $\mathrm{N}$ & \multicolumn{1}{|c|}{$\begin{array}{c}\text { Marginal } \\
\text { Percentage }\end{array}$} \\
\hline Nivel importancia & Nada interesante & 16 & $6,7 \%$ \\
cultivo sustrato & Poco interesante & 54 & $22,6 \%$ \\
& Una técnica más & 102 & $42,7 \%$ \\
& Importante & 62 & $25,9 \%$ \\
& Imprescindible & 5 & $2,1 \%$ \\
Más seguridad de & Poco importante & 172 & $72,0 \%$ \\
obtener buenos & Importante & 47 & $19,7 \%$ \\
resultados & Muy importante & 20 & $8,4 \%$ \\
Valid & & 239 & $100,0 \%$ \\
Missing & 3 & \\
Total & & 242 & \\
\hline
\end{tabular}

Tabla A5.6. Coeficientes estimados, error estandar y significatividad del Modelo de Regresión Multinomial Ordinal para la variable "Más seguridad de obtener buenos resultados" frente a "Nivel de importancia del cultivo en sustrato"

\begin{tabular}{|c|c|c|c|c|}
\hline & & Estimate & Std. Error & Sig. \\
\hline \multirow[t]{4}{*}{ Threshold } & {$\left[\mathrm{A} 11 \_\mathrm{Im}=1\right]$} & $-4,762$ &, 539 &, 000 \\
\hline & {$\left[\mathrm{A} 11 \_\mathrm{Im}=2\right]$} & $-2,925$ & ,488 &, 000 \\
\hline & [A11_Im = 3] &,- 872 & ,459 & 057 \\
\hline & {$\left[\mathrm{A} 11 \_\mathrm{Im}=4\right]$} & 2,270 & ,565 & ,000 \\
\hline \multirow[t]{2}{*}{ Location } & {$\left[\mathrm{A} 12 \mathrm{c} \_\mathrm{Se}=1\right]$} & $-2,397$ & ,492 &, 000 \\
\hline & {$\left[\mathrm{A} 12 \mathrm{C} \_\mathrm{Se}=2\right]$} & $-1,011$ & ,530 & ,056 \\
\hline
\end{tabular}

Estadístico $\chi^{2}=39,045 ;$ Grados de libertad $=2 ;$ P-valor $=0,000$ 
Tabla A5.7. Número de casos y porcentaje marginal para cada nivel de las variables "Nivel de importancia del cultivo en sustrato" $y$ "Periodo de producción y comercialización más amplio"

\begin{tabular}{|ll|r|r|}
\hline & & N & \multicolumn{1}{|c|}{$\begin{array}{c}\text { Marginal } \\
\text { Percentage }\end{array}$} \\
\hline Nivel importancia & Nada interesante & 16 & $7,1 \%$ \\
cultivo sustrato & Poco interesante & 50 & $22,2 \%$ \\
& Una técnica más & 97 & $43,1 \%$ \\
& Importante & 57 & $25,3 \%$ \\
& Imprescindible & 5 & $2,2 \%$ \\
Periodo producción & Poco importante & 174 & $77,3 \%$ \\
y comercialización & Importante & 32 & $14,2 \%$ \\
más amplio & Muy importante & 19 & $8,4 \%$ \\
Valid & & 225 & $100,0 \%$ \\
Missing & & 17 & \\
Total & & 242 & \\
\hline
\end{tabular}

Tabla A5.8. Coeficientes estimados, error estandar y significatividad del Modelo de Regresión Multinomial Ordinal para la variable "Periodo de producción y comercialización más amplio" frente a "Nivel de importancia del cultivo en sustrato"

\begin{tabular}{|c|c|c|c|c|}
\hline & & Estimate & Std. Error & Sig. \\
\hline \multirow[t]{4}{*}{ Threshold } & {$\left[\mathrm{A} 11 \_\mathrm{Im}=1\right]$} & $-3,951$ &, 515 &, 000 \\
\hline & {$\left[\mathrm{A} 11 \_\mathrm{Im}=2\right]$} & $-2,244$ & ,463 & ,000 \\
\hline & {$\left[\mathrm{A} 11 \_\mathrm{Im}=3\right]$} &,- 320 & ,440 & ,468 \\
\hline & {$\left[\mathrm{A} 11 \_\mathrm{Im}=4\right]$} & 2,594 &, 580 &, 000 \\
\hline \multirow[t]{2}{*}{ Location } & {$\left[\mathrm{A} 12 \mathrm{~d} \_\mathrm{Ca}=1\right]$} & $-1,522$ & ,467 &, 001 \\
\hline & [A12d_Ca=2] &,- 873 &, 547 & , 111 \\
\hline
\end{tabular}

Estadístico $\chi^{2}=12,100$; Grados de libertad $=2$; P-valor $=0,002$ 
Tabla A5.9. Número de casos y porcentaje marginal para cada nivel de las variables "Nivel de importancia del cultivo en sustrato" y "Mejor control climático"

\begin{tabular}{|ll|r|r|}
\hline & & \multicolumn{1}{|c|}{$\begin{array}{c}\text { Marginal } \\
\text { Percentage }\end{array}$} \\
\hline Nivel importancia & Nada interesante & 16 & $6,6 \%$ \\
cultivo sustrato & Poco interesante & 56 & $23,2 \%$ \\
& Una técnica más & 102 & $42,3 \%$ \\
& Importante & 62 & $25,7 \%$ \\
Mejor control & Imprescindible & 5 & $2,1 \%$ \\
climático & Poco importante & 169 & $70,1 \%$ \\
& Importante & 46 & $19,1 \%$ \\
Valid & Muy importante & 26 & $10,8 \%$ \\
Missing & & 241 & $100,0 \%$ \\
Total & & 1 & \\
\hline
\end{tabular}

Tabla A5.10. Coeficientes estimados, error estandar y significatividad del Modelo de Regresión Multinomial Ordinal para la variable "Mejor control climático" frente a "Nivel de importancia del cultivo en sustrato"

\begin{tabular}{|cl|r|r|r|}
\hline & & & & \\
\hline Threshold & {$\left[\mathrm{A} 11 \_\mathrm{Im}=1\right]$} & $-3,576$ &, 448 &, 000 \\
& {$\left[\mathrm{~A} 11 \_\mathrm{Im}=2\right]$} & $-1,774$ &, 387 &, 000 \\
& {$\left[\mathrm{~A} 11 \_\mathrm{Im}=3\right]$} &, 076 &, 369 &, 836 \\
& {$\left[\mathrm{~A} 11 \_\mathrm{Im}=4\right]$} & 3,021 &, 550 &, 000 \\
Location & {$\left[\mathrm{A} 12 \mathrm{e} \_\mathrm{CCl}=1\right]$} & $-1,009$ &, 396 &, 011 \\
& {$\left[\mathrm{~A} 12 \mathrm{e} \_\mathrm{CCl}=2\right]$} &,- 973 &, 458 &, 034 \\
\hline
\end{tabular}

Estadístico $\chi^{2}=6,479$; Grados de libertad $=2 ;$ P-valor $=0,039$ 
Tabla A5.11. Número de casos y porcentaje marginal para cada nivel de las variables "Nivel de importancia del cultivo en sustrato" y "Mejor aplicación del riego"

\begin{tabular}{|ll|r|r|}
\hline & & $\mathrm{N}$ & \multicolumn{1}{|c|}{$\begin{array}{c}\text { Marginal } \\
\text { Percentage }\end{array}$} \\
\hline Nivel importancia & Nada interesante & 16 & $6,6 \%$ \\
cultivo sustrato & Poco interesante & 56 & $23,2 \%$ \\
& Una técnica más & 102 & $42,3 \%$ \\
& Importante & 62 & $25,7 \%$ \\
Mejor aplicación & Imprescindible & 5 & $2,1 \%$ \\
del riego & Poco importante & 50 & $20,7 \%$ \\
& Importante & 145 & $60,2 \%$ \\
Valid & Muy importante & 46 & $19,1 \%$ \\
Missing & & 241 & $100,0 \%$ \\
Total & & 1 & \\
\hline
\end{tabular}

Tabla A5.12 Coeficientes estimados, error estandar y significatividad del Modelo de Regresión Multinomial Ordinal para la variable "Mejor aplicación del riego" frente a "Nivel de importancia del cultivo en sustrato"

\begin{tabular}{|rl|r|r|r|}
\hline & & & & \\
\hline Threshold & [A11_Im = 1] & Estimate & Std. Error & \multicolumn{1}{c|}{ Sig. } \\
& [A11_Im = 2] & $-2,100$ &, 409 &, 000 \\
& [A11_Im = 3] &, 002 &, 318 &, 000 \\
& [A11_Im=4] & 3,035 &, 996 \\
Location & [A12f_Ri=1] & $-2,664$ &, 415 &, 000 \\
& [A12f_Ri=2] &,- 890 &, 323 &, 000 \\
&
\end{tabular}

Estadístico $\chi^{2}=48,826$; Grados de libertad $=2$; P-valor $=0,000$ 
Tabla A5.13. Número de casos y porcentaje marginal para cada nivel de las variables "Nivel de importancia del cultivo en sustrato" y "Se recolectan más kg/hora"

\begin{tabular}{|ll|r|r|}
\hline & & Marginal \\
& & 16 & Percentage \\
\hline Nivel importancia & Nada interesante & 55 & $22,7 \%$ \\
cultivo sustrato & Poco interesante & 103 & $42,9 \%$ \\
& Una técnica más & 61 & $25,4 \%$ \\
& Importante & 5 & $2,1 \%$ \\
Se recolectan & Imprescindible & 178 & $74,2 \%$ \\
más kg/hora & Importante & 52 & $21,7 \%$ \\
& Muy importante & 10 & $4,2 \%$ \\
Valid & & 240 & $100,0 \%$ \\
Missing & & 2 & \\
Total & & 242 & \\
\hline
\end{tabular}

Tabla A5.14. Coeficientes estimados, error estandar y significatividad del Modelo de Regresión Multinomial Ordinal para la variable "Se recolectan más kg/hora" frente a "Nivel de importancia del cultivo en sustrato"

\begin{tabular}{|rl|r|r|r|}
\hline & & & & \\
\hline Threshold & [A11_Im = 1] & $-4,407$ &, 677 &, 000 \\
& [A11_Im = 2] & $-2,571$ &, 636 &, 000 \\
& {$[$ A11_Im = 3] } &,- 505 &, 616 &, 412 \\
& [A11_Im = 4] & 2,576 &, 722 &, 000 \\
Location & [A12g_Rec=1] & $-2,007$ &, 639 &, 002 \\
& [A12g_Rec=2] &,- 404 &, 666 &, 544 \\
\hline
\end{tabular}

Estadístico $\chi^{2}=33,422 ;$ Grados de libertad $=2 ;$ P-valor $=0,000$ 
Tabla A5.15. Número de casos y porcentaje marginal para cada nivel de las variables "Nivel de importancia del cultivo en sustrato" y "Se puede reciclar el agua de drenaje"

\begin{tabular}{|ll|r|r|}
\hline & & N & \multicolumn{1}{|c|}{$\begin{array}{c}\text { Marginal } \\
\text { Percentage }\end{array}$} \\
\hline Nivel importancia & Nada interesante & 16 & $6,8 \%$ \\
cultivo sustrato & Poco interesante & 54 & $23,1 \%$ \\
& Una técnica más & 100 & $42,7 \%$ \\
& Importante & 59 & $25,2 \%$ \\
& Imprescindible & 5 & $2,1 \%$ \\
Se puede reciclar & Poco importante & 146 & $62,4 \%$ \\
el agua de drenaje & Importante & 65 & $27,8 \%$ \\
& Muy importante & 23 & $9,8 \%$ \\
Valid & & 234 & $100,0 \%$ \\
Missing & & 242 & \\
Total & & \\
\hline
\end{tabular}

Tabla A5.16. Coeficientes estimados, error estandar y significatividad del Modelo de Regresión Multinomial Ordinal para la variable "Se puede reciclar el agua de drenaje" frente a "Nivel de importancia del cultivo en sustrato"

\begin{tabular}{|cl|r|r|r|}
\hline & & & & \\
\hline Threshold & [A11_Im = 1] & $-3,871$ &, 477 &, 000 \\
& [A11_Im = 2] & $-2,091$ &, 419 &, 000 \\
& [A11_Im = 3] &,- 192 &, 397 &, 629 \\
& [A11_Im = 4] & 2,733 &, 557 &, 000 \\
Location & [A12h_Dre=1] & $-1,416$ &, 430 &, 001 \\
& [A12h_Dre=2] & $-1,113$ &, 460 &, 015 \\
\hline
\end{tabular}

Estadístico $\chi^{2}=11,318$; Grados de libertad $=2$; P-valor $=0,003$ 
Tabla A5.17. Número de casos y porcentaje marginal para cada nivel de las variables "Nivel de importancia del cultivo en sustrato" y "Se evita la desinfección del suelo"

\begin{tabular}{|ll|r|r|}
\hline & & \multicolumn{1}{|c|}{$\begin{array}{c}\text { Marginal } \\
\text { Percentage }\end{array}$} \\
\hline Nivel importancia cultivo & Nada interesante & 15 & $6,3 \%$ \\
sustrato & Poco interesante & 56 & $23,5 \%$ \\
& Una técnica más & 102 & $42,9 \%$ \\
& Importante & 60 & $25,2 \%$ \\
Se evita la desinfección & 5 & $2,1 \%$ \\
del suelo & Imprescindible & 65 & $27,3 \%$ \\
& Poco importante & 141 & $59,2 \%$ \\
Valid & Importante & 32 & $13,4 \%$ \\
Missing & Muy importante & 238 & $100,0 \%$ \\
Total & & 4 & \\
\hline
\end{tabular}

Tabla A5.18. Coeficientes estimados, error estandar y significatividad del Modelo de Regresión Multinomial Ordinal para la variable "Se evita la desinfección del suelo" frente a "Nivel de importancia del cultivo en sustrato"

\begin{tabular}{|ll|r|r|r|}
\hline & & & & \\
\hline Threshold & [A11_Im =1] & $-3,208$ &, 415 &, 000 \\
& {$[$ A11_Im $=2]$} & $-1,346$ &, 343 &, 000 \\
& {$[$ A11_Im $=3]$} &, 515 &, 332 &, 121 \\
& {$[$ A11_Im $=4]$} & 3,388 &, 536 &, 000 \\
Location & [A12i_EDe=1] &,- 794 &, 400 &, 047 \\
& [A12i_EDe=2] &,- 451 &, 362 &, 213 \\
\hline
\end{tabular}

Estadístico $\chi^{2}=3,888$; Grados de libertad $=2$; $\mathrm{P}$-valor $=0,143$ 
Tabla A5.19. Número de casos y porcentaje marginal para cada nivel de las variables "Nivel de importancia del cultivo en sustrato" y "Se reduce la cantidad de fitosanitarios"

\begin{tabular}{|ll|r|r|}
\hline & & $\mathrm{N}$ & $\begin{array}{c}\text { Marginal } \\
\text { Percentage }\end{array}$ \\
\hline Nivel importancia cultivo & Nada interesante & 16 & $6,7 \%$ \\
sustrato & Poco interesante & 55 & $23,1 \%$ \\
& Una técnica más & 102 & $42,9 \%$ \\
& Importante & 60 & $25,2 \%$ \\
& Imprescindible & 5 & $2,1 \%$ \\
Se reduce la cantidad de & Poco importante & 115 & $48,3 \%$ \\
fitosanitarios & Importante & 90 & $37,8 \%$ \\
& Muy importante & 33 & $13,9 \%$ \\
Valid & & 238 & $100,0 \%$ \\
Missing & 4 & \\
Total & & 242 & \\
\hline
\end{tabular}

Tabla A5.20. Coeficientes estimados, error estandar y significatividad del Modelo de Regresión Multinomial Ordinal para la variable "Se reduce la cantidad de fitosanitarios" frente a "Nivel de importancia del cultivo en sustrato"

\begin{tabular}{|c|c|c|c|c|}
\hline & & Estimate & Std. Error & Sig. \\
\hline \multirow[t]{4}{*}{ Threshold } & {$\left[\mathrm{A} 11 \_\mathrm{Im}=1\right]$} & $-2,858$ &, 402 &, 000 \\
\hline & [A11_Im = 2] & $-1,022$ & ,333 & ,002 \\
\hline & [A11_Im = 3] & ,929 & ,332 & ,005 \\
\hline & {$\left[\mathrm{A} 11 \_\mathrm{Im}=4\right]$} & 3,845 & ,544 & , 000 \\
\hline \multirow[t]{2}{*}{ Location } & {$\left[A 12 j \_R F=1\right]$} &,- 611 & ,366 & ,095 \\
\hline & [A12j_RF=2] & ,471 & ,377 & ,212 \\
\hline
\end{tabular}

Estadístico $\chi^{2}=17,344 ;$ Grados de libertad $=2 ;$ P-valor $=0,000$ 
Tabla A5.21. Número de casos y porcentaje marginal para cada nivel de las variables "Nivel de importancia del cultivo en sustrato" y "Más caro en todo"

\begin{tabular}{|ll|r|r|}
\hline & & Marginal \\
& & 16 & Percentage \\
\hline Nivel importancia & Nada interesante & 56 & $23,6 \%$ \\
cultivo sustrato & Poco interesante & 103 & $42,6 \%$ \\
& Una técnica más & 62 & $25,6 \%$ \\
& Importante & 5 & $2,1 \%$ \\
Más caro en todo & Imprescindible & 42 & $17,4 \%$ \\
& Poco importante & 71 & $29,3 \%$ \\
Valid & Importante & 129 & $53,3 \%$ \\
Missing & Muy importante & 242 & $100,0 \%$ \\
Total & & 0 & \\
\hline
\end{tabular}

Tabla A5.22 Coeficientes estimados, error estandar y significatividad del Modelo de Regresión Multinomial Ordinal para la variable "Más caro en todo" frente a "Nivel de importancia del cultivo en sustrato"

\begin{tabular}{|ll|r|r|r|}
\hline & & & & \\
\hline Threshold & [A11_Im =1] & $-2,423$ &, 274 &, 000 \\
& [A11_Im = 2] &,- 610 &, 174 &, 000 \\
& [A11_Im=3] & 1,229 &, 189 &, 000 \\
& [A11_Im =4] & 4,136 &, 471 &, 000 \\
Location & [A12m_Car=1] &, 653 &, 329 &, 047 \\
& [A12m_Car=2] &, 441 &, 273 &, 106 \\
\hline
\end{tabular}

Estadístico $\chi^{2}=5,129$; Grados de libertad $=2$; P-valor $=0,077$ 
Tabla A5.23. Número de casos y porcentaje marginal para cada nivel de las variables "Nivel de importancia del cultivo en sustrato" y "Lo veo muy arriesgado"

\begin{tabular}{|ll|r|r|}
\hline & & $\mathrm{N}$ & $\begin{array}{c}\text { Marginal } \\
\text { Percentage }\end{array}$ \\
\hline Nivel importancia & Nada interesante & 16 & $6,6 \%$ \\
cultivo sustrato & Poco interesante & 56 & $23,1 \%$ \\
& Una técnica más & 103 & $42,6 \%$ \\
& Importante & 62 & $25,6 \%$ \\
& Imprescindible & 5 & $2,1 \%$ \\
Lo veo muy & Poco importante & 48 & $19,8 \%$ \\
arriesgado & Importante & 82 & $33,9 \%$ \\
& Muy importante & 112 & $46,3 \%$ \\
Valid & & 242 & $100,0 \%$ \\
Missing & & 0 & \\
Total & & 242 & \\
\hline
\end{tabular}

Tabla A5.24. Coeficientes estimados, error estandar y significatividad del Modelo de Regresión Multinomial Ordinal para la variable "Lo veo muy arriesgado" frente a "Nivel de importancia del cultivo en sustrato"

\begin{tabular}{|c|c|c|c|c|}
\hline & & Estimate & Std. Error & Sig. \\
\hline \multirow[t]{4}{*}{ Threshold } & [A11_Im = 1] & $-2,289$ & ,279 &, 000 \\
\hline & [A11_Im = 2] &,- 434 & 184 & ,019 \\
\hline & [A11_Im = 3] & 1,645 & 219 & ,000 \\
\hline & [A11_Im = 4] & 4,847 & ,508 &, 000 \\
\hline \multirow[t]{2}{*}{ Location } & [A12n_Arr=1] & 2,185 & ,356 & 000 \\
\hline & [A12n_Arr=2] & ,384 & 270 & 155 \\
\hline
\end{tabular}

Estadístico $\chi^{2}=42,931$; Grados de libertad $=2$; P-valor $=0,000$ 
Tabla A5.25. Número de casos y porcentaje marginal para cada nivel de las variables "Nivel de importancia del cultivo en sustrato" y "Es más difícil de manejar"

\begin{tabular}{|c|c|c|c|}
\hline & & $\mathrm{N}$ & $\begin{array}{c}\text { Marginal } \\
\text { Percentage }\end{array}$ \\
\hline \multirow{5}{*}{$\begin{array}{l}\text { Nivel importancia } \\
\text { cultivo sustrato }\end{array}$} & Nada interesante & 16 & $6,6 \%$ \\
\hline & Poco interesante & 56 & $23,1 \%$ \\
\hline & Una técnica más & 103 & $42,6 \%$ \\
\hline & Importante & 62 & $25,6 \%$ \\
\hline & Imprescindible & 5 & $2,1 \%$ \\
\hline \multirow{3}{*}{$\begin{array}{l}\text { Es más difícil de } \\
\text { manejar }\end{array}$} & Poco importante & 67 & $27,7 \%$ \\
\hline & Importante & 88 & $36,4 \%$ \\
\hline & Muy importante & 87 & $36,0 \%$ \\
\hline Valid & & 242 & $100,0 \%$ \\
\hline Missing & & 0 & \\
\hline Total & & 242 & \\
\hline
\end{tabular}

Tabla A5.26. Coeficientes estimados, error estandar y significatividad del Modelo de Regresión Multinomial Ordinal para la variable "Es más difícil de manejar" frente a "Nivel de importancia del cultivo en sustrato"

\begin{tabular}{|rl|r|r|r|}
\hline & & & & \\
\hline Threshold & [A11_Im = 1] & $-2,097$ &, 287 &, 000 \\
& [A11_Im = 2] &,- 255 &, 205 &, 212 \\
& [A11_Im = 3] & 1,687 &, 236 &, 000 \\
& [A11_Im =4] & 4,696 &, 497 &, 000 \\
Location & [A120_DMa=1] & 1,479 &, 314 &, 000 \\
& [A120_DMa=2] &, 730 &, 282 &, 010 \\
\hline
\end{tabular}

Estadístico $\chi^{2}=22,930$; Grados de libertad $=2$; P-valor $=0,000$ 
Tabla A5.27. Número de casos y porcentaje marginal para cada nivel de las variables "Nivel de importancia del cultivo en sustrato" y "Se depende de empresas o técnicos que asesoren"

\begin{tabular}{|ll|r|r|}
\hline & & $\mathrm{N}$ & $\begin{array}{c}\text { Marginal } \\
\text { Percentage }\end{array}$ \\
\hline Nivel importancia & Nada interesante & 16 & $6,6 \%$ \\
cultivo sustrato & Poco interesante & 56 & $23,1 \%$ \\
& Una técnica más & 103 & $42,6 \%$ \\
& Importante & 62 & $25,6 \%$ \\
Se depende de & Imprescindible & 5 & $2,1 \%$ \\
empresas o técnicos & Poco importante & 38 & $15,7 \%$ \\
que asesoren & Muy importante & 138 & $57,0 \%$ \\
Valid & & 66 & $27,3 \%$ \\
Missing & 242 & $100,0 \%$ \\
Total & 0 & \\
\hline
\end{tabular}

Tabla A5.28. Coeficientes estimados, error estandar y significatividad del Modelo de Regresión Multinomial Ordinal para la variable "Se depende de empresas o técnicos que asesoren" frente a "Nivel de importancia del cultivo en sustrato"

\begin{tabular}{|c|c|c|c|c|}
\hline & & Estimate & Std. Error & Sig. \\
\hline \multirow[t]{4}{*}{ Threshold } & {$\left[\mathrm{A} 11 \_I \mathrm{Im}=1\right]$} & $-1,998$ & ,303 &, 000 \\
\hline & [A11_Im = 2] &,- 167 & 232 & ,471 \\
\hline & [A11_Im = 3] & 1,713 & 259 & ,000 \\
\hline & {$\left[\mathrm{A} 11 \_\mathrm{Im}=4\right]$} & 4,655 &, 505 & ,000 \\
\hline \multirow[t]{2}{*}{ Location } & {$\left[\mathrm{A} 12 \mathrm{p} \_\mathrm{DET}=1\right]$} & ,971 & ,379 & ,010 \\
\hline & [A12p_DET=2] & ,993 & ,281 & ,000 \\
\hline
\end{tabular}

Estadístico $\chi^{2}=13,589 ;$ Grados de libertad $=2 ;$ P-valor $=0,001$ 